\title{
KIN-MAKING IN THE Reproductive PENUMBRA: SURROGACY IN AOTEAROA NEW ZEALAND
}

BY

HANNAH GIBSON

A thesis

submitted to Te Herenga Waka | Victoria University of Wellington in fulfilment of the requirements for the degree of

Doctor of Philosophy

Te Herenga Waka | Victoria University of Wellington 2021 



\section{Abstract}

As many as one in four New Zealanders experience infertility. Some choose to pursue surrogacy as an option to make a family because traditional surrogacy and gestational surrogacy are legal in Aotearoa New Zealand on an altruistic basis. Straddling the two reproductive worlds - 'traditional' and 'technological' - surrogacy in Aotearoa New Zealand offers us a ripe site for analysis and rethinking how kinship is made and unmade within what I refer to as the reproductive penumbra. Surrogacy as a reproductive practice exists outside of, or in the shadows of, heteronormative reproduction and mainstream Euro-American kinship. Surrogacy also asks people to enter an unknown reproductive space and navigate myriad processes, institutions, and legislations to realise their plans to make kin non-normatively. Drawing on three years of multi-sited ethnographic fieldwork, in this thesis I unpack what kinpractices, narratives, rituals, rules, and relationships are mobilised within and between the various landscapes involved in surrogacy in Aotearoa New Zealand. I outline how people make kin in the multiple shadows they inhabit and move through during their surrogacy journeys. These range from the intimate and inter-personal relationships in the surrogacy community, the fertility clinic, and inside the embryology laboratory, to the institutional and regulatory processes and the state. Through their negotiation of these spaces that are situated in the shadows of the colonial state, everyday legality, and motherhood ideologies, intended parents and surrogates disrupt, to varying degrees, pervasive ideas about kinship with different interpretations and enactments of reproductive participation. Through detailed narratives of people wanting to and helping make kin in the shadows, this research on surrogacy complicates societal understandings of the co-constructed nature of kinship, motherhood, and reproductive medicine. Rather than positioning kin-making in shadows as inherently negative, this thesis celebrates the potentiality and plurality of reproduction that underpins and emerges from surrogacy. 



\section{Acknowledgements}

Just as a multitude of people are required to create a baby via surrogacy, this thesis is a collaborative effort. It would not exist without those intended parents and surrogates who welcomed me into their lives. Thank you for trusting me with your stories of grief, hope, and joy. You have shown me that kinship is about patience, perseverance, and a willingness to trust the unknown (even when it has ended in heartache). I dedicate this research to you.

I could not imagine going through this doctoral journey without my two supervisors and mentors. Dr Catherine Trundle and Dr Nayantara Sheoran Appleton, thank you for believing in me and supporting me for the past four and a half years. Our intellectual musings and your emphasis on looking at data with compassion have been priceless. Thank you for your enthusiasm and for being incredible champions of my writing.

To my parents, David and Ann Gibson, and sister Erin, thank you for being my biggest champions. Dad, as I grew up on the farm in Scotland, you were the first person who taught me that families are made in more ways than one - aged five, I asked why the chicken was sitting on a duck egg alongside her own, and you answered, 'why not?' As simple as that. Mum, you are as constant as a heartbeat and my hero. Thank you for your continuous willingness to read my work. Lastly, to Gran and Auntie Janet, who are no longer with us. This thesis is for you.

To those at Reprosoc at the University of Cambridge, thank you for welcoming me into the fold and providing feedback for my writing on traditional surrogacy. Professor Sarah Franklin, thank you for the mentorship. A special thank you to Dr Marcin Smietana, whose endless enthusiasm for my work spurred me on, and to Dr Katherine Dow (who read endless pieces of writing, both for this thesis and other endeavours). Thank you to other inspiring scholars who have been mentors and support along the way, Dr Elly Teman, Professor ZsuZsa Berend, Professor Marcia Inhorn, Dr Ayo Wahlberg, Dr Ken Daniels, Dr Damien Riggs, Dr Lucy van de Weil, Dr Karen Jent, and Dr Noémie Merleau-Ponty. 
To all my friends on Level 9 (and 10), thank you for your support and friendship. And to my other proof-readers, I cannot thank you enough. Some of you have read earlier drafts and others in the final weeks before submission. In no particular order, Dr Sharmila Rudrappa, Professor Nicole Asquith, Veronica, Zoe, and Simone.

To Nina, Sue, Mythily, Abs, Cynthia, my fellow PhD students in my online writing group, you have made this path easier!

A huge thanks to those organisations who funded my research and supported my vision. I began my $\mathrm{PhD}$ without any scholarship and within the first year was incredibly thankful to obtain several funding opportunities. In no particular order, Wellington Graduate Women $\mathrm{PhD}$ scholarship, Auckland Medical Aid Trust PhD scholarship, and Graduate Women New Zealand Fellowship. This would not have been written if it were not for you believing in me.

Finally, to Dora. Thank you for your daily dances, support, humour, and love. Your belief that I can do anything and seeing how proud you are for every small step I take has held me together. I could not have asked for a better life partner. And to my sidekick, Mr Darcy, with whom every day is an adventure. 


\section{Table of Contents}

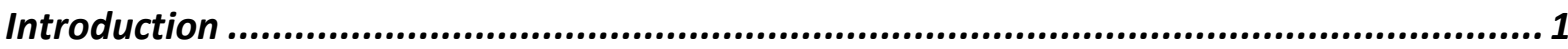

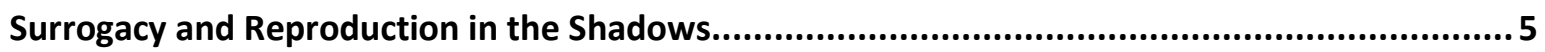

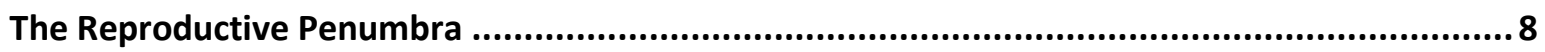

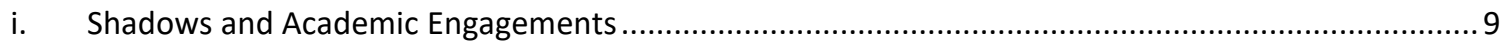

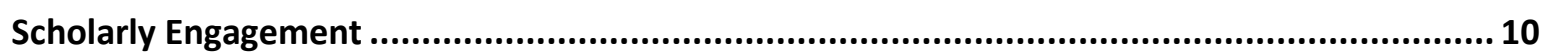

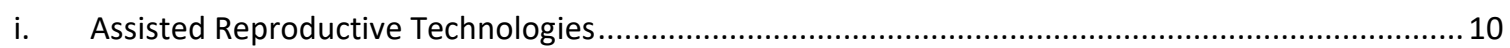

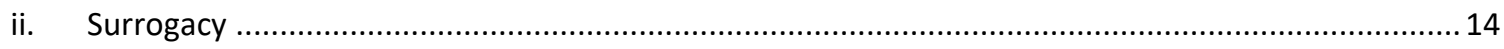

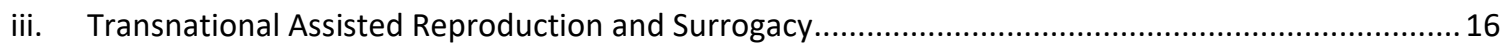

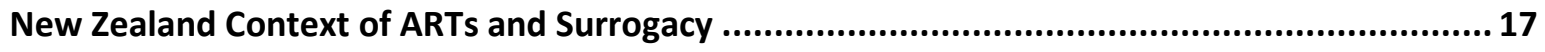

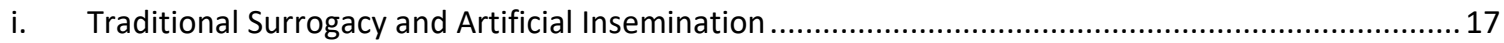

ii. The Privatisation of Fertility Medicine and Uptake of Gestational Surrogacy in New Zealand ..........18

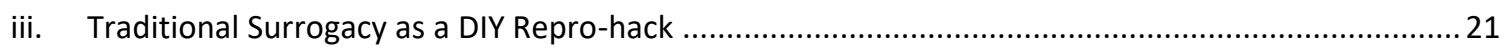

iv. Academic Engagement with Surrogacy in Aotearoa New Zealand ..........................................23

Shadow One - the Shadow of Colonialism on Māori Reproduction and Kin-making ................. 24

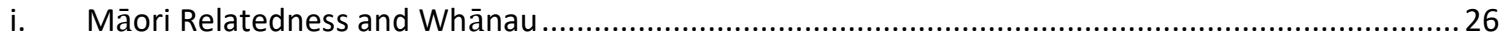

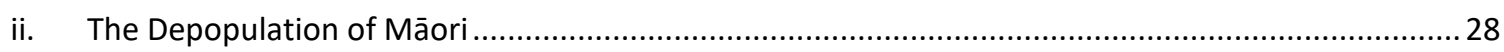

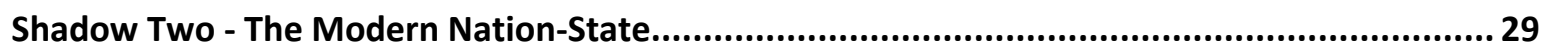

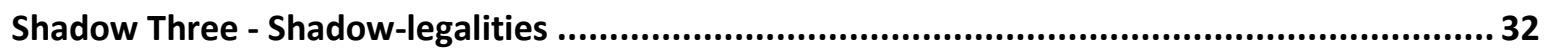

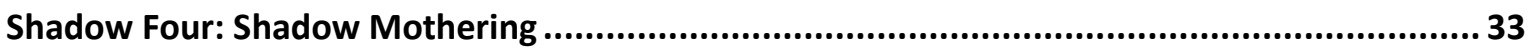

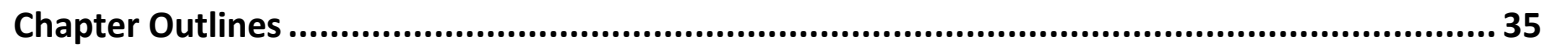

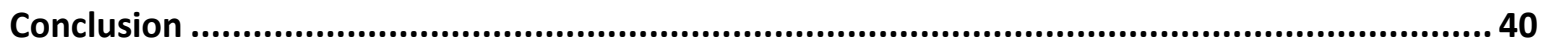

Chapter 1 Methods and Positionality: on Surrogacy Research.................................. 43

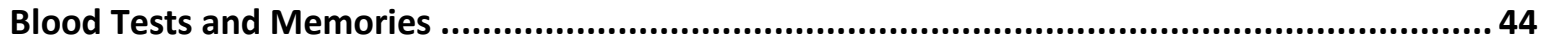

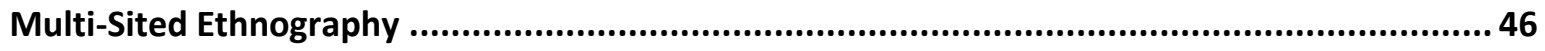

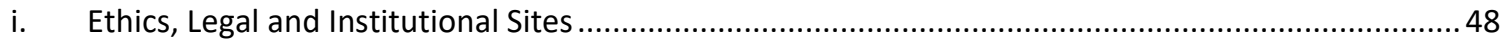

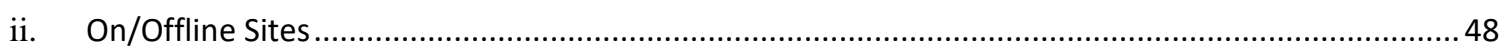

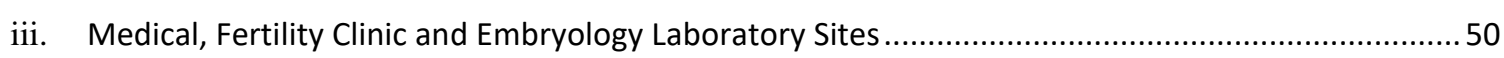

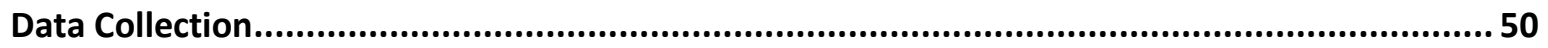




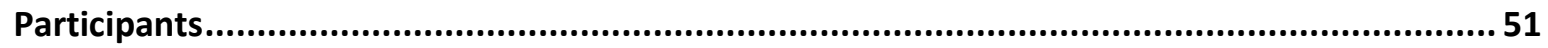

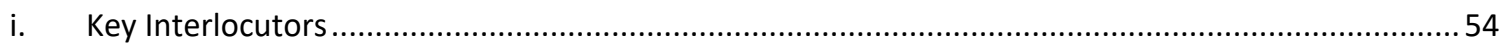

ii. Building Rapport................................................................................................................. 59

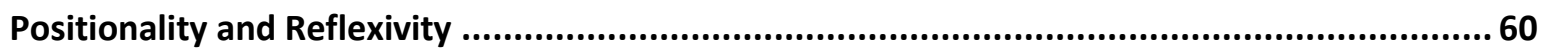

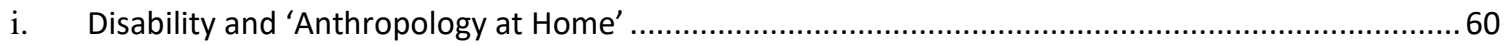

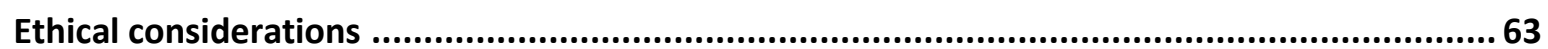

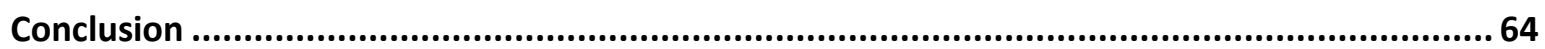

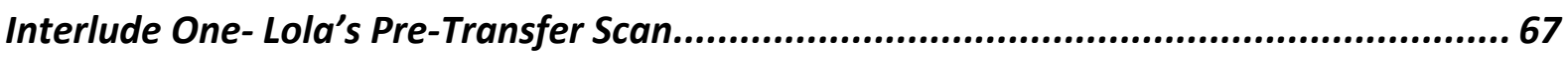

Chapter 2 Surrogacy Laws in the Shadows of the State ............................................... 71

Regulatory Debates on ARTs and Surrogacy in New Zealand 1983- 2003 ................................ 73

i. Introduction of the Human Assisted Reproduction Act 2004 and Ethics Committee ...................... 74

ii. Implication of Non-Inclusive Legilsation and Privatisation of Fertility Medicine .............................77

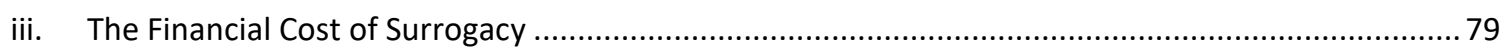

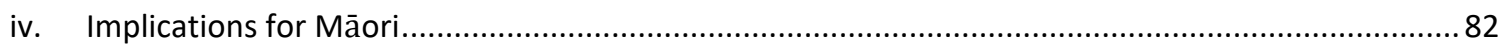

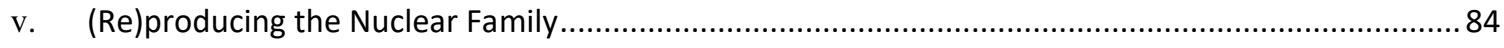

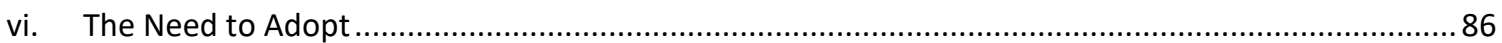

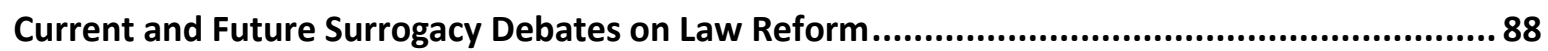

i. Changing Discriminatory Terminology and Calls to Banish the Adoption Model .............................8 88

ii. Rethinking Surrogacy Laws Project and a Radical Proposal for a New Model .................................89

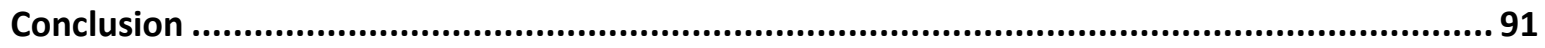

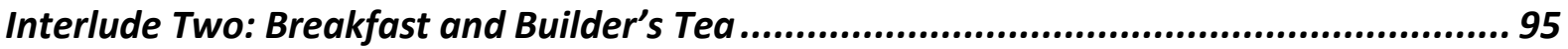

Chapter 3 'Doing It Our Way': Participation and Kinship in Traditional Surrogacy

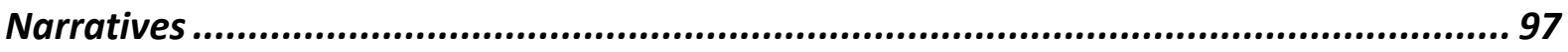

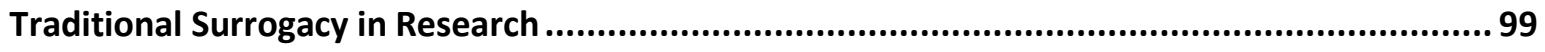

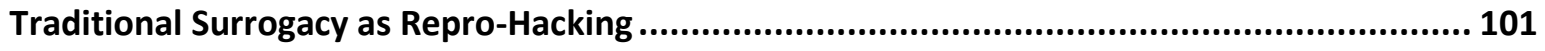

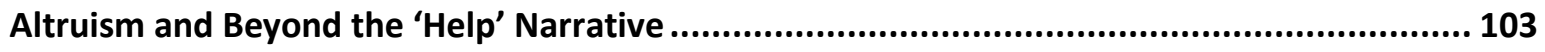

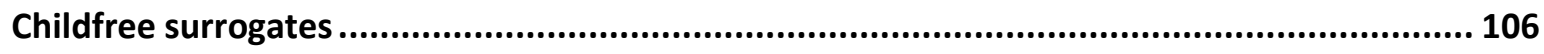

The Polarisation of and Discomfort with Traditional Surrogacy ............................................... 109

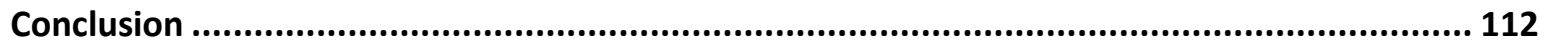

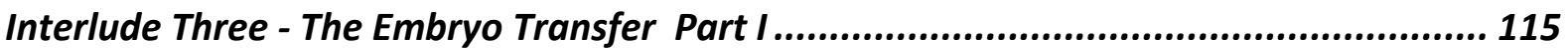


Chapter 4 Surrogacy and Shadow-legalities: The Informal Rulebook for Making Kin through ART in Aotearoa New Zealand ............................................................... 117

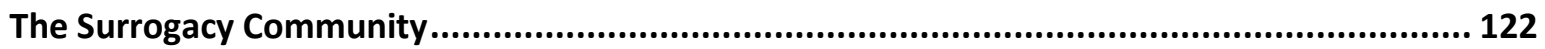

i. $\quad$ Rule One: Following the Community Rules to be Successful ................................................... 123

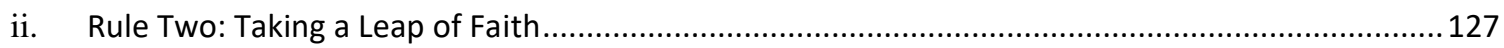

iii. Rule Three: Navigating 'Socially Acceptable' Norms Around Exclusivity ........................................ 130

iv. Rule Four: Mitigating Risk Through (Informal) Legal Contracts ............................................... 132

Understanding Surrogacy Shadow-Legalities: Informal Rules and Kin-making ..................... 135

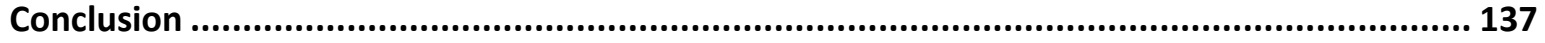

Interlude Four - The Embryo Transfer Part II ....................................................... 140

Chapter 5 Making Kin Under the Microscope........................................................ 143

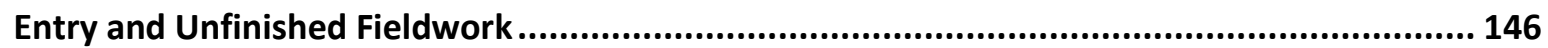

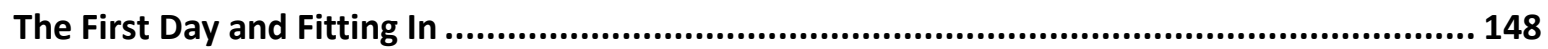

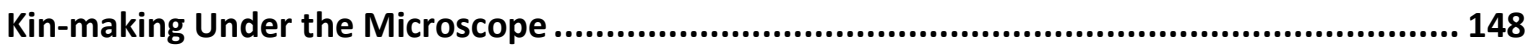

i. Mimicking the Womb and Giving Nature a Helping Hand ......................................................... 149

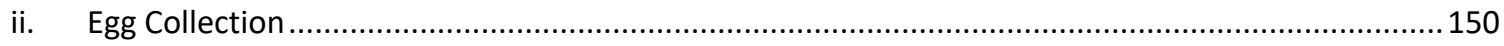

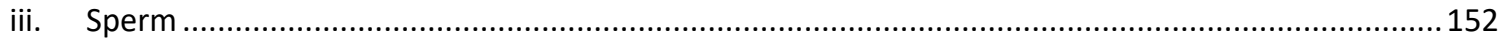

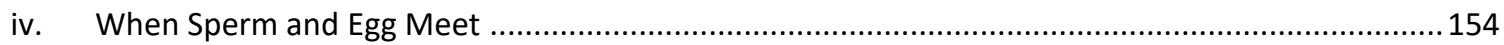

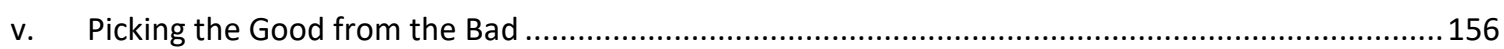

Tender Interactions and Custodianship ........................................................................... 158

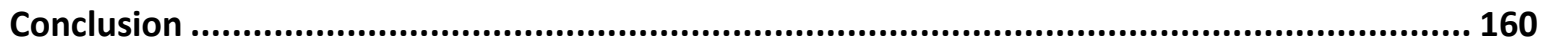

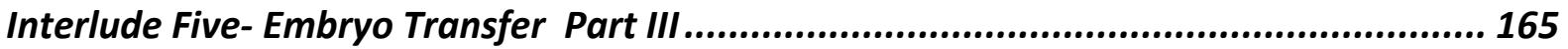

Chapter 6 Shadow Mothering in the Home in Aotearoa New Zealand....................... 167

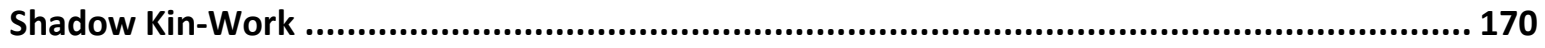

Mothering in the Shadows................................................................................. 171

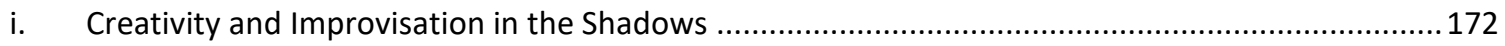

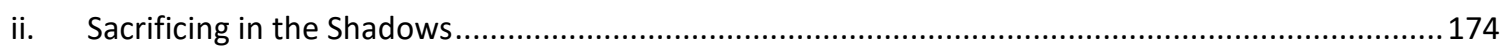

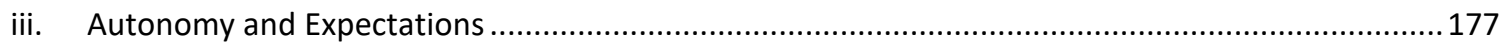

iv. Excluding and Including the Surrogate in Baby-Showers ...................................................... 178

v. Connection and Disconnection in the Shadows ................................................................... 182

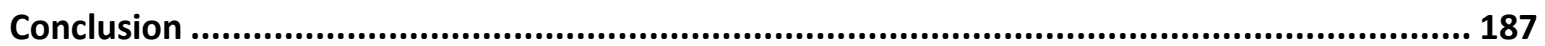




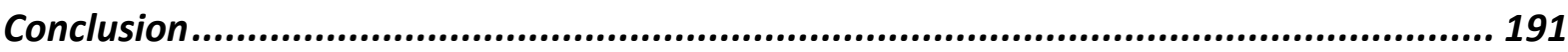

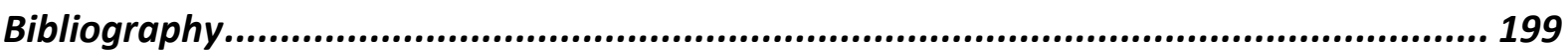

APPENDIX \#1: Research Project Information Sheet............................................... 236

APPENDIX \#2: Consent to Participate in Research Form .......................................... 238 


\section{Table of Figures}

Figure 1: Embryo. Watercolour by Hannah Gibson Error! Bookmark not defined.

Figure 2: Expanding Embryo. Pencil Drawing by Hannah Gibson 43

Figure 3: Spermatozoon. Photograph by Hannah Gibson 97

Figure 4: Before It Hatches. Photography by Hannah Gibson 117

Figure 5 Shades of Pink in the Petri Dish. Pencil Drawing by Hannah Gibson 143

Figure 6 Recreating Sperm as Fireflies: Photography by Hannah Gibson

Figure 7: ICSI. Pencil drawing by Hannah Gibson 154

Figure 9: The gendered script of the heroic and the passive egg. Photography by Hannah Gibson 155

Figure 8: Foregrounding the egg to change the script. Pencil drawing by Hannah Gibson 155

Figure 10: Babysitting. Watercolour by Hannah Gibson 167

Figure 11: Petals Make a Beautiful Embryo. Photograph by Hannah Gibson 191

All artwork created by Hannah Gibson 



\section{$I_{\text {matate }}$}

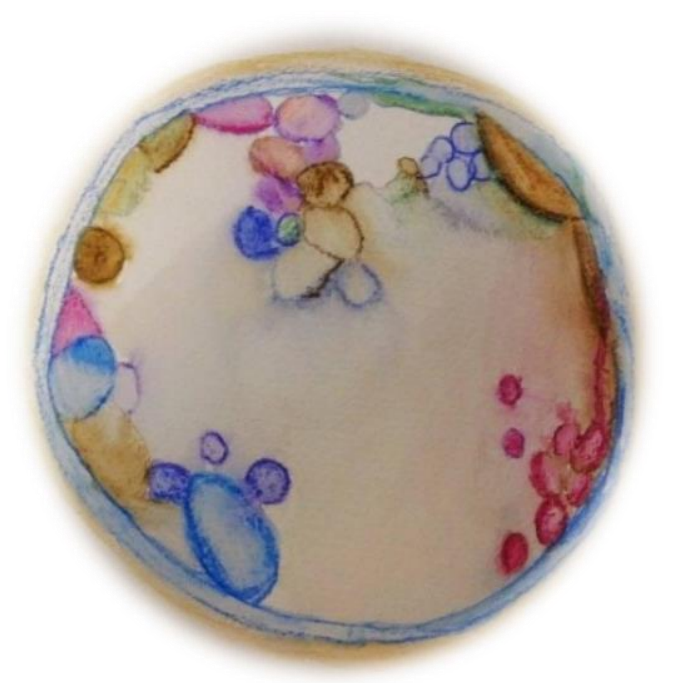

Figure 1: Embryo. Watercolour by Hannah Gibson

On the $2^{\text {nd }}$ of October 2020, I received an invitation from Lola to attend a barbeque. Lola has been both a traditional and gestational surrogate and helped me substantially as I mapped out the field of surrogacy for this research project ${ }^{1}$. The barbeque to which Lola invited me to was a special one, as it was an opportunity to meet Donna and Sam and their daughter, to whom Lola gave birth approximately a year ago as a gestational surrogate. I remember sitting with Lola and Donna two years prior over lunch when they self-matched some months before via an online forum for those wanting to create a family via surrogacy. The last time I saw Lola before $\mathrm{I}$ received the invitation to the $\mathrm{BBQ}$, she was wearing a $\mathrm{t}$-shirt with the words 'EXTREME babysitting' written across the front, which is an apt way to describe her experience as a surrogate. In 2017, amidst my fieldwork exploring surrogacy within Aotearoa New Zealand (hereafter New Zealand) between 2016-2020, Lola invited me into her world of

\footnotetext{
${ }^{1}$ The first surrogacy, where Lola donated her own egg and conceived via home insemination using a syringe filled with the intended father's semen, was followed by a gestational surrogacy journey where she was implanted with an embryo belonging to her last set of intended parents, Donna and Sam.
} 
non-normative kin-making as she was undertaking her first attempt at gestational surrogacy with her second set of intended parents ${ }^{2}$, Celeste and James (who equally welcomed me into the fold). Sadly, after spending a few years going through the processes of obtaining approval to go ahead with implanting the embryo into Lola, they were unsuccessful - and unfortunately had no more viable eggs or embryos. However, they eventually welcomed a baby girl into their lives via a traditional surrogate. The invitation to that BBQ amongst friends (who once were research participants) reminded me of the importance of understanding surrogacy and how it re-configures kin that is not solely reliant on biological, as a family is made beyond heteronormative expectations. Through my research, I show that traditional surrogacy complicates normative kinship to make visible possible interesting ways kin-making is undertaken in the shadows. In turn, it pushes the boundaries of our understanding of the coconstructed nature of kinship, motherhood, reproductive medicine, and the state.

Within Euro-American kinship ideology, when people talk about reproduction or 'the family', they imagine a heterosexual married couple who conceive a baby (via intercourse) inscribed with a fusion of the mother and father's genetic material. Kin is divided into blood relations and non-blood relations, assuming that the genetic relationship reflects this delineation (Thompson 2002, 178). Even though some of us do not see ourselves reflected in this ubiquitous image, it is an essential reference point. Family structures such as solo-parents, blended families, fostering, adoption, or queer families are rendered non-conventional and, in worst cases, deviant within mainstream Euro-American kinship ideology. Speaking about assisted reproductive technologies (ARTs), feminist anthropologist Sarah Franklin (1993, 27) writes that 'such innovations make clear that marriage, procreation, and the biological family are not the sole "natural" means of perpetuating the human race'. Despite this changing context, other family forms have not displaced the hegemonic nuclear family, and scholarship continues to describe its pervasiveness and privilege in law, institutions, medical spaces, and political debates within Euro-American contexts. Through my research, I contribute to this scholarship

\footnotetext{
${ }^{2}$ Intended parents is a term used throughout academic and popular literature, and within the surrogacy community itself. It simultaneously denotes couples at any stage of the surrogacy journey, ranging from before to after the surrogacy journey. In turn, women who intend to be the mother of the baby, are referred to as intended mothers (or IM for short), and men who intends to be the fathers are intended fathers (or IF). Neither necessarily signify the genetic relationship between the intended parents and the resulting baby, as in the example of gay or heterosexual couples and traditional surrogacy.
} 
by outlining the new and novel ways kin-making in the shadows is productively and innovatively working with/in these hegemonic structures to make visible new possibilities.

The opening paragraph of this thesis provides a snapshot of people creating kin via gestational surrogacy $^{3}$. It is the most controversial and elusive of the assisted conception techniques (with or without technology) involving three or more parties, the uptake of surrogacy has always been highly politicised in the countries where it is legal. Part of the discomfort that surrogacy elicits from people is because, as a cultural anomaly within Western kinship ideologies, it challenges our understanding of what reproducing kin looks like. In New Zealand, when people want to create a family and are presented with the news, or already know, that they cannot conceive and/or gestate a foetus to live birth, surrogacy is an option. While domestic commercial surrogacy or paying a woman to carry a child is illegal in New Zealand, the law does permit altruistic (also known as 'compassionate') surrogacy. Both traditional surrogacywhere a woman donates her egg and gestates the foetus for the intended parents-and gestational surrogacy - where a woman is implanted with an embryo and gestates the foetus she has no genetic relationship to-are legal on an altruistic basis. Therefore, prohibiting commercial surrogacy. The law does not prohibit New Zealanders from going overseas for commercial transnational surrogacy. However, no agreed upon global response to the movement of reproductive materials and bodies, combined with convoluted national laws that offer little protection to babies born of surrogacy overseas ${ }^{4}$, makes it a complex and risky practice.

In traditional surrogacy, which is also known as partial or genetic surrogacy, the surrogate is the genetic mother and, typically, self-inseminates at home using a syringe pre-filled with the intended father or sperm donor's semen. Traditional surrogacy is first mentioned in the story of Abraham and Sarah in The Book of Genesis in the Bible ${ }^{5}$. In comparison, gestational

\footnotetext{
${ }^{3}$ Within this scene, Lola's own history as a traditional surrogate continues to be realised (for example, her decision to be a gestational surrogate was because she had already been a traditional one).

${ }^{4}$ New Zealand will not supply a passport to any child born of surrogacy overseas and intended parents must apply for a special visa (unless the child is born in the US and Canada, who will be granted a passport) at the discretion of the Minister of Social Development. The intended parents must apply to adopt the babies once they return to New Zealand.

${ }^{5}$ When unable to conceive a child, Sarah said to her husband, 'behold now, the LORD has restrained me from bearing: I pray thee, go into my maid [Hagar]; it may be that I may obtain children by her'. (Genesis 16:2). Then in Genesis 30:3, Rachel, the 'barren' wife of Jacob, said to him, 'behold my maid Bilha, go into her; and she shall bear upon my knees, that I may also have children by her'.
} 
surrogacy, also known as 'clinical', is technologised, and the surrogate is implanted with an embryo belonging to the couple known as the 'intended parents'. Alternatively, it can involve the intended father's sperm and an egg donor in some cases with gay couples or if the intended mother does not have viable eggs. Known as In Vitro Fertilisation (IVF), it is a relatively new procedure that emerged with the ascendence of assisted reproductive technologies (ART). Since the first successful IVF related birth of Louise Brown in Great Britain in 1978, and then in 1983 in New Zealand, IVF has been 'constructed as a solution to the disruptions of infertility' (Walhberg and Gammeltoft 2018, 5). It also marked the moment where assisted conception and reproduction evolved from being an unregulated area to one that ultimately came under surveillance by fertility clinics and the state.

In gestational surrogacy, both intended parents and surrogates must engage with fertility specialists, nurses, embryologists, counsellors, and an ethics committee to seek approval before the surrogate can be implanted with an embryo. In other countries where both gestational and traditional surrogacy are legal (including Australia, the UK, Canada, some US states), gestational has become the preferred surrogacy option. In New Zealand, those participants who choose to do traditional surrogacy do so often due to technological defeat, the financial cost associated with the privatised fertility interventions, or until recently, denied entry based on sexuality. Unlike gestational, traditional surrogacy is practised in more informal settings: people have the freedom to start home inseminations when they choose to. Unless they decide to attend counselling or require a specific medical intervention ${ }^{6}$, there is no engagement with any government officials or medical professionals. The two types realign after the baby is born. Regardless of genetics, as the 'birth mother', the surrogate and her partner's (if she has one) names go on the birth certificate. For the intended parents to be legal parents, they must file for adoption once the surrogate has officially put the baby up for it. Their kin-making is not reflected in the current judicial practices and requires the intended parents and surrogates to reconfigure their re-configuring of kinship to be recognised by the state. Surrogacy becomes further delegitimised and, because recognition is vital to transfer legal parental status from the surrogates (and her partner) to the intended parents, they have no choice but to comply. Within each chapter, I examine the explicit and implicit narratives of having to negotiate the legitimacy

\footnotetext{
${ }^{6}$ For example, if a traditional surrogate does not manage to conceive easily, then there is the option for intended parents to pay for them to see a gynaecologist.
} 
of their kinship from the shadows, not only to the state but to broader society that stigmatises the practice.

\section{Surrogacy and Reproduction in the Shadows}

Those who practice surrogacy in New Zealand, whether traditional or gestational, do so without any reference to how it works ${ }^{7}$. How do they find someone to carry a baby for them? Is it legal? What are the crucial questions to ask? What are the red flags that warn them to not venture down a surrogacy journey with this particular person? People often ask these questions at the start of the journey. Unlike other countries where surrogacy is legal, there are no surrogacy agencies in New Zealand that provide guidance, in part because of the smaller population of approximately 5 million, and the prohibition of advertising for a surrogate or the creation of surrogacy agencies. My research shows that on further exploration, people discover that the legislation is ambiguous and, in some parts, archaic - and importantly does not adequately reflect or support the way people choose to make kin via surrogacy. Instead, they must conform, even if they resist in other ways, to a space designed to recognise and reinforce a heteronormative kin structure. In other words, because they cannot have a baby via 'natural conception', they are pushed to the peripheries, or shadows, of the heteronormative approach to making kin. From here, they must negotiate their parenthood with those institutions that privilege the nuclear family. Riggs and Due $(2010 ; 2013 ; 2014 ; 2019)$ propose that, regardless of sexuality, those who create kin outside of the heteronormative ('heterosex') method experience 'reproductive vulnerability':

Whilst reproduction is indeed a hallmark of contemporary citizenship, the cultural capital arising from this is still differentiated by mode of reproduction, with reproductive heterosex retaining the norm against which other modes are compared. This norm...[produces] "reproductive vulnerability", namely vulnerability arising from being located outside of the norm. (Riggs and Due 2013, 956)

In this thesis, I propose that surrogates, by making kin for others and not themselves, also experience reproductive vulnerability at different stages of the journey. Surrogates and

\footnotetext{
${ }^{7}$ Of course, people will likely have seen the different television shows or media stories about surrogacy and be aware of what it is, but they do not understand the specific steps to take.
} 
intended parents, by varying degrees, step into or are pushed into the shadows, an obscure and sensationalised space, because of this vulnerability. Yet, their narratives reveal that vulnerability, like shadows, are not inherently negative or a problem of powerlessness. Instead, Gibson and Bell's $(2018,197)$ assert that experiences of health and illness 'simultaneously create and require a range of different interconnected vulnerabilities, some of them harmful, and some of them life affirming'. In this thesis I show that reproductive vulnerability is not solely tied to discrimination from the political, public, and legislative structures that uphold heteronormative kinship discourses. Instead, reproductive vulnerability can lead to improvisation and the potential to reconfigure kin in new ways within the shadows to which they have been relegated. Importantly, in connecting with others in the surrogacy community, vulnerability becomes the basis of individual and collective empowerment ${ }^{8}$.

As I discuss in chapter four, the vulnerability and uncertainty that people experience when they join the surrogacy community is eased by embracing the tried and tested assisted conception techniques and technologies. These include the in/formal rules of conduct that have emerged within the surrogacy community to help guide those new to surrogacy. Yet, all parties must surrender to reproductive precarity and, for intended parents, the last chance or opportunity to have the baby they have hoped and tried for, some for many years. All these elements accumulate, and people end up engaging in both worlds: the strict medical/ethical gaze and regulations in one and the elusiveness of a reproductive narrative and world unknown to them in the other. In this thesis, each chapter holds the tension between these two overlapping aspects.

I use the term 'kin-work' throughout my chapters to denote that different people along the surrogacy journey undertake aspects of creating kin via surrogacy. The framing of work that is involved in kin-making beyond the simplistic understanding of biology, is in part inspired by Laura Brigg's (2017) expansive interpretation of reproductive labour:

Reproductive labor is the work necessary to the reproduction of human life - not only having and raising children but also feeding people; caring for the sick, the elderly, and those who cannot work; creating safety and shelter;

${ }^{8}$ For example, Carl, a lawyer and intended father, successfully fought for his right to co-adopt his two children born via traditional surrogacy, with his male de-facto partner (rather than having to marry as per the law until these recent changes). 
building community and kin relationships; and attending to people's psychic and spiritual well-being. Most reproductive labor is done by people understood to be women, and because it is historically unpaid work - critical to the production and maintenance of a labor force but outside the formal system of work, wages, and production - we often think of it as belonging to a private sphere - the opposite of the public, where politics and economics live. (Briggs 2017, 2)

Brigg's argument is based on the convincing premise behind the dichotomous private/public sphere that is so pervasive in Western society, that all politics are reproductive politics. Speaking specifically about the US, she states that all the major political questions and polarising debates, including 'welfare, immigration, policing, schools, abortion, reproductive technology... all of these are reproductive politics questions.... [including] gay marriage, civil rights and the long Black freedom movement, social security and pensions...all have reproductive politics at their core or as a critical component' (Briggs 2017, 2-3). Conversations about abortion, immigration, refugees, the economy, LGBTQ+ rights, race, and class 'center around questions of children, households and families (or, to put it the other way, our conversations about reproductive politics are deeply about race, just as they are about sexuality)' (Briggs 2017, 4). These conversations also implicate assisted reproduction, particularly about privilege, race, class, gender, economics, and conceptualising what kind of future we aspire to have. Importantly, and as Briggs so aptly argues, reproductive politics are as much about how to raise children as it is about the (re)production of children.

Taking inspiration from Briggs (2017), I propose that politics in New Zealand is about reproductive politics, of which reproductive labour is a part. Broader political debates involve issues relating to surrogacy. The ineligibility of some intended parents, the need to adopt their own children, and the privatised fertility industry link to and impact on political discussions about welfare, public policy, the politics of gender and bodily autonomy, ethnicity, (dis)ability, and sexuality. Further, 'reproductive politics is not only about governments' regulation of sexuality, marriage or child rearing but also how reproductive knowledge is communicated and circulated' (Dow 2019, 190). Dow's point is evident in the media bias, with New Zealand magazines and newspapers featuring the stories of predominantly white, heterosexual, and married couples (Michelle 2006). Additionally, public unease and negative media portrayals of ARTS shape political debates (Michelle 2007). These factors influence which types of 
families will be created in fertility clinics and which are discouraged from reproducing, inhabiting the shadows, or the peripheries, of acceptable family forms.

\section{The Reproductive Penumbra}

Light is the experience of inhabiting the world of the visible, and that its qualities of brilliance and shade, tint and colour, and saturation are variations, upon this experience. (Ingold 2000, 265)

Straddling the two reproductive worlds - 'traditional' and 'technological' - surrogacy in New Zealand offers us a ripe site for analysis and rethinking how kinship is made and unmade within what I refer to as the reproductive penumbra. Inspired by Nordstrom's (2000) concept of 'shadow economies' or networks that may on the surface be seen as disruptive spaces, the reproductive penumbra denotes a nebulous space that exists outside of, or in the shadows of, heteronormative reproduction and kinship ideologies (even if certain practices or beliefs work to reinforce normative kinship). In the space between the light and the umbra ${ }^{9}$ lies the penumbra (umbra is Latin for 'shadow' and pen means 'almost'). As the partially shaded region of the umbra, the penumbra is then a quasi-shadow. When the penumbra is looked at through the lens of reproduction, it provides a glimpse of a space where people reject and accept kinship simultaneously. Yet, instead of the penumbra being a space between invisibility and visibility, it is a place where people celebrate a plurality of reproduction. It is an ontological mutability where improvisation exists because it has evolved out of necessity. Here, the liminal elements of shadows are celebrated, which can only exist in response to light, yet also be defined as the absence of it. And in this absence of light, what new 'constellations of relations' (Strathern 1995b, 26) will be made? How does surrogacy complicate and re-configure normative kinship within New Zealand? As a provocation, the reproductive penumbra invites us to be curious about what kin-practices, narratives, rituals, rules, and relationships are mobilised within and between the institutional, private, medical, and regulatory landscapes involved in surrogacy. Suppose we begin from the premise that kinship is nimble and malleable. In that case, the potentiality of what kinds of relations people make and unmake within different sites become visible and essential.

\footnotetext{
${ }^{9}$ The umbra is the part of a shadow that is created when an impervious object completely conceals the light-source.
} 
We must look at what it is that is fully visible and inhabiting the light to understand the essence of the shadows in the context of surrogacy in New Zealand. It is equally important to examine what causes the umbra and penumbra to form in the first place; what seemingly impervious object blocks our view? Otherwise, we face the possibility of assuming that what we see, or think we see, has always been an a priori experience of 'inhabiting the world of the visible' (Ingold 2000, 265). It is only in understanding the shape and composition of the object or entity that produces arguably superficial boundaries between light and dark. Then, we can begin to see the implications of inhabiting either the shadows or the light. In the context of surrogacy in New Zealand, various metaphorical objects cast shadows that determine who or what inhabits the light, the penumbra (or quasi-shadow), and the umbra itself.

\section{i. Shadows and Academic Engagements}

Through this thesis, I attend to monolithic institutions like 'motherhood', 'science', and 'state' casting their shadows - while also acknowledging the shadow of colonialism in a settler context. Some scholars use the term 'shadows' to interpret or describe arduous and incomprehensible experiences that impose certain darkness on those who have lived through those experiences. These include children who are born of and grow up under a 'shadow' of sexual assault (Van Ee and Kleber 2013) and incest (Lev-Wiesel 2006), living with 'shadow mothers' who have mental health conditions (Hannan 2014), 'shadow children' born of mothers who were addicted to cocaine (Rist 1990), 'shadow education' as supplementary lessons outside of education (Lee and Shouse 2011), and Iranian mothers of deaf children living in the 'shadow of shame and stigma' (Ebrahimi et al. 2016). In this case, the darkness depicts a time of toil in opposition to the light or easier times. It also suggests a deficiency as if mothers are unable to be 'good' mothers because of the perceived troubled circumstances that their children were born from and/or into. In chapter six, I also explore the darker side of surrogacy and the cases where the intended parents do not appreciate the surrogate's role.

Nordstrom (2000) and other scholars (Ferguson 2006; Galemba 2008; Sampson 2003) focus on a specific level of shadow spaces or practices. These range from the global shadow economies - which refer to the movement of power, money, goods, and people outside of any formal state governance - to the micropolitics of interactions in the private sphere (Macdonald 2011) and reproductive labour. Other ethnographies have also used the shadow as an image for less imperceptible ideas (Bluebond-Langer 1996; Liu 2000; Stoller and Olkes 1987), or tool 
(Behar 1993; Das and Poole 2004, 30; Frank, Raper and Cheylan 2000; Crapanzano 2006). In this thesis, I outline how shadows, as key elements of the reproductive penumbra, are layered on top of one another through all stages of surrogacy, ranging from the intimate and interpersonal relationships in the surrogacy community, at the fertility clinic, and inside the embryology laboratory, to the institutional and regulatory processes and the state. However, before I attend to the various shadows, I want to turn to my research focus, shaped by my scholarly engagement within the anthropology of reproduction and critical kinship studies.

\section{Scholarly Engagement}

\section{i. Assisted Reproductive Technologies}

Since Louise Brown was born in 1978, an estimated 8 million IVF babies have been born globally (Yovich 2020), with the global IVF industry thought to be worth $\$ 36.2$ billion a year by 2026 (GVR 2019). Louise Brown's birth signalled the moment that the 'creation of humans through assisted reproductive technologies (ARTs) became a reality' (Dow 2019, 314). IVF was the basis for other technologies such as pre-implantation genetic diagnosis and Intracytoplasmic Sperm Injection (ICSI) that would shape the kinds of kin people were creating. The recent edited volume by Walhberg and Gammeltoft (2018) on selective reproduction in the twenty-first century explores how local moralities across different cultural contexts play out. Other evolved technologies that are at the forefront of medicine include regenerative medicine and embryonic stem cell research (Franklin, 2018; Jent 2018; MerleauPonty, Vertommen and Pucéat 2018; Rapp 2011). As they have provided people with opportunities to create new formations of kin, these advancements in reproductive medicine have made the biogenetic elements of human relationships more visible than ever before (Strathern 1995). In literally taking reproduction from the private sphere and into the biomedical laboratory, ARTs redefine the traditional family and the reproductive model as biological and technological (Franklin 1995; 2008). More than any other technology, IVF simultaneously complicates at the same time it reinforces the traditional Euro-American understanding of kin.

Ten years before Louise Brown's birth, in 1968, Schneider argued that the anthropological study of kinship until that point was treated by anthropologists as something that occurred in 'primitive' cultures and was approached with scientific enthusiasm. The emphasis was on drawing kinship diagrams and using complex terminology to describe how people socially 
organised themselves around biological ties (Morgan 1871). Reproduction was treated as something that reflected biological relationships, and kinship was considered a universal system that could be classified. This view assumed that kinship and social bonds were 'natural' categories and systems. In his influential ethnography, American Kinship: A Cultural Account $(1968,27)$, Schneider argued that kinship was an artefact of culture and not solely on blood relations. He writes that:

The cultural universe of relatives in American kinship is constructed of elements from two major cultural orders, the order of nature and the order of law. Relatives in nature share heredity. Relatives in law are bound only by law or custom, by the code for conduct, by pattern for behaviour. They are relatives by virtue of their relationship, not their biogenetic attributes.

Schneider distinguishes between the categories of relationships defined by nature ('father', 'mother', 'daughter', and 'son') and those the law created, such as husband and wife. This contribution became known as the cultural approach to kinship and signalled for the first time that relationships that exist in law are naturalised as if they reflected nature. Then in his 1984 ethnography, A Critique of the Study of Kinship, Schneider developed his earlier ideas further, highlighting the value people put on, and the tracing of, biological ties as the basis for inheritance and genealogy are specific to Euro-American kinship ideology. By placing the microscope onto Western society, Schneider also destabilised the earlier assumptions of the universality of kinship as we understand it. The seminal collection of essays, Gender and Kinship: Essays Toward a Unified Analysis, from feminist anthropologists Jane Collier and Sylvia Yanagisako in 1987 was the launch of critical kinship studies. They situated gender at the core of anthropology and kinship, and alongside other feminists such as Rayne Rapp, they deconstructed the analytical categories popular in anthropology, nature/culture, reproduction/production, and private/public. Building on this, Strathern (1992a, 1992b) and Franklin (1997) explored how kinship is naturalised in an English context, and Carsten (2004) in cross-cultural sites. Building on the work of Collier and Yanagisako, their theoretical contribution on the social construction of biological relatedness became the foundation of critical kinship studies that has since developed into a multi-disciplinary field of inquiry. 
Later critiques would condemn Schneider's focus on heterosexual married couples who conceived and birthed their children 'naturally'. A central catalyst for this debate was the rise of ARTs as an answer for disrupted fertility. In response, the anthropology of reproduction and Science and Technology Studies (STS) scholarship has grown exponentially in the last three decades. Collectively, scholars map and explore how ARTs and other fertility interventions are accepted/rejected and practised within local landscapes and in response to the global phenomenon that Inhorn and Patrizio (2012) describes as 'Cross Border Reproductive Care'10. In the context of Euro-American kinship, the central claim they all make is that even though a minority use ARTs as a fertility intervention, they change and shape cultural knowledge of how we think about and understand relations with one another and relatedness as a whole (Edwards 2000; Franklin 2008; Strathern 1995, 2005). They interrogate the foundations on which EuroAmerican kinship ideology was built (Franklin 1997; Carsten 2000, 2004; Franklin and McKinnon 2000). Namely, that kinship exists a priori to culture, as a static category steeped in nature. They explore how normativity has been naturalised, challenged, resisted, and played out by those creating kin formations in different contexts (Thompson 2005; Mamo 2007).

According to scholarship by Modell (1989), Ragoné (2003) and Teman (2003), people rationalise their use of ARTs in surrogacy by way of naturalising them, or as Thompson (2002) claims, strategic naturalising. To this end, Franklin $(1997,162)$ contends that it is IVF as "the embedding of a technological sequence within a larger sequence of "life's progression" [that] helps naturalise the technology itself as "giving nature a helping hand"'. This renders technological conception as 'work of/by nature', which attempts to naturalise, or re-biologise, the technology and thus reproduction itself. In other words, in the same way it is possible for technology to "“adjust" the facts of life, so too is this "adjustment" process a ubiquitous feature of social life, and in particular, of social relationships and ties' (Franklin 2006, 550). Strathern (1992) describes this extension of nature, or the use of natural science to create the biological family, as 'after nature'. This interpretation is made possible by what Strathern (1992) describes as 'literalisation' or of 'making visible' or explicit those implicit discourses, ideas, practices, and meanings, and in this case, of/about kinship. Due to the debates surrounding surrogacy and ARTs more generally, norms of motherhood, femininity, and kinship become

10 Also known as 'fertility tourism, reproductive tourism, procreative tourism, transnational reproduction, reproductive travel ("reprotravel"), or reproductive exile' (Salama et al.), it refers to people travelling overseas for fertility treatments such as IVF, ICSI, sperm and egg donation, and commercial surrogacy. 
“literalised', by which [Strathern] means they are exposed to active attention, which can have the knock-on effect of making them seem less certain because they appear made rather than given' (Dow 2017, 100). Linked to the naturalisation of biology was a second line of inquiry into:

the role of sex - and specifically the binary conceptualization of men and women and the resultant naturalization of heterosex- in the production of kinship categories...[and] the cultural normalisation of heterosexuality serves the purposes of capitalism, namely to ensure the production of surplus capital via the production of a particular social unit - namely the heterosexual couple. (Riggs and Peel 2016, 8)

This highlights the critical kinship studies focusing on examining which kinds of families have historically, and continue to be, valued in Euro-American kinship ideologies. As well as to what extent this has impacted the legal protection of families that do not fit the nuclear family typology. As discussed at the start of this introduction, those who do not create families via heterosexual intercourse are reproductively vulnerable and open to more challenges and stigmas in their journey in creating families and practicing kinship.

By the twenty-first century, despite the proliferation of research on 'human reproduction, as a biological phenomenon that is socially constituted and culturally variable through space and time', non-normative approaches to reproduction were still neglected (Van Balen and Inhorn 2002). Scholarly interest has evolved and, in the past two decades, we have seen how new kin configurations that do not conform to any specific trajectory are possible, particularly with the fragmentation of bodies and reproductive material that occurs in surrogacy and gamete donation (Almeling 2011,143; Berend 2016; Nahman 2013; Grebeldinger 2013; Teman 2010; Thompson 2002). With IVF, kinship has become nimbler, and no longer can genetic material be the only basis for motherhood or parenthood. At the same time, ethnographic examples, particularly in Euro-America, highlight the preference of biogenetic kinship as the marker of 'real' parentage (Ragoné 1998, 129). Franklin (1995; 2002), Inhorn and Birenbaum-Carmeli (2008), Levine (2008) and Satz (2007) contend this emphasis on genetic links is the impetus for infertile couples seeking ways to have children using their genetic material. On the surface, ethnographies published on egg and sperm donation, both in the US (Almeling 2011), and globally (Nahman 2013) challenge the importance of biogenetic relatedness in family 
formation by demonstrating the value people place on social or intentional parenting. Other scholars such as Thompson (2005), Mamo (2007), and Nordqvist (2012; 2014) discuss the way queer families use ARTs as tools to mimic dominant heteronormative narratives and essentially emulate heterosexual family structures.

\section{ii. Surrogacy}

Anthropologist and surrogacy scholar, Teman $(2010,1)$, writes that academic inquiry into the ethical, religious, legal, and broad social considerations highlighted by surrogacy reflects a sense of uneasiness with it. This uneasiness relates to concerns over the commodification of women and children, the inequalities that can arise between classes and ethnicities, and the idea that people might be 'playing with nature' or exploiting and placing a value on a woman's reproductive labour. Surrogacy is practised within different contexts, cultures, and jurisdictions, with often uneven power relations underpinning the practice, particularly transnational surrogacy. The acceptability of IVF and surrogacy differs across nations and often depends on the local religious, moral, and cultural context, alongside whether there is access or the ability to pay for it. Themes that emerge from the literature on surrogacy are not easy to separate from themes found within research about ARTs.

Anthropologists have explored how women navigate situations like surrogacy, where more than one woman can be the candidate for the role of mother. In her research in a fertility clinic in the US, Thompson $(2002,177)$ describes both gestational surrogacy and egg donation as procedures that draw on substance and genes as relevant categories of kinship, but 'distribute the elements of identity and personhood differently'. For example, people render genetic links irrelevant or relevant depending on who will be the parent to the eventual baby. In her 2005 ethnography Making Parents, The Ontological Choreography of Reproductive Technologies, Thompson writes that, rather than the common perception of ARTs as there to make children, they are different biotechnological advances that make parents. She argues that ARTs require a complex assemblage of people, technologies, genetic material, tools, and techniques to hopefully achieve the goal of parenthood for the couples that enter the clinic. With all these moving parts, and given how ARTs can cast doubt on the relationship between people and their offspring, they 'demand as much social as technological innovation to make sense of the biological and social relationships that ARTs forge and deny (Thompson 2005, 5). The social innovation required is what she refers to as ontological choreography, which is 'the dynamic 
coordination of the technical, scientific, kinship, gender, emotional, legal, political, and financial aspects of ART clinics' as a means to provide 'parents, children, and everything that is needed for their recognition as such' $(2005,8)$. Ontological choreography works to determine who qualifies as a parent, what qualifies as kinship, and why.

In her ethnography—aptly titled Birthing a Mother: The Surrogate Body and the Pregnant Self - on gestational surrogacy in pro-natalist Israel, Teman (2010) explores how medical, institutional, and private spheres all provide the opportunity for the intended mother to be recognised as the only mother, from before the birth of the baby. Teman describes surrogates' inventiveness in inverting early feminist critiques of and fears about surrogacy as medicalisation ${ }^{11}$ and objectification of, and disconnection between a woman and her body. Surrogacy becomes a relational practice of positive empowerment, where surrogates find ways to emotionally detach the foetus via the development of a close friendship and bond with the intended mother, which, in turn, sheds any maternal claims to the foetus. This then allows space for the intended mother to assert herself in the role. At the level of the state and fertility clinics, where IVF is fully funded (and only available for married women), the intended mother's name is noted in the medical records as the impending baby's mother, thereby reconfiguring her as the pregnant self. Ziff $(2020,2)$ similarly writes about the medicalisation of the surrogate body in the US to contextualise how surrogates navigate biomedical control and power inherent to gestational surrogacy. Specifically, the pre-IVF phase of the arrangement is crucial because surrogates can negotiate their needs, for example, in terms of what intervention they would allow.

In her book Labor of Love, Jacobson (2016) explores how US surrogates, intended parents, and agencies work together to replace the stigma associated with the term 'wombs for rent' by emphasising it as a moral avenue to parenthood. Reframing surrogacy as a sacrifice makes it less threatening than the connotation of exploitation and commodification of babies. She also argues that, rather than transgressing normative understandings of family, surrogacy practices

\footnotetext{
${ }^{11}$ Medicalisation refers to the 'biomedical tendency to pathologize otherwise normal bodily processes and states' (Inhorn, 2006, 354). An example is the pathologisation of 'natural' stages of life, including menarche and menopause, into conditions requiring biomedical mediation. Ziff $(2020,3)$ writes that the 'medicalisation of birth and infertility [is] the expansion of medical jurisdiction and its use as a mechanism of social control through the medical gaze and surveillance'. See further discussion in Brubaker and Dillaway (2009), Fox and Worts (1999), Ginsburg and Rapp (1995), and Inhorn and Birenbaum-Carmeli (2008).
} 
are underpinned by the permanence of biology in kinship. In her ethnography The Online World of Surrogacy (2016), Berend provides a different snapshot of US surrogacy, focusing on American surrogates themselves. She describes different methods and less stringent regulations than in Israel, but a similar mindset within the intended mother-surrogacy dynamics in the US, where surrogates focus on enabling other women to fulfil their maternal roles. Berend's indepth snapshot of surrogacy is based primarily on analysing a public online surrogacy forum in the US where gestational and traditional surrogates create meaning about their experiences together. Berend's findings have helped me to frame my fourth chapter about the online surrogacy community.

\section{iii. Transnational Assisted Reproduction and Surrogacy}

Globally, surrogacy is positioned, especially in the commercial context, with different framings of reproductive labour based on diverse socio-cultural, political, legislative, moral, and ethical landscapes ${ }^{12}$. This thesis does not explore cross-border reproductive care-the practice of people travelling into other jurisdictions for assisted reproduction and surrogacy services-yet it is important to acknowledge the work taking place in this arena. Research highlights the concern of the commodification and exploitation of reproductive labour, body parts, ova, and sperm produced through transnational reproductive services (Pfeffer 2011). Within this rhetoric is the "harmful effects as a result of neoliberal policies which privilege the reproduction of elite women and create a pool of "bioavailable" (Colen 2005, 83) poor women of the global South willing to engage in the potentially risky sale of their eggs [and wombs] for moderate financial gain' (Grebeldinger 2013, para 14). Many feminist anthropologists (see Bergmann 2011; Inhorn 2011; Markens, 2007; Whittaker and Spier 2010) argue that this exploitative nature of transnational reproductive services causes stratified reproduction. Ginsburg and Rapp (1991) describe how stratified access to ARTs locally and 'among disadvantaged segments of the (global) population' are implicated in the globalization of these technologies (Inhorn and Van Balen 2002, 5). These are also inextricably connected to transnational surrogacy (Deomampo 2013, 2016), and the role of the media in representing transnational reproductive care (Riggs and Due 2013; 2017). These ethnographies also outline the role of state and national governments in regulating reproduction and kin-making - both for local surrogates and

\footnotetext{
${ }^{12}$ Some ethnographic examples of how local moralities converge with pronatalist aspirations of (re)producing more people using ARTs include a focus on Egypt (Inhorn 1994; 2003a; 2003b); Israel (Kahn 2000, Prainsack 2006, Teman 2010), India (Bharadwaj 2016) and China (Wahlberg 2016).
} 
international parents ${ }^{13}$. In addition to not exploring international surrogacy, I do not write about the debate around commercial versus altruistic surrogacy. This is not to bypass the critical discussions around whether, as reproductive labour, surrogacy should be compensated ${ }^{14}$. Instead, the focus of my chapters is on understanding the composition and nuance of the kinwork required to help with everyone's eventual goal of creating kin vis-a-vis surrogacy

\section{New Zealand Context of ARTs and Surrogacy}

\section{i. Traditional Surrogacy and Artificial Insemination}

While traditional surrogacy has its origins in the first documented application of artificial insemination in London in the 1770s by John Hunt (Ombelet and Robays 2015), surrogacy and legal scholars typically trace it back to two stories in the Bible mentioned at the start of the chapter. In many ways, both the biblical and technological stories are foundational, yet artificial insemination has become the preferred method because it did not require sexual intercourse, which helped reduce any connotations of infidelity. Before the development of assisted reproductive technologies (ARTs) in the 1970s, artificial insemination was the only option available to couples requiring a surrogate, which meant that the resulting baby would be genetically related to the intended father and the surrogate who gestated and birthed them. Traditional surrogacy, sometimes referred to as 'genetic surrogacy', is thought as mimicking natural conception, and in contemporary times, it is typically performed via home insemination. Even though it has substantially less medical input and higher success rates than gestational surrogacy, traditional surrogacy has unique risks. These include the fear of emotional distress for the surrogate when it is time to 'give up' the baby to the intended parents and the intended mother struggling to accept the baby as hers (van den Akker 2017). With no mandatory counselling, people have fewer formal opportunities to discuss their worries or concerns. Traditional surrogacy is more stigmatised than gestational because it challenges the foundations of Euro-American reproduction and kinship ideologies grounded in one man and one woman make a child.

\footnotetext{
${ }^{13}$ See van Wichelen $(2016 ; 2018)$ for valuable insights into the legalisation of parenthood via international surrogacy and adoption in the age of globalisation and biotechnology. van Wichelen 2016, 26) writes about the implications of legal justifications for parenthood at the intersection of law and biotechnology that ultimately changes the ethics and rights around surrogacy.

${ }^{14}$ This is something that I tackle more in-depth in an article I will publish next year, thinking through the implications of recompense versus Walker and Van Zyl's (2017) proposal for the professional model of surrogacy that would mean mandatory service fees paid to the surrogate, outlined in chapter one.
} 
The case that influenced political debates in the UK and in New Zealand on the ethics of surrogacy, particularly around who should be the legal parent of the baby born as a result, was the infamous Baby M case. An American traditional surrogate, Mary Beth Whitehead, refused to relinquish the baby born in 1986 to the intended parents (New Jersey Supreme Court 1987). A Member of Parliament at the time, Dianne Yates, cited this case as justification for an altruistic and well-regulated model in hopes this would avoid exploitation and commodification in New Zealand (Yates et al. 2015). Since Mary Beth Whitehead was a traditional surrogate, this further fueled the societal stigma and fear that traditional surrogate is exploitative of women. In combination with this, the increasing availability of gestational surrogacy (for those who could afford it), and the privatisation of fertility interventions, assisted reproduction evolved from being an unregulated area to one that ultimately would be under surveillance by fertility clinics and the state. In this thesis, I do not claim which type of surrogacy has less risks or is more appropriate to practice. Instead, my focus is to render visible the experiences and voices of my participants, highlighting the complex yet beautiful experiences of making non-biologically related $\operatorname{kin}^{15}$ in the technological contemporary. To show that kin-making in the shadows, via surrogacy, is a site of analysis because these shadows uncover questions about normative kinship.

\section{ii. The Privatisation of Fertility Medicine and Uptake of Gestational Surrogacy in New Zealand}

Assisted Reproductive Technologies (ARTs) and how they complicate our understanding of kinship, either by themselves or within the context of surrogacy, have been instrumental in framing my research. The first successful birth from gestational surrogacy occurred in the US in 1985. It was the first procedure to provide women who were unable to conceive or/and gestate a foetus to live birth the opportunity to have a baby that is biogenetically related to her. The uptake of gestational surrogacy in New Zealand did not occur until the 1990s, and even then, it was not a common practice. Before the Human Assisted Reproductive Technology Act (HART) 2004 Act was created, a handful of gestational surrogacy arrangements took place. Parallel to this legislation, the legality of surrogacy and what role the state should play in regulating it continued to be debated within the increasingly neo-liberal approach to governance. In New Zealand, there is no legislation pertaining to surrogacy alone, and the incorporation of it into existing regulatory frameworks has always been highly politicised.

\footnotetext{
${ }^{15}$ Although intended mothers have no biological connection to the baby born of traditional surrogacy, the intended father does. Since my participants were primarily intended mothers, I examine kinship from their perspective.
} 
While the initial controversy surrounding IVF and oocyte (egg) donation was eventually replaced by growing acceptance of the technologies, surrogacy has remained polarising even though it has been one of the many diverse family structures since the 1980s (and earlier for traditional surrogacy $)^{16}$.

The proliferation of ARTs in New Zealand has never been without bias. Before the first baby born of IVF in Auckland in 1983, assisted conception in the form of artificial insemination was only offered as an option on a case-by-case basis to heterosexual and white married couples at the discretion of doctors in public hospitals (Lovelock 2010). Discussed in-depth in chapter two, when New Zealand's first private fertility clinic opened in 1987, in Auckland, this same bias followed, where 'economic status, sexual orientation, disability, ethnicity, and marital status determined inequitable access' (Lovelock 2010, 140). Between 1980s and 2003, submissions made to parliament on ARTs reveal discomfort with technologies and practices delineating from the 'natural trajectory' of reproduction. Those who did not fit with the targeted demographic, including single women, lesbians, and gay couples, conceived via home insemination ${ }^{17}$. The involvement of more than 'a [heterosexual married couple] ... shifts procreation from the legitimate realm to the illegitimate in New Zealand' (Lovelock 2010). The fertility clinic became the legitimising site, where the cost of fertility interventions combined with regulations have been used to demarcate who may enter, restricting certain citizens from creating kin in this space ${ }^{18}$.

Michelle $(2006,110)$ writes about the increasing cultural anxiety of what ARTs may mean for the future of New Zealand, especially after lesbian couples and single women won their legal challenges to fertility clinic policies that barred them from accessing donor gametes (New Zealand Ministerial Committee on Assisted Reproductive Technologies 1994; New Zealand Listener 1995). Until recently, gay men were only permitted to access fertility clinics after

\footnotetext{
${ }^{16}$ One example is that it is still seen as unpalatable according to the British medica (van den Akker, Fronek, Blyth and Firth 2016; van den Akker, Camara and Hunt 2016).

${ }^{17}$ Queer kinship research invaluably contributes a parallel discourse of how those self-identifying as LGBTQIA+ have practiced and participated in debates about kin-making 'from local to global, from fairly low-tech to highly technologized, from reliance on social and community networks to reliance on multiple organizational entities' (Mamo and Alston-Stepnitz 2015, 2). See Mamo (2003), Nordqvist $(2012,2014)$, and Smietana (2017) for more discussion.

${ }^{18}$ Legislative restraints do not stop those citizens who are wealthy enough to travel to other jurisdictions where commercial surrogacy and egg donation are legal, and have different options depending on their budget.
} 
discrimination complaints based on gender and sexuality were made against the governing committees. However, ARTs remain an option that not everyone can access, whether due to the cost, not qualifying for the maximum two IVF rounds, or until 2016, a lack of access for gay couples. When I discussed the success rate of funding applications with John Peek, my contact from Fertility Associates (the largest fertility clinic franchise in New Zealand), he said that the only people e offered the public funding route will likely get it. This is because the criteria for funding is so well defined that fertility doctors have a clear idea of who is eligible and who is not. He wrote:

\begin{abstract}
All applications are successful...In New Zealand, about half of all IVF cycles are privately funded, so by this measure we could say the potential demand for public funding is twice the existing demand. However, many people don't have the financial resources for private treatment. (John Peek, personal communication, $7^{\text {th }}$ December 2020)
\end{abstract}

My first question was: 'what kinds of people are deemed eligible?'. As I write in chapter one, in my experience with a fertility clinic as a single woman, I received no help to access funding, even though I would have passed the criteria. This implicit bias against those in lower-income brackets, single women, those with unexplained infertility (who have a five-year waiting list), or 'social' infertility such as gay couples or lesbians, sits alongside the more explicit barriers that Māori and Pacific Peoples face ${ }^{19}$. The current system disadvantages some more than others. Equitable access to ARTs ultimately requires enough financial security. Even those intended parents who are fully funded for two IVF rounds are required to pay for the add on costs incurred, such as individual and joint counselling appointments, the ethics application, and any extra medical tests or treatments required by the fertility clinic.

On the surface, the vast array of research in critical kinship studies that focus on gestational surrogacy gives the impression that it has eclipsed traditional surrogacy as the preferred option in contemporary times. Further, most studies conducted in different cultural contexts reveal a preference for a genetic and gestational relationship (Lasker and Borg 1994; Krishnan 1994;

\footnotetext{
${ }^{19}$ In an online news article (Vezich, 4 November 2020), Dr Gudex from the fertility clinic Repromed in New Zealand says that 'Māori and Pasifika patients don't access publicly-funded IVF as much as the rest of the population and concern has been raised that the [higher than average Body Mass Index] criteria could be a reason for this.
} 
van den Akker 2007) ${ }^{20}$. According to van den Akker (2017), before gestational surrogacy became most common, two-thirds of Great Britain's surrogate babies born before 2000 were conceived using traditional surrogacy. In the US, only three out of the thirty surrogates Ragoné interviewed as part of her fieldwork were gestational, while Thompson (2005) describes almost the flip side, with a small proportion of participants going down the traditional route. In Canada, where traditional surrogacy is also legal, by 2003, ninety-five per cent of surrogacies were gestational (Busby and Vun 2010). In New Zealand, statistically, the number of gestational surrogacy cases seeking ethics approval increases each year, from seven in 2006 to twenty-two in 2014. However, anecdotal accounts from the surrogacy community suggest that traditional surrogacy is still popular and could reflect fifty per cent of cases. Unlike gestational, which requires fertility interventions, traditional can be practised under the radar, making it harder to access information about it. In this thesis, I show that whether the popularity of traditional surrogacy results from necessity (for intended parents) or an intentional choice (by surrogates), making kin in the shadows can decentralise the monopoly of privatised fertility medicine. In turn, it challenges the state's attempt to control who can reproduce.

\section{iii. Traditional Surrogacy as a DIY Repro-hack}

From the shadows, in comparison to gestational surrogacy, those practising traditional surrogacy challenge its framing as pre-technological and outdated. Instead, it is a modern and valuable method and an enactment of reproductive participation in the shadows. Traditional surrogacy garners less scholarly attention than gestational surrogacy for several reasons. Firstly, as mentioned above, the exponential uptake of ARTs has seen a rise in gestational surrogacy, both overseas and here in New Zealand. Secondly, there are fewer countries that have legalised it. Since the 1980s, gestational surrogacy was either introduced into countries where traditional surrogacy is prohibited (including Greece, Israel, Ukraine, Laos, Georgia, Russia, and India before it was banned), or became a second opportunity for those people who could afford it in countries like New Zealand, UK, and Canada, where only traditional surrogacy was available. This means that scholars can more readily access research participants that have engaged with gestational surrogacy. Thirdly, ARTs provide an array of research topics and continue to capture the imagination and attention of anthropologists, sociologists, and related disciplines. The following sections consider the ethnographies focusing on implications of techno-biological reproduction. In comparison, assisted reproduction scholars

\footnotetext{
${ }^{20}$ See Miall (1989) and Petitfils et al. (2017) for exceptions.
} 
and theorists typically position traditional surrogacy as a pre-technological answer to female factor infertility (Teman 2010). The few exceptions, including Berend (2016), Imrie and Jadva (2014), Jadva et al. 2003, Ragoné (1994), Shaw (2008b), and Thompson (2005), contrast with the countless literature on gestational surrogacy.

How gestational surrogacy and traditional surrogacy are treated in New Zealand - one in need of regulation and one relegated to the shadows or peripheries of such regulations - have informed the direction of my inquiry. On the surface, the technology bias in critical kinship studies responds to the constantly evolving assisted reproductive technologies that manipulate reproduction in new ways. If my participants only practised gestational surrogacy, it is unlikely I would have noticed the lack of ethnographic research that foregrounds traditional surrogacy. As shown in the methods section, more than half of the surrogates and half of the intended parents in this research engaged with traditional surrogacy, and as such, it has been centre stage in this study. My fieldnotes and interviews contain the many conversations and notes about the nuances and innovations employed by those practising it. These chapters collectively show that, rather than solely being an assisted conception technique that pre-dates gestational surrogacy, traditional surrogacy is future-facing.

While technology helps us to push boundaries of human intervention in reproduction and kinmaking, traditional surrogacy also pushes boundaries - just not technological ones. Traditional surrogacy contemporises home insemination as what I refer to as a DIY repro-hack, which enables intended parents to overcome the economic barriers of ARTs and gestational surrogacy. For surrogates, they are those typically denied entry into the clinic, such as childfree women who want to create kin for others, or those women who may potentially pass the criteria to be gestational surrogates. Nevertheless, they decide to help those intended parents who cannot access the clinic. The term 'repro-hack' is a play on the idea of DIY-bio, a do-it yourself biology movement that spreads 'the use of biotechnology beyond traditional academic and industrial institutions and into the lay public... it represents a direction translation of hacking culture and practices from the realm of computers and software into the realm of genes and cells' (Keulartz and van den Belt 2016, 1). Emerging in 2008, the practice hacks processes and procedures traditionally found in a purely clinical setting. I argue that those who do home insemination are repro-hacking the technologies (i.e., ARTs) that have attempted to replace or eclipse them. The hacker ethic is one of ingenuity, which is performed in intimate settings, to find ways to disrupt networks, and, in the DIY-bio movement, disrupt the hegemony of 
scientific knowledge and synthetic biology. Certainly, DIY-bio is not all about tinkering, according to Kelty (2010), but also circumnavigating the technology that they cannot or choose not to access.

Despite being practised in the peripheries of assisted reproduction options, 'repo-hacking' pushes the limits of the state regulations, which have privileged the nuclear family since colonisation. In this sense, traditional surrogacy becomes inverted and revolutionary. In chapter three, traditional surrogates' narratives exemplify this in two ways. Firstly, their motivations go beyond the 'help' narrative often associated with altruistic surrogacy and are more creative and imaginative than those found in gestational surrogacy. Secondly, the focus on childfree surrogates, who choose to create kin for others without wanting children for themselves, challenges the societal expectations of motherhood. For some intended parents, it is their last chance at creating a family. Their decision to seek a traditional surrogate result from reconceptualising what family means for them in the face of technological defeat or barred access to the clinic, whether financial, legislative, or other. However, in hacking a system that allows certain New Zealanders to reproduce in the fertility clinic, traditional surrogacy enables people to rework how they make kin. It is also a provocation against the states' reproductive boundaries and the privatisation of fertility medicine. In the following sections, I make visible the shadows that have created the system in which traditional and gestational surrogacy is practiced.

\section{iv. Academic Engagement with Surrogacy in Aotearoa New Zealand}

Research with a New Zealand surrogacy focus has been primarily undertaken by scholars outside of anthropology ${ }^{21}$. In addition to Daniels and Hargraves (1997), and Daniels' (2003) overviews and discussion of policies that impact on surrogacy, other scholars have examined the archaic legislation and regulation of surrogacy (Baird 2019; Baird and Powell 2020; Masselot and Powell 2019; Powell 2015, 2017, 2019; Wilson 2017, 2018, 2019), the ethical and philosophical debate on whether surrogacy should move towards a compensated practice (Van Zyl and Walker 2015; Walker and Van Zyl 2015; 2016; 2017; 2020), and crossdisciplinary discussion on the implications of the HART Act 2004 and proposed changes (Yates et al. 2015). Sociologist Rhonda Shaw conducted qualitative research on surrogacy and

\footnotetext{
${ }^{21}$ One exciting project funded by a Marsden Grant in 2019 is being undertaken by anthropologist Sharyn Davies, sociologist Rhonda Shaw, and Elizabeth Kerekere, entitled 'Accessing Assisted Reproduction: Social Infertility and Family Formation'.
} 
ARTs, including a project with four surrogates alongside egg donors (2008b) (described in chapter three), and, more recently, a pertinent article (2020) outlining the dangers of enforcing surrogacy arrangements ${ }^{22}$. This body of work has been useful in shaping some of my own questions about surrogacy, as has the work undertaken by anthropologist Ruth Fitzgerald and colleagues (Legg, Fitzgerald, and Frank 2007; Fitzgerald, Legge and Frank 2013; Fitzgerald, Legge and Park 2015), particularly on fertility clinics and the ethics of embryology (discussed in chapter five). Rather than focus on only one aspect of surrogacy, I contribute an ethnographic depiction of the experiences and narratives of intended parents and surrogates as they inhabit and move through the various shadows that are the myriad surrogacy processes. In this thesis, I identify four shadows: the shadow of colonialism; the modern nation-state; shadow-legalities; and shadow mothering.

\section{Shadow One - the Shadow of Colonialism on Māori Reproduction and Kin-making}

The first and most pervasive shadow within New Zealand is that of colonialism and British imperialism, which has shaped and continues to privilege contemporary Pākehā ${ }^{23}$ notions of the nuclear family in New Zealand at the cost and deprivation of Māori kinship concepts. In this section, I briefly explore the timeline of the British colonisation of Aotearoa ${ }^{24}$ and the key ideologies that underpinned the systemic marginalisation, depopulation, and erosion of Māori culture. In particular, colonialists and subsequent governments have prioritised legislative approaches and practices that continue to undermine how Māori reproduce and raise their family.

The first contact between Europeans and Māori ${ }^{25}$ began in the seventeenth century with explorer, Abel Tasman, arriving briefly in 1642, followed by James Cook, who came in 1769 (the first of three voyages). By the 1830s, with pressure from the British government, the Imperial Crown of Great Britain began to colonise Aotearoa steadily. In 1840, an agreement-

\footnotetext{
${ }^{22}$ Discussed more in-depth in chapter two, Shaw's work is timely and challenges the claims made by Walker and Van Zyl (2017) that a 'professional surrogacy model', that would involve enforcing surrogacy arrangements, is the answer to the current ambiguous and piecemeal regulations.

${ }^{23}$ Te Reo Māori for white/or European descent.

${ }^{24}$ Since colonisation was something that happened in Aotearoa, in the sections about colonisation, I use 'Aotearoa' as opposed to New Zealand.

${ }^{25}$ I want to be mindful that Māori are not a homogenous group, despite effort by the state to claim otherwise. Rather, they have diverse worldviews and realities (Irwin 1992; Pihama 2001; Le Grice 2014). When I refer to Māori as a group, my intention is to privilege non-western perspectives whilst acknowledging that not all Māori think the same way about reproduction.
} 
the founding document, Te Tiriti o Waitangi (The Treaty of Waitangi)—established a partnership between the British Crown and Māori, signed by Crown representatives and Māori chiefs. However, due to the English version being poorly translated into Māori ${ }^{26}$, rather than creating unity and confirming Māori sovereignty and rights over land and resources, both sides assumed different outcomes and significance of meaning. The 1840s and 1860s conflict over sovereignty and land led to various battles (known collectively as the New Zealand Wars) throughout Aotearoa between different iwi $^{27}$ and British troops. The resulting British confiscations of 98 percent of Māori land (Glover, Dudgeon and Huygens 2004), in addition to unfair prices in legitimate sales, destabilised the collective Māori population and their social fabric. The newly established Crown-led government created the Native Land Act 1862 and subsequent Native Land Court in 1865 to support their vision.

Māori collectivism ${ }^{28}$, at odds with the British ethos of individualism, was destroyed in several stages. Colonial tactics included dehumanisation, violence, and deception, to alienate Māori from their land and resources, culture, language, and kinship practices, and stripping them of their sovereignty (Smith 2012). The implementation of assimilation and integration policies into a Pākehā legal, legislative, and health system increased alienation and inequitable access to opportunities, jobs, culturally appropriate education and health care, and housing. According to Moeke-Pickering $(1996,4)$, 'the impact of this was that inappropriate structures worked to break down traditional Māori society by weakening its base - the whānau ${ }^{29}$, hap $\bar{u}^{30}$, and iwi

\footnotetext{
${ }^{26}$ For example, in the Māori version, iwi Chiefs understood the Crown was promising Māori a guarantee of land ownership and iwis/hapū' 'te tino rangatiratanga', chieftainship, autonomy, and authority over their lands, physical and cultural resources (taonga), and affairs. Māori gave the Crown governance (kawanatanga) over their own subjects. Whereas in the English version, the Crown had the sovereignty over the land, guaranteeing to Māori the undisturbed possession of their properties, emphasising ownership rights, but granted the Crown sole rights for land sales for British settlement and establishment of a government to maintain peace and order. In Article Three: both versions gave Māori the Crown's protection and the rights of British subjects, with the promise of equality.

${ }^{27}$ Iwi denotes the extended kinship group in Te Reo Māori, and most often refers to a 'large group of people descended from a common ancestor and associated with a distinct territory' (Māori Dictional 2020). It also means 'bone'

${ }^{28}$ Mikaere $(1994,125)$ writes that the very survival of Māori people and culture was 'absolutely dependent upon everyone who made it up, and therefore each and every person within the group had his or her own intrinsic value. They were all a part of the collective; it was therefore responsibility to see that their respective roles were valued and protected'.

${ }^{29}$ This translates to 'extended family', but it has greater depth and nuance in the Māori world view, including the spiritual, physical, and emotional dimensions that are based on whakapapa (the line of descent from one's ancestors - see the next page for a more comprehensive translation).

${ }^{30}$ In Te Reo Māori, hapū means the state of being pregnant (verb), as well as a kinship group or clan (or sub-tribe).
} 
(Ministerial Advisory Committee 1988)'. Kinship and wider belonging are foundational to Māori culture and identity and were denied under the colonial regime. Dismantling familiar kinship structures combined with introduced diseases, deprivation of living conditions, limits on access to resources, and continuous warfare led to the radical depopulation of Māori from $100,000-200,000$ to 50,000 at the start of the $20^{\text {th }}$ century (Glover and Rousseau 2007, 123). This devastation of the Māori population was considered by the British as integral to dismantle their kin-making.

\title{
i. Māori Relatedness and Whānau
}

Depopulation was accompanied by colonial policies that sought to dismantle Māori gender and sexuality, compounded by historians' misrepresentation of Māori customs and beliefs. Māori scholars Ani Mikaere, Elizabeth Kerekere, and Leonie Pihama argue against trying to actualise a Māori worldview concerning kinship, sexuality, and gender through a Pākehā lens. As Mikaere (1994, 125) writes:

\begin{abstract}
The roles of men and women in traditional Māori society can be understood only in the context of the Māori world view, which acknowledged the natural order of the universe, the interrelationship or whanaungatanga ${ }^{31}$ of all living things to one another, and to the environment, and the overarching principle of balance.
\end{abstract}

There was no separation of the private/public sphere or designated gendered roles, and tāne ${ }^{32}$ and wāhine ${ }^{33}$ shared leadership (Mikaere 1994; Pere 1994). In stark contrast, British men, and women, particularly after industrialisation ${ }^{34}$, were traditionally organised into roles by gender. The nuclear family (otherwise known as the heteronormative family) comprised a mother,

\footnotetext{
${ }^{31}$ Close connection between people or kinship.

${ }^{32}$ Male.

${ }^{33}$ Female.

${ }^{34}$ Industrialisation in the eighteenth century in England marked a shift from largely agricultural economic activity that was carried out by human labour to the introduction of machine manufacturing that steam-powered machinery from the $1850 \mathrm{~s}$, which increased productivity and reduced production controlled by human activity. For families, this meant a shift from a family work unit comprising of husbands, wives, and children, to a separation of the private/public realm and the gendered division of labour (Levine 1985). The small nuclear family as a unit of social organisation is understood within anthropology and sociology as a result of the urban industrialisation, which replaced an extended family structure that would span several generations that stayed in the same location.
} 
father, and children, who lived together as a social unit. In comparison, 'that no individual words existed for the te reo Māori terms of 'mother', 'father', 'wife', 'husband', 'daughter', 'son', 'sister', 'brother', 'aunty', 'uncle' shows that the British nuclear family was not the standard in Māori society' (Kerekere 2017, 42).

As one of the central tenets of reproduction within Māori ontology, whakapapa embodies an interconnection with the natural landscape and human ancestry ${ }^{35}$. The term encompasses both a connection to past relations and future generations, and within both is the reliance on the nurturance of qualities, tikanga ${ }^{36}$, and culture (Glover, McKree, \& Dyall, 2008; Manihera \& Turnbull, 1990). Reproduction is thus a shared investment, where the raising of the children is the responsibility of the wider whānau ${ }^{37}$. According to Māori scholar Moeke-Pickering (1996, 1), 'more than an extended family social unit, whānau was based on kinship ties, shared a common ancestor, and provided an environment within which certain responsibilities and obligations were maintained'. This includes whāngai, which was widely practised when the colonisers arrived (Graham 1948; Firth 1959). The term whāngai refers to a child raised by kin members who are not their biological parents. Also known as atawhai or tamaiti whāngai, the practice of whāngai literally translates 'to feed or nourish' (Mead 1994) and is often considered by many as informal. Māori do not always apply to legalise the shift in parental status. In their kaupapa research explicitly exploring the whāngai practice, McRae and Nikora $(2006,12)$ summarise that their participants commonly believed that:

The customary practice ensures decision making remains within the whānau group as opposed to being controlled by external agents as is the case for adoption/foster care; and boundaries are attached to adoption/fostering while openness, fluidity and flexibility typifies the practice of whāngai.

\footnotetext{
${ }^{35}$ This is reflected in the dual parallels between reproduction of the natural world. For example, whenua is both the placenta/afterbirth and land/ground/earth; whannau is loosely translated to 'extended family' and 'to be born and give birth' (Moorfield, 2013). Similarly, hapū refers both to a kin group and the state of being pregnant/conception in the womb.

${ }^{36}$ Māori values

${ }^{37}$ This does not mean that Māori kinship systems remain static and bound by kin-based relationships only, but rather 'contemporary understandings of whānau have broadened to meet the demands of new urban communities, where shared experience or common purpose may bond people as whānau (Mead 2003; Metge 2014).
} 
In the legal sense, adoption is steeped in historical racial bias, which promotes Western ideas of kin formations. At the same time, it belongs to a broader legal apparatus with roots in British colonial governance that creates a system where life and all its processes (birth, school, health, marriage, adoption, death) require recognition from the state. One of the key themes of this thesis is how colonial racialised policies have shaped the understanding of kin, biology, and in turn, kinship law. Speaking to the impacts colonisation had on sexuality perspectives, McBreen $(2012,63)$ argues that 'we need to be clear that homophobia does not come from tikanga ${ }^{38}$. It comes from the colonisers. Whakapapa is about inclusion - there needs to be an excellent reason to exclude or demean someone in any way. Who they sleep with is not a good reason'. Sexuality and gender fluidity were celebrated before colonisation but pathologised as deviant after colonisation (Kerekere 2017, 21). While homophobia, transphobia and biphobia have made it challenging for LGBTQAI+ Pākehā aspirations of wanting to reproduce and to be accepted within society, some takatāpui report tension between homophobia within their whānau ${ }^{39}$ and the perception that having children is integral to life, regardless of sexuality (Glover, McKree and Dyall 2009). Issues of sexuality need to be considered when looking at ARTs and surrogacy because queer families alongside others want the opportunity to have children.

\section{ii. The Depopulation of Māori}

Māori kinship practices contrast with Eurocentric kinship ideology, and reproduction is 'an area where [Māori] have been subject to colonial control and marginalisation (Le Grice and Braun 2016, 152). At the core of colonialism was scientific racism that emerged during the Enlightenment, when race 'was constructed on the premise that there was a relationship between visual markers of difference, such as skin colour, and other physical features and invisible properties, such as intelligence' (McKinley 2005, 483). This equation of difference with inferiority was underpinned by scientific standards and provided the rationale for excluding those deemed 'inferior' (Schiebinger 1989). In Aotearoa, some notable examples include the colonial scientific strategy of making Māori women more 'desirable',

\footnotetext{
38 Takatāpuhi signifies same-sex attraction between men, women and transgender people, and 'encapsulates not only aspects of one's own sexuality but also components of one's cultural identity (2007, 16). Takatāpuhi academics Linda Waimarie Nikora, Ngahuia Te Awekotuku and Virginia Tamanui $(2013,2)$ also include intersex, queer, butch, tomboy, and kamp in their definition.

${ }^{39}$ See Kerekere (2017) for an in-depth exploration of takatāpuhi.
} 
'controllable', and 'European-like', and in turn, less 'promiscuous' and 'sexual' 40, by increasing the proportion of 'European blood' in the Māori population via interracial marriage and reproduction (McKinley 2005, 485). Since then, political agendas have replaced Māori approaches to self-identification with biological delineation for cultural affiliation ${ }^{41}$ - central to British and European forms of social relationships ${ }^{42}-$ and enacted legislation that promotes monogamous, heterosexual unions as the only legitimate form of partnership from which children could be created. An example of this process was that, in addition to removing Māori from their land, the Native Land Act 1909 invalidated Māori customary marriage, which forced wāhine Māori to marry according to the transposed British legal definitions that defined them as property of their husbands (Mikaere 1994).

Other techniques for power and normalisation in Aotearoa have included the eugenics movement and population control tactics, which attempted to increase the fertility of the nondisabled, married, heterosexual, and white while decreasing the fertility of all others (Wanhalla 2007). When this lens is applied, it provided arguments for limiting of Māori reproduction and anyone else who does not fit this narrow categorisation of what family 'should' look like (Le Grice and Braun 2016). Mikaere (1994) argues that the impact of colonisation on Māori and the challenges of rectifying harm to Māori within a Pākehā legal system has and continues to disrupt Māori culture, relatedness, and knowledge systems via legislative control. Colonialism opposed how Māori thought about and practiced kinship, and the Crown's Eurocentric views naturalised the nuclear family as a priori.

\section{Shadow Two - The Modern Nation-State}

The pervasiveness of colonial policies and discourses continue to privilege the nuclear family as it has been defined within British legal structures. This is visible in the negative representation of Māori reproduction in contemporary media and some academic accounts

\footnotetext{
40 This is similar to "Women of Color" in the United States, who are represented as sexually promiscuous and incapable of taking responsibility in reproductive decision- making or mothering' (Le Grice and Braun 2016, 152).

${ }^{41}$ For example, Māori were classified on blood quantum under the Māori Affairs Act 1953, based on the misguided and racist assumption that culture, behaviour, and identities are biologically determined (Broughton 1993; Moeke-Pickering 1996; Thomas 1992). Later expanded to focus on descent in an Amendment in 1974, 'the reality is that the blood quantum mentality has fuelled the undermining of Māori identity' (Moeke-Pickering 1996, 4).

${ }^{42}$ See Smith (2011) for more discussion on colonial ideas about gender, sexuality, religion, and property law.
} 
focusing on Māori teenage births (Samson 2000), representations of child abuse as inherent to Māori (Le Grice 2014; Raymond 2012) and racist accounts of Māori reproduction (Green 2011). Le Grice $(2014,42)$ argues that:

Māori sexual and reproductive subjectivities are presented as a counterpoint against Pākehā who are considered not 'at risk', 'over-represented', 'unwanted' and 'unintended' in sexual and reproductive health matters (Green, 2011). Negative statistics about rangatahi ${ }^{43}$ Māori including high rates of pregnancy, abortion and sexually transmitted infections paint a negative view of their sexuality, without acknowledging their potential for aspiration and a positive future. Policy interventions are premised on an assumption that researchers, medicine and the State 'know' Māori better than Māori know themselves, and rarely permit intersections with Māori knowledges, experiences and understandings.

This combination of systemic discrimination against Māori knowledge and tikanga, and negative portrayals of Māori reproduction, simultaneously pushes Māori further into the peripheries of society as it spotlights it as something not to emulate or take seriously. Le Grice explores the disinclination to incorporate Māori tikanga into educational and medical settings concerning sexual education, abortion, maternity, and reproduction. For example, legislation implemented requirements for birth attendants to be certified midwives, and for women to be encouraged to birth at a hospital (Mead 2003) ${ }^{44}$. However, Palmer (2002) writes that in rural areas, Māori were more able to practice traditional birthing practices. Even though policies have evolved to make accessing maternity services easier, Māori continue to experience barriers (see Dwyer 2009, and Rumball-Smith 2009 for examples), and higher instances of matenal and infant disparaties compared to Pākehā, including low birth weight, neonatal and maternal death, and less access of obstetric interventions (Rumball-Smith 2009). More recently, Harris, Stanley, and Cormack (2018) describe the significantly higher and overlapping forms of discrimination that Māori, Pasifika, and Asian ethnic groups report in relation to physical and mental health in contemporary contexts. Parker, Pause, and Le Grice

\footnotetext{
${ }^{43}$ Te Reo Māori for the younger generation or younger people

${ }^{44}$ See Harte (2001), Palmer (2002), Rimene, Hassan and Broughton (1998), and Mead (2003) for discussion on the various cultural values that were not followed during births.
} 
(2019) argue that racialised Western discourses of pregnancy fatness produce pervasive reproductive injustices that work to render fat Māori and Pacific women unsuitable to mother. The authors, writing against this racism, call on a centring of Indigenous epistemologies of reproduction to move away from discourses that do not support the dignity of indigenous women in their transition to parenthood.

When the reproduction of Māori is seen as a problem, there is less likelihood that policies relating to infertility and assisted reproduction will consider the needs of Māori. Glover (2008, 5) posits that assumptions that Māori experience good fertility, alongside the 'focus on problematising Māori pregnancies ${ }^{45}$, has perhaps contributed to the apparent lack of interest in declining fertility rates among Māori'. For example, the policy document, Access to Infertility Services: Development of Priority Criteria do not consider infertility among Māori, their unique concerns, or their ability to access ARTs (Glover 2008). Within the wider health system, it is Māori and Pacific peoples who have the highest burden of disease and experience poorer outcomes in comparison with Pākehā (Came-Friar, McCreanor, Haenga-Collins, and Cornes 2018). Māori voices have consistently been underrepresented within research and policy/legislative debates on ARTs and reproduction more generally (Hall and Metge 2002). Since the mid-2000s, Māori scholars Glover (2008), and Reynolds and Smith (2012) have undertaken substantial Māori health research projects. This work highlights that for some Māori, ARTs and the laws governing them do not align with their world views because it forces a Western system of kinship with an emphasis of the individual rather than the collective (Glover et al., 2008; Le Grice and Vaughan 2016, 156). Many Māori also worry about what consequences they could have for whakapapa. 'Māori...may balk at any suggestion that any aspect of existence - already born, gamete, or embryo - be owned or be separated from its important source of whakapapa' (Reynolds and Smith 2012, 136) ${ }^{46}$. This complicates the practice of assisted reproduction.

\footnotetext{
${ }^{45}$ See Le Grice (2014), McKinley (2005), and Smith (2013) for more discussion on the frequent representation of Māori women as the 'exotised other', sexually promiscuous, and incapable of controling their fertility.

${ }^{46}$ Despite consensus that the baby has a wairua (spirit) prior to being born, there are debates over when this occurs, ranging from when the foetus takes on a form resembling a baby, when it is conceived (Pere 1994), or when it develops eyes and a brain (or the ability to think and perceive) (Manihera and Turnbull 1990; Mead 2016).
} 
The shadow of colonialism has had a devastating impact on Māori and has worked to undermine every aspect of their culture - and in turn, creating minimal understanding of the complex ways of making kin in Aotearoa. Colonialism is the shadow that continues to loom large on our knowledge of what mothering, fathering, and parenting means in contemporary New Zealand, which implicates all New Zealanders who do not reflect the white, heterosexual, and nuclear family unit. It is a suffocating shadow that requires everyone who inhabits it to carefully think out how they might create kin within legal, medical, and institutional landscapes that render them deviant from the outset.

\section{Shadow Three - Shadow-Legalities}

Nordstrom (2006) has spent her career researching 'shadow economies' and 'shadow industries', or extra-legal ${ }^{47}$ economies of globalised movement of goods, services, and people in 'systems of association and exchange that occur outside the law'. In her fieldwork on warzones, Nordstrom has mapped the implicit exchange routes people use to gather the goods, weapons, technologies, and medicines required to wage war, using an in-demand payment system that includes gold, drugs, and human labour. She uses the term 'shadows' rather than 'illegal' or 'criminal' because the transactions and networks are not exclusively illicit and exist in opposition to legal or 'legitimate' economies. Instead, while transactions are done outside of formal or state channels, they are not void of governance. Shadow economies are spaces where culture is created, 'governed by rules of exchange, codes of conduct, hierarchies of deference and power - in short they are governed by social principles.... and not marginal to the world's economies and politics, but central' (Nordstrom 2000, 37). Inspired by Nordstrom's depiction of shadow economies with an internal learned culture where shared rules and codes of conduct shape people's experiences, I have developed the concept shadow-legalities vis-avis reproduction to denote the implicit and explicit rules created within the surrogacy community in New Zealand. I use shadow-legalities instead of shadow laws or informal rules or social norms because shadow-legalities exist in response to the absence of laws to protect their kin structures.

Surrogacy in New Zealand mobilises a nuanced understanding of shadow-legalities as it refers to the networks that operate under the radar of the law but are only possible because the law is

\footnotetext{
${ }^{47}$ In her research, Nordstrom $(2003,298)$ describes the idea of the 'extra-legal', which she states 'refers to all activities that fall outside legality as it is formally defined and used in law and law enforcement. This includes illegal, illicit, informal, and undeclared, unregistered, and unregulated actions'.
} 
designed in a particular way. Shadow-legalities also frame those interactions between people and their interpretation or mimicking of laws in the formal sense of the word. As a set of parameters, shadow-legalities are the implicit and explicit rules that people create to regulate the community's practical and interpersonal relationships. In this work I show that when people find themselves immersed in the ambiguity of the various processes and spaces where surrogacy is practiced, having a road-map helps them feel in control and counteracts some of their reproductive vulnerability. I develop this in chapter four, where I focus on how the surrogacy community functions.

\section{Shadow Four: Shadow Mothering}

In addition to shadow economies, I am also inspired by Macdonald (2011), who introduced the term 'shadow mothers' to describe the quasi-mother role that nannies, and au pairs are expected to fill in the lives of the children they look after. Writing specifically on mothers who work outside of the home, Macdonald $(2011,110)$ argues that the au pair/nannie is encouraged to do all of the care-work 'as if she were the mother, before she vanishes upon the real mother's return, leaving no trace of her presence.... often termed reproductive labor or "women's work", shadow work is devalued, frequently invisible and usually unpaid'. However, this framing has limitations when thinking about kinship and mothering under surrogacy. Who is the 'real' mother here, and who is the 'shadow' mother? Surrogacy complicates who and how we think about mothers (birth mothers, biological mothers, caregiving mothers, etc.) and, through my work, push the boundaries of how we engage with 'shadow mothers' conceptually. It is particularly valuable in illuminating the tensions inherent in navigating the various mothering roles and one another's feelings.

In departing from Macdonald's work, I use the term 'shadow mothering' to complicate mothering. Anthropologists have not settled on a unified definition of 'mothering' because there is such diversity and contradictions between different cultures. Walks and McPherson (2011) argue that part of the problem of defining mothering is that it can be understood separately as both a sexual-biological process and a gendered social engagement. Notably, although the act of mothering is feminised, it is not only performed by females, nor are biological processes associated with motherhood necessarily confined to one person. This is exemplified in accounts of cis men breastfeeding or transmen experiencing pregnancy and birth (Ryan 2009; Ware 2009; Reents 2003). In my research, some intended mothers choose to 
induce breast milk to experience feeding their baby, who has been gestated by and potentially genetically related to her surrogate. I also move away from the boundaries that the mothers in Macdonald's account established with the nannies/au pairs. My participants often navigate intimate moments of the pregnancy together, such as when they host joint baby shower celebrations. These moments demonstrate a rewriting of a traditional ritual - parenting without the presence of the foetus or child. Surrogates cannot fragment themselves from the foetus, and Teman's (2010) findings in surrogacy in Israel, in my research, the participants do not use the medicalisation of reproduction as a vehicle to psychologically separate themselves from their growing belly. However, they give the intended mother ways of bonding with the foetus through touch and sound, such as using headphones on the belly with the intended parents reading stories, which uses the technology to participate in an intimate activity and opportunity to feel involved in the pregnancy.

Compared to how other academics employ the use of 'shadows' in the previous section, I propose that shadow mothering is not inherently lacking or deficient in relation to 'mothering' but an integral part of kin-making. I base my definition of mothering within this thesis on the multitude of acts, both biological and social, that contribute to the care-work required to create and take care of kin. These include but are not limited to gestating, everyday tasks, taking responsibility for the impending baby's future care-work, caring for the baby, looking after their health, nutrition, and education. I describe surrogates as performing 'shadow mothering' because in everyone's mind, the role of parenting (that is, in raising the child) is the definition of 'a mother'. My intention is not to reject this understanding. On the contrary, I show how the mother, the intended mother ${ }^{48}$, is supported in this endeavour by different people in various ways and settings. Rather than a role based on a specific gender, it speaks to the fragmentation of surrogacy that mobilises various facets of kin-work. This thesis focuses specifically on the integral role of the surrogate because she is the one who gestates the foetus and is part of the journey throughout. Even though she may be seen as mothering in some imaginings, she is making kin non-biological for others and not herself.

The shadow of the modern nation-state, shadow-legalities, and shadow mothering are continually in flux and altered by the movement of bodies, ideas, and encounters. They do not

\footnotetext{
${ }^{48}$ I spent very little time with gay intended fathers, which has shaped the focus of this thesis, rather than an explicit decision to solely focus on intended mothers.
} 
exist in isolation from one another, and significantly, have been shaped by the pervasive and far-reaching impacts of colonialism. This larger shadow looms large and seeps throughout each chapter (even if not explicitly discussed in detail). In addition to their devastating impact on Māori kinship, colonial policies have defined what kind of family will be privileged in legislation, the Family Court, and the criteria for the funding of fertility treatments. It mobilises the other shadows my participants inhabit by influencing the context and conditions in which people make kin via surrogacy. Nevertheless, being relegated to the shadows is not solely oppressive. My participants' stories and experiences reveal an improvisation born of marginalisation. In other words, in reconfiguring kin in a society that privileges heteronormative expectations of what a family should look like, intended parents and surrogates disrupt, to varying degrees, the constraints they found themselves in, to begin with.

\section{Chapter Outlines}

In various sections above, I highlight how the modern nation-state continues to forward colonial understandings of kinship. The state also undermines those who cannot (in the case of intended parents) or choose not to (in the case of surrogates) create kin via natural conception. I also outline the four different shadows, the historical colonial context, the modern nationstate, shadow-legalities, and shadow mothering. These helps frame and examine my participants' narratives and experiences as they negotiate the uncertainty and unknown processes in their surrogacy journey. Chapter One, 'Methods and Positionality, Reflections on Surrogacy Research', outlines a multi-sited ethnographic approach to gathering data from my participants who live throughout New Zealand. I introduce key participants and explore my positionality and how this has influenced my experiences and perspective since I began this research. As a disabled academic who is also infertile, I have experienced what it is like to inhabit the peripheries of conversations with friends about having children and feeling incredibly disconnected from the mainstream avenue to have a family. As I discuss in chapter one, one of the reasons I have not been able to freeze my own eggs and preserve my infertility is that I was discouraged from pursuing public funding when I applied to as a single woman at the age of thirty. While my story is not my research focus, my own experiences became the basis for building meaningful rapport with my participants, who felt like I was invested in this research because I understood some of their journeys. As I experienced heteronormative reproductive bias first-hand and felt defeated, I had a better vantage point to critically observe 
how surrogacy operates in the shadows of big institutions like the state and mainstream EuroAmerican motherhood ideologies.

Following this, in Chapter Two, 'Surrogacy Regulation in the Shadows of the State and Heteronormative Reproduction', I set the scene for the rest of the thesis. Here I outline and unpack the various juridical practices and legislation on surrogacy in New Zealand that continue to extend the lingering shadow and heritage of settler colonialism that better supports and privileges the idea of the nuclear family. I explore how they make and reject kinship via surrogacy and regulate bodies, eligibility, and relationships in addition to the technologies. However, in their current state, they do not adequately reflect or support how people choose to make kin. This is seen in the barriers to access gestational or clinical surrogacy services, including eligibility to access funding and the restrictive state and medical criteria. This results in some citizens being encouraged to reproduce more than others.

The legislation is also ambiguous and, with no reified Act for surrogacy, official guidelines are scattered across several pieces of legislation, some of which was established before the first IVF procedure was successfully performed in 1978 in the UK and introduced into New Zealand shortly after. Consequently, there is tension and disconnect between legislation that recognises, to varying degrees, surrogacy kinship practices, and the legal policy and practices in family law that have no framework to distinguish between surrogacy and adoption. Specifically, intended parents and surrogates must present a different version of kin to be recognised as the legal parents by to the State, which treats surrogacy akin to adoption. I propose that the combination of ambiguity and undermining the way this community chooses to create kin pushes them into the reproductive penumbra. From this vantage point, intended parents and surrogates must negotiate institutions and official guidelines whilst navigating the daily unknowns of creating kin via surrogacy. This chapter concludes with proposing that for those barred entry to clinical surrogacy, they must contemplate possibilities beyond the regulations that will still allow them access to state recognised procedures. This site of tension and new reality is traditional surrogacy.

In Chapter Three, titled "DDoing it Our way": Participation and Kinship in Traditional Surrogacy Narratives', I examine how exclusionary shadows of the legislation and regulatory committees, privilege normative motherhood and kinship, and leads to innovation in the form of traditional surrogacy. Focusing on the narratives of traditional surrogates who help to create 
kin for those intended parents for which traditional surrogacy is a necessity. As arguably the most elusive and misconstrued of the two types of surrogacy, it is pushed further inside the reproductive penumbra of legislative, regulatory, and public discourse about kin. The traditional surrogates that welcomed me into their lives include childfree women ${ }^{49}$ and women with children who would not pass the strict ethical or medical criteria and thus be denied entry into the clinic, as well as those who may qualify to be gestational surrogates but deliberately deft state interference to reproduce on their own terms. For traditional surrogates (and intended parents), the elements that shape the reproductive penumbra they reside in include societal expectations of motherhood, public and medical discourses that suggest traditional surrogates must be donating their eggs for money. The idea they would do it altruistically makes people uncomfortable and challenges their perception that a woman would want to give up 'kin of her own' intentionally. Their experiences and voices bring to the forefront the under-researched topic of traditional surrogacy in general, with a particular focus on women who do not want children of their own but choose to contribute their eggs and gestate the fetus for another. Their collective stories reveal multi-layered motivations that align with and diverge from the 'help' narrative that is often associated with altruistic surrogacy and the idea of 'good mothering'. I show that through their negotiation of stigma to make/resist kin, traditional surrogates in New Zealand disrupt pervasive and heteronormative ideas about kinship and motherhood with different interpretations of reproductive participation.

Chapter Four, 'Dating and Serenading in the Shadows: The Informal Rulebook for Making Kin with/out ART in Aotearoa New Zealand', is set in the surrogacy community itself. It is a private and online surrogacy support forum in New Zealand and is a safe space for intended parents and surrogates to seek mutual support, advice, and a hopeful match. With no official 'how to' guide and due to the prohibition on advertising for a surrogate in New Zealand, both surrogates and intended parents encounter complexities in their journey to make kin in ways and spaces that some would deem unconventional. While those practising gestational surrogacy have a degree of medical and ethical guidelines before they find a surrogate and during the subsequent periods, those doing traditional surrogacy create kin mostly outside of any formal guidance. For many, this is both liberating as it is potentially risky because they take on the technical intricacies of home inseminations as well as finding a match. In this nebulous space that

\footnotetext{
${ }^{49}$ Out of the 303 applications that ECART have received, four included childfree surrogates, three childfree surrogates were unsure whether they desired a family in the future or not.
} 
connects the traditional with the technological, people mobilise a particular form of legality, which conceptually operates as shadow-legalities, a set of explicit and implicit rules that govern peoples' behaviours and experiences of surrogacy. By using language and rituals associated with the dating world, relationships are carefully crafted with the understanding that there is the right recipe for success, which offers the differently positioned participants a sense of security and belief in the 'system'. Desirable and undesirable behaviour is judged online and offline, shaping the shadow-legalities around traditional and gestational surrogacy in New Zealand.

Leading on from the site where shadow-legalities are mobilised is Chapter Five, 'Making Kin Under the Microscope'. Beyond the fertility doctors in their pristine suits and ties that new and returning patients see when they enter the clinic, a group of embryologists in their indistinctive scrubs preside over the embryology laboratory in the back of the fertility clinic. The 'lab' as it is referred to, is the hub where bodies, technologies, sex cells, hopes, and dreams flow in and out. In the laboratory itself, intended parents hoping to create their family via IVF and a surrogate are one of the countless other couples, but with their reproduction fragmented differently. Everything is run in militarised fashion, and in the thorough preening and prepping of sperm and eggs before they are placed in a petri dish together in the hope of fertilisation, reproduction appears to be fully mediated by science. Yet, as much as embryologists can mimic the body and womb via technology and do everything possible to have viable gametes and embryos, they must still rely on 'nature', for the fertility interventions to work or not. I propose that it is in the awareness of the elusiveness of reproduction and preciousness of embryology life stages that help them cultivate a sense of care and nurturance towards the gametes and embryos, and by association, the patients they interact with as part of their job. Care becomes the mechanism that marries the world of science and the art of (re)producing life. I make visible the intricate relational care work that embryologists do in the lab at a microscopic level and in the moments of transition and nurturance of the gametes and embryos. This shows how embryologists contribute to the composition of kinship via ARTs and gestational surrogacy. In the shadows of reproduction under the microscope are also those stories of technological defeat or the reproductive materials that will not be made visible in this site due to the barriers for entry.

In the final chapter of this thesis, Chapter Six, 'Shadow Mothering in the Home', I focus on the intimate landscape of the home where surrogates and intended mothers utilise the 
fragmentation of the 'mothering' role that is inherent to surrogacy to their advantage by working together to ensure that the intended mother is the 'only mother' the child will know. I propose that surrogates enact a type of shadow mothering, which is not suggestive that they are in any way seen or feel like the central 'mother', but instead supports the intended mother in her own journey. I show that the motherhood ideology needs extending to make space for mothering taken on by surrogate mothers, which works to sperate in order to make kin for others. Surrogacy pregnancy, relationships, narratives are never static but determined by the continually changing negotiation of light and shadows produced by and between the intended mother and surrogate. Many times, surrogates and intended mothers readjust how the scene is set up as they continually renegotiate their roles as shadow mother and the mother. I examine the interplay between light and shadows to make visible the creativity, tensions and challenges that can arise as part of the process, and how they are navigated well, or not. I refer to surrogates as shadow mothers or them practising shadow mothering because ultimately, this reflects the pre-determined intention that everyone accepts and works towards: that the intended mother is the mother, regardless of how many women have been involved in the creation and gestation.

This thesis also includes five interludes. In thesis interludes, I provide an ethnographic snapshot that takes place over five days in May 2017 when I followed Lola (and her family) and her intended parents Celeste and James' in their surrogacy journey. They welcomed me into their lives at one of the most critical and vulnerable stages: the implanting of Celeste and James' embryo into Lola, who was their gestational surrogate. In these interludes, I show the array of people who become involved in facets of kin-making, from the initial fertility doctor who checks Lola's uterus lining, the embryologist who met us and got her ready for the implanting on her day of ovulation, the second fertility doctor, Ralph and their two children who sat patiently in the waiting room, to Celeste and James, who were the reason they were all there to begin with. In expanding the idea of kinship as occurring between more than two people, I reveal the unassuming moments where family is made, not just in the gestational kin-work that Lola agreed to undertake but between the two families themselves. When the implantation was not successful, this did not erase the efforts put in. Just as this story highlights the precarity of reproduction, it shows the nimbleness of kinship itself as it is made and unmade in the shadows. Different constellations of relatedness were made, with Celeste and James' going on to have a baby via traditional surrogacy with another surrogate, and Lola enduring the preparation all over again and successfully giving birth to a baby for Donna and her husband. 
These six chapters are followed by a conclusion where I focus on the aftermath of surrogacy: the celebration of families. While there were clear celebratory moments of joy when babies are born, surrogacy also creates unexpected friendships and community with others also on this journey. This is what ultimately anchored me through the challenging days of fieldwork, and making sense of the extensive fieldnotes, interviews, and experiences. Whether babies born of surrogacy were biologically related to both intended parents, or one, or neither, the intended parents and surrogates I have got to know over the past three years have reconfigured their understanding of kinship to suit their own circumstances. This thesis demonstrates that making kin in the shadows is a group effort that challenges the institutions and regulations that create boundaries around what kinship looks like and who can reproduce using Assisted Reproductive Technologies.

\section{Conclusion}

Surrogacy in New Zealand is a complex practice that simultaneously makes visible colonialist policies that continue to shape kinship legislation, as it demonstrates the nimbleness of kinship itself. This thesis presents a snapshot of various integral elements or topics that shape how people un/make kin via both traditional and gestational surrogacy. In chapters two, three, and four, I highlight how the modern nation-state continues to forward colonial understandings of kinship. The far-reaching shadows of colonisation are visible in the legislation and judicial practices that continue to privilege the ideological nuclear family. This pervasive shadow also mobilises other kinds of shadowy spaces and everyday practices. With no reified set of legislation, the privatisation of fertility medicine and strict ethics criteria results in some citizens being encouraged to reproduce via ARTs and gestational surrogacy more than others. Focusing specifically on shadowy spaces that emerge in the context of surrogacy, I explore the various legislative, bureaucratic, institutional, and private landscapes intended parents and surrogates engage with and navigate as part of their journeys. Whereas gestational surrogacy involves the input of countless medical professionals and engagement with several government processes, traditional surrogacy involves less input and scrutiny. The one similarity is postbirth, when regardless of what type of surrogacy is practised (and regardless of genetic relatedness), everyone must go through an adoption process to transfer parental status from the surrogate to the intended parents. 
When people cannot, or choose not to, create a family via natural conception, they become reproductively vulnerable and are pushed into what I term the reproductive penumbra. The reproductive penumbra represents a literal and conceptual space that is at the peripheries ${ }^{50}$ of legislation. It is a place from which surrogates and intended parents are exposed to different discourses regarding surrogacy. Rather than existing in opposition to the ideological nuclear family model, instead, the reproductive penumbra emerged in relation to and because of it. Work by Macdonald (2010) and Nordstrom (2000) have influenced my conceptual framework of the reproductive penumbra. Whereas they focus on globalised shadow economies (Nordstrom) and the micro-politics of relationship work (Macdonald), I show how shadows, as key elements of the reproductive penumbra, are implicated with one another through all stages of surrogacy, ranging from the intimate and inter-personal relationships, in the surrogacy community, at the fertility clinic and inside the embryology laboratory, to the institutional and regulatory processes, and the state. These uncover that from the level of conception to raising children is not limited to parents. Instead, different people at different times and in different ways all provide an element of kin-work. In particular, chapters three, five and six, reveal how it is enacted at each level, from the lab, via home insemination, and in everyday rituals performed by surrogates and intended parents, to the courtroom where the adoption order is granted. In each of these spaces, surrogacy has a crucial role in subverting mainstream discourses of reproduction. In drawing attention to the innovative ways that kin is made in the shadows, my research reveals that in working with/in and against embedded mechanisms that perpetuate a colonial understanding of kinship, intended parents and surrogates make evident new reproductive possibilities.

\footnotetext{
${ }^{50}$ In making the bold claim that those who do not create kin via natural conception, are pushed into the peripheries of reproductive politics, it is important to note that being able to have a baby without the assistance of others does not guarantee everyone a seat at the table. Those families who do not reflect the ideological nuclear family or whose right to reproduction has been subject to scrutiny or control (such as for Māori and/or disabled people), continue to experience discrimination.
} 

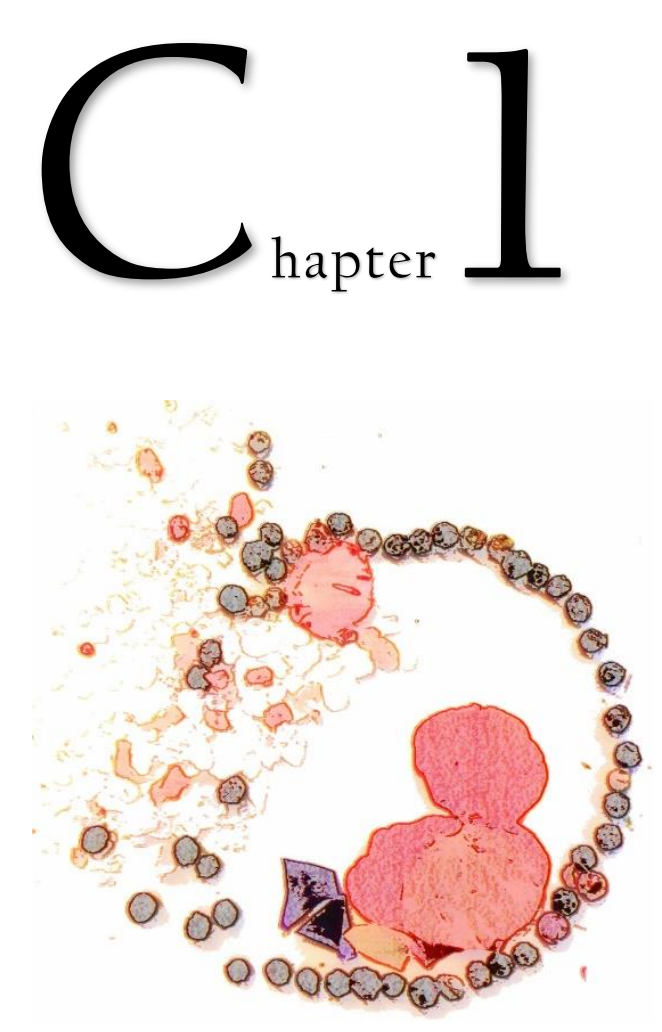

Figure 2: Expanding Embryo. Pencil Drawing by Hannah Gibson

\section{Methods and Positionality: on Surrogacy Research}

\section{FIELDNOTE 7 MARCH 2017}

I'm ready to call the blood collection laboratory and tell them to flush my blood specimen away, or at least not give me the $A M H^{51}$ (Anti-Mullerian Hormone) test results of my egg reserve. Even as I was paying at the counter afterwards, I felt the desire to run back into the room and say it had been a mistake, and I didn't need to know. Instead, all I remember is the technician's idle chatter as I sat there in the blue 'blood taking' chair that countless people have sat on before me, armrest on either side and me sitting too high off the ground for my feet to reach it. Waiting with my sleeves rolled up to show her my superficial surface veins. As I watched the needle being guided into a wispy one, tipped slightly to allow the blood to flow out

\footnotetext{
${ }^{51}$ Anti-Mullerian Hormone (AMH) is a hormone that is secreted cells in developing egg sacs in the ovaries and the AMH blood test is used to check the level of hormones in the blood. It is thought by the medical community to be a good indicator of a woman's egg reserve; the higher number, the better her chances of getting some eggs during the extraction phase of IVF. Basically, the AMH test exists because of assisted reproductive technologies.
} 
slowly, one vial for my kidney function and the next for my AMH, I felt like I was being suffocated.

\section{Blood Tests and Memories}

When I was 17 years old, doctors discovered that I was born with a rare disease that left me without a reproductive system apart from one ovary. Fourteen years later, I put off getting this blood test done for the best part of a year. First, it sat on my desk, peeking out from under books about surrogacy, infertility, and reproduction. Then it sat in my drawer. Finally, when I felt like it was time, I found myself at the laboratory having blood drawn. What will it mean if it the reserve is low? And what will it mean if it is decent? Either possibility scared me. I had no definite reason for it other than the wanting the option of using my eggs in the future if I wanted to. The paradox is that since I was born without a womb, I would meet the criteria for funded fertility treatment for surrogacy, but only if I want to have a baby now. The week prior, during a free fifteen-minute phone consultation with a nurse at a fertility provider, she said access to any fertility interventions was only possible through private funding or finding a sperm donor and surrogate willing to help. With one ovary that is situated further up in my abdomen, I was told it is likely I would need a lot more cycles than two to get a decent amount of eggs. 'What about if my lack of a womb was the result of cancer treatment?' I asked the nurse. 'Ah, that would be different', she replied.

Four days after I had the blood test, my GP called me with the good news: I have better than average AMH for women my age. I was immediately relieved, but also, this cloud of exhaustion hit me as the tension eased. Harvesting and freezing my eggs before their viability declines as I get older is not an option because I cannot self-fund it. Questions ran through my mind, should I lie and say I want to get pregnant to get eggs harvested? Why is the government not allowing women like myself to freeze our eggs?

As I write this, I remember how, aged 17, the gynaecologist told me about my condition in reference to what it would cost me in relation to others. As I lay in the hospital bed, which ironically was a mother and baby's room ${ }^{52}$, groggy from a laparoscopy, he pulled out a paper towel from the dispenser in the wall. He drew the female reproductive system on it. He circled

\footnotetext{
${ }^{52}$ I still get nightmares where I remember the empty bassinet next to my bed, and of hearing the babies crying in the rooms on either side of mine. I have never experienced that sense of vulnerability again.
} 
one ovary, and then crossed the rest out with a pen. This rudimentary drawing came to represent my move into the shadows of normative reproduction. The gynaecologist skirted over the ensuing kidney disease, auditory processing issues, skeletal abnormalities, and autonomic dysfunction that would slowly infiltrate those involuntary anatomical functions we do not even give a second thought to; the beating of the heart, temperature regulation, blood pressure, the ability to digest food, control of the bladder muscles. Instead, the gynaecologist's grief was centred around my inability to conceive and gestate a foetus and (wrongly) predicted the years of operations it would take before I could be capable of sexual intercourse, and in turn, be a 'good' wife.

Another moment. A motherly South African radiologist who spent hours over several sessions trying to find my solitary ovary. 'It likes to hide'. They knew I had one, she said, because my hormones are regulated. Thus, begun the hunt for the elusive ovary. It gave the illusion, she added, that it was not there. I became a bit of a novelty in the department, and the radiologist who would come out to the MRI scanner to check I was okay, peeking in through the top, said I had the most fascinating case she had seen in a while. Now, I have shone a light on the elusive embryo once again. And yet, the visibility is only partial. The new knowledge, printed on a slip of paper, is mediated by expensive technologies and the fallout of bureaucratic decisions that rendered any knowledge unusable.

These stories do not signal the start of my surrogacy journey, but part of my positionality and the vantage point from which I entered this complex world of non-normative kin-making that exists because of people's desire to have a family. My experience of lying in a hospital bed and then during scans, highlights the elusiveness of reproduction, of the invisibility of the ovary and the missing reproductive organs that the doctor implied are necessary to create kin. But what kind of kin? One that does not deviate from the heteronormative conventional family. My body, without these organs, was troublesome and relegated to the shadows of normative ideas of reproduction, sex, and kinship. These stories also emphasise one of my central arguments in this thesis: how government regulations shape our reproductive decisions and, in turn, dictate who can and cannot reproduce. 
This dissertation is based on three years of multi-sited ${ }^{53}$ ethnographic fieldwork between 20162019, which entailed an immersion (as much as possible) into the local surrogacy community and networks of people involved in the practice in New Zealand. In the first section, I describe my multi-sited ethnographic approach to gathering data and documenting as much as I could both in main sites and the more transitionary spaces related to surrogacy. From here, I describe the data collection techniques of participant observation, semi-structured interviews, spending time with people and technologies, and through the written medium. Integral to this was learning to build rapport with my participants in surprising ways, some that were uncomfortable and yet valuable to fieldwork experience. This is followed by tables that outline my participants' basic demographics before introducing some of the key interlocutors that feature throughout the thesis. Next, I consider the ethical considerations and briefly describe what topics I have not covered given space restrictions. Finally, I interrogate my positionality as a disabled anthropologist and as someone with experience of infertility alongside working with surrogates and families grappling with their kin-making options.

As mentioned above, surrogacy is one of the more complex and elusive assisted reproductive practices that, from the outside, is daunting, whether you want to make kin like many of my participants, or wish, as I did, to understand how kin is made. As is typical of anthropology, my goal from the planning stages was to make visible the voices and experiences of those whose culture or phenomena I wanted to understand better. Conceptualising those who practice surrogacy as a community in and of itself helped me to anchor myself in some of their stories. Despite being spatially dispersed, many created their community predominantly online and at a few in-person meet-ups each year.

\section{Multi-Sited Ethnography}

Conventionally, anthropological fieldwork is associated with leaving the familiar and spending long periods (typically several months or more) in a field site entirely unknown and often located overseas within an unfamiliar culture. Falzon $(2016,2)$ describes it as 'an eclectic methodological choice which privileges an engaged, contextually rich and nuanced type of qualitative social research, in which fine grained daily interactions constitute the lifeblood of the data produced'. Rooted in anthropology, an ethnography results from extensive and in-

\footnotetext{
${ }^{53}$ There were periods where I spent most of my time in 'the field', sometimes a few months at a time. Other times, it was responsive fieldwork - finding out about a scan or being told of another participant who was happy to share their story with me.
} 
depth fieldwork that typically involves participant observation, a technique of being immersed, or inhabiting, to some extent, the world of one's participants. Centrally, it involves 'deep hanging out', a term first coined by anthropologist Clifford Geertz (1973), whereby attentiveness to the quotidian moments and narratives of those people and groups we wish to know more about presents researchers with an opportunity to write 'thick description'. The challenge for me was how to do this within a disparate field site. With a population of just over five million, those who practice surrogacy are scattered throughout the North and South Islands. Surrogates and their intended parents may live in the same town/city or an entire island away. With more intended parents than surrogates available, the former must often be willing to travel or fund any travel costs for the surrogate.

In breaking with, or challenging, the conventional single-sited ethnography, in 1995 anthropologist George E Marcus wrote about a methodological movement called multi-sited ethnography. The name denoting a process of empirically following cultural logic or phenomena that do not exist in bounded spaces but is embedded and constituted within and across multiple sites. Marcus $(1995,96)$ states:

This mode defines for itself an object of study that cannot be accounted for ethnographically by remaining focused on a single site of intensive investigation... This mobile ethnography takes unexpected trajectories in tracing a cultural formation across and within multiple sites of activity that destabilize the distinction, for example, between lifeworld and system, by which much ethnography has been conceived. Just as this mode investigates and ethnographically constructs the lifeworlds of variously situated subjects, it also ethnographically constructs aspects of the system itself through the associations and connections it suggests among sites.

As well as allowing people to compare different cultural contexts, multi-sited ethnography is particularly useful when wanting to understand a complex practice such as surrogacy, where the practice is spatially dispersed both in terms of physicality and 'juxtaposition of data' (Falzon 2016, 2). The various sites, or sojourns, that I moved through were well travelled by intended parents and surrogates. However, rather than a linear trajectory, the unpredictability of whether assisted reproductive techniques or technologies will work, and the hurdles along 
the way, means that some people may need to repeat steps or begin the process again. By chance or mimicking this precariousness, my fieldwork did not follow a sequential path. Instead, I became immersed in several storylines at once, some of which were not straightforward. This is where the internet became invaluable.

\section{i. Ethics, Legal and Institutional Sites}

As mentioned in the introduction and chapter two, ethics approval must be sought within New Zealand for procedures such as IVF for gestational surrogacy. Under the Human Assisted Reproductive Technology (HART) Act 2004, the Ministry of Health established the Advisory Committee on Assisted Reproductive Technologies (ACART) in 2005, which has a broad monitoring role and develops guidelines for the Ethics Committee on Assisted Reproductive Technology (ECART) to follow. The latter meets six times a year and are tasked with weighing up the various ethical considerations and approving/deferring/declining each application. I did attend one of these meetings but agreed to not document or write about anything that I heard which made attending any further meetings futile. I plan to attend an ACART meeting in the future to present my doctoral findings to them once it is submitted and have had the opportunity to meet some of the committee members at two conferences based in New Zealand on ARTs and surrogacy ${ }^{54}$. Beyond that, I have interacted with several different government officials, but the conversations were all considered 'off the record'. I interviewed and received valuable input from Margaret Casey QC, who does the most work with both international and national surrogacy cases, in terms of the legal context. We had a plan for me to attend some adoption hearings or speak with some judges experienced in surrogacy cases, but this never eventuated.

\section{ii. On/Offline Sites}

I spent much of my fieldwork in the homes of participants dotted around New Zealand. Some I only met once, whereas others I either kept in regular touch with online or saw more than

\footnotetext{
${ }^{54}$ The first was a day conference aimed at exploring the future of ARTs in New Zealand, run by the Department of Health. When I asked the organiser if I could attend, he said that tickets would only be available for the key scholarly and public figures in this arena and that he could send me a copy of any appropriate publications of presentations afterward. Somehow, I managed to convince him that while that was entirely understandable, if a ticket does become available, I would appreciate attending, adding that I hoped to contribute my own fresh findings as part of my four-five years of dedicated research into ARTs and surrogacy in New Zealand. I felt arrogant and cringed when I hit the send button. It either did the trick, or a ticket became available organically, and I am content not knowing. The second conference was organised by the Canterbury Law School in Christchurch as part of their research grant to explore surrogacy law reform in New Zealand (more discussion in chapter two).
} 
once. With four participants, I interviewed them via Skype or phone and then when I travelled to their region, I visited their homes or met in a coffee shop. This made the face-to-face meetings easier and less awkward. One of my favourite fieldwork moments was visiting Cathie, an intended mother via gestational surrogacy, twice. Several months prior, our initial Skype call lasted 2-3 hours, and she was expecting her twins, being carried by her sister. When I arrived at her home, I was delighted to meet Cathie's sister and the two new additions to her family. When I visited intended parents, if their journeys were complete, I often encountered the babies/children and spent time with them in their own homes, which I hope made them feel more comfortable. On one of my trips to a large city, I was invited to stay a night or two with a set of intended parents and their young baby born via traditional surrogacy months earlier. When I sat on the sofa and held him, I felt a surge of different emotions; happiness to see them so happy, and an appreciation of everything they went through leading up to that moment.

Much of the relational work of surrogacy takes place online. The main hub or closed online forum, featured in chapter four, is central to the surrogacy community and is described via my participants' narratives and descriptions. It is a private space and haven for those wanting to create kin via surrogacy and it is ever present in the thesis. The main reason that I did not want to intrude in this space by reading conversation threads, was to only include those people in my research who wanted to participate. Even asking would have felt wrong. Those who meet on the main online closed forum (the focus of chapter four), do meet in person (and sometimes their first interactions are at a meet-up), but unless all parties reside in the same region of New Zealand, they continue getting to know one another, and keep in touch during fertility treatment, and pregnancy, via digital mediums such as Facebook Messenger, texts, and videocalls. In this sense, my fieldwork mimicked this pattern of relational work conducted over several formats.

As mentioned above, the ability to stay in touch with multiple sites at once, particularly the journeys of my main participants (intended parents and surrogates) helped me capture much more than if I had not utilised online and written communication mediums. Beyond the private messages containing updates, sometimes joyous and other times sad, and photos of embryos or family news, I still see the passing milestones of losses and birthdays of children born via surrogacy on the newsfeeds of those participants who added me as friends on Facebook. At regular intervals, the intended parents sometimes post photos taken of the combined families together. 


\section{iii. Medical, Fertility Clinic and Embryology Laboratory Sites}

Two main private fertility providers service privately and publicly funded patients. Founded in 1987 by Dr Freddie Graham and Dr Richard Fisher, who introduced IVF to New Zealand, Fertility Associates is the largest provider with clinics in five main centres and a clinic in Malaysia. Repromed is smaller, with its main clinic in Auckland and consultancy rooms in Hamilton, Tauranga, and Whangarei at the top of the North Island. Lastly, Fertility Plus is associated with Auckland District Health Board, providing publicly funded and private fertility treatments. I made initial contact with a few fertility clinics at the start of my $\mathrm{PhD}$, sending them a 'Research Project Information Sheet' (see Appendix 1) and in the emails accompanying my 'Invitation to Participate' in my research (see Appendix 2). This resulted in the eventual tour and interview with two counsellors from two different clinics, as well as informal conversations and interactions with fertility doctors ${ }^{55}$, and a week of participant observation in an embryologist laboratory (I dedicate chapter four to this site). In addition, I was lucky enough to establish a key contact with one of the science managers from a fertility clinic who has been there for any technical questions since the beginning of my $\mathrm{PhD}$.

Both traditional and gestational surrogates are likely to move through similar medical sites during pregnancy, including clinics for ultrasound scans, midwifery appointments, and obstetrician appointments where necessary. I attended three ultrasound scans, saw the photos, and heard about countless more; sat waiting with a surrogate to have her blood taken; and attended a hospital after the birth of a baby. I hoped to attend more, as discussed in the ethical consideration section, and a birth, but I ended up travelling overseas and missed it.

\section{Data Collection}

Spending substantial time with my participants over a three-year period provided an extensive experience where I got to hear and see various actors' perspectives and the challenges they encounter locally and overseas. I used a mixture of situational techniques to gather their stories,

\footnotetext{
${ }^{55}$ It became challenging organising interviews with the different doctors, partly due to a mutual clashing of schedules, and by the time we did manage to, I was at a physical limit and in discussion with my supervisors, I decided to move forward with my thesis without these interviews. The informal chats with doctors took place in corridors during tours, when I was in an embryology lab, and when I accompanied Lola to appointments. I also met two fertility specialists during an ethics committee meeting I attended who were curious about my research, particularly traditional surrogacy, which was the one thing that all doctors asked me about because it was elusive and they had no idea how many people practiced it.
} 
such as observing in fertility clinics, both in and out of the laboratory, taking a participant to a baby scan, and attending a baby shower. I sat down with participants to conduct semi-structured interviews at a place of their choice, which lasted 1-3 hours. The conversation would often take shape organically depending on who I was speaking to and their experiences thus far relating to reproduction and fertility. In medical appointments, coffees with extended families ${ }^{56}$, ultrasound scans, and the embryo implantation I attended, I tried to be minimally intrusive and observe rather than speak unless whoever I was with talked to me first. I observed and was typically introduced either as a friend or, as Lola told one doctor, that I was learning about surrogacy. For the more dynamic and informal gatherings, baby showers, hospital post-birth, and staying with some families in their homes, I relied on writing my notes afterwards or in the evenings. I felt more comfortable having my notebook out when I spent the week in the embryology lab because this was more of a conventional observational setting. I did not want to rely on my own mind to remember technical details, with so much unfamiliarity. I was invited to record the interviews with two lawyers (one of whom was also an intended father), but I was asked not to record the conversations I had with any government officials, one of whom I regularly saw for coffee (she had a role relating to surrogacy)., They did not want to be seen speaking on behalf of their government department. To respect their position, I do not include any quotes from them, but their input allowed me to critically engage with the surrogacy legislation, for which I am thankful.

\section{Participants}

Once I received Ethics Approval for my project (Approval Number 22968, 26 May 2016), I contacted all the owners/moderators of several online surrogacy forums in New Zealand, and they agreed to put up my invitation for people to take part in my research project. Alongside a snowball effect and connections made through some smaller online support groups, this resulted in me following to a lesser or greater extent twenty surrogates and their families (twenty-three people in total), and twenty-five intended parents scattered throughout New Zealand. The table containing their information and demographics are on the next two pages.

\footnotetext{
${ }^{56}$ I was invited to meet the parents of two surrogates, one of which was serendipitous as the mother herself was also a surrogate some years ago and shared some wonderful memories.
} 


\section{i. Intended Parents}

In the table below, I outline the basic information of the intended parents I spoke with, of which ten attempted gestational surrogacy, two that were unsuccessful, and six out of seven intended parents who went overseas for transnational surrogacy did gestational. Nine intended parents attempted traditional surrogacy, one of which took place overseas, and one who was unsuccessful. One set of intended parents practiced both gestational and traditional surrogacy. Two sets of parents were gay, and two were single. To maintain as much anonymity as possible, I provide essential information to give a picture of the demographics. Table 1 reflects a mixture of intended parents (IPs), the intended mother (IM) ${ }^{57}$, and the intended fathers (IF) ${ }^{58}$. I have identified if they live in the North Island (NI) or South Island (SI) and if they practised gestational surrogacy (GS) or traditional surrogacy (TS).

Table 1

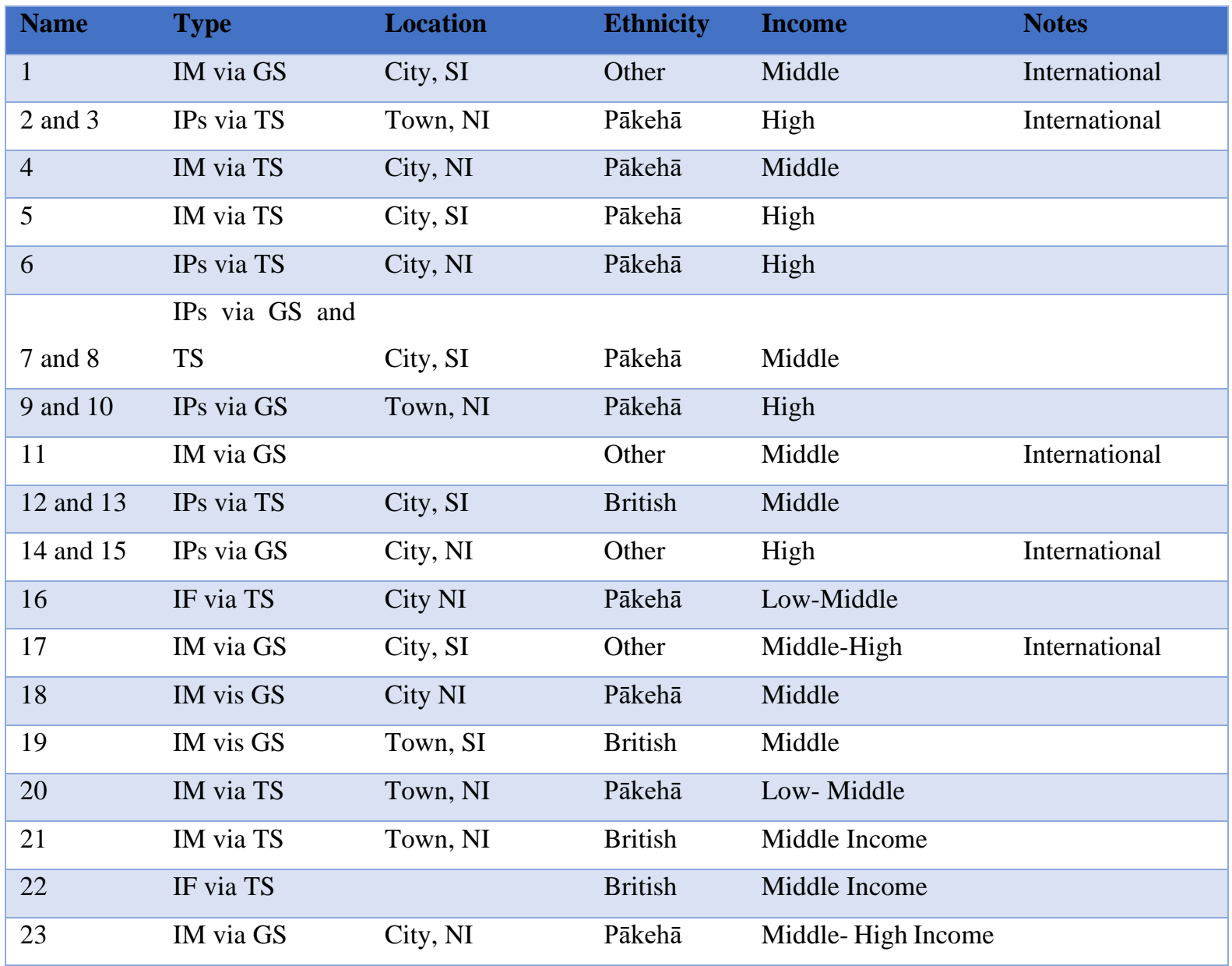

\footnotetext{
${ }^{57}$ All intended mothers except one (who was single) were in a heterosexual relationship, but I wanted the table to reflect who I spoke with during my fieldwork.

${ }^{58}$ Two intended fathers were gay, and one was a heterosexual single.
} 


\begin{tabular}{|llllll|}
\hline 24 & IM vis GS & City, NI & Pākehā & Middle-High Income & International \\
\hline 25 & IPs via GS & Rural, NI & Pākehā & Middle-High Income & International \\
\hline
\end{tabular}

\section{ii.Surrogates}

Everyone except two surrogates identifies as Pākehā $\bar{a}^{59}$, fourteen as traditional (TS) surrogates, eight as gestational surrogates (GS) and out of these two were both. Six surrogates were single at the time of fieldwork. With traditional surrogacy practised outside of any surveillance, it is almost impossible to know how many exist. However, anecdotally, several of my participants have indicated that to their knowledge, approximately fifty percent of surrogates in New Zealand practice traditional surrogacy.

Table two

\begin{tabular}{|c|c|c|c|c|}
\hline Surrogates & Surrogacy & Location & Ethnicity & Income \\
\hline 26 & GS x 2 & City, NI & Pākehā & Middle \\
\hline 27 & GS x 2 & City, NI & Pākehā & Middle \\
\hline 28 & GS x 1 & Rural, NI & Pākehā & Low-Middle \\
\hline 29 & GS x 1 & City, NI & Māori & Middle \\
\hline 30 & GS x 1 & Town, NI & Pākehā & Low-Middle \\
\hline 31 and 32 & GS + partner x1 & Town, NI & Pākehā & Low-Middle \\
\hline 33 and 34 & $\mathrm{TS}+$ partner $\mathrm{x} 1$ & Town, NI & Pākehā & Low- Middle \\
\hline 35 and 36 & $\begin{array}{l}\text { TS/GS + partner } \\
\mathrm{x} 2\end{array}$ & Town, NI & Other & Middle \\
\hline 37 & TS x 1 & City, NI & Pākehā & Low-Middle \\
\hline 38 & $\mathrm{TS} \times 2$ & Town, SI & New Zealand/Other & Low-Middle \\
\hline 39 & TS $x 2$ & Town, NI & Pākehā/Māori & Low-Middle \\
\hline 40 & TS $x 2$ & Town, NI & Pākehā & Middle \\
\hline 41 & TS x 1 & Town, NI & Pākehā & Low \\
\hline 42 & $\mathrm{TSx} 2$ & Town, SI & Pākehā & Middle \\
\hline 43 & TS $x 1$ & City, NI & Pākehā & Low-Middle \\
\hline 44 & TS/GS x2 & City, SI & Pākehā & Low-Middle \\
\hline 45 & TS $x 1$ & Town, NI & Pākehā & Low \\
\hline 46 & TS x 1 & City, NI & Pākehā & Low-Middle \\
\hline 47 & TS $x 1$ & Town, SI & Pākehā & Middle \\
\hline 48 & TS x 5 & Town, NI & Pākehā & Low-Middle \\
\hline
\end{tabular}

\footnotetext{
${ }^{59}$ In line with Margaret, $(2017,1)$, the Pākehā that I refer to in my thesis are white (particularly European) immigrants who have continued to come and live New Zealand as beneficiaries of colonisation. Although contemporary immigrants might not consider themselves Pākehā, by reducing it to only encompass those who were born here, we are not taking any responsibility for their place in a system that disadvantages Māori.
} 
In getting to know intended parents, it became clear that the reasons behind choosing one type of surrogacy over the other were not static or linear. For four sets of intended parents, knowing that they would need the help of an egg donor on top of a surrogate to gestate the foetus resulted in them choosing traditional because they felt comfortable with the surrogate donating her egg. After spending hundreds of thousands of dollars, four further intended parents could no longer afford the clinic costs, and instead opted for traditional surrogacy. Unfortunately, by the time many intended parents know they need a surrogate, they have already spent a substantial amount of money trying IVF themselves, or at least freezing embryos (with or without donated eggs) in preparation. Two sets were denied access to the clinic (one gay couple and one single woman who required both sperm and egg donation). For another three sets of intended parents who needed an egg donor, they wanted the separation and boundary between the surrogate and the foetus that gestational surrogacy and the clinic provided.

During fieldwork, in addition to the intended parents and surrogates who became my 'main' participants, meaning it is their stories I am telling, I also learnt a lot from other people. In particular, the week spent in an embryology laboratory (explored in chapter five) and the five embryologists who took time to show me all the various features and techniques involved in their work. This project felt like a multi-sited project both geographically and in terms of diverse social arenas I explored as I followed the processes and practices involved in creating kin via the two types of surrogacy. I tried to be strategic when travelling and visiting the homes of participants within North and South Islands, fitting in several per trip. I was lucky enough to be hosted by one set of intended parents, which was a very poignant few days as I found myself holding their baby born from surrogacy some months prior. I still talk with a handful of participants regularly and am routinely updated by others via online messages, text messages or emails.

\section{iii.Key Interlocutors}

Below, I take the opportunity to introduce you to some of these amazing interlocutors, who helped me understand and unpack the space wherein kin is made in Aotearoa New Zealand. These are five surrogates who became my main participants and are featured throughout the chapters. This does not mean that I did not connect with intended parents, on the contrary, I am 
still in regular contact with many. These five surrogates became my anchors, but they do not reduce the input from the many other participants who spent a lot of time with me. Thus, this is a snapshot rather than comprehensive profiles for everyone.

\section{$\underline{\text { Lola }}$}

Lola has been a traditional and gestational surrogate for two sets of intended parents. Her experiences feature throughout the thesis which reflects the amount of time I spent with her and her family, and because she has had experiences with both types of surrogacy. Her first, traditional surrogacy, grew out of a desire to help others create a family and a curiosity of seeing what a child would look like with her genetics mixed with a man's (other than her partner or husband) genes (discussed further in chapter three). This is quite an unusual motivation to admit because most of my participants avoided any sexual connotation when discussing traditional surrogacy. It is only now that I realise how open Lola was with me, since she would never have told this to her intended mother or the community. When we met, she was ready to be implanted with the embryo of her second set of intended parents, having been through mandatory counselling, medical checks, and ethics approval. My first glimpse of Lola was when she walked onto a train platform when I handed her a takeaway mochaccino (she hated early mornings) and accompanied her to a scan to check the thickness of her uterus lining (I write about this in the interludes). We spoke all the way from the station, and she was excited about my research, as I would come to know, incredibly invested in letting me see and be part of as much as possible.

While I worried that I would be intrusive, hanging around and witnessing experiences and conversations that were personal and potentially traumatic, Lola continued to invite me to everything. Over the three years, I was introduced to her husband Ralph and two boys, and two sets of intended parents (one of these journeys was unsuccessful and features in the interludes between chapters). When her first intended mother via gestational surrogacy, Celeste, began to update me separately on events and sent me a photo of the embryo from the implanting into Lola I had observed, I realised I was being included in their excitement and anticipation that it would be successful. As I write in the interludes, their collective and then separate stories, when they both moved on to a new surrogate/intended parent, became the heartbeat that existed in conjunction with, a distinctive pulse of which I was aware, and to which I kept coming back. 
It was even on one of their weekend trips to my home that I had my first quasi date with my current partner, who went to the cinema with us to watch a superhero movie (and ironically, we have since had to sit through it again on a visit when we minded Lola and Ralph's sons for an evening so that they could go out for dinner and a movie). Lola and I have been in contact through the exciting parts of the journey, like the transfer of embryos and the birth, and the sad points, such as when one embryo transfer did not result in pregnancy. When her husband and children were travelling overseas for three weeks, Lola and I went to eat Italian food and talk to keep her mind occupied on the night of the flight. It was over aperitives that Lola grabbed her phone, declaring she has a friend who was currently pregnant as a gestational surrogate with whom it would be good to talk.

\section{$\underline{\text { Ruby }}$}

All my participants contributed and add richness to this ethnography, some of which are featured more prominently in some places. One of these is Ruby, a traditional surrogate to a boy for one couple and a girl to a sole parent. She invited me to stay with her for a night when I travelled to her part of New Zealand - with communication all done quite briefly over email. When I got there after a long day of travelling, over wine, we became engaged in conversation about different authors we love. I spied Elly Teman's 2010 ethnography, Birthing a Mother: The Surrogate Body and the Pregnant Self, sharing with Ruby that this book influenced my own decision to pursue surrogacy as a topic. Ruby exclaimed that as her motto, she had adopted Teman's description of surrogacy as 'making a mother' rather than a baby, which motivated her throughout her pregnancies to make sure the intended mothers were as involved as much as possible. When we finally sat down to eat, I had consumed a few glasses of wine on an empty stomach, and unfortunately, it caused a quick drop in blood pressure, not helped by the fatigue of travelling. Ruby quickly moved around the kitchen island bench and helped me lie down on the sofa. Once feeling better, we joked that this was a creative way to break the ice and build rapport. Ruby was in her 40s when she decided to be a surrogate, choosing traditional because the government regulations dictating who could and could not access gestational surrogacy infuriated her. In response, she wanted to help those who may not have been accepted, or for whom the need to find an egg donor and surrogate would have complicated things. 'I could be both!' Ruby said. She was also aware of how expensive ARTs can get and raising her daughters while working and studying simultaneously and surviving off a low income, she wanted to 'help the underdog'. It was also possible, Ruby shared, that the clinic would have rejected her as a surrogate because she was at high risk for complications. Instead 
of seeing this as a reason to reconsider, she proceeded with the surrogacies with a mixture of caution and optimism.

At one level, Ruby's role as a surrogate is one of the many things she has done to take a stand against the state. For example, as an anti-Trans Pacific Partnership Agreement activist, she has submitted d written and oral submissions to parliament. 'I wanted to do everything I possibly could to be able to look after my children in the eye and have them know that I did everything I could to try and stop it' (Ruby, personal communication). In addition, Ruby did street performances, blockaded a weapons conference, and boycotted any corporations who have been identified as causing damage to the environment. On the morning after I slept at Ruby's house, over a cup of steaming tea she shared her plans to build a house out of containerships in Northland, to relocate and be in a safer place in the future if tsunamis or environmental disasters struck. To prepare for this, each year she had taken her 9-year-old daughter to learn a new skill so she could be self-sufficient and able to survive with the bare necessities. Her dedication to living sustainably and teaching her youngest daughter sat nicely alongside her stories the previous evening.

\section{$\underline{\text { Kelly }}$}

Kelly was the first surrogate to send me an email after she saw my invitation to participate on the online surrogacy forum, when the moderator posted it. A traditional surrogate, she was childfree and four months pregnant. We met shortly afterwards in a noisy cafe, and I was nervous since it was my first participant, but she has this uncanny ability to set me at ease despite the chatter around us. For the rest of her pregnancy, and afterwards, we met often for coffee or lunch near where she lived, moving from café to café to see who had the best date scone in town (this being Kelly's craving during her pregnancy). When she went to her postgraduate ceremony, she invited me to meet her parents for coffee, saying it would be an opportunity to see their perspective. Kelly was always ready to answer all my questions and let me tag along for an ultrasound scan. Within 24 hours of having an emergency caesarean section, I got a text from her with the news of the baby boy's birth. I made my way to the hospital and encountered her in a bed, with an adjoining bathroom and other hospital room where one of the intended fathers had the baby. After the birth, we met less often but kept in touch. As I write this, the baby boy she carried for her intended fathers has already turned four years old, and she sees them occasionally for playdates when they are all in the same region. I feature her story throughout the thesis. 


\section{Heather}

Heather is the moderator and community 'mother' of the closed online surrogacy forum. Her patience in answering all my questions over Facebook messenger, mainly to clarify things in the final 6 months of writing my thesis, has been invaluable. Heather was initially an egg donor for a couple, but they failed to conceive despite several egg collections and embryo transfers. After years of getting sick with Hyperstimulation Ovarian Syndrome, she could not physically continue. Having got to know her intended parents, Heather offered to be a traditional surrogate, becoming pregnant quickly. After a miscarriage at ten weeks, they tried home insemination again three months later, which was successful and led to the birth of a baby girl. According to Heather, the intended parents acted like the pregnancy did not exist, perhaps because of the fear of miscarriage. This lack of concern or care troubled Heather, who lost confidence in the intended mother. I remember her sharing that after the birth, 'I needed a sign that she would love the baby, I didn't get it'. Although Heather gave the baby over to them, she was given no opportunity to meet her properly, a ritual that is encouraged in the community. Heather experienced what she thought was post-natal depression, and after 8 weeks of waiting, was finally contacted by the intended mother and invited to visit. Seeing how happy the baby was, and sitting quietly with her, Heather felt an immense sense of relief and her depression eased almost immediately. In retrospect and after the birth of her second surrogate baby, Heather realised that she was so emotionally distressed post-birth with the first because she had lost confidence in the intended mother. In comparison, her second experience carrying for Paula was a positive one, and the lack of depression was a stark contrast with the first. Heather did not realise it at the time, but having the intended mother acknowledge the pregnancy was important to her.

\section{Madison}

When I first met Madison, it was on a scheduled Skype call, and she seemed shy. I was also awkward as she was one of the first surrogates I got to know, but we muddled through the first while and got into a rhythm with the conversation. What helped us bond was our mutual love of dogs and steampunk. Madison was a traditional surrogate for a gay couple twice, and like Kelly, she has no children of her own by choice. She became a surrogate after reading an article about people struggling to conceive and was upset that she had a womb and supposedly was fertile, while they were not. This spurred her into tentatively joining the online surrogacy forum, where Madison met 'the dads'. She had no type of recipient in mind, and quickly ended 
up meeting and 'falling for' ${ }^{60}$ the intended fathers. When we met, the youngest of the two children was two years old, and she kept in touch with them, but did not have any mothering role. In our first meeting, she told me that she had no desire to have children of her own whatsoever, although her parents took on the grandparent role, giving the two boys three sets of grandparents. This unconventional family has redefined the traditional parameters of what a family looks like. In the next three years, we met in real life when I was visiting her region of New Zealand. She had been babysitting the two boys, something she did not do very often, and which she found utterly exhausting, she confessed. We have promised one another that we will attend a steampunk festival together sometime.

\section{iv. Building Rapport}

My story blurred with that of the intended mothers I met, and during some conversations, I felt an opening, where they assumed I understood how infertility felt. Recognition based on a shared embodied knowingness. In these moments, I most felt like an insider ${ }^{61}$, such as being able to understand and communicate using medical jargon. Sharing is an excellent way to build rapport and helped make my participants more comfortable. In her ethnography, The Vulnerable Observer, anthropologist Ruth Behar $(1996,4)$ argues that self-exposure can be productive, that 'when you [speak] vulnerably, others respond vulnerably'. Despite wanting to make sure that my own experience was not the focus of the interviews, as I became friends with some of my participants, it would inevitably emerge organically. For example, one participant contacted me after hearing from someone else in the surrogacy community that I was also infertile, saying that she was happy to talk with me since my interest in the topic was more than 'just curiosity'. Her words made explicit the stakes of my research - people were trusting me with their stories, some of which they may not have told others outside of their immediate circle, if at all. As I wrote last year, 'not being open about my own medical experiences would be akin to saying, "I want to know your pain, but I am unwilling to share mine". This makes me wonder if my vulnerability is the price to pay to collect such rich data'. (Gibson 2019, 77).

\footnotetext{
${ }^{60}$ This phrase does not indicate any romantic feelings were involved in the surrogacy arrangement. What are considered romantic phrases in mainstream society are used in the community, without any romantic or sexual connotation.

${ }^{61}$ Anthropologist Nayantara Sheoran Appleton writes about her experiences of conducting research 'at home' in India and having to navigate the constantly redrawn boundaries of her insider/outsider status (Sheoran 2012)
} 
Building rapport with participants helps to establish trust with participants. Like Behar's (1996, 4) fieldwork experiences in Cuba and Spain, this enabled me to break down the researcherresearched divide to a certain degree, and the clients opened up more. By disclosing part of my own experiences, the interviews became conversational and supportive. We gained one another's trust, which is a type of interaction described by Low and Merry (2010, S207) as a central component of engaged anthropology. Having the interviews semi-structured also allowed for topics to emerge as we went along. I have been there for some of the most vulnerable parts of their journeys and seen the daily implications of technological triumph and defeat, of running out of options, of miscarriages and nail-biting waits for test results. Equally, participants have sent me notifications and news of newly born babies, or long-awaited arrival of 'the day', aka the Adoption Hearing. My main goal of fieldwork was to listen and document participants' stories, who are typically un(der)represented in political and legislative debates about the regulation of surrogacy. To this end, I planned to render visible, as much as possible, the various reproductive processes they experience and the spaces they move through on their journeys. This meant also moving through and examining the junctures between the unique private, institutional, legal, ethical, academic, medical, and public landscapes that are connected to the entire surrogacy experience.

\section{Positionality and Reflexivity}

i. Disability and 'Anthropology at Home'

I was born and grew up in Scotland and moved to New Zealand in 2002 when I was 16 with my parents and siblings and have predominantly resided here for more than half of my life. Interestingly, I do not necessarily see New Zealand as 'home' ${ }^{\text {'62 }}$, maybe because my formative years were in Scotland. Paradoxically, when I return 'home', I miss New Zealand and my familiarity with my life here. When brainstorming about locations and topics for my fieldwork, I was initially invested in going overseas (in part because I read a lot of 'conventional' ethnographies). Then the reality of what fieldwork would entail physically became the deciding factor. I live with several rare and chronic illnesses, and my health and body are precarious. I often downplay their impact with a shrug and quip, 'it's not like I have known anything different', in response to people asking how I cope. I know what I need to do to stay out of the hospital. It was a candid conversation with my primary supervisor early in the $\mathrm{PhD}$ journey

\footnotetext{
${ }^{62}$ For me, home is where my partner is and as a migrant themselves, it has always been a malleable construct with the possibility of being anywhere.
} 
that made me realise I needed all the support I could get for the next several years. This meant staying in New Zealand.

Conducting fieldwork as a disabled anthropologist with a precarious body had several unique challenges. I had no option to leave my illnesses at home when I travelled to different locations around the country for fieldwork. It demanded my attention in the hours between interviews and the evening when I sat trying to write up fieldnotes:

As graduates engaged in qualitative research we become aware early on that our most important 'tool' is our physical and mental selves, which allow us to go into the field and sit alongside others, see the world from their perspective, document their stories, and occupy whatever space they allow us to. Collecting data is thus a very embodied experience. We must rely on our bodies. And on our minds. We hone our skills of observation in order to recall details about the connections we make with our participants, though we rarely talk about how cognitive skills become impaired when we are tired (Gibson 2019, 74).

For the first year of fieldwork, I tried to stay invested in all aspects of my life. Then in the second year, juggling the competing demands of fieldwork, expectations as a graduate student, and the other identities I was still expected to nurture, as a daughter, partner, aunt, and friend, became overwhelming. I was utterly exhausted, not least because of my expectations of wanting to do what any able-bodied person could ${ }^{63}$. At the same time, I was envious of people who had good health. Living with fatigue that never leaves you, that sits in your bones, muscles, tissue, and skin - and severe pain has made every step of this journey a challenge. I found myself in and out of the hospital, in between fieldwork trips, and at the end of 2018, the doctors told me that my kidney was no longer stable. To give me longer, I would have to stop taking some pharmaceuticals that helped me function. Nevertheless, I persevered, learning how to adapt, and decided that I would simply just focus on trying to get through each task. That meant

\footnotetext{
${ }^{63}$ It only occurred to me when writing this section that having an able body does not make people invincible or more capable. Embodied vulnerability in the field is not solely only experienced by those of us with precarious bodies. I have not met a graduate student, particularly in anthropology, who have not experienced physical, mental, and emotionally toil of fieldwork.
} 
being strategic with my energy. I do not include this to sound like a martyr, but to simply highlight experiences that usually remain in the shadows.

I took my personal circumstances as an opportunity to interrogate the pervasive and implicit anthropological assumptions that underpin my own experiences. One is the idea that during fieldwork we must rely on our body and mind as our primary 'tool' of building rapport, collecting data, staying immersed in an unfamiliar field site, and having the energy to fight fatigue as we write our notes at night. Thus, anthropology is a fully embodied experience. Having written about this previously (Gibson 2019, 74), I outline the relationship between fieldwork and researcher as:

Conceptualising our bodies and minds as 'tools' is laden with ableist and dare I say masculinist assumptions about the anthropologist's physical self and capabilities. This ideal is conveyed in undergraduate classes, in ethnographies about anthropologists travelling to foreign lands and 'establishing rapport' and engaging in 'deep hanging out' with others. Ethnographies, lectures, and conversations with mentors and peers have given me the impression that fieldwork is a rite of passage, that some form of 'culture shock' is expected. We are encouraged to accept this traumatic 'entry' into the field as a given. I do not see my body represented in anthropological literature. Although I was assured by a few mentors that it would be possible to undertake postgraduate research if this was my goal, I never got the impression in the wider community that an anthropologist could be as I am.

This feeling of existing in the periphery of graduate school, of 'traditional fieldwork', felt very much like I was inhabiting the shadows. I continue to be an unexpected and unconventional anthropologist, in a discipline that was not made for my kind of body ${ }^{64}$.

${ }^{64}$ This sentiment is echoed by Friedner, Kasnitz, and Wood who published a blog post for Anthrodendum in 2018, arguing that they wish they had known anthropology as a discipline is ableist, how 'anthropologists still assume that other anthropologists will be normatively speaking and hearing', and like other minorities, disabled anthropologists must spend most of their energy making space in the discipline for themselves. 


\section{Ethical considerations}

According to the Code of Ethics laid out by the Association of Social Anthropologists of Aotearoa/ New Zealand (ASAA/New Zealand), the researcher's primary responsibility is to their research participants. In surrogacy, some participants are part of controversial cases within the media. Therefore, protecting their privacy as much as possible is paramount. Further, the surrogacy legislation in New Zealand regarding what constitutes compensation of reasonable expenses incurred (or that which is legal) is vague. Therefore, there is the possibility that people may be perceived to be engaging in prohibited acts, which may include anything beyond the necessary medical expenses, for example, pregnancy massages. To protect their identity and stories, I have anonymised people and locations as much as possible. I am especially aware that this research involves telling the origin stories of children, and protecting their identities is paramount. I have changed the sex of children and omit any specific details.

Surrogacy is a practice chosen by many after years of attempting to have a baby via natural conception. It can be an arduous and emotional journey. Spending time with people and asking them to relive painful experiences can potentially cause upset or distress. Those participants who are in the middle of their surrogacy journey are particularly vulnerable because pregnancy often does not occur after the first attempt of assisted conception, whether in the clinic or home setting. I am therefore mindful that I have been welcomed into the lives of participants who might hear difficult news at times, for example, if they have disappointing test results (where there has been no pregnancy, or a surrogate may have miscarried), or personal health concerns. My response to this was to give participants space where they required it. This was a bit of a balancing act in wanting to support people who tell you intimate things and not inflict more upset by asking questions when inappropriate. As mentioned in the section on building rapport, sometimes the most poignant moments that helped cultivate a sense of trust and comfort for the participant, were to be open about my own experiences of infertility. This sometimes had the effect of giving whoever I was speaking to space to share what they wanted or needed to at that moment.

At the same time, a downside to my openness was how draining it could be some days. This made me realise how impossible it is to separate the researcher from the topic or the researched. Communication is a dynamic and shared experience that required attentiveness. I tried to give everyone my full attention, and yet I was still balancing other things in my life that did not 
stop. The few times when I did pull over to the side of the road in the car and cried were in response to adrenaline, required to be present in interviews or visits, suddenly crashing. Fatigue or hearing particularly traumatic stories tended to overwhelm me, especially if I recognised any of my own story in them. To ease or lessen the impact of this, my approach was two-fold. Firstly, to decompress experiences in the field, I had the support of my supervisors either via email, telephone, or face to face. Secondly, I continued to have appointments with a therapist I saw before fieldwork started to talk about the impact of some experiences. In addition, given my compromised physical health, I tried, successfully at times, to establish times of rest between days of intense fieldwork (Pollard 2009).

\section{Conclusion}

One of the benefits of doing multi-sited ethnography was that it allowed me to see my main participants in various stages and spaces throughout their surrogacy journeys. Due to the limited amount of fertility clinics, each will likely have seen more than one gestational surrogacy arrangement. Besides these, lawyers' offices and/or courtrooms, people's private homes felt more transitionary in that as their journeys end, they retain a link to all the other spaces with which they have engaged. When the baby is born, they begin parenting as all other new parents do, and their story becomes more about this role. There are certainly challenges and ongoing negotiations between participants and institutional, legal, regulatory, medical, and private landscapes. My fieldwork planning was to capture this the best I could. What became clear throughout is that although there are a vast number of complex processes to surrogacy, underpinning the unknown assisted reproduction outcomes or surrogacy experiences is a clear goal that both intended parents and surrogates have. To make parents, make kin, and do it in a way that they are comfortable with. Although many are scattered throughout New Zealand, they remain a community through the online space and occasional meetups in different cities. When I think back to my field-site, I imagine an entire map of the North Island and South Island, with invisible lines connecting me to each site, home, clinic, hospital, lawyers' offices, government departments and universities.

In this chapter, I have explored my methods and positionality in this research. The fieldwork became an intense experience, and alongside living with debilitating physical illnesses, there were several times when I had to regroup and check in with supervisors and friends who became supportive. We all knew that my precarious health would be a constant throughout the process, which helped me to prepare contingency plans. My illness has always been a shadow 
that I inhabit; I live on the periphery of an able-bodied world that does not often make space for bodies like mine. It was not until I began writing about the reproductive penumbra and the framing of my research that I encountered another shadow: I too live in the reproductive penumbra, not fitting in with mainstream conversations of how families are made, and feeling like people do not understand what it is like to live without a reproductive system. This positionality meant that I had many moments where I felt vulnerable as I spoke with participants who had been through traumatic experiences, especially the intended mothers. As I have written, many said they only wanted to talk to me because I was invested in making sure that people understand how surrogacy is practised, in bringing awareness to it. However, being a 'vulnerable observer' to quote Ruth Behar again meant that I had to navigate my role as an anthropologist, hear their stories, and connect beyond that with my own vulnerable corporeality and grief. Different mentors have taught me along the way that fieldwork and ethnography is not about perfect research, but about bearing witness and sitting beside one's participant on their journey, listening to their story. My own experiences became central to sensing the theoretical reproductive penumbra, and the framing grew organically as I sat with my data and reflected on my participants' experiences in relation to 'normative' kin-making. By inhabiting shadows, too, it was less a matter of creating a framework than sitting quietly and letting the idea emerge in my writing. 


\section{Interlude One- Lola's Pre-Transfer Scan}

\section{FIELDNOTES 10 May 2017}

After months of anticipation, it is finally the day of Lola's Pre-Transfer Scan, in preparation for the implanting of Celeste and James' currently frozen embryo. Lola was a traditional surrogate a few years prior, and instead of the clinic, doctors, and ethics approval, she became pregnant via home insemination. This time, for over twelve months, Lola, her husband Ralph, and Celeste and James, have been going through the various medical and ethical approval processes before embryo implanting could begin. It consisted of countless medical checks to assess any medical risks the implanting and pregnancy may pose to Lola, counselling sessions with Ralph and then as a group with Celeste and James, and a lengthy application to the Ethics Committee on Assisted Reproductive Technology (ECART) to ask for their approval. Celeste and James already have a daughter born via gestational surrogacy four years ago. Lola offered to be a gestational surrogate for them after meeting them in person at a small group gathering of people who have been through, hope to, or will do surrogacy sometime. Lola wanted her second and final surrogacy journey to be a 'sibling surrogacy,' otherwise known as helping a couple have a second child. Unfortunately, it is harder to find a surrogate if you have already had a surrogacy baby because there are more intended parents than surrogates in New Zealand.

Lola's specific reason for being a gestational surrogate rather than traditional second time round is because she had already fulfilled her curiosity to see what kind of child her genetics would make if mixed with a different man than her husband. She does not talk about this with others in the community because it is taboo to reference any link of intimacy, sexualised or not. Of course, nothing sexual occurs, but people are careful given how controversial it is within wider society. Plus, not all surrogates or intended parents would feel comfortable talking about this. The societal discomfort is exemplified by the comments people have casually made (in every environment I go into) about the practice when they find out what I am researching. They ask (sometimes rhetorical) questions like: 'How much are they getting paid for that?', 'Oh, that's a bit weird, isn't it?', 'That's not natural. Why can't people just 
adopt?' Of course, I also have very pleasant conversations with people about it, who are curious and think it is a wonderful way to make kin.

Today is also the first day that I meet Lola, and I feel pretty anxious about making a good impression, especially given that it a big day. I offered to collect Lola off the train and be her driver for the morning. She is very open about my attending everything. Her intended mother, Celeste, lives on another Island and could not be here for this pre-transfer scan to see if Lola's uterus lining is thickening. I almost feel like I have taken on her role for the day, although, of course, I have not. Yet, I am taking on some tasks, such as taking Lola to the scan, a practice typically done by the intended mother. Plus, it is nice to be doing *something* as opposed to just observing. I arranged to collect Lola from the train, accompanying her to the clinic as her support and because she was keen for me to see as much of the journey as possible.

Lola lay on her back with a sheet covering her naked lower half in the tiny room with a bed, monitor, 'dildo like wand' (Lola's description of the vaginal 'transducer' probe). I was sitting at her head as we both watched the screen in front of us. The doctor had lubricated the probe. In a short space of time, and slipped it under the sheet and up inside Lola's vagina. Suddenly, we saw a shape defined in white on the dark background, moving in parallel with the doctor's hand. 'So, you are going to be a surrogate? That's wonderful of you to do', she said, on hearing Lola's affirmative response. Shortly, the doctor proclaimed, 'ah, there's the lining', in an appreciative tone. I looked at the screen and struggled to locate anything beyond the blackness with white specks. Finally, she said how good Lola's uterus and lining were looking, her commentary giving shape to the image. 'The lining of the uterus is $14 \mathrm{~mm}$, and we need above $8 \mathrm{~mm}$ to go ahead and do an embryo transfer'. The Dr sounded delighted, exclaiming 'well done!' to Lola. The requirement of a thick lining is also checked alongside the oestrogen levels in a blood test (which Lola had directly after), because good oestrogen levels to stimulate and prime the growth of the 'receptive' lining is needed. The doctor measured the lining on the screen, taking horizontal and vertical measurements. Next, she moved her hand slightly, depicting what she said was a follicle. This also appeared to be good news. 'Everything looks perfect'. To me, it looked like a dark mass, like any scan I have ever had personally on my abdomen or shoulder (more recently) - something that had meaning but remained incomprehensible to me. 
Technology is fascinating but remains an enigma even when it comes into our purview. Is it in these moments that we defer to the doctor's expertise, relying on them to translate its meaning, code, and rate whether our bodies perform well? It has its own language, the shapes meaning specific things only when those shapes are learned. Even Lola, a midwife and has seen ultrasound scans and had her own two babies and one surrogate baby, said during this scan that it is so different to a pregnancy scan, where at least something is discernible. That here, she could understand nothing. The doctor said that it was something she would have to trust her, that what seemed magical could be interpreted and relayed. Yet, the words she spoke were only understandable if you knew what 'good lining' meant. To my ears, I could only tell this was good by the happy tone of her voice, that Lola had somehow managed to achieve a perfect environment and had pleased the doctor.

The scan was over in five minutes. The doctor gently but swiftly pulled the scanner out. As Lola got dressed, I sat next to the doctor as she typed what appeared to be the measurements into a file onscreen. Lola joined us, with her red converse trainers in hand, putting them on as the doctor said that it seems like such a long journey to make for a five-minute scan. Once out of the consultation, a nurse handed Lola a paper bag, stating that she would get more instructions later. It was very vague sounding, and Lola tried to confirm where she would get blood taken to determine her oestrogen levels and if she would need the 'trigger injection'65 in preparation for the embryo transfer. The nurse was concerned that the contents of the bag could not be put into a fridge until 3pm, stating it needed to be kept under 25 degrees. I suggested that we come back for it before taking Lola to the train station, and Lola asked the nurse if that would work, telling the lady it was up to me since I was her taxi.

${ }^{65}$ A trigger injection contains hormones that trigger ovulation. 

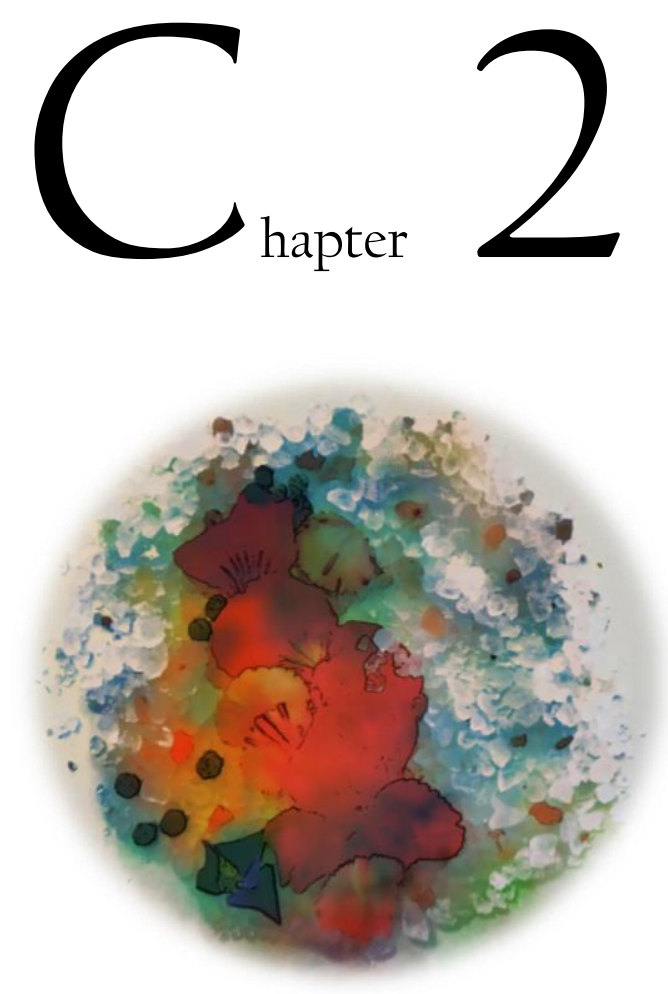

\section{Surrogacy Laws in the Shadows of the State}

Celeste and her husband James always knew that if/when her cancer went into remission, creating a family would involve the help of others: medical professionals and a surrogate. When Celeste was diagnosed with cervical cancer in her 20s, her oncologist advised that she begin treatment before she had a chance to freeze her eggs. This involved a hysterectomy, although luckily, she was able to keep her ovaries. When Celeste went into remission and was two years clear from any cancer, she and her husband began contemplating having a family. If they wanted a biologically related child, their only option was gestational surrogacy, which alongside traditional surrogacy, is legal in New Zealand on an altruistic basis. With the help of a fertility doctor, Celeste and James successfully applied for two rounds of publicly funded IVF. Celeste underwent an egg collection, and each egg was fertilised with James' sperm. The resulting embryos were frozen in a vat of liquid nitrogen in their local embryology laboratory, nestled among thousands of other embryos, for future use. They had no surrogate and had to find someone willing to undergo the arduous clinical treatments at this stage. In their journey to have a baby via gestational surrogacy, the vast array of input from others would include 
fertility specialists, counsellors, embryologists, nurses, an ethics committee, and the state to varying degrees.

In Aotearoa New Zealand (hereafter New Zealand for the remainder of the chapter), the Human Assisted Reproductive Technologies Act (HART) 2004, defines surrogacy as 'an arrangement under which a woman agrees to become pregnant for the purpose of surrendering custody of a child born as a result of the pregnancy' (section 5b). The HART Act was created to regulate the use of certain Assisted Reproductive Technologies (ARTs), of which gestational surrogacy is one. The other type of surrogacy that is practised in New Zealand is traditional surrogacy. Much like artificial insemination, traditional surrogacy is legally permissible, and because no ARTs are involved, it is practised outside the remit of the fertility clinic or state-appointed ethnics committee, as discussed below. The pregnancy is achieved via home insemination, with the surrogate self-inseminating with the intended father's/donor's sperm using a syringe. Despite its name alluding to something pre-technological, I propose that traditional surrogacy is practiced as a DIY repro-hack, which enables those intended parents who cannot afford the financial cost of ARTs or would be denied entry into the clinic, a chance to create a family. As discussed in the legislative timeline below, ART and surrogacy legislation have been created in a legal vacuum and response to medical, political, and public concern over a lack of regulation. The archaic and piecemeal legislation, alongside the state and privatised fertility medicine, create a network of power that produces barriers to non-conventional forms of kinmaking in contemporary New Zealand. Depending on which kind of surrogacy intended parents and surrogates practise, these barriers include the multiple criteria to access state funded Assisted Reproductive Technologies (ARTs), the legal and medical costs of surrogacy, the requirement for ethical approval, and the mandatory engagement with Family Courts. These ultimately determine the ineligible from the eligible and results in some citizens being encouraged to reproduce more than others.

This chapter outlines and unpacks the various juridical practices and legislation pertaining to surrogacy in New Zealand that continue to extend the lingering shadow and heritage of settler colonialism that privileges the idea of the nuclear family, and 'natural conception' as a priori, or at the very least, something to be emulated as much as possible. Those who create kin via surrogacy inhabit what I refer to as the reproductive penumbra, or the shade of heteronormative reproduction and all the laws and institutions supporting it. For example, New Zealand family law is at odds with the legislation, presenting surrogacy as a practice akin to adoption. To be 
recognised by the state as the legal parents, regardless of the genetic relationship, all intended parents must apply to formally adopt their baby under the 1955 Adoption Act. This places them in a legally liminal phase for months that involves scrutinising their appropriateness as parents. The combination of the ambiguity and pervasiveness of the heteronormative nuclear family within surrogacy legislation and institutional spaces undermines how surrogacy community chooses to create kin. Those who are barred entry to clinical surrogacy must contemplate possibilities beyond the law which will still allow them access to state recognised procedures.

\section{Regulatory Debates on ARTs and Surrogacy in New Zealand 1983- 2003}

There is no one reified surrogacy legislation in New Zealand, but instead fragmented policies attempt to regulate it. Incorporating it into legislation has always been highly politicised and a 'potentially divisive area of law because it involves both a woman's choices about her body and the sometimes-conflicting interests of the potential child and the intending parents' (Douglass and Legge 2019, 1). In 1978, Louise Brown, the first successful IVF baby, or 'testtube baby', was born in the UK. Five years later, after the first successful birth via IVF in New Zealand in 1983, the Royal Society of New Zealand, the New Zealand Law Society, the Medical Council of New Zealand, and the New Zealand Medical Association published a statement outlining widespread concern about the lack of review and monitoring of ARTs (including IVF and artificial insemination) (Daniels 2003). They requested that the government appoint a committee to consider the legal, moral, and social issues arising from ARTs (Royal Society of New Zealand 1985). In 1985, the Justice Department released an issues paper, New Birth Technologies - An Issues Paper on AIDF, IVF and Surrogate Motherhood (Justice Department of Law Reform Division 1985), a title that ironically did not capture the fact ARTs were developed to primarily intervene in conception and not the birth. Further, the paper failed to identify any clear consensus on how to proceed with a policy that would address issues arising from the emergence of ARTs. Out of one hundred and sixty-four submissions, almost a quarter stated the need for a committee that would oversee the use of ARTs. Daniel's (1990) survey of one thousand and four hundred readers of a woman's magazine revealed that approximately eighty percent of respondents agreed that there should be legislation to control future ARTs developments.

Between the 1980s and 2003, submissions made to the New Zealand Parliament on the use of ARTs reveal a discomfort with technologies and practices that delineated from the 'natural 
trajectory' of reproduction. The length of time it took for legislation resembled a similar trajectory in the UK, and 'reflects how fundamentally these technologies shook common assumptions about the nature of human life (Dow 2017, 151) ${ }^{66}$. During this period, the legality of surrogacy and what role the state should play in regulating it continues being debated within the increasingly neo-liberal approach to governance. Again, New Zealand surrogacy legislation closely follows that of the UK, where 'many politicians and public commentators, including those strongly in favour of ART, saw surrogacy as one of the most troubling forms of ART, and the government's committee of inquiry led by Mary Warnock ${ }^{67}$...expressed deep-seated concerns about surrogacy' (Dow 2017, 151). In 1995, the National Ethics Committee on Assisted Human Reproduction (NECAHR) replaced the 1993 Interim National Ethics Committee on Assisted Human Reproduction (INECAHR) to consider the ethical aspects of new, untried, or innovative assisted reproductive proposals, to ensure the rights of patients, donors and any resulting children are protected, and to develop ethical guidelines in the field of assisted human reproduction. Then in 1997, Member of Parliament Dianne Yates introduced the Private Member's Human Assisted Reproductive Technology Bill to Parliament, intending to provide guidelines that, as well as regulating other assisted reproductive procedures. This would allow applications for the consideration of non-commercial IVF surrogacy on a caseby-case basis in New Zealand.

\section{i. Introduction of the Human Assisted Reproduction Act 2004 and Ethics Committee}

Following on from Dianne Yates' Private Member's Bill on Human Assisted Reproductive Technology, surrogacy evolved from being an unregulated practice to one that ultimately would be under surveillance of fertility clinics and the state. In 2004 the Human Assisted Reproductive Technologies Act (HART 2004) was created under the assumption that certain assisted reproductive procedures, surrogacy included, would have inherent ethical and medical complexities that had to be thought through and considered before being approved, with specific guidelines to which everyone involved in surrogacy arrangements must adhere ${ }^{68}$.

\footnotetext{
${ }^{66}$ Dow $(2017,188)$ goes on to argue that 'another common feature of public debates about ART is the idea that people who cannot reproduce through heterosexual intercourse should not jump straight to ART but also think about adoption, fostering, co-parenting, kinship care, or even embracing childlessness. Whilst there is much to be said for remembering that ART is not the only answer to childlessness, it is also patently unfair to put responsibility for the world's parentless children onto any specific group (and especially so when that group is already subject to stigma and unequal access to resources)'.

${ }^{67}$ See Committee of Inquiry into Human Fertilisation and Embryology 1984
} 
In the six out of fifty-four pages that surrogacy is considered, the Act (s.3) outlines two key goals of legislative processes for regulating ART: to promote the health, welfare, and dignity of women and children, and to protect them from exploitation and commodification. Consequently, surrogacy is not enforceable by or against any person $(\mathrm{s} 14,1)$, and parental status can only be transferred via the adoption process ${ }^{69}$. Commercial surrogacy, or paying the surrogate a fee, is prohibited as 'every person commits an offence who gives or receives, or agrees to give or receive, valuable consideration for his or her participation, or any other person's participation, or for arranging any other person's participation, in a surrogacy arrangement' (s14, 3) (HART Act 2004). Yet, in line with other countries where only altruistic surrogacy is legal, those practising gestational surrogacy will spend a significant amount of money on fertility clinic fees (incurred through the collecting, storing, transporting human embryos or gametes, counselling, fertility tests, insemination or IVF, fertility specialist fees, fertility drugs and pregnancy tests), and legal fees of the surrogacy (HART Act 2004).

Before the fertility clinic could transfer their embryo into their surrogate, Celeste and James were required to obtain ethics approval. Under the HART Act, the Advisory Committee on Assisted Reproductive Technologies (ACART) (s 35) was established in 2005 to take on a broad monitoring role and to develop guidelines for the newly created Ethics Committee on Assisted Reproductive Technologies (ECART) (s 27) which were to come. ECART replaced NECAHR, and is tasked to assess, grant permission, and monitor applications that fertility clinics made on behalf of their patients. ECART meet six times a year throughout New Zealand and either approve, approve with conditions, defer, or decline the treatment. Although the Human Assisted Reproductive Technology Order 2005 outlines that IVF is an established procedure and can be done at the discretion of the fertility clinic when it is used for surrogacy arrangements, an application for ethical approval must be made. Important to note is that medical professionals who do not apply for ethical approval are breaking the law and liable for a fine (not exceeding \$50,000) and potential criminal action (HART Act 2004). Statistically, gestational surrogacy applications to ECART have continued to increase since the committee was established, going from seven applications in 2005-2006 to twenty-two in 2014-2015 ${ }^{70}$.

\footnotetext{
${ }^{69}$ The woman who gives birth, regardless of whether from a surrogacy arrangement or not, is legally the birth mother. Under Status of Children Act 1969, the intended parents must file an Adoption Order to adopt the baby.

${ }^{70}$ his figure comes from their 2014-2015 annual report, which is their most recent published report. Any requests for updates on these figures have gone unanswered.
} 
Between 2005 and 2018, three hundred and three applications (including reconsiderations) involving the use of ARTs in gestational surrogacy were considered. Twenty-one of these included an egg donor and one embryo donation. As of 2015, there have been fifty-four live births via gestational surrogacy (ECART 2018), and Powell (2015) writes that in 2012-2013, out of the one-hundred and-fifty adoptions in New Zealand, eight percent were surrogate born.

ECART base their decisions on the fertility clinics' information given on behalf of their patients in an application form. The eight sections include 1) the application summary and demographics of intended parents and 'birth parents', information of existing embryos and all medical, counselling, and legal information; 2 and 3) a report by medical specialist for intended parents and 'birth mother', including the intended mother's medical history or diagnosis of unexplained fertility that prevents pregnancy ${ }^{71}$, confirmation of independent medical advice and the 'birth mother's' medical history and potential risks; 4), 5) and 6) individual and joint counselling reports for intended parents and the 'birth parent(s)' that include if the 'birth mother' has completed her family ${ }^{72}$, and if not, the potential future implications of IVF and pregnancy. In addition, this application form must include intentions between parties about ongoing contact, day to day care, guardianship and adoption of any resulting child; 7) and 8) reports by a legal advisor for intended parents and separate report with independent legal advice for 'birth parents'.

Another factor that must be discussed in the application to ECART is who will become the guardians of any child born via surrogacy if the intended parents die. This is important because it demonstrates that the intended parents take full responsibility for the child's wellbeing, and do not expect the surrogate and her family to provide that. Further, a reading of the minutes published by ECART after each of their six meetings a year, reveals the significance they place on the surrogate's children having been considered, particularly how surrogacy will impact them. In the case of an egg donor being used and a surrogate, the donor's children must have had counselling to understand any implications of genetic relatedness. These instructions and

\footnotetext{
${ }^{71}$ See section Current and Future Surrogacy Debates and Regulations, for more discussion on the gendered language used in the application form. Despite ACART (2012) publishing guidelines to rectify this, the ECART application form itself has not changed language to include same sex male couples.

${ }^{72}$ More recent readings of the minutes published after each ECART meeting show that on a rare occasion it has granted consent to applications where the surrogate has not necessarily finished her family, as long as she is aware of the risks associated with pregnancy that includes complications that may lead to the removal of her uterus or difficult in conceiving again.
} 
the role of the Ethics Committee were created to maintain the interests of those who are vulnerable within surrogacy arrangements, especially of any current or future children born and the surrogate. If parties have not discussed the potential issues that may arise, then the application and counselling sessions provide an opportunity to do so. At the same time, I discuss below some of the consequences of the current legislation and their encouragement of some citizens to reproduce using gestational surrogacy more than other citizens.

\section{ii. Implications of Non-Inclusive Legislation and Privatisation of Fertility Medicine}

When I spoke with Celeste one wintery afternoon in May 2017 on skype, she was awaiting news on whether Lola was pregnant from an embryo transfer I attended ${ }^{73}$. Three years prior, Celeste and James were granted approval from ECART relatively quickly to proceed with their first surrogate. However, it was financially expensive despite the publicly funded IVF rounds because they had to pay for everything else, including the individual and joint counselling sessions, lawyers' fees for both parties, travelling costs, and any other fertility interventions required. Their son was born, and two years later, they met Lola at a local meet-up for surrogates and intended parents. When my video call with Celeste took place, she was in a liminal phase of not knowing what she would do if Lola's pregnancy test returned negative. She had conflicting feelings about the idea of traditional surrogacy:

Celeste: That's hard to answer. [Our son] is biologically both James' and mine. And that's meant more to me than I realised.... I am absolutely certain I would have loved a child that I had that was completely non-biologically ours. Had no doubts about it. But having a child who's genetically mine has meant more than I realised, in terms of being able to look at photos and compare photos and talk about behaviours and all of those other things. But anyway...we hadn't really thought any more about whether or not we would consider having a child that was genetically just Chris' and someone else and not me.

Hannah: Absolutely, and I guess that at the moment you're actually just taking everything as it comes.

\footnotetext{
${ }^{73}$ Their journey is explored through the chapter interludes.
} 
Celeste: $\quad$ Yeah, because if you think about ... there's so many other options. I guess losing this one [embryo] last week, I think has brought it a bit closer to home that we might actually have to think of some other possibilities. Are we okay with just our son (laughs)? Are we okay with one child, given that I thought we might not have any? How important is it for him to have a sibling? How important is it for me for that to be a genetic sibling or not at all? How important is it for me, for him to have a sibling full stop? Whatever method they arrive at.

Hannah: Yeah.

Celeste: I think my current thinking is that I am more determined for him to have a sibling than I am to worry about any genetic connection with that child, specifically me.

Unfortunately, their second attempt with Lola was unsuccessful. With no embryos left, they made one last effort with an egg collection, but unfortunately, Celeste's Anti-Mullerian Hormone $(\mathrm{AMH})^{74}$ count was very low, and she did not produce any viable eggs. They had the option of finding an egg donor and trying again or doing traditional surrogacy. In the end, because they had an acquaintance who was happy to be a traditional surrogate and given how challenging it is to find a surrogate, and the waitlist for egg donors, they chose that route. At the time of writing this, they have a toddler and in our regular check-ins, Celeste said she was besotted with her, as much as she was with her first child.

Certainly, Celeste and James experienced multiple challenges in their journey to create a family, of which the financial cost and implications of archaic legislation are discussed below. However, while they are, as I argue in the introduction, reproductively vulnerable because they must create kin using a non-normative approach, they are also less likely to experience the axes of discrimination than those who are in same-sex relationships, single, disabled, Māori and other ethnic minorities, and those of lower socioeconomic status. As a white middle class and heterosexual married couple, both IVF and gestational surrogacy were developed with Celeste and James in mind. This section explores some of the implications of non-inclusive legislation

\footnotetext{
${ }^{74}$ A hormone that is secreted by cells in follicles, an Anti-Mullerian Hormone (AMH) test is usually a good indicator of egg reserve.
} 
and the privatisation of fertility treatment across the axes of gender, sexuality, race, and dis/ability. Of course, inequalities and biases can manifest differently between and within groups of people. This is not a complete representation of the entire contemporary debates about ARTs and surrogacy in New Zealand, but it is a snapshot of some of the central issues and discourses. These include the intersecting implications of the financial barrier to funding; the bias against Māori who continue to experience the impacts of colonialism; and the way legilsation concerning surrogacy continues to (re)produce the idea of the nuclear family by not recognising families made through surrogacy and requiring them to present themselves as adoptive parents.

\section{iii. The Financial Cost of Surrogacy}

In New Zealand, funding for ARTs is split between the private/public sectors, with fertility clinics providing services to clients both through the public system and the private system. One of the ongoing contentious issues in New Zealand is that funding is only available for some (Michelle 2006, 111). Although Celeste and James met the criteria for public funding of two IVF cycles, this did not include the clinical and other costs associated with surrogacy. This included the counselling sessions, the medical tests the surrogate required, the application to ECART, lawyers' fees, and the travelling involved. Another participant, an intended mother via gestational surrogacy and egg donor, Tina, stated, 'I reckon that [our nine failed cycles spanning four years] would have paid for our fertility specialist's sports car he drives around in ${ }^{75}$. The tens and hundreds of thousands of dollars that IVF treatment and the added processes cost restricts people who cannot pay for these treatments. For heterosexual couples where the infertility is unexplained, or it is hoped that with medical interventions, the woman may conceive, they go through extensive and arduous fertility tests and treatment even before they qualify for two government-funded IVF treatments. The cost implications of ARTs are a global issue, and apart from pronatalist Israel, where IVF is fully funded, ARTs are an expensive assisted conception option ${ }^{76}$.

\footnotetext{
${ }^{75}$ Interestingly, intended parents did not articulate concern about the cost of raising their intended children after these costly procedures.

${ }^{76}$ Moran (2015) predicted that the global fertility industry would be worth US $\$ 21.6$ billion. See Whittaker, Inhorn and Shenfield (2019), and Bergmann (2011) for more discussion on the uptake of 'across border reproductive care' that sees people moving across national borders to access more affordable (and in some cases legal) treatment. For an overview of the ethical complexities, including the politics of commodification and exploitation of surrogates that can occur see Deomampo (2013); Inhorn and Patrizio (2015); Kroløkke, Halmø, and Pant (2012); Lozanski and Shankar (2019); Pande 2011; Rudrappa (2015); Schurr (2019); and Vora (2009).
} 
Since 2000, patients' eligibility for publicly funded assisted reproduction procedures is achieved by ranking them using a Critical Priority Access Criteria (CPAC) system. CPAC was developed to provide a guideline for rationing treatments so that those considered most in need can access them. However, the primary purpose of the CPAC in relation to assisted reproduction is to optimise the chance of successful pregnancy and birth (Farquhar, Wang \& Sullivan, 2010). As part of this, the CPAC restricts the maximum of two publicly funded cycles $^{77}$ to those who obtain 65 points or above on the CPAC questionnaire. Things that will influence the CPAC scoring include the length of infertility diagnosis (the minimum is different depending on whether there is a clear cause of infertility. Where there is none, the couple must have been trying to conceive for four years); the cause of infertility (as above, if it is 'unexplained', then it is more challenging to access funding), previous ART treatments; a woman's age (they must be thirty-nine years old or less at the time of their consult); and the clinical likelihood that ARTs will be successful ${ }^{78}$. The application is declined if they already have children twelve years of age or under. If a CPAC score of 65 and above (out of 100) is reached, couples go onto the waiting list of approximately eight to twelve months, which is in line with other specialist health care in New Zealand.

Within the current criteria, those who do not have a BMI of 32 or lower are automatically ineligible to receive public-funded unless they lose weight ${ }^{79}$. The wait, coupled with the abovementioned requirements, all impact the success rate of IVF (Gillett and Peek 1997; 2012) . $^{80}$ Despite the documented variation in average BMI between ethnicities (Gallagher et al., 1996; Metcalf et al. 2000; Swinburn et al. 2004) and the inaccuracy of it predicting disease factors in Māori and Pasifika communities (Kruger et al. 2015), it continues to facilitate racial bias, and stratifies access to ARTs and health care for Māori and Pasifika. The use of non-ethnic specific BMI categorisation and other criteria help to (re)produce the ideal body - white, slender, and

\footnotetext{
77 This can be two IVF cycles that include egg collection, fertilisation with the partner, or donor sperm in the laboratory and implanting of the embryo, or four IUI (intra-uterine insemination) attempts.

${ }^{78}$ If they have co-morbidities (including health conditions, previous drug use, a smoker, weight - over or under), these will negatively affect their score.

${ }^{79}$ The BMI is an anthropometric measure of body fat and ubiquitous chart that doctors use every day to determine whether their patients are underweight, "normal', overweight, and obese. The problem is that it does not distinguish between different types of body mass or provide an accurate representation of a person's health. Developed in the 1800s to understand the average body-mass of the Belgium population, it has since been transferred into clinical contexts internationally (Humphreys 2010).
} 
middle class (Parker, Pause and Le Grice (2020, 102). Parker, Pause, and Le Grice $(2020,99)$ argue that scientific and popular representations and discourses have 'consistently highlighted the higher incidence of pregnancy fatness among socio-economically disadvantaged and ethnic minority women, while representing the cause of fatness as almost singularly the result of poor individual lifestyle choice'. Moreover, contemporary discourses conflate pregnancy fatness and obesity with 'poor maternal choices' and blame the obesity epidemic on indigenous and women of colour (see Sanders 2019). Targeting some bodies more than others, science and medicine are a racial and colonial project intent on securing white supremacy' (Parker, Pause and Le Grice 2020, 99).

Consequently, by the time gestational surrogacy is an option, likely, intended parents have already used the funded IVF cycles earlier in their journey and paid for a substantial amount of further cycles. This is if citizens can afford the initial costs, to begin with. At Fertility Associates, the largest fertility provider in New Zealand, each IVF cycle with a fresh embryo transfer (which is the costliest out of all the treatments) costs between $\$ 10,695-\$ 12,695$ (as of September 2018). Other additional fees may be required, such as consultations with fertility doctors, a counsellor, tests, and further procedures, making assisted reproductive medicine and technologies expensive ${ }^{81}$. This means that those who may qualify medically, have their own eggs and a surrogate, but do not have the funds required to do gestational surrogacy, may be pushed further into the reproductive shadows. The only two options left is to go into significant debt or consider traditional surrogacy, although, for both types of surrogacy, people must set aside at least $\$ 10,000$ for the lawyer's fee ${ }^{82}$. This is an added challenge and further restricts access to those with lower socioeconomic status. Those intended parents who have done gestational surrogacy all have similar stories about the debt one can go into hoping each cycle will work. It is not unusual to spend hundreds of thousands of dollars on these efforts. One of the intended parents I got to know, who also eventually ended up choosing traditional surrogacy, had exhausted all their funds on both trying to conceive using an embryo with the intended mother's egg and then with an egg donor.

\footnotetext{
${ }^{82}$ If people cannot afford a lawyer, then the other option would be to not have the adoption order, which is a risk to both the intended parents and the child. I did not know anyone who had chosen not to do the adoption order, but I would be told anecdotes about the intended parents who 'took the baby' and did not contact the surrogate again or apply for adoption.
} 


\section{iv. Implications for Māori}

As explained above, funding is structured to discourage Indigenous and women of colour from reproducing, with consequences for who can access ARTs for fertility interventions. Parker, Pause, and Le Grice $(2020,105)$ contend that:

this undermining of Māori and Pasifika women's reproductive selfdetermination, coupled with the silencing and erasure of their own knowingness about reproduction (see Le Grice and Braun 2016), constitues a reproductive abuse that positions the racist and colonizing intentions of past eugenic and reproductive control policies right at the center of this contemporary moment in reproductive politics.

Alongside this, the government and the colonial judicial system has had and continues to have, an insidious influence on Māori. Salient examples of the shadow and pervasiveness of settler colonialism include tactics to control how Māori reproduce and practice kinship, which is evidenced in the same and legislation that governs the use of ARTs. For example, the widely practised whāngai is not easily translated into the Western concept of adoption but is often conflated with it ${ }^{83}$ (Pihama 1997). While New Zealand's first Adoption Act in 1881 focused primarily on Euro-centric kinship structures and did not encroach on whāngai practices, it prohibited it in its traditional form. The Native Land Claims and Adjustment and Amendment Act 1901 required registration of whāngai children (in the Native Land Court) as the only way to inherit lands of whāngai parents (McRae and Nikora 2006). The Adoption Act 1915, and the subsequent Adoption Act 1955, promoted secrecy to protect childless British and European couples (Bradley 1997). Under the guise of protecting the child, the 1955 Act legally established closed adoption, which from a Māori perspective alienates the child from their kin group and thus 'sever[s] a child's birth identity and heritage.... as an act of cultural violence' (Bradley 1997; Griffith 1997; McRae and Nikora 2006, 2).

\footnotetext{
83 'Adoption or foster care tends to be mainly focused on the interests of the child. The institution of whāngai, while being cognizant of the interests of the child, is weighted more towards establishing, nurturing, and cementing relationships between individuals, families, and broader relational networks' (McRae and Nikora 2006, 1). Māori scholars have cited this as well as a potential response to infertility, as it is common for a grandparent to whāngai a mokopuna (grandchild) in order to pass on ancestral lineage, tikanga (values), as well as whānau and hapū knowledge (Glover, 28; McRae and Nikora 2006
} 
In the first study of Māori attitudes towards ARTs in 2005-2006, Glover (2008) writes that for some, infertility is a suppressed phenomenon in part because of the stereotype of Māori as over-populating. Seen in the radical depopulation of Māori and the "permutations of state attempts [ through biologically-determined delineation] to define and enforce particular definitions of 'a Māori'...practices and beliefs around reproduction [have been] a particular focus of anxiety and intervention' (Glover and Rousseau 2007, 124). Anderson, Snelling, and Thomlins-Jahnke (2012) also state that despite their findings that very few Māori utilise ARTs, there is a specific intent by legislators to respect Māori needs, values, and beliefs. However, in practice, by universalising the criteria for funded IVF, and not considering the inequitable access for health interventions more generally for Māori, their needs are not being met. These sit alongside the higher infertility rates that Māori experience across New Zealand (Pihama 2012; Righarts et al., 2015; van Roode et al., 2015). For reproduction more broadly, young Māori women are much less likely to have their birthing goals considered (Pihama 2011).

Mead $(2003,341)$ highlights that there is not a position on surrogacy within Māori tikanga ${ }^{84}$, and it must be analysed in terms of potential consequences. As a practice that aims to create new mauri ${ }^{85}$, Māori must consider what influence this may have on the child, now and in the long-term. In their retrospective review of case law involving ARTs from 1990 to $2000^{86}$, Legge, Fitzgerald and Frank $(2007,17)$ argue that despite the previous Act's neglect of nonconventional families, the HART Act's 2004 requirement of a national register of gamete donors and donor offspring has been a positive step to reflect 'new' ideas of families. They suggest that it is an essential expansion of legislation to reflect better Māori tikanga and structures of relatedness, particularly the centrality of whakapapa. However, a recent paper by Fitzgerald, Legge, Rewi and Robinson (2019) suggests that Māori bioethical concerns have been excluded within parliamentary debates when regulating frozen embryo storage. They describe the 'predominantly Pākehā [New Zealander of European Descent] parliamentarians' extraordinary neglect and oversight when considering the views of Māori parliamentarians on the cultural significance of these forced maximum storage times for the wider minority Māori population' (Fitzgerald, Legge, Rewi, and Robinson 2019, 11). Instead, creating 'one size fits all' guidelines for the destruction of embryos, overlooks the harm of disposing culturally

\footnotetext{
${ }^{84}$ Te Reo Māori for values

${ }^{85}$ Te Reo Māori for life force or essence

${ }^{86}$ Their paper explores twelve legal cases (eleven involved artificial insemination and one surrogacy) within this period involving issues related to guardianship, custody, adoption, or access to children born of the ARTs. In each, a biogenetic understanding of kinship is privileged.
} 
distinctive kin ties and disregards both the guiding principles of ACART and, more importantly, the Treaty of Waitangi ${ }^{87}$.

\section{v. (Re)producing the Nuclear Family}

As with other countries, the development of IVF in the UK, and its subsequent introduction in New Zealand, was to treat infertile heterosexual couples. According to Lovelock (2010), in 1970s New Zealand, artificial insemination (and fertility medicine more generally) was available in public hospitals before being a privatised and commercialised fertility service only serving heterosexual couples ${ }^{88}$. When the first fertility service provider, Fertility Associates, was established in Auckland in 1987, their targeted demographic was heterosexual married couples based on the assumption that a 'child's best interests' 'were served by having parents who were in a committed heterosexual relationship' (Daniels and Burn 1997; Michelle 2006, 14). This suited the Euro-American cultural discourse of naturalised reproduction and ARTs as part of the 'hope for a cure' narrative (Franklin 1997, 155) ${ }^{89}$. Those who did not fit these criteria, including single women, lesbians, and gay couples, primarily try to conceive via home insemination ${ }^{90}$. At the same time that assisted reproduction legislation evolved under the Human Rights Act 1993, 'it became illegal to discriminate in the provision of goods and services based on disability, family status, or sexual orientation... [leading to] successful legal challenges subsequently established that public, as well as private fertility clinics, cannot lawfully deny [any of the above]' (Michelle 2006, 14). Unfortunately, institutional practices,

\footnotetext{
${ }^{87}$ The Treaty of Waitangi gives a moral imperative to consider any concerns of partnership, participation, and protection, including healthcare provision which encompasses ARTs (Ministry of Health 2018).

${ }^{88}$ Finally, after years of no explicit legal recognition, artificial insemination within a clinic setting was recognised as an 'established procedure' that could be done under the discretion of the fertility doctor under Part 1 of the Human Assisted Reproductive Technology Order 2005.

${ }^{89}$ Franklin $(1997,322)$ argues that IVF has a very double-edged character. On one side, it is a technology that signals choice based on an expectation and 'hope for success at each stage, hope for a resolution, hope for the future, and mostly about a child.' Hope becomes a provocation to carry on even though assisted conception often fails. On the other side is the financial, physical, and emotional cost women must endure as they continually negotiate each new choice they have to make.

${ }^{90}$ Queer kinship research invaluably contributes a parallel discourse of how those self-identifying as LGBTQ+ have practiced and participated in debates about kin-making 'from local to global, from fairly low-tech to highly technologized, from reliance on social and community networks to reliance on multiple organizational entities Mamo and Alston-Stepnitz (2014, 2). Also see Dahl (2018), Eng (2010), Mamo (2003), Smietana (2017), Smietana, Thompson and Twine (2018).
} 
the cost of ARTs, and legislation continue to restrict certain citizens from creating kin via clinical interventions ${ }^{91}$.

Alongside the HART Act 2004, the Status of Children Act 1969 and the Adoption Act 1955 regulate surrogacy by default. With no single piece of legislation that considers each part of the surrogacy process, all those involved, particularly regulators, have had to grapple with several Acts that some scholars (Powell 2019; Walk and Van Zyl 2017; Wilson 2017) deem archaic, discriminatory, and initially created to support the idea of the nuclear family at all costs. 'The HART Act itself is concerned only with the law, ethics and policy of ART.... [and as yet] there is no corresponding downstream family law legislation that recognises [surrogacy arrangements] to give parental status to the intending parents of any child born' (Douglass and Legge 2019, 2). Although the Status of Children Amendment Act 1987 attempted to resolve some of the issues with the earlier Act, it still failed to reflect non-conventional family formation. Any change since then has been slow. As discussed below, it was not until August 2013 that The Marriage (Definition of Marriage) Amendment Act 2013 changed the wording to 'spouse' instead of heterosexual couples, allowing same-sex marriage and providing gay married couples the opportunity to jointly adopt their child ${ }^{92}$. Notably, in the Re Reynard (2014) adoption case, Judge Coyle argued that granting the adoption order 'in favour of samesex male couples 'creates a legal fiction' (at [17]) and a 'clear biological fiction' (at [18]) as it 'records that these children have two fathers and legally do not have a mother (at [18])'. Given the law changes did not allow this to be a determinative factor, the order was granted. However, the judge's discomfort only six years ago was palpable in this hearing ${ }^{93}$.

Several scholars and researchers based in New Zealand argue that the piecemeal legislation makes everyone vulnerable (Powell 2019). Conversely, those who enter a surrogacy arrangement, whether traditional or gestational, must do so with the knowledge that either party can change their minds. For example, whilst the surrogate has the choice to keep the baby, the

\footnotetext{
${ }^{91}$ Legislative restraints do not stop those citizens who are wealthy enough to travel to other jurisdictions where commercial surrogacy and egg donation are legal and have access to a wider range of options depending on one's budget.

${ }^{92}$ Re Pierney was the case where the first same sex male couple successfully petitioned to jointly adopt their children born of traditional surrogacy as a de-facto couple.

${ }^{93}$ In Margaret Casey, the intended fathers' lawyer's response, she argued 'that is no different to a heterosexual couple entering into surrogacy agreements and then seeking to adopt their children, in that a legal fiction will be created for those children as well. Indeed, any adoption order creates such a legal fiction’ (Re Reynard 2014, 18).
} 
intended parents also have the option of not following through on the surrogacy arrangement. They could decide not to adopt the baby, leaving the surrogate with a child she did not intend on having. ACART $(2013,2)$ do accept that this is a significant risk for the surrogate. Thus, while on the surface, the law protects the surrogate's bodily autonomy and right to change her mind and keep the baby she has carried, it does not reduce her vulnerability.

\section{vi. The Need to Adopt}

On the $5^{\text {th }}$ of October 2020, Celeste sent me photos of her second child's $2^{\text {nd }}$ birthday party. Born of traditional surrogacy, her daughter arrived more than one year after their failed attempts with Lola. A cake, a big number 2 balloon, and his brother was grinning into the camera next to her. One of my favourite photos was earlier in the year, of her sitting on the benchtop in the kitchen helping to make a cake - holding a spatula in one hand and batter smeared across her upper lips. In May 2020, Celeste sent me a video of her two children dancing in the autumn rain outside their home. Then in September 2020, we had a Facebook messenger conversation about the mandatory adoption route and neither of their names going on the birth certificate, even though James provided his genetics. '[But] James and I didn't care! We trusted the system would spit us out as parents! It's more frustrating how long it takes!! The baby was born in October [2018] and we didn't adopt til end of May [2019]'. The wait can be agonising, as intended parents and their surrogates exist in a liminal state on one level and go about their daily lives on another. '[The] anxiety was worse until we got the birth [certificate]', she wrote. And the day itself, she said, always comes down to whether the judge is sympathetic ${ }^{94}$ and progressive. When talking about the liminality itself and the disjuncture between their family and how they had to present themselves to the Family Court, she wrote:

I never doubted at any stage that we would be given our baby, and in my head, they were my baby all along. [This was] helped by [our first] surro[gate] as [she was] always talking about 'your' baby. For me, the biggest and most meaningful step was the adoption, and that was the biggest

\footnotetext{
${ }^{94}$ Noted earlier in the chapter, Celeste and James are less likely to experience discrimination based on their ethnicity, socioeconomic status, and sexuality. That judges must be 'sympathetic' and progressive enough to make the adoption ruling means that other intended parents may battle additional barriers. Māori scholars have written extensively on Māori experiences of the justice system and the systemic discrimination based on colonialist attitudes. For example, see Bold-Wilson (2018), Brittain and Tuffin (2017), Jackson (1987), and Tauri (2005).
} 
'finally'. We were just like everyone else after that, nothing hanging over us. And seeing our names on the birth certificate with our baby was huge'.

My conversation with Celeste and the sections above demonstrates how the current laws in New Zealand are less supportive of Māori and non-conventional ${ }^{95}$ family formations, which results in a disjuncture between how people practice or would like to practice kin and the institutions and judicial practices currently in place. Regardless of her genetic link, the surrogate and her partner, who has no genetic link, are documented as the birth (and thus, assumed to be the biological) parents. This part of the process is the one that frustrates intended parents and surrogates the most. Although many, like Celeste, accept that it is 'how things are done' and a step that they must take. Unless they have legal parental status, the state does not recognise the relationship between the intended parents and the child.

In practice, it can take approximately six months or more until the adoption hearing occurs, followed by the issue of a new birth certificate. Some intended mothers struggle more than others with the liminality this stage of the process brings to their lives. Anna, an intended parent who had a son via traditional surrogacy, was anxious for the first six months of his life, waiting for 'adoption day'. Even with guardianship, she felt insecure, fearing her child could be taken from her, even though her surrogate had no intention nor desire to keep him. Consequently, Anna did not feel comfortable or enjoy being a mother until the new birth certificate was created with her and her husband's (who was the genetic father) names on it. In Anna's mind, having legal parental rights was the only way she could start to trust that she would not lose her baby. For Tina, an intended mother via gestational surrogacy and overseas egg donor, it was:

\begin{abstract}
'Just rubber stamping and it's just paperwork. We just got over it and thought "this is just the process, we have to follow it, there's no other way. We don't wanna make it harder for ourselves". We went to court when they were about 3 months old, all the [initial] paperwork had to be in the courts by the time they're about 4 weeks old. And then you're just waiting in line and because we're obviously not an 'urgent' in the family courts... [and then
\end{abstract}

\footnotetext{
${ }^{95}$ The current law also does not recognise the intentions of more than two people to jointly parent a child together (i.e., co-parenting).
} 
when we saw the judge, she] stamped the papers and off we [went], you know we barely sat down and then we [were done]'.

The 'rubber stamp' that Tina refers to is in part a reflection of the work that goes on outside of the Family Court to make the adoption hearing as quick and straightforward as possible. In other words, to give the Judge (who makes the decisions based on their own discretion) no reason to decline the order. Intended parents and surrogates are aware of what is required each stage in the run-up to an adoption hearing ${ }^{96}$. While some of the processes involve engagement with institutional bureaucracy, others, what I call shadow-legalities (that I discuss in chapter four), mimic standard features of the law. However, even though adoption law stipulates that the baby must stay with the birth mother until they are 10 days old before guardianship can be transferred, in practice intended parents usually circumvent this by obtaining special dispensation to take the baby home after the birth (it requires that the surrogate verbally confirm to their social worker from Oranga Tamariki that they agree and are not being coerced). After this, all parties are obliged to work with the New Zealand Family Court for the adoption order to be filed and eventually accepted at a hearing approximately six months later. Again, this is how intended parents and surrogates inhabit the shadow of the law without necessarily breaking it.

\section{Current and Future Surrogacy Debates on Law Reform}

\section{i. Changing Discriminatory Terminology and Calls to Banish the Adoption Model}

One significant turning point in legislation reform arose in 2012 when ACART (2012) received a complaint through the Human Rights Commission that found the Guidelines on Surrogacy Arrangements Involving Providers of Fertility Services 2007, discriminated based on gender (although ACART uses the term 'sex') and sexual orientation. In response, ACART issued a consultation paper for the public to provide feedback on the proposed changes to the guidelines. Consequently, in 2013, ACART (2013) acknowledged their error in referring to the 'intended mother' as needing a 'medical' reason to access gestational surrogacy using ARTs. By 2015, this resulted in the first gay couple doing surrogacy via a fertility clinic and gaining ECART

\footnotetext{
${ }^{96}$ Interestingly, one of the only three cases where the adoption order sought was not granted was because "the affidavits filed before the court did not provide sufficient information to allow the court to make final decisions" (Re CGL 2012, 19) and "the court must be aware of more than the fact that they are the biological parents and that they wish to have parenting and guardianship orders made' (Re CGL 2012, 20).
} 
approval. Since then, there has been an increase in the number of applications made by gay couples to ECART (for example, in the two meetings that have taken place thus far in 2020 (reduced because of Covid-19), ECART has approved three gay couples' applications and declined one).

From 2015-present time, three distinctive voices ${ }^{97}$ became involved in the space of potential surrogacy law reform. Gestational surrogacy also gained more media coverage after two public figures spoke about their journeys creating families via surrogacy. The notable one was Member of Parliament Tamati Coffey, who, as a gay intended father, used his personal experience of having to formally adopt his biological son with his partner (New Zealand Herald 2019) as the impetus to submit the Improving Arrangements for Surrogacy Bill in 2019, because 'the technology has quickly outpaced the legislation' (Coffey, Facebook Live 2019). The proposed Bill seeks the transferal of legal status from the surrogate to the intended parents once the baby is born, the development of a national register of surrogate and donor information to make it easier for children or adults to find information about their origins, and the option of paying a surrogate compensation if she is not working.

\section{ii. Rethinking Surrogacy Laws Project and a Radical Proposal for a New Model}

Between 2015-2018, the Law Society funded legal scholars (and subsequently some social scientists) at Canterbury University to conduct Rethinking Surrogacy Laws, with goals that included 'considering the effectiveness and appropriateness of the current regulations of surrogacy in New Zealand', and 'evaluat[ing] different options for the regulation of surrogacy, including domestic and/or international law reform, or amendment to regulatory guidelines'. I was sent some empirical data from their analysis of 32 ECART applications, adoption court proceedings, ${ }^{98}$ and results from a survey they sent to the public on their views. Wilson's (2018,

\footnotetext{
${ }^{97}$ In the past decade, public and the media are other sites of disparate voices that continue to debate surrogacy in New Zealand and the increasing uptake of transnational surrogacy. It is often the surrogacy arrangements that have gone wrong that are reported (Woulfe 2013), such as in Thailand (Hurley and Kilgallon 2015), and Mexico (The Guardian 2016; Baker Wilson 2016) or the issues with the New Zealand regulatory approach (Dastgheib 2011). More recently, media and newspaper reports have centred on Covid-19 related problems such as babies born of surrogacy being stranded in their country of birth (Bonnett 2020).

${ }^{98}$ The latest case they include in their report exemplifies the discomfort some judges have with the archaic laws. 'It can never have been the intent of the legislature to put impediments such as the form of consent to adoption in the way of such a surrogacy arrangement as was entered into here. It is the intent and effect of the surrogate mother's actions that are crucial, not the form used. The 1955 Act is long overdue for reform. International gestational surrogacy was probably only a dream when this legislation was passed. The Act is no longer fit for purpose.' (Re Witt 2019, 16).
} 
72) online survey of one-hundred and eight-five New Zealand based child and family lawyers revealed that seventy-four respondents favoured enforceable surrogacy contracts, and fifty-four respondents preferred the existing legislation of unenforceable arrangements. They have also published in different forums (Powell 2017, 2019; Masselot and Powell 2019; Powell and Natalie Baird 2020; Wilson 2018, 2018, 2019), with some of their arguments included in this and subsequent chapters ${ }^{99}$.

One of their research findings included results from a questionnaire where they received 557 responses that provide a snapshot of the public perception of surrogacy in New Zealand. Some of the pertinent results included that:

- 75 percent of respondents described themselves as New Zealand European/Pākehā, and 5 percent as Māori;

- 95 percent of respondents identified themselves as heterosexual;

- 58 percent of respondents identified themselves as married, and 11 percent in a de-facto relationship;

- 29 percent of respondents identified themselves as having a household income of $\$ 100$ 149,000 , and 19 percent had a household income of $\$ 150,000$;

- 12 percent of respondents have received fertility assistance of some kind, with 3 percent of respondents adding they have been involved in surrogacy;

- 54 percent of respondents approve of surrogacy, and 30 percent do not object to it;

- 44 percent of respondents indicated they did think that surrogacy in New Zealand is legal. In comparison, 29 percent of respondents thought that surrogates 'could recieve direct expenses in the way of medical bills and lawyer bills' (Rethinking Surrogacy Laws n.d, 15) (which is already permissible under the HART Act). Further, 8 percent thought that 'compensation for any pain/suffering/inconvenience caused by the pregnancy and birth was permitted' (15). Only 5 percent were against the surrogate receiving anything at all, including gifts.

\footnotetext{
${ }^{99}$ Powell has since moved back into practicing law, but her contribution to the contemporary discourses is ongoing. In the cited papers, Powell advocates for surrogate mothers to receive compensation. Outside of this thesis, which does not have scope for the complexities inherent in the debates about commercial surrogacy and compensation, I am publishing an article with Associate Professor Rhonda Shaw, where we explore the topic.
} 
The feedback around the legality of surrogacy and financial compensation was in response to a hypothetical arrangement involving the intended parents, surrogate and an egg donor. 'One hundred and eighty-five respondents described themselves as 'unsure' (18). Most respondents 'looked to identify two legal parents' ${ }^{100}$. In comparison to forty-two respondents who said that they did not think that the government should reconsider surrogacy legislation, one hundred and ninety respondents answered 'yes, soon (within the next 5 years)' and ninety-seven responded 'yes but not urgently' (55).

In conjunction with these legislative debates around surrogacy law in New Zealand is the work of ethicists Walker and Van Zyl (2017), who advocate for a 'professional model' of surrogacy as an alternative centrally regulated approach to either altruistic or commercial surrogacy, where the surrogate would get a 'service fee'. This model would involve a multidisciplinary regulatory body that would "oversee the screening and "selection" of surrogate mothers...this means that surrogates could not put themselves forward without being vetted for approval' (Shaw 2020, 22). Surrogates would also be required to relinquish all their legal rights to the child, with parentage determined at birth, thus rescinding the need for adoption. 'If a surrogate cannot make a promise in advance to relinquish the baby, she cannot enter a surrogacy contract (Walker and Van Zyl 2017, 9). While the scholars echo concern by others (Wilson 2017; Powell 2019) that all parties remain vulnerable under the current legislation, if their proposed model were to be adopted, there could be dangerous implications. Shaw (2020) outlines concerns, including the implication that surrogates would be screened and trained to align their values with that of the intended parents. 'While the authors are concerned to ensure that surrogates act according to the right motivation to relinquish the baby, the idea of schooling surrogate mothers in line with the values of the professional model derogates their autonomy and would remove surrogates' right' to change their mind' (Shaw 2020, 23).

\section{Conclusion}

This chapter has introduced the regulatory framework on surrogacy in New Zealand unpacking some of the judicial practices and legislation that reinforce the idea of heteronormative reproduction and the nuclear family. On the one hand, the state's role is parental and hands-on guidance in making sure that women (who must undergo more invasive procedures, even in

\footnotetext{
${ }^{100}$ As discussed in chapter three, Strathern (2005a) argues that socially, the role of the surrogate is never in question, but the real categorical doubt is who the 'real parents' are.
} 
cases where men are infertile) and children associated with or born of assisted reproduction are not exploited. On the other hand, ambiguous surrogacy law privatised fertility care, and persistent race, sexuality, and class- based barriers greatly influence the access people have to ART options; something I have found in my case. This (re)enforces stratified reproduction and renders many citizens who inhabit the reproductive penumbra ineligible to access gestational surrogacy in New Zealand. In their current state, the legislation does not adequately reflect or support how people choose to make kin, and contemporary debates demonstrate that it is a highly politized and divisive topic. Even as the regulatory landscape evolves in response to a changing society, such as the admittance of same-sex couples into the clinic (Douglass and Legge 2019; Legge, Fitzgerald and Frank 2017), equitable access is still not possible for all those who desire to create a family via surrogacy.

Conceptually, the lived experience of surrogacy can never entirely leave the shadows because those who practice it must bargain from the shadows and present their family composition in a way that the current legislation recognises. Regardless of whether people create a family via gestational or traditional surrogacy, all intended parents must present their family formation differently to be recognised as the legal parents. Even though guardianship provides the latter with some decision-making rights ${ }^{101}$, it is a liminal phase of discomfort and even fear for some. For Anna, although she knew that Ruby would never want to 'take the baby back', she still lived in fear. Thus, each part of the surrogacy journey involves different tensions between intimate and institutional landscapes. New Zealand surrogacy law demands things of the surrogate and intended parents; in the case of gestational surrogacy, the process can begin if the surrogate is medically and psychologically suitable ${ }^{102}$, the intended parents are deemed suitable by Oranga Tamariki to adopt the baby born of surrogacy, and the intended parents can adopt the baby in the Family Court.

\footnotetext{
${ }^{101}$ In guardianship, the parents' legal rights are intact, and they have the power to terminate the guardianship. Adoption terminates these rights.

${ }^{102}$ All parties must attend individual and joint counselling sessions and the counsellor's report is attached as part of the ECART application. These sessions are to see if the surrogate is being coerced, if the surrogate's partner agrees, and provides a space for everyone to discuss what might happen in the event that the foetus is diagnosed with a genetic condition. They also discuss who will be given guardianship of the baby in the unfortunate event that the intended parents die (in reading the ECART meeting minutes, they do not approve of an application if the intended parents have any intention of asking the surrogate to take on that role), and how they will discuss the child's conception with them.
} 
The scholarly and public discourse on the future of surrogacy policy in New Zealand provides valuable points to consider. One of the most interesting features of the petitions, research and discussions is the lack of attention to traditional surrogacy and those who practice it. What are their experiences? How do they negotiate making kin within a space that is shaded by heteronormative ideas about the family? How are they rendered (in)visible within narratives other than their own? With more than half of my participants making kin via traditional surrogacy, I am drawn to how it has been forced more into the shadows of legislative and scholarly discourse. Chapter three further develops this site of tension, whereby traditional surrogates (and by association, intended parents) are positioned as or feel they are acting immorally. At the same time, some traditional surrogates relish the agency to have children for those citizens barred from accessing gestational surrogacy due to socio-economic status, age, ethnicity, and health. The following chapters in this thesis prioritise the narratives of surrogates and intended parents to make visible and unpack the various processes and relationships that those practising surrogacy experience. Ultimately, in this liminal and nebulous shadow of the law, intended parents and surrogates get creative in their quest of creating kin in the contemporary vis-à-vis surrogacy in New Zealand. 


\section{Interlude Two: Breakfast and Builder's Tea}

\section{FIELDNOTES 10 May 2017}

It is after the pre-transfer scan and blood test, and Lola has not had breakfast yet. As we sat waiting for her to be called in the blood laboratory, I asked if she liked crepes. There's a French café close to our location and is where I take anyone visiting me if we end up in this part of town. Sitting in the waiting room, she whispered, 'I meant to take a photo of the ultrasound scan machine for Celeste, but I forgot'. When she was called, Lola got up and motioned for me to go with her. The blood test was quick, with only one vial required. After, we came directly to the café, and sat at a table by the window. Lola orders 'builder's tea' with her food, and we speak about non-specific things, nothing baby related. It seems strange that I only met Lola in real life this morning and have already been in an examination room all before breakfast. Meeting Lola for the first time, I had no idea how comfortable she would be at talking about her experience as a surrogate. She is quiet, carries a book everywhere and gives you her full attention when talking to you. I soon find out that she is very open with her surrogacy journey. The conversation flows easily, but we agree that maybe we should find a quiet spot somewhere for a short informal interview since she has time to pass before catching the train home. Before we leave, Lola pays for my food and drink, 'Celeste said it's on her. She's so thankful you were able to be here when she couldn't be'. For a moment, I don't know what to say - I saw my collecting and driving Lola from appointment to appointment the least I could do after she has agreed to welcome me into her life for the foreseeable future. I decide just to accept and say thank you, but couldn't help myself from adding, 'it isn't necessary though'.

The comedy of the interview was that the wind had picked up outside, and finding a quiet spot was not possible unless we found another café or sat in the car. We end up perched on a low wall next to the dock nearby, huddled with our jackets on. It seems strange to be out in the open, but no one is around. Lola is probably one of the most open out of my participants when sharing her views. She has absolutely no qualms in sharing that in addition to wanting to help others have a baby, when she was a traditional surrogate a few years ago, she was motivated by a curiosity of how a child with her genes and the intended father's would look. 
Not long after, we discuss the intricacies of home insemination, to which she tells me about an older midwife she knew who told her that if she masturbated after self-inseminating using a syringe, it might improve her chances of conceiving. 'Maybe an old wives' tale', she says. We both laugh, me partly in shock and fascination. 'Did you?' to which she replied, 'Of course!'. Lola has a refreshing openness that I later come to appreciate. As discussed in the next chapter, Lola and other surrogates do not publicly share these things with other members of the surrogacy community. It is partly because it is taboo to frame home insemination as having sexual connotations or infidelity involved, even if everyone knows there is not ${ }^{103}$. It is also to make sure intended mothers do not feel uncomfortable either. For Lola, a medical professional, talking about things more clinically is second nature. Almost mechanical, reminding me of growing up with my nurse mother.

\footnotetext{
${ }^{103}$ Heather, a traditional surrogate, told me that she did not try the masturbation technique because for her, it crossed a boundary, and she did not want to equate pleasure with it, nor attach anything sexual to the act home inseminating. This is something that is hugely dependent on personal approaches, and most surrogates I got to know exist on a spectrum - for some, it would feel strange, and for others, it was not an act that they mentally connected to the intended parents or the surrogacy.
} 


\section{$\mathrm{C}_{\text {haper }} 3$}

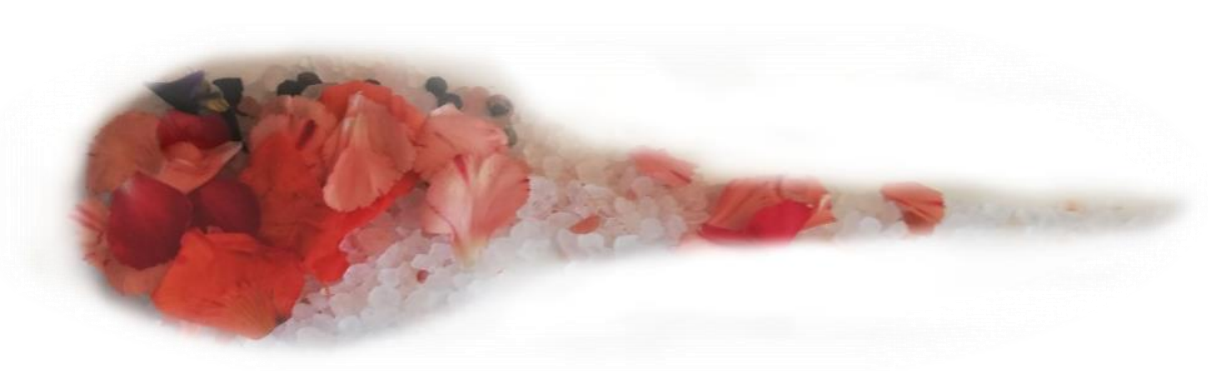

Figure 3: Spermatozoon. Photograph by Hannah Gibson

\section{'Doing It Our Way': Participation and Kinship in Traditional Surrogacy Narratives}

On an extended fieldwork trip, Ruby invited me to stay at her house. In her open plan kitchen and living room, I noticed a mixture of fiction (particularly sci-fi) and non-fiction in her overflowing bookcases (and later in the room I slept in, books surrounded me, making me feel like I was a child in my family house). Conversation flowed easily between us, despite this being our first meeting. A self-proclaimed surrogacy activist, Ruby told me she was passionate about women's reproductive rights and reducing the stigma around surrogacy. She had been able to conceive and give birth to three daughters and donate her eggs in her 20s, stating motherhood for her was based on intention rather than biogenetic ties. The idea of surrogacy came onto her radar when she was younger, but her husband did not agree. She joked that his refusal was one of many reasons she decided to leave him, exclaiming, 'it's my body! I'll do what the fuck I like with it!'

In the second chapter, I set the legislative and regulatory scene in which surrogacy is practised in New Zealand (hereafter New Zealand). As argued, the combination of fragmented and archaic laws, the privileging of nuclear family formations, and inequitable access to funded 
fertility treatment mean that some people are encouraged to reproduce via gestational surrogacy more than others. As arguably the most elusive and misconstrued of the two types of surrogacy, traditional surrogacy, and those who make kin via traditional surrogacy, are pushed further inside the reproductive penumbra of legislative, regulatory, and public discourse on kin. For traditional surrogates (and intended parents), the elements that shape the reproductive penumbra in which they reside include societal expectations of motherhood and public and medical discourses that suggest traditional surrogates must be donating their eggs for money. The idea that they would do it altruistically makes people uncomfortable and challenges their perception that a woman would not want to give up 'kin of her own' intentionally.

In response, in this chapter, I focus on the narratives of traditional surrogates in New Zealand, a category that has had substantially less focus on surrogacy and assisted conception scholarship. These surrogates help make families for those intended parents for whom traditional surrogacy is necessary, whether because of reproductive technological defect, lack of financial support or other constraints that prevent access to ARTs required for gestational surrogacy. For surrogates, traditional surrogacy is an option to help and support those who are denied entry into the ART clinic. According to New Zealand regulations, some of these traditional surrogates may not qualify to be gestational surrogates, such as women who have previously had high-risk pregnancies. Other women who would likely be eligible to be gestational surrogates choose to deliberately defy or reject technological intervention and state interference to reproduce on their own terms because they do not want to be told who can and cannot have a family via surrogacy. Government policies, state and private fertility clinics all create a network of power over reproduction. Within this space, traditional surrogates must constantly negotiate their agency and societal stigma while helping to make kin.

Two key narratives that contribute to scholarship on different interpretations of reproductive participation in contemporary New Zealand emerged from my ethnographic research. The first reveals multi-layered motivations that align with and diverge from the 'help' narrative that is common within the context of altruistic surrogacy. They include personal fulfilment, curiosity, wanting to do something unique, and seeking to heal from grief. The second narrative follows 
on from this, bringing to the forefront the under-researched topic of childfree ${ }^{104}$ surrogates, those women who do not want children of their own but choose to contribute their egg and gestate the foetus for another. As one of the most divisive polemic themes from my research, childfree traditional surrogates encounter more suspicion than traditional surrogates who have children because of the assumption that a woman cannot be certain she can give up a baby unless she has experienced pregnancy before. Placed within a broader exploration and perception of traditional surrogacy and traditional surrogates within wider society, I argue that these narratives disrupt the heteronormative kinship narrative inherited from settler colonialism and pervasive within Western society. Here I show that kin-making does not always focus on making family for oneself or limited to singular narratives. Rather, through the stories of traditional surrogates, I outline the nimbleness of kinship and show how they celebrate novel ways of kin-making in the contemporary.

\section{Traditional Surrogacy in Research}

Six months after we first met, during a skype chat one evening, Ruby and I were trying to make sense of why people often react uncomfortably to traditional surrogacy. She recalled once, when a stranger found out she was a surrogate, he praised her. Yet when she mentioned she was a 'traditional surrogate', he was shocked, exclaiming, 'you're giving up your own baby?' Affronted, Ruby replied, 'I'd never give up my babies! These aren't my babies!' Whilst Ruby's own family supported her, the cultural anxieties ${ }^{105}$ around traditional surrogacy are pervasive. Public opinion globally is that surrogacy is the least acceptable form of assisted reproduction (Cicarelli and Beckman 2005; Edelman 2004; Poote and van den Akker 2008), often misrepresented as the intended father having sexual intercourse with the surrogate (Lovelock 2010; Teman 2010). In contemporary times, it highlights tensions already found within donor egg/sperm/embryo and queer kinship research because it fragments the hegemonic idea of the nuclear family (Mamo 2003). 'The act of surrogacy itself causes less contention than the

\footnotetext{
${ }^{104}$ Following (Bartlett (1994) Campbell (1999; 2003) and Nandy (2017), I refer to women who have no desire to be mothers as 'childfree' rather than childless because it stands for an affirmative choice. 'Childless' is used within popular vernacular to describe both voluntary and involuntary childlessness, and 'implies an incompleteness and deficit in an individual's life and identity, as if s/he lacks something $\mathrm{s} / \mathrm{he}$ ought to have. Thereby, it seems to endorse the cultural mandate of childbearing which is problematic' (Nandy, 2017, 25). See Shapiro (2014) and Park (2005) for further discussion on distinctions between voluntary childlessness and 'childfreedom'.

105 The negative cultural or societal response to traditional surrogacy that I explore in the thesis is another example of the remnants of Euro-American kinship ideology and practices that were introduced by settler colonialists. Māori ideas of relatedness are vastly different and more fluid.
} 
question it poses about who might be the "real" mother' (Strathern, 1998, 185). In this light, people who practice traditional surrogacy find that 'the role of the surrogate is not under dispute; [legally] it is the "real" parent about which there is categorical doubt' (Strathern 2005, $57)$.

There has been little in-depth qualitative research that engages explicitly with traditional surrogacy, and the motivations of traditional surrogates themselves. One reason for this is that the uptake of couples seeking gestational surrogacy rose in popularity as the more preferred method $^{106}$ in nations like the US, UK, and Canada, whereby 2003, ninety-five percent of Canadian surrogacy arrangements were gestational (Busby and Vun 2010). In other nations such as Israel, which has one of the highest numbers of fertility clinics per capita globally, the prohibition of traditional surrogacy means that the impactful research by Teman (2010) consequently only focuses on gestational surrogacy. Notable exceptions are Ragoné's (1994) research of American traditional surrogates, and Berend's (2016) contribution of American traditional surrogates' narratives from her analysis of an online surrogacy forum. A few quantitative British studies (Imrie and Jadva 2014; Jadva et al. 2003) explore the level of satisfaction traditional surrogates) convey from having helped others create a family. In New Zealand, Shaw (2008b) interviewed both traditional and gestational surrogates (four in total) alongside egg donors. Beyond Ragoné's writing, was written over 25 years ago within a commercial context, this thesis contributes a fresh anthropological exploration of traditional surrogacy.

In thinking through the local context, it is useful to situate it among other ethnographic work that explores surrogates' motivations, and narratives of altruistic surrogacy (Berend 2016; Markens 2007; Ragoné 1996; Rudrappa 2015; Teman 2008). I juxtapose altruistic and commercial jurisdictions as well as traditional surrogacy with gestational surrogacy because there are overlaps between them in terms of making and denying kin even when there are some risks involved. These include the personal motivations surrogates have that go beyond a desire to help others, regardless of whether it is altruistic or commercial surrogacy, have a family and the negotiation of societal judgement.

106 Traditional surrogacy in these jurisdictions remains legal, while the US allows it under their privatised health system. 


\section{Traditional Surrogacy as Repro-Hacking}

When Ruth opened the door on a Thursday evening, her intended parents, Harry, and Meredith, stood on the step, smiling nervously. In their first two attempts to conceive a few months earlier, they had collected a 'home insemination kit', which contained an ovulation predictor kit, various sized syringes (the 1 millimetre one led to the successful conception), prenatal vitamins like folic acid and evening primrose, and small containers to hold the sperm (before it is drawn into the syringe). On this day, Ruth was ovulating, and Harry and Meredith had flown in. As in the past two unsuccessful attempts, the plan was to do three home inseminations per trip, once the first night, the following morning and the second evening before they flew back home. At the first time, Meredith and Ruth sat in the lounge waiting for Harry who was in the bathroom. After ten minutes passed, he opened the door far enough to pop his head around and say it was a bit too cold. A heater was grabbed from the bedroom, and it began again. Once Harry had finished, he used a syringe to pull up the sperm, wrapped it in tissue, and handed it to Meredith, who then passed it over to Ruth.

I began my fieldwork not thinking about home insemination beyond the rudimentary understanding that a surrogate self-inseminates using a syringe which contains the intended father's, or donor's, sperm. I am ashamed to admit that I thought it was an ad-hoc attempt at pregnancy because ARTs had failed to work. Instead, the vignette above denotes a sophisticated and carefully planned out reproductive collaboration and 'low-tech' (Michelle 2006) option. Yet even though each action is separate from the other, there is an understandable awkwardness, the latter of which is in stark contrast to the clinical encounter in the embryology laboratory. The embryologists focus on 'success' and 'viable' gametes and embryos. Whereas with traditional surrogacy, in an (idealised) conception encounter using home insemination, it is about conceiving successfully (and becomes a 'repro-hack', a technological technique by itself), and the need to maintain positive relationships between the adults involved. Over the past four years, the traditional surrogates I got to know all told variations of the same story, with wisdom and 'success tips' they had passed on to one another. These combine technical advice with decorum. Keep the sperm warm by carrying the syringe wrapped in tissue under the armpit on its journey from (usually) the bathroom to the surrogate. Either the intended father/mother or the surrogate can pull back the plunger in the syringe, drawing in the sperm 
from the cup ${ }^{107}$. Place a menstrual cup inside afterwards. Lie with the legs up after selfinseminating. Do not make any reference to the fact that the intended father has just masturbated in your bathroom. It gets easier after the first few attempts. The sperm is always handled with delicacy ${ }^{108}$.

A DIY ethos of tinkering to achieve the best results runs throughout accounts of home insemination. As explored in the introduction, the anthropologists of reproduction and critical kinship studies scholars tend to talk about traditional surrogacy as a pre-technological answer to infertility, only skimming the surface of the practice. In her research on lesbian couples, Mamo (2007b, 374) frames home-insemination and IVF within a continuum, which she calls 'hybrid-technological' practices: 'the technologies used ranged from the simple (i.e., donors masturbating into a jar, women self-inseminating using turkey-baster technology), to more "medical" (i.e., syringe technology), to advanced (i.e., intrauterine insemination, in vitro fertilization)'. These encompass the different settings, techniques, and interpersonal relationships that lesbian couples may go through in their journey to have a family. Often, Mamo (2007b, 381) writes, peoples are not strictly 'low-tech' or 'high-tech', but a combination of both. Some of her participants' narratives reveal a mixture of romance and non-medicalised preparations, with more technical terms such as 'frozen sperm', and 'ovulation detection kits'. Similarly, as mentioned, in New Zealand, some surrogates and intended parents rely on ovulation kits or other technologies as part of their attempts to conceive via home insemination. By using romance, lesbian couples rely on the cultural script of 'natural' reproduction involving intimacy and sexual relations (Mamo 2007).

Even though home insemination requires the same logic as donor insemination for lesbian couples or single women, where traditional surrogacy diverges is that it involves no intimacy or sexual components (even though it is stigmatised as if it did have by critics and society). With the legitimacy of the fertility clinic and the greater acceptability and popularity in most countries of gestational surrogacy, traditional surrogacy has become no less unremarkable and unexciting to research or write about. I argue rather than a primitive approach to assisted reproduction, home insemination and traditional surrogacy are DIY repro-hacks. Taking

\footnotetext{
${ }^{107}$ Although the preferred method appeared to be the discreet syringe being handed over to the surrogate, some like Heather, a traditional surrogate, used to be a nurse and preferred to do it herself. ${ }^{108}$ This is in stark contrast to how sperm is thought about within the embryology laboratory when being used for gestational surrogacy - explored more in chapter five.
} 
inspiration from the DIY bio-hacking philosophy, which rose out of both the DIY biology movement in the US in the 1960s with explicit references to hacking and the idea of open sources and decentralisation of knowledge (Delfanti 2013, 1), repro-hacking is a helpful way to re-consider traditional surrogacy as a modern and valuable assisted conception method that allows both surrogates and intended parents the opportunity to simultaneously circumvent and re-shape the way we think about the practice in relation to ARTs.

\section{Altruism and Beyond the 'Help' Narrative}

After divorcing her ex-husband and allowing some time to pass, the now single Ruby chose the traditional surrogacy route when she was close to 40 years old, stating 'the government would never have let me be a gestational surrogate anyway', referring to her high-risk pregnancies and increasing age. Even if she could, Ruby disliked the strictly regulated laws surrounding gestational surrogacy in New Zealand, which controlled what a woman decides to do with her body. Although it was not her initial reason to become a traditional surrogate, this way, she could help others have a family, but on her own terms, as well as fight against 'the system'. Thus, she could help make a mother. Time spent with other surrogates revealed that they too had multi-layered motivations that aligned with and diverged from the 'help' narrative commonly associated with the concept of altruism. However, they are articulated differently depending on the people and circumstances, such as if the surrogate is childfree (more discussion below). These include Lola, who, as both a traditional and gestational surrogate, aptly sums up what other participants often alluded to - 'if anyone says they don't get something out of being a surrogate, they are lying'. She was motivated to be a traditional surrogate because in addition to wanting to help others have children, she had no desire to undergo medical interventions. Lola also had 'a curiosity to see what kind of child my egg and another man's sperm would make'. When she decided to become a gestational surrogate after this, it was because she was content with her experience as a traditional one. In this sense, wanting to help others have a family is also juxtaposed with wanting to get something out of the experience. Some surrogates wish to do something special with their lives and have a unique story to tell others, or because they enjoy pregnancy, which is consistent with surrogates' motivations in other altruistic jurisdictions (Blyth 1994; Jadva et al. 2003; Jadva, Imrie and Golombok 2015 Ragoné 1996). 
Although Ruby had several reasons for wanting to be a traditional surrogate, during my first visit, she admitted that her main reason to become a surrogate was because her second daughter had died in her sleep years earlier, aged two. 'To not have known her or be able to understand that 'heart bursting' love that us mothers have for their children is to me, an even more unimaginable horror. I had this strong need to [be a surrogate and] fill someone else's "hole" as if somehow it will help to offset my loss'. Ruby's desire is underpinned by an intimate encounter with the precarity of life itself. This is not identified as an explicit motivation within assisted conception and surrogacy scholarship, but Shaw (2008b, 21) does describe two of her participants who donated eggs in New Zealand as having 'experienced encounters with death...these women felt compelled to reaffirm the value of life by symbolically expressing these feelings through the donation of reproductive gifts'. By inverting the heartache and pain of losing her daughter unexpectedly, Ruby found purpose and a need to give another the joy of motherhood. Shaw $(2008 \mathrm{~b}, 11)$ refers to motivations of personal fulfilment as their 'body project', whereby egg donors and surrogates conceptualise their form of assisted reproduction as a way to work on their own self-identity and value. A literal interpretation of the term is apt to also frame women who practice surrogacy to have a physical transformation. For example, one of my participants wanted to do surrogacy because she found when she was pregnant with her own daughter, her chronic health condition went into remission. Not wanting any more children but wanting to experience pregnancy again coincided with her desire to help infertile women.

In countries that only allow altruistic surrogacy, it is framed within state regulations and public discourse in opposition to commercial surrogacy, with surrogates not receiving any money in return ${ }^{109}$. The language of self-sacrifice was used in conversations I had with intended parents - with the surrogacy seen as the 'angel' that brought them their happiness. This sentiment is present in Shaw's $(2007,16)$ description of the features of the altruistic act that firstly 'seeks to increase or enhance another's welfare, life chances or pleasure, not one's own. Second, an altruistic act is voluntary. Third, an altruistic act expects no external reward or reciprocation ${ }^{\prime 10}$. Yet, the narratives above show that wanting to help create kin for others is not done as a selfless act but is part of a more complex set of motivations. In the first

\footnotetext{
${ }^{109}$ In New Zealand (and the UK and Canada) they can receive 'reasonable' expenses such as pregnancy related costs.

${ }^{110}$ See May and Tenzek (2016) Pande (2011), Rubin (1975), Ruparelia (2007), Shaw (2003; 2007; 2008a; 2010), Strathern (1988), Tober (2001), Yee (2009), for more discussion the relationship between altruism and gift giving in the context of gender and reproduction.
} 
ethnography on surrogacy, Surrogate Motherhood: Conception in the Heart, anthropologist Helena Ragoné (1994) claims that women became surrogates not for entirely selfless nor financially motivations ${ }^{111}$, but to feel empowered and to transcend their role as mothers. This contrasts with research conducted by Teman and Berend (2020), who alongside Jacobson (2016) and Ziff (2019), found that women in relationships tend to approach surrogacy as a unit alongside their husband and children who provide support. Teman and Berend (2020) describe this unit as a heterosexual nuclear family, which is not a transferrable framework of consideration. My own research supports both premises, that every surrogate gets 'something' out of being a surrogate. Additionally, relationships were not fundamental for surrogates to be successful. Although many, like Lola and Heather, attest their success to the support from their partners, those without partners, like Ruby, Madison, and Joy, were as positive. In other words, things can go wrong regardless of whether surrogates live in a nuclear family dynamic or not. Interestingly, the reason Kelly, a traditional surrogate introduced below, did not want to have children herself at this point was because she did not want to be a single mother. Being a surrogate, however, was something she saw as an experience with an end date ${ }^{112}$.

The link between simultaneously helping others and doing it out of self-interest is what Shaw (2007, 303), in citing Schmidtz (1996), refers to as 'the altruism paradox', where habituated concern or regard for others is inextricably connected to one's self-regard. Within countries that allow commercial surrogacy and egg donation, altruism is 'framed as an affective, altruistic act and an invitation to exercise reproductive mobility' (Shaw in Yates et al. 2015, 50). Similarly, surrogates who contributed to the online surrogacy forum that Berend (2016) followed for ten years all relay emotional desires to help others, emphasising altruistic reasons to deemphasise money as a primary incentive. The representation of commercial surrogacy as involving altruistic elements is also a common discourse in egg donation in the US - Almeling, (2011) describes how egg donor agencies in the US choose women based on whether their psycho-social analysis confirms they have an altruistic and nurturing nature ${ }^{113}$. In addition, Smietana (2017) discusses how affects and emotions help gay fathers facilitate the commercial aspect of surrogacy. These cases further explicate the blurring of the boundaries that separate commercial and altruistic surrogacy, demonstrating that it can be about both in the US.

\footnotetext{
${ }^{111}$ Ragone (1996) mentions a surrogate who refused her dad's offer to pay her not to be a surrogate.

112 This links to the discussion in chapter five on 'intensive mothering'.

${ }^{113}$ See Almeling (2011), Jacobson (2016), Markens (2007) and Briggs (2017) for more in-depth discussion about reproductive labour and capitalism.
} 


\section{Childfree surrogates}

Just as women have various motivations to become surrogates, whilst some in New Zealand aligned with trends found in other countries, others are more unique. This was also clear when talking to Kelly, Madison, and Joy, the three childfree surrogates I got to know during fieldwork. The following narratives reveal how a woman can create kin for others without having any desire to do so for herself.

At a busy brunch spot, I met Kelly. She was the first surrogate to email me after seeing the outline of my research project posted on a surrogacy forum. Kelly had biked from her nearby home she shared with one other person, had piercing blue eyes, an open smile and the bottom of her light blonde hair was dyed magenta. At 35, she had recently qualified as a social worker, having previously worked in the design world in New Zealand and in the UK. Now settled in a new job, Kelly was four months pregnant for a gay couple living over 500 kilometres away. Sitting on bar stools at high tables, the only ones available, I asked Kelly what motivated her to be a surrogate and if she had specific criteria for intended parents in mind when she joined the surrogacy group. Slowly eating her date scone (which I learnt became a favourite of hers, as we met in a different café each time to see how good their version might be), she pondered this. She explained that she knew she wanted a gay couple because if she chose a heterosexual couple, then the woman might be jealous of Kelly's ability to conceive and gestate a foetus. She laughed lightly, adding that she had the idea that gay men would dote on her, which we found out as time passed, was not the case. As a single, childfree traditional surrogate, she would not have been approved for gestational surrogacy, but regardless she did not want to do it because of all the medical treatments and needles involved. She also thought it unfair to make people pay all that money if she could 'just do home insemination'. At 35, she wanted to see what it was like to be pregnant in case she never got the chance to or did not want to become pregnant in the future. At the time of writing this, the boy that Kelly gestated and gave birth to is now three years old, and she does not regret her decision, even though she acknowledged that some intended parents and surrogates might find her a 'wild card' despite her assurance that she would have given the baby to the intended parents regardless of whether there were post-birth complications that could make her infertile.

The regulation that a woman should ideally have finished her family is in the HART Act 2004 in case the surrogate has complications in the pregnancy that could impact her ability to fall 
pregnant or gestate again in the future. These regulations may make some sense when we look at Kelly's indecision about a future desire to have her own children. Yet, part of her reason to be a traditional surrogate was that she was clear about what she wanted in the present day, knowing that her future may not have children in it. Her resistance to societal expectations ${ }^{114}$ reflected in the HART Act was also a central motivating factor, seeking to redefine parameters of who can be a surrogate. Beyond Kelly's case, the regulations also do not consider that some women do not want to have children but are happy to gestate one for someone else. Two of the three childfree surrogates in my research, Madison, and Joy, knew that they did not want to have children, and their decisions to become surrogates were out of compassion for others. They both understood that there were people who wanted children as strongly as they rejected the idea. 'It wasn't a big thing for me to do', Madison told me during our first meeting, not mentioning until later that she had complicated pregnancies the two times she carried for a gay couple. She had significant morning sickness but saw it as something temporary, downplaying her role because it 'only lasted for nine months, and [the intended parents] are the ones that have to do all the tough stuff', signalling the raising of the children. Even now, four years after the last birth, what surprises her the most is that although she is introverted, she enjoys joining conversations with other women on the ups and downs of pregnancy and 'being invited into the club'.

One evening on loud-speaker, I had a two-hour conversation with Joy, a traditional surrogate twice to different heterosexual couples.

Hannah: It's such a huge thing to help with though, isn't it?

Joy: But not to me.

Hannah: No?

Joy: Because to me, it's something I don't want. This is what so many people don't understand.

However, Joy's parents understood. Nervous, she sent them a handwritten letter because she wanted to give them time to digest the information. Within a few days, her mother called and said 'go for it. We'll support you'. Like Madison, Joy did not see her role as anything special:

\footnotetext{
${ }^{114}$ See Burgess (2019) for general discussion on New Zealand State regulation and interventions in women's bodily autonomy and pregnancy.
} 
It's not a big thing, because I don't like kids. It's not something that I've dreamed about and wanted all my life... you know how some women just, they're not complete unless they have children. That's not me...it was honestly no different than donating blood. It just took a lot longer and was a bit harder on my body.

When I asked Joy how she felt now, looking back, she was quick to point out that she has no more feelings towards the two babies she gave birth to than she does to her nieces and nephews, 'and I hate the little buggers [in general]'. Like Madison, Joy seemed to downplay her role, comparing it as an act akin to donating blood - giving something that is of value to others that she is physically capable of doing. Joy's casualness is almost blasé, which was intriguing, especially because she developed gestational diabetes during the pregnancy that had to be managed. On the one hand, their minimisation of what they sacrificed to create kin contrasts with efforts involved in home insemination (it took Kelly nearly a year to become pregnant), the physical and hormonal changes of pregnancy, childbirth, not drinking for nine months, and putting time and work into making sure the intended parents felt involved and expectant. On the other hand, they saw it as less of a 'big deal' compared to surrogates who already had children. In my interview with Joy, I wrongly assumed that it was a big act of self-sacrifice, which signals the pervasiveness of the cultural trope of motherhood as inexplicitly linked to womanhood and thus consequential. Instead, their narrative disrupts the enormity that is usually attached to these events and experiences. They acknowledge the importance of parenthood for others. As Madison said, 'I read about a couple dealing with infertility and felt sad for them', but she had no desire to have this version of relatedness herself. It is important to note that the childfree surrogates never minimised ed the significance of what it might mean for the resulting children and that it was likely they would have questions in the future. Further, their narratives support the idea that motherhood/parenthood is intentional and a choice, and that the period following the birth is the important part - where the intended parents take on their roles fully as the only parents the children will know.

However, although Madison, Kelly and Joy felt they knew themselves, even members of the closed online surrogacy community were not entirely comfortable with their presence. Openly stating that being a surrogate was no big deal is provocative, especially in a space where surrogates are held in high regard because they are willing to give a lot to help others create their family. When Joy first joined the group, she remembered that someone did a poll that 
asked if 'intended parents would be happy to have a childless surrogate', and although they did not name Joy, she said that it was clearly about her because she was the only one on the forum at the time. Similarly, at different points in my fieldwork, if I even uttered the words 'childless surrogate $^{115}$, government advisors, lawyers and other surrogacy researchers overseas were shocked and classified it as potentially dangerous. Despite Madison, Joy, and Kelly having no regrets some years after the children's births, the discomfort people feel in response reflects a normative discourse that assumes a woman cannot know whether she can give up a baby unless she has experienced pregnancy. Even within a surrogacy community that promotes the idea that a woman can gestate, deliver, and relinquish a child to another, their fears align with those outside the community. Surrogates usually have children of their own, and any divergence from this, raises alarm bells.

\section{The Polarisation of and Discomfort with Traditional Surrogacy}

In this chapter, I have made visible the narratives of traditional surrogates, who are frequently misunderstood by society, and within wider cultural expectations of what the Euro-American conventional family should look like in the West. 'Critics normatively discuss surrogacy by drawing on cultural 'myths' regarding motherhood... while ignoring surrogates' own understandings of relationships and relatedness' (Teman and Berend 2018, 297). While childfree surrogates do experience additional discrimination associated with their decision to be childfree, traditional surrogates, in general, are open to judgement. Critics are pessimistic about the practice, asserting that the woman who gives birth is always the mother of the child (Stefansdottir, 2018), that surrogacy is exploitative of the surrogate and the child (Overall 2013) and is ultimately a way for society to control women's reproduction (Deomampo 2013, 171; Hubbard 1984). The debate within feminist discourse is nuanced, with those calling for a ban on all forms (see Thompson 2002 for a more exhaustive discussion), claiming that men are simply using women's wombs as 'empty vessels' (Corea 1985), and reflective of classism and racism (Rothman 1989; Davis 1993). Meanwhile, liberal feminists 'defend a woman's right to use her body as she chooses, even if that means being a surrogate' (Markens 2007, 17), claiming it as a mark of reproductive and democratic freedom and is like other wage contracts

\footnotetext{
${ }^{115}$ Despite the evolution from the term 'childless' to 'childfree' within my scholarship, I want to acknowledge that the former was part of my (and others) vernacular for a substantial period during my fieldwork, and how I often would bring it up in interviews, unconscious of the connotations mentioned earlier in the article.
} 
(in consideration of commercialised surrogacy). As Markens (2007, 18) explores, opponents and supporters of surrogacy often have similar ideologies about the 'sanctity of family'.

Besides Ruby, other traditional surrogates have experienced similar adverse reactions from the public or friends/family that manifests as a fear that a surrogate is making a mistake by donating her own egg as well as gestating the foetus, as if providing her egg raises the stakes for her to regret handing the baby over. This discomfort echoes the argument by Michelle (2006), where assisted reproduction methods are becoming normalised, but not when it deviates from either the heterosexual patriarchal nuclear family, or desirable motherhood ${ }^{116}$. The vast legal battle and media coverage of the infamous Baby $\mathrm{M}$ case made it one of the most talked about stories, often used as a cautionary tale to warn people of what might go wrong. This is despite the report that $1 \%$ of surrogacy cases in the US end in court battles (Teman 2008). Empirical research in altruistic contexts such as the UK (Blyth 1994; Jadva and Imrie 2014; Jadva et al. 2004; van den Akker 2003), Canada (Yee, Goodman and Librach 2019), and countries where both commercial and altruistic surrogacy are legal, such as the US (Baslington 2002; Berend 2016), shows that surrogates report high levels of satisfaction in gestating and giving a baby to intended parents. In their longitudinal study in the UK, Jadva, Imrie, and Golombok (2015, 373) found that, ten years after having given birth, both gestational and traditional surrogates 'may find the weeks following the birth difficult...but do not experience psychological problems 6 months or 1 year later' and remained positive about the experience overall.

Teman and Berend $(2018,296)$ write that 'for surrogates in the US and Israel, maternity, bonding, and kin-ties are not automatic outcomes of pregnancy, but a choice'. By basing her relationship with her own children on intention and love, Ruby shows that non-bonding and being willing to make kin for others is also a choice. They become traditional surrogates without any intention to be 'motherly' but instead are motivated by the desire to make kin, albeit for others. This choice does not disregard the biogenetic connection but deemphasizes it to help support the vision of kin that they are helping to create ${ }^{117}$. The idea that motherhood and kinship are culturally constructed has been argued by Critical Kinship scholars (Dow 2019; Franklin 1997; Teman 2010; Weiss 1994), problematising the assumptions within psychosocial

\footnotetext{
${ }^{116}$ Undesirable or 'unnatural' mothers, according to Michelle $(2006,113)$ are those who are single and lesbian. Given the public distrust of families that do not follow the nuclear family ideal, I would add those women who 'give up' a baby they are genetically related to or receive a baby that they are not genetically related to.

${ }^{117}$ See Faircloth and Gürtin (2018) for discussion on the naturalisation of 'the desire to parent' itself.
} 
studies that postulate that a lack of maternal instinct or mother-child bonding is due to psychological issues (Alhusen 2008; Ciccarelli 1997, 2; Condon and Corkindale 1997 Resnick 1990; Teman 2008). Jacobson $(2016,5)$ writes:

Despite historical and cultural variations in what it means to be a mother, the unity of motherhood today is framed as part of nature itself...[and] thanks to their female instinct, women naturally love, understand, and have empathy for and a connection to the children they beget and birth.

Therefore, assumptions about a woman's ability to function successfully as a surrogate are down to (lack of) a character trait, positioning such women as deviant and abnormal (Teman 2008). This feeds cultural anxieties that surrogacy is a potentially dangerous practice, regardless of most cases going well.

The childfree traditional surrogates I met inhabit the most elusive category of surrogates and garner suspicion. Voluntary childfree women deviate from the 'dominant, mainstream or the most acceptable way of being a mother or woman' (Nandy 2017, 8), burdening them with having to justify their decision, whereas choosing to reproduce does not, resulting in 'unwanted empathy when it is assumed one's childlessness is not voluntary' (Hintz and Brown 2019, $62)^{118}$. They are othered and 'uniquely liminal in ways that are destructive to moral agency' (Gotlib 2016, 327). Similarly, the decision to undergo sterilisation is stigmatized and met with negativity and fears the woman will regret her decision (Gillespie 2000; Hintz and Brown 2019). In this context, Madison, Joy, and Kelly's decision to help create a family, while being resolute in their own choice to be childfree, destabilises the cultural script in the West that says motherhood is an essential part of womanhood (Harrington 2019; Letherby 1999, 2002; Hintz and Brown 2019; Gillespie 2003) and a crucial element of a woman's self-worth and fulfilment (Meyers 2001; Peterson and Engwall 2013). For these childfree surrogates, surrogacy does not reaffirm their own love for motherhood as it may do for the other surrogates. Whilst Kelly was primarily motivated by wanting to experience pregnancy, Madison and Joy's narratives reveal they became surrogates through compassion for others who dream of something they 
themselves do not. In this way, surrogacy is the means to help create kin for others, not to replicate a version they themselves want.

\section{Conclusion}

With the proliferation and globalization of ARTs, gestational surrogacy is a popular option for intended parents seeking to create a family via surrogacy, not least because it is the only legal option in some countries. Conversely, in the last two decades, traditional surrogacy has received less scholarly focus than gestational surrogacy. The research that does exist highlights that although the biogenetic and gestational relationship between the surrogate and foetus/resulting baby presents extra ethical considerations, traditional surrogates have the same level of contentment and positive experiences as gestational surrogates. In New Zealand, half of the surrogates I got to know during fieldwork were traditional surrogates, providing a rare opportunity to understand and make visible their narratives and experiences. I propose that, situated on the periphery of regulations and privatised fertility medicine, surrogates can hack the same criteria that denies them entry to the clinic. Of course, hacking a system does not necessarily improve it, but it might highlight its weaknesses. The risks are also more complex ${ }^{119}$ and heightened in traditional surrogacy, because outside of the clinic and ethics guidelines, people must coordinate the 'how to' themselves ${ }^{120}$. As hackers work in the shadows, so do those practising traditional surrogacy, more so than those doing gestational surrogacy.

This does not mean that in every case, surrogates would choose traditional over gestational. Still, the narratives within this chapter reveal how participants were determined to help those intended parents who require a traditional surrogate, whether they would pass the clinical and ethics criteria to do surrogacy or not. In the case of childfree traditional surrogates, they were denied entry to the fertility clinic because they do not have children of their own. Other traditional surrogates, like Ruby, deliberately choose this route to circumvent the regulations that stipulate who they can or cannot carry a baby for. Traditional surrogates' other motivations to donate their egg and gestate a foetus for nine months for others are neither purely selfish in

\footnotetext{
${ }^{119}$ For example, there is the risk that the intended father gives the surrogate a sexually transmitted disease via the self-insemination, and with surrogates donating their genetic material, it is important that they only consider traditional surrogacy once they have contemplated what giving a genetically related child would mean to them, if anything.

${ }^{120}$ This is where the surrogacy community step in, as shown in the next chapter.
} 
nature nor selfless, and the narratives in this chapter reveal that the altruistic/non-altruistic dichotomy in the context of surrogacy and assisted conception more broadly is superficial and ideological. Altruistic surrogacy is not just about altruism. Instead, traditional surrogates are motivated by the desire to help others create kin and find personal fulfilment of some kind in the process. Through strict criteria that restricts access to gestational surrogacy, and the legislation that only identifies the birth mother as the 'real mother', the state determines what kin ought to look like. Surrogates, in general, navigate these boundaries of what kin-making looks like, but it is traditional surrogates who explicitly challenge cultural assumptions about motherhood. These include the nimbleness of what kin can look like. What is kin for one family can be altogether different to another. Traditional surrogates give voice to the fact that women are willing to make kin, just for someone else. In the case of childfree surrogates, the fear people have, particularly other surrogates, shapes and reinforces the very stigmas they are trying to dismantle in the first place - that motherhood or parenthood are 'natural' rather than built on intent and choice. Although traditional surrogacy might challenge heteronormative understandings of motherhood, the disapproval of childfree surrogates reflects that the practice does not necessarily subvert narratives that womanhood equates to being maternal for everyone. Taken together, these accounts encourage a more expansive conceptualisation of kin and kin-making under different reproductive options. 


\section{Interlude Three - The Embryo Transfer}

\section{Part I}

\section{FIELDNOTES 14 May 2017}

It was a big day when I first met Lola's husband Ralph and their two children. Lola's intended parents, Celeste, and James, were flying in for the hopeful transfer of their embryo into Lola's womb.

Although I only met Lola in person days earlier, I was quickly invited into their lives. On arrival, Lola and her family parked their car as I stood outside of the fertility clinic nearby with a cake box in my hand. It always feels strange being a part of an event that holds so much significance for others, as if I may be imposing. I have learned that the best thing I can do in these situations is to be aware that as much as I try to be undisruptive, I remain an outsider. I hoped that the cupcakes made my presence more tolerable. I need not have worried, though, because, within a few minutes of shaking Ralph's hand, he pressed the fertility clinic's intercom button, he said: 'this is Lola and family, and Hannah', which put me at ease. As we rode the elevator, Lola filled me in. Celeste and James' flight was delayed, and no one knew if they would make it in time. By this point, Lola had begun drinking the copious amount of water required to help visualise her womb via ultrasound. 'You'll have to take a video of the transfer', she said. I replied that I would take photos and videos of everything. Like the scan, I felt slightly more comfortable being there now that I had an official 'role' to play.

The waiting room was empty. Lola sat down with Elliot, her son, beside her, while Ralph chose a sofa opposite to me, and I placed the cupcakes on the coffee table. Cameron, their youngest, moved freely around the room, at one point standing directly next to me, then under my seat and peering up at me as he lay on the floor. His curiosity put me at ease. Not long after, both boys gravitated toward the cupcakes. 'You can have one, if you like', I said, which delighted them. The ensuing conversation had an ease to it, and Ralph seemed as excited about the transfer as Lola, which reminded me of her comment three days prior at the pre-transfer scan: 'I wouldn't be able to do this without Ralph'. A slim lady came into the room not long into our wait to introduce herself as their nurse. Lola told her that the plane was delayed, but that 
Celeste was at peace with the fact she would not be there in time. The nurse said that since their transfer was the only one for the day, the fertility doctor was happy to wait for the intended parents.

In between tracking Celeste and James' flight on her phone, Lola showed me a photo and message her first intended mother posted on her social media, saying, 'Happy Mother's Day Auntie Lola!' Handing me her phone, she said, 'you should use this for your research', adding that it is a sign that she has no emotional connection because she looks at the photo without any motherly feelings. In comparison to how she felt about her own sons, 'who have my eggs too, I don't think that Jack, the 'surrobaby', is particularly beautiful'. During this conversation, Lola continued to drink water, becoming visibly more uncomfortable. The embryologist came out at one point, stating that: 'the first embryo didn't thaw, but the second one did and it's beautiful'. Both were three-day-old embryos. Lola continued to track Celeste's flight, refreshing the page on her phone every few minutes. Then the nurse popped her head around the corner to say that the doctor was on his last scan, so they had to get her ready now. 

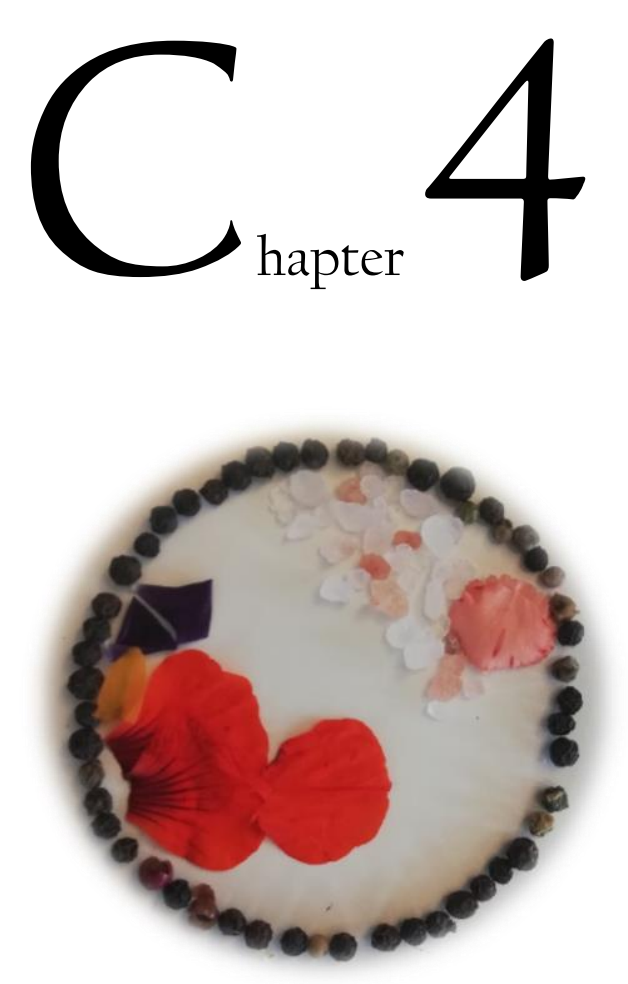

Figure 4: Before It Hatches. Photography by Hannah Gibson

\section{Surrogacy and Shadow-legalities: The Informal Rulebook for Making Kin through ART in Aotearoa New Zealand}

Sitting in the corner of a room that was filled with the adults' lively chatter and children's laughter, Madison was nervous. Not good at small talk, she wasn't sure why she was there and felt self-conscious. Although she had spent the last six months online, looking over profiles and getting to know people at the same stage of life as her, via group threads and eventually private messenger chats, she worried that the couple with whom she felt a connection would match the picture she had in her mind. She had already been disappointed once before, even before meeting anyone in real life, by a couple she approached privately to ask if they wanted to get to know one another better. Although they replied enthusiastically, she didn't know they were also chatting with another woman at the same time until she got their message of rejection. However, the new couple, Tray and Charlie seemed promising and had excitedly agreed to meet almost instantly. Beneath the nerves, Madison hoped this would be the end of her search. 
Eventually, she spied Tray and Charlie winding through people as they smiled and said hello to everyone. They seem friendly, she thought. As if they could feel her eyes on them, they looked over and gave a wave in greeting. Just before they arrived at her side of the room, a ball landed at Tray's feet. Checking from where it came, he collected it up, and took it back outside to the group of older kids who were playing soccer on the lawn. 'He'll make a great father', Madison thought, also noting his strong facial features as he returned to her corner. Madison got up, and saw Tray and Charlie seemed just as nervous as she was, which made her relax a bit. Over the afternoon, despite Madison's shyness, she found herself opening up as they talked about commonalities they shared. It was a promising first meeting, and they agreed to be in touch to arrange a more private date, in a quiet café or restaurant where they could talk properly without distraction.

Between the initial meeting and second date, they kept in daily contact, and Madison appreciated the effort the couple was putting in to get to know her more. While she was at work, she checked her phone often because all she could think about was the potential future she had with Tray and Charlie. On the day of the second date, when Madison walked into the café and sat down at their table - she felt giddy. They were attentive and ticked all her boxes. She kept quiet about it though, and instead, they conversed about trivial stuff alongside more serious aspirations and hopes for the future. Including what they all wanted out of a relationship. Although members of the surrogacy forum advised her to not rush into anything, she didn't want to finish the date without being honest about her feelings. 'It's not like you declare yourself and don't have time to get to know them further', she told herself. During a lull in the conversation, she took a deep breath and leaned closer towards Tray and Charlie, who instinctively did the same. 'So...how about we make a baby?'

Out of all the assisted reproduction options available in New Zealand, surrogacy is the least practised and the most elusive to those who consider it an option to help create a family. On the surface, high-tech gestational surrogacy and low-tech traditional surrogacy seem in opposition to one another. While those practising gestational surrogacy have a degree of medical and ethical guidance before they search for a surrogate and during the subsequent periods, in contrast, those doing traditional surrogacy practise mostly outside of any formal guidance, and for many people this is both as liberating as it is potentially risky, because they take on the technical intricacies of home inseminations alongside finding matches. They are also less likely to seek private counselling (which is compulsory in gestational surrogacy) 
before they begin their fertility journeys because it is seen as an extra cost or unnecessary. However, rather than dichotomous, between these two types of surrogacy, there is a nebulous space where surrogates and intended parents co-constitute vulnerability. Both experience uncertainty around finding their match or locating a surrogate or intended parent, the intricacies involved in developing relationships, and cultivating trust with those they agree to begin their reproductive journey with. The complexities of surrogacy are manifold as they try and make kin in ways and spaces that some would deem 'non-traditional'. Riggs and Due $(2013,1)$ suggest that universally, 'reproduction via heterosex remains the most valued form of reproduction', and people who reproduce outside of normative spaces, including social or medical infertility, experience 'reproductive vulnerability', regardless of sexuality. As discussed in the introduction, while their writing predominantly focuses on Australian couples and transnational surrogacy, I propose that the term is transferable to the local context ${ }^{121}$, in which both intended parents and surrogates in New Zealand are, to varying degrees, reproductively vulnerable. In this chapter, I posit that reproductive vulnerability is a feature of the reproductive penumbra and is produced in part by the lack of reference point on 'how to' create kin via surrogacy and the disjuncture between legislative and judicial practices discussed in chapter two.

In their search for support, guidance and a potential match, many intended parents and surrogates turn to a nebulous community that comes together on the internet, where different support forums become a central part of their journey. There is no social guide on 'how to find a surrogate' in a country that prohibits couples from publicly advertising for someone to carry their baby. Thus, to manage their reproductive vulnerability, people develop and find ways to navigate the uncertainties they face in a legally ambiguous landscape. Throughout my research, I saw patterns where surrogates and intended parents modelled their search on another process that they are familiar with: online dating. Members of the surrogacy community employ rituals and language associated with the dating world to give them a sense of control in response to the precarious aspects of assisted reproduction. From their search online for a partner to agreeing to go on a first 'date', relationships are carefully crafted with an unspoken assumption that there is a 'recipe for success'. The 'right' behaviours that are promoted in the community include who can make the first contact, discussing important topics, and only dating one

${ }^{121}$ The five sets of intended parents who did go overseas are not included in this chapter, thus the emphasis on the local rather than including transnational surrogacy. 
potential match at a time; just as the 'wrong' behaviour can get you removed from certain online communities. In this chapter, I show how both desirable and undesirable behaviour is judged in various ways and how these shape informal rules around traditional and gestational surrogacy in New Zealand. The idea that if they follow the rules, they will be successful in their surrogacy journey helps them mobilise a particular form of legality, what I call 'shadowlegalities'. I propose that this code of behaviour conceptually operate as shadow-legalities to offer the differently positioned participants a sense of security and belief in the 'system'.

Anthropologists who research 'shadow spaces' have largely looked at informal economies and, in contrast with alarmist ideas of illicit networks that exist primarily underground and disconnected from legitimate economies, in today's neo-liberal and globalised politicaleconomy, the formal/informal, licit/illicit, legitimate/criminal often merge (Ferguson 2006; Galemba 2008; Sampson 2003). At the same time, Nordstrom $(2000,36)$ uses the term 'extrastate' to draw attention to how they 'work both through and around formal state representatives and institutions.... [whereby] states and shadow networks exist simultaneously, each phenomenologically different, each representing distinct forms of authority and politicoeconomic organisation'. Importantly, shadow networks are not necessarily illicit, but a space where culture is created, 'governed by rules of exchange, codes of conduct, hierarchies of deference and power - in short, they are governed by social principles....and [are] not marginal to the world's economies and politics, but central' (Nordstrom 2000, 37). Compared with the terms 'shadow laws', 'social norms', or 'informal rules', shadow-legalities encompass both the quasi laws within the surrogacy community and the system under which these laws operate. According to Merriam-Webster, the term legality is an 'observance of law', and the 'quality or state of being legal'. The shadow-legalities that make things possible for many in the surrogacy world are not tied simply to the rules themselves but are also the framework they inhabit. They help people to navigate both the surrogacy community and satisfy the requirements of the formal legal system they must engage with at various stages ${ }^{122}$.

\footnotetext{
${ }^{122}$ If surrogates and intended parents follow the rules of decorum and mitigating risk, then this enhances the chances for success. For example, if parties demonstrate that they have gotten to know one another properly, have taken time to talk about the risks and cultivated the metaphorical relationship, this is valuable for both the ECART application and the mandatory engagement with Ministry of Social Development in the leadup to adoption day. Of course, as will be shown, this is not a failproof framework, but the rules have been created in response to the institutional and ethics requirements.
} 
Rather than focus on the traditional interpretation of shadows economies as a globalised movement of goods and services across borders, shadow-legalities is useful to examine how people navigate and respond to the ambiguity found in local institutional and intimate landscapes of kin practices in the context of New Zealand surrogacy. Taking inspiration from shadow economies that may on the surface be seen as disruptive spaces that lack rules of governance, informal rules, shadow-legalities denote the ambiguous spaces that exist outside of, or in the shadows of, heteronormative reproduction (even if certain practices or beliefs work to reinforce normative kinship). In turn, actors must find ways to establish their own informal rules, code of conduct and social legitimacy. As a set of salient and explicit rituals and narratives created by more senior members of the surrogacy community, shadow-legalities work as a set of parameters. These guidelines of engagement are established and reinforced by senior members as informal rules, which in turn provides new members with a sense of agency and hope that they may be successful. Ultimately, actors create their own quasi-legal system by abiding by communally agreed upon rules, or a malleable roadmap of sorts to manage interpersonal relationships. This means that people interpret advice and rules of engagement to suit their own goals and, while rules are not strictly enforced, actions are monitored and judged.

I use shadow-legalities instead of 'informal rules' because it is a useful concept to understand how everyday rituals of kin-making in the surrogacy community are inspired by, embedded in, and in response to the absence of official laws and legal processes. For example, on the surface, surrogacy is a mode of building and maintaining kin functions outside of the traditional symbolic logic of heteronormative reproduction and the law (Goodfellow 2015). However, underpinning peoples' rituals and narratives within the surrogacy context are often beliefs that seek to work on and around the law to validate their kin-making. These include marriage and birth. Although shadow-legalities do not have the force of the law, they are used to cultivate trust between parties rather than erase vulnerabilities inherent in surrogacy itself. Instead of functioning as two separate spaces, as the public/private or legal/illegal, the relationship between state regulatory guidelines and the informal rules and network formed by members of the surrogacy community can be blurry and overlap at times, as I will discuss. In this chapter I outline four 'informal rules' that the community members feel that they must abide by, to belong to the community and hopefully be successful in their surrogacy journeys. The first rule is: following the rules helps your personal surrogacy journey; the second rule asks you to take a leap of faith if you want to be successful; the third rule asks you to think about the 'socially acceptable' norms around exclusivity when on a surrogacy journey; and finally, the fourth rule 
offers guidance on how to mitigate risks inherent in some surrogacy arrangements. Combined, these rules help shape the shadow-legalities that kin-making requires for surrogacy arrangements in New Zealand.

\section{The Surrogacy Community}

In New Zealand, it is illegal to advertise for a surrogate ${ }^{123}$, and laws that govern the practice (such as what counts as compensation for expenses) are vague, leaving both intended parents and surrogates vulnerable to a degree (Shaw 2008). While in other jurisdictions such as the United States (US), surrogacy agencies have typically been the mediatory and had control over the matching process (Berend 2016), online matching and in-house surrogates within fertility clinics have de-centered the monopoly that agencies once had over the process (Berend and Guerzoni 2019) ${ }^{124}$. With no history of agencies mediating between actors in New Zealand, some intended parents rely on friends of family offering to carry a baby for them. Other people turn to Making Babies through Surrogacy (MBS), the central closed online forum where most surrogates and intended parents match. Although some of my participants met through other platforms (social media, campaigns, real-life and other online groups), this chapter focuses on MBS because of its centrality in their lives and the influence it has on how people think about surrogacy and relationships more broadly. The forum is a private space where people interested in doing surrogacy, and donor insemination to a lesser degree, can get guidance and support from those who have already been through it. During fieldwork, I saw a copy of the initial rules people are required to agree to when they apply for the forum, but to maintain anonymity, I have chosen to use the phrasing and wording that my participants use, which is helpful because it is their interpretation of the rules and how it influences their journeys that I focus on here. In the following sections, I unpack the beliefs that underpin unspoken protocols or expectations, some of which reinforce how a metaphorical romance within the surrogacy context might mimic practices that usually result in the legal recognition of relationships between actors such

\footnotetext{
${ }^{123}$ In comparison, other jurisdictions, including The Netherlands, Canada, and the UK, where only altruistic surrogacy is legal, they do have agencies that help make those matches.

${ }^{124}$ Despite the prohibition of commercial surrogacy in the UK, they have official surrogacy agencies that provide support to all parties at a cost. Brilliant Beginnings is the only surrogacy matching agency in the UK, and offers two packages, the 'Surrogacy Support Package' aimed at arrangements where the intended parents already know the surrogate costs approximately NZD \$7,806 (at time of writing, October 2020), and a full 'Surrogacy Pathway' package for NZD \$24,886. Since surrogates are altruistic in the UK, the agency does close their application process in response to surrogate availability. Their matching services include 'removing the pressure on [intended parents] to market [themselves] and doing the hard work of making sure that [they] and [their surrogate] are a good fit before [they] even meet' (Brilliant Beginnings 2020).
} 
as marriage or birth certificates. At the same time, romance functions as a way for people to connect in a non-legal way as they get to know one another.

\section{i. Rule One: Following the Community Rules to be Successful}

I had the urge to impress Heather, who runs the MBS forum, alongside other senior members. She is well respected in the community and people seek her advice, and in a sense, she was the proverbial anthropological gatekeeper. If the interview went badly, it would impact whether other people wanted to talk to me. Fortunately, when I arrived at her house, she opened the door with a welcoming smile that put me at ease within moments. I quickly felt like an old friend sitting down at her kitchen table rather than a researcher collecting data. Over steaming tea mugs and biscuits, I felt the surrogacy community gates opening for me. Heather was forthright on the dynamics of MBS. No 'voyeurs just reading and not posting', 'journalists after a juicy story', and 'people with bad intentions' could join. If discovered, and Heather assured me she had dealt with all three of these 'types' of people, they would be kicked out immediately. This is to ensure that the group is a haven for its members who often share details of their lives that even their extended family or friends do not know. However, even though they get to know others who understand their experiences, it is still high stakes for intended parents. While there are other forums they might find surrogates, MBS is the busiest and thus most promising.

Early on in my fieldwork, it became apparent that my participants' language when discussing their experiences was reminiscent of my own experiences of searching for love online in the past. Although following rules and relying on feelings seem opposing, they work in unison. In the following sections, I examine the interplay between the two and highlight that basing specific processes and informal rules on familiar pathways that legally recognise relationships like marriage enables the formation of shadow-legalities. These make people within the surrogacy community feel more in control of the unknowns inherent in surrogacy. The informal rules that enable local shadow-legalities are not so much created as they are transposed from established approaches to love and procreation. They become something people practising surrogacy feel they have control over, underpinned by the assumption that if people follow the rules of what other, already matched, members did, they too might be successful. 
In the past few decades in the UK and US, there has been a rise in the number of official agencies that help facilitate matches between egg/sperm donor, donor recipients, surrogates, and intended parents. Alternative popular spaces include online matching forums for individuals and couples wanting to get to know their potential donor/surrogate in a more informal setting (Almack 2006; Mamo 2013; Nordqvist 2010). 'The internet is producing and expanding the possibilities for the queer intimacies that consolidate into new family forms' (Mamo 2013, 232). Jadva, Freeman, Tranfield and Golombok (2018) write that more and more people searching for sperm donors prefer to avoid the financial, legal, and practical costs associated with clinic donation ${ }^{125}$. According to Bjork-James $(2015,113)$ :

The proliferation of cybercommunities and computer-mediated communication has radically altered how we live, communicate, and gather, share, and produce knowledge. This is particularly true for families, as new media technologies have impacted how families form, interact, and understand themselves and the world.

As more people rely on digital cultures to help create families, offline and online worlds merge (Hallett and Barber 2014). Many new kin formations would not exist without the capabilities of the internet or groups that help facilitate connections ${ }^{126}$. Ethnographers are increasingly positioning online spaces and digital technology as objects of study and sites of 'circulations, reimaginings, magnifications, deletions, translations, revisionings, and remakings of a range of cultural representations, experiences, and identities' take place (Coleman 2010, 488). Those seeking matches on MBS unmake, create, and reimagine different family formations together, reinforcing the relevance of family and the nimbleness of its content. Although online environments can be spaces where uncertainty is heightened, be it matching with a potential romantic partner (Gibbs, Ellison, and Lai 2011), or locating a surrogate or intended parents (May and Tenzek 2016), they also provide a certain degree of creative freedom to users. This is mobilised in how people are encouraged to present a version of themselves to potential

\footnotetext{
${ }^{125}$ See Bergen and Delacroix (2019), Bossema et al. (2014) and Freeman et al. (2016) for more discussion on bypassing sperm banks for online informal sperm donor matching.

${ }^{126}$ In her ethnographic research on transnational surrogacy in India, Deomampo (2016) discovered that European and American couples who used Indian women as surrogates connected with one another online, bonding on their experiences, with some referring to their children, who had never met off-line, as 'cousins'. Deomampo stresses how Indian surrogates were narrated out of their roles and spoken about in terms of consumerism and not kin. This greatly reinforces the racial and class divide.
} 
matches, and when surrogates have the autonomy to 'stalk' those intended parents they are interested in without having to engage in private messages.

Both scenarios have high stakes because they have the goal of creating kin, in whatever way it may manifest. My participants, who were all seeking platonic relationships that would end in the surrogate gestating the baby for the intended parents, found the dating and romance terminology traditionally used in Euro-American contexts a helpful framework to describe their experiences and feelings. With more people wanting babies than those willing to be surrogates in New Zealand, I was curious about the specific process of finding a match on the forum.

Madison: On the site there's rules there. It's got to be the surrogate approaching the IPs. The IPs can't just ask surrogates "Will you have my baby?” That would be awkward.

Hannah: What is the process of finding IPs?

Madison: It's easier for the surrogates because when we join, we can look at all of the discussions everyone has had before and look to see whose personality we connect with, or who we want to know better. It's very matched like a dating thing. You see a couple you might like the look of. It is a relationship. You might tentatively say, "Would you like to meet for coffee or something? Have a chat?" No obligation.

Madison is a traditional surrogate who gestated siblings for her intended parents. Her narrative reveals the power dynamics at play for new members and how rules on initial contact off the forum impact surrogates and intended parents differently. Carl, an intended father via traditional surrogacy, told me that: '[For intended parents], it's not just good enough to log on, put up your advert, sit back and wait for the babies to roll in because it ain't gonna happen'. He refers to the unspoken rule: be active. Tina, an IP via gestational surrogacy, similarly stated, 'you have to actually make an effort and engage in conversations with other people and not come on and assume you'll automatically have someone go "ok I'll have your baby for you". [You have to] build up the rapport and friendships'. If a 'newbie' joins and claims to have read the rules but immediately posts an advertisement and messages surrogates privately, then Heather quickly removes both '[And I ask] them to read the rules to see what they did wrong. Usually, they apologise and its fine. Strike two, they are out, though - if they continue to try and message surrogates'. Enforcement of the rules is strictly adhered to to maintain a safe space 
for everyone and to protect the surrogates from being bombarded by offers. Offensive comments are also prohibited, and promptly 'deleted and dealt with via private message - [and the] member will get deleted if it happens again' (Heather). Heather was also quick to point out that 'I would never tell someone not to go ahead with someone - even if it's a huge red flag to me - I give them the information, and they can do with it what they will'. Heather's approach to enforcing rules and dealing with new and seasoned members demonstrates a maternal caring role that is also hierarchical and authoritarian. The need to remove messages and warn people when they break the rules also reflects the risks involved for members.

In the US context, Berend $(2016,22)$ found that respect is often gained by those who 'do their homework' and try to fit in. On MBS, intended parents must be patient, become invested in the journeys of others by commenting on their posts, and wait at least one month before they can put up their own advert inviting interested surrogates to contact them ${ }^{127}$. Being active and engaged with others on the forum allows surrogates to 'vet' potential intended parents from afar and signals the weight of such actions on reproductive opportunities. 'This part is affectionately referred to as "stalking", according to Carl. At the same time, senior members try to steer people in the right direction. Beth, a gestational surrogate, is a go-to community member when people have worries or questions. For her, it is vital that people do not rush into anything, particularly when it comes to traditional surrogacy, because this could have negative consequences for the relationships themselves and the wider surrogacy community. To stay in the community, they must follow the rules.

The power dynamic and initial rules can be daunting for some intended parents, even within the parameters of the rules. Celeste, who had a hysterectomy, but was able to keep her ovaries because of cancer treatment in her early 30s, found that even when she sparked up a friendship with someone on the forum, she felt too awkward to ever bring up the topic of surrogacy in case she was seen to be using someone just for their womb. 'In my reading of the law...surrogacy is something that you can't put pressure on anybody to do, so me asking anybody or even bringing it up is an indication of pressure, I think'. Although this central tenet allows people to have something concrete to do in response to any uncertainty they might feel, Sonia's experience reveals the anxiety this can create and how it may influence behaviour,

\footnotetext{
${ }^{127}$ Embedding their plea for a surrogate within their infertility story and invitation to contact them is a creative way of circumventing the formal prohibition on advertising and the disapproval of intended parents who want a surrogate but are unwilling to engage with others in the surrogacy community.
} 
particularly the intended parents. As Anna (an IP via traditional surrogacy) found, the pressure can take its toll, 'I would spend at least an hour [each working day], researching and creating relationships and working on my profile, encouraging others and being there for others, building relationships. All I thought about was surrogacy and the fear that no one would pick me'. This profile maintenance is reminiscent of dating sites and how people feel pressured to craft an ideal and attractive self. In the end, Anna left the site not long after, feeling discouraged. For Lola's second set of intended parents, beyond being active on the forum, they were lucky that others from the forum already knew them in real life:

With [my second IPs], she's super active on the forum, there are people that have met them, who knew that they were decent people... that was why I narrowed it down to them, but definitely being active on the forum was really important because you get more of a picture of who they are and the fact they're not just 'Hey I wanna baby come and find me!' kind of thing.

At the same time, some surrogates are aware of the unbalanced power dynamic. Lola was uncomfortable and worried that intended parents feel the pressure to say yes to any offer they get, whether there were red flags or not. 'For surrogates it's easy, there will always be another IP around the corner. That's why I [try] not to gloss over or make myself [look like someone I'm not], cause there's no point, I'd be wasting both of our time'. Still, surrogates also must negotiate unknowns, even if they have done it before, because each relationship is new. 'It may seem that IPs would be [more vulnerable] initially - IPs can be lied to, strung along, ripped off, but then surrogates can be lied to, strung along and ripped off just as much' (Heather). My participants shared that they feared that their IP might expect them to get pregnant after the first implantation of the embryo/home insemination and wondered if they will have support during the pregnancy and/or a difficult birth. The many unknowns between intended parents and surrogates produce co-dependencies on these informal rules that members must adhere to remain a part of MBS and hopefully have (re)productive surrogacy arrangements.

\section{ii. Rule Two: Taking a Leap of Faith}

I really liked them, so that evening [after the event], 'cause I never take long to do things, I emailed Celeste to say 'oh you know, I'm kind of in the market for an IP, and I really liked 
you and James and do you wanna get to know each other... and see if this is something that could work?' (Lola)

Alongside active engagement and making sure not to overwhelm surrogates, another popular piece of advice is to not 'jump into' surrogacy arrangements. According to Heather, if you go in with 'guns blazing,' there is a huge possibility it will go pear-shaped. Similarly, according to Beth, a gestational surrogate:

Yeah, when people have rung me from the forum, and they've met someone and they're gonna start and I'm like 'oh my god this is just a disaster waiting to happen. It's gonna ruin it for the other people as well'. Jumping into bed before you've said 'hello, yeah'.

Despite this, there was a contradiction between advice not to rush and the reality that for many surrogates, they choose their matches based on intuition and often quite quickly, as seen in the opening narrative. When Lola met the couple, who would soon become her first intended parents, she did not see any point in waiting because she felt they were a great fit. Heather echoed the sentiment, 'It's a feeling', referring to her instinctual decision to be a traditional surrogate twice. In the story at the start, Madison likened the first and second meetings she had with the gay couple she would go on to carry two children for via traditional surrogacy as 'kinda like love at first sight' ${ }^{\prime 28}$, adding:

[My IP] is so easy to talk to and we just seemed to have the same ideas about stuff. We met for dinner and coffee and stuff a few times, but I pretty much offered straight away... on our first date. I was easy.... I think I was probably quite lucky that they weren't weird.

According to Berend $(2016,66)$, in her research based on a surrogacy forum in the US, surrogates discuss the importance of getting to know prospective intended parents before deciding, yet conversely, at some level, 'a leap of faith' and gut instinct is privileged. She describes online conversations where surrogates use the phrase 'it was meant to be', and within

\footnotetext{
${ }^{128}$ While some people use romantic discourse when discussing searching and matching, there is no romance or sexual relations involved.
} 
the Israeli context, Teman (2010) similarly discusses how people rely on intuitive connections as a basis for choosing one another. In New Zealand, I propose that 'taking a leap of faith' functions alongside pragmatism as a rule because it helps members navigate notions of choice and calculation to find a match process. People are expected to engage in both pragmatically, like the intended parents not being allowed to contact surrogates, while relying on their own intuition to ultimately choose a match. Whether it turns out well or not is another factor, which I will explore in the discussion section below.

An example of combining intuition and pragmatism is when Tracey, a 28-year-old single mother of three girls, offered to be a traditional surrogate to Louise and Mike, who were in their early 50s. They had tried to carry a baby to term for many years, followed by using eggs from donors, without any success. I was lucky enough that when I flew into the region where Tracey lived, Louise and Mike were there for a scan. I met the latter two first, at a coffee shop the night before I was due to attend a local morning tea for those connected to surrogacy in some way, a gathering where I would meet several potential participants. When Louise and Mike arrived and sat down, they looked tired but had smiles from ear to ear, still in shock all these months later that Tracey chose them. Almost serendipitously, Louise was very close to withdrawing from the forum after no luck in finding a match, and then one day got a message from Tracey. When I interviewed Tracey the next day and asked her why she chose Mike and Louise as her intended parents, she was candid:

Aww Louise's posts, because I've read through quite a few different ones and initially I thought they were too old, they were outside of my age spectrum, but of all the comments I read, hers was the most upbeat, and she commented lots on other peoples' posts, so she was very supportive of other people and very involved and I was like well, her responses sound like something I would say, so I re-evaluated to myself, I was like well how much does age matter, and how much does it matter these days when people are living for longer anyway. With better health.

Despite initially thinking Louise and Mike were not a suitable match due to their age, Tracey changed her mind and offered to be a surrogate as a direct result of Louise's engagement on the forum. 
Given that my participants endure an uncertain and physically and emotionally intense journey together that eventuates in kinship being created, it was unsurprising to me that many describe their relationship with one another with intimate, romance terminology. Berend $(2012 ; 2016$, 65) and Teman (2010) identify similar ways surrogates compare matchmaking with intended parents to dating, where the language of love echoes a common ground, everyone is familiar with. 'This language, learned and internalized, creates both a cultural conceptualisation of surrogacy and a ground for action' (Berend 2012,914). Romantic narratives used by many surrogates and intended parents 'situate [their] interaction[s] in the intimate sphere, where baby making belongs' (Berend (2016, 67). Although Ragoné (1994) describes the use of romance terminology in her narratives, based on her anthropological research in the US context, at the time of her research, surrogacy agencies did the matching. Berend's $(2012 ; 2016)$ recent work is more helpful to compare with the New Zealand online surrogacy forum context. The public online group where she conducted her ethnographic research demonstrates a move from (or expansion of) an agency-focused organisation to a space where surrogates work collectively to talk about the cultural and emotional significance and implications of their roles. In particular, the surrogacy forum that Berend bases her research on has similar features to MBS, such as older members remaining on the forum to advise and guide newer surrogates. The informal rules provided by one societal framework - online dating - allow the constitution of another set of informal rules in spaces where kin-making via surrogacy is undertaken. In 'taking a leap of faith', both intended parents and surrogates participate in beneficial practices to all involved - in legal terms 'all parties involved'. This informal rule mobilises the online spaces and how they constitute contemporary shadow-legalities within the sphere of surrogacy.

\section{iii. Rule Three: Navigating 'Socially Acceptable' Norms Around Exclusivity}

Every day [I spoke with my IP]. It was midnight, I'm still in bed texting.

[My husband] tells me, 'Oh my gosh, you've got two marriages'. I'm like,

'Yeah, I do. Yep'. It was really ingrained. You go looking for someone that you can see this long-term relationship with, and it becomes like a second marriage. (Nora, a traditional surrogate)

Although some of my participants refer to the 'matching process' and beyond as having several possible 'ways' to happen, there are specific ideas about socially acceptable norms and appropriate behaviour that are assumed. Two related norms are the expectation of transparency 
around and exclusivity to current or previous matches. When members hide any information from their potential matches, it can make for awkward situations. For example, if people do not heed the unspoken rule of not dating anyone else while getting to know their potential match. However, to focus on one demonstrates that people are capable of commitment and taking it seriously. For Lola this meant:

Okay now we're exclusive kind of thing (laughs), I'm not looking for other people, for now, and I think if you were to try and say that straight up, say you're in a pool of people I'm looking at [it would be awkward].

Lola's views on exclusivity also extended somewhat to feelings akin to cheating when she offered to be a surrogate for her second couple. She did not want her first intended parents to take offence, even though their journey together had ended a few years previously. Similarly, Celeste, an IP whose two last embryos and implanting attempts with her gestational surrogate, Lola, failed before seeking a traditional surrogate, wanted to talk with the surrogate who carried their first baby, before she wrote about it on the forum. Not all intended parents and surrogates will feel this way. Still, it was a common expectation that no one would surprise or shock anyone they have previously embarked on a surrogacy journey with by publicly announcing a new relationship. Here we see how the language of dating is tied up with the language of cheating.

The idea of exclusivity is underpinned by the hope that this potential match could be 'the one/s'. This does not mean that it is a practice followed 100 percent of the time by everyone, but 'serial daters' are generally considered inappropriate by many of my participants. Heather also mentioned the bad manners of intended parents trying to match with a surrogate whilst on a personal fertility treatment. '[When IPs are] still trying other fertility avenues - [it] means they are not committed to only surrogacy/donor'. Instead, an expectation is that intended parents will enter the forum to commit to surrogacy and follow the established rules of engagement and etiquette. I found from talking to several surrogates that when they felt they could trust their intended parents, they really committed to wanting to help them. For example, Heather began her journey with her first intended parents as a gestational surrogate but offered to be a traditional one when this route was unsuccessful. Madison also prioritised the relationship and commitment to her intended parents over the type of surrogate she was willing to be: 
I was happy to do whatever method was needed, but it was more the matchup that was important. I think it's more important that you get on with your IPs and that it is a proper match. It is quite an intense relationship when you're trying to conceive. It was more like looking for a couple that I got on with rather than what a couple needed... [and] finding someone that I could trust that they would look after me [during the pregnancy].

Exclusivity is more than worrying about hurting previous matches but acknowledging the surrogacy children that are born. Heather highlighted the seriousness of relationships, claiming that in comparison to dating for romance, in surrogacy 'the stakes feel much higher for me. A child is involved, and I have to have supreme trust that it works out for that child - whereas dating, it's myself and my feelings and if there is a child from a relationship it is in my care with surrogacy the child is not'. Especially for those who create family via traditional surrogacy, being transparent with their previous and current/potential families means alerting everyone to the biogenetic kinship links created across families. Even if the adults involved do not see them as important, the children might. Nora, a traditional surrogate for four families, told me that the relationship breakdown with one of her sets of intended parents was because the intended parents did not want to acknowledge Nora's children as siblings, denying her requests for this that they agreed to before and during the pregnancy.

\section{iv. Rule Four: Mitigating Risk Through (Informal) Legal Contracts}

The emotional connection surrogates feel or wish to feel with their couple is linked to the fact that surrogacy involves a giving of oneself that in the modern Western cultural context is appropriate only in loving personal relationships. (Berend 2012, 926)

A lot (though not all) of these rules that engender forms of shadow-legalities around surrogacy draw from dating because they involve familiar protocols and rituals, which I will return to in the conclusion. Rule four diverges from these in through the creation of an informal legal contract, referred to as 'letter of intent', before any assisted fertility begins, to mitigate risk. Mnookin and Kornhauer (1979) introduced the aptly named term 'shadow of the law' to discuss the alternative ways of thinking about how legal negotiations happen outside of the courtroom in relation to divorce proceedings. Specifically, they argue that 'rules and procedures used in court for adjudicating disputes [can] affect the bargaining process that occurs between [parties] 
outside of the courtroom' (italics in the original) (Mnookin and Kornhauer 1979, 951). Although they advocate for people to be given more power to work more informally:

For those allocational decisions that directly affect children - that is child support, custody, and visitation - parents lack the formal power to make their own law. Judges, exercising the state's parens patriae are said to have responsibility to determine who should have custody and on what conditions. Private arrangements.... are possible and common, but agreements cannot bind the court, which, as a matter of official dogma, is said to have an independent responsibility for determining what arrangement best serves the child's welfare. (954-955)

In the context of surrogacy in New Zealand, with there being little structure to support nonnormative relationships compared to the nuclear family, those practising traditional or gestational surrogacy must go through state mandated processes to have the chance to present themselves at adoption arrangements. Intended parents are aware of what they must do and say to Oranga Tamariki to be recognised as competent adoptive parents. The surrogate must give a convincing performance of not being coerced into giving the baby up once born. Beyond this, intended parents and surrogates find ways to make the formal legalities as streamlined as possible. One process that helps some people navigate their relationships is the 'letter of intent', a technique utilised in the shadow of the courtroom to help facilitate the formal interactions with the law. In this section, I describe the way this non-legally binding document is used as a practical method to cultivate trust and establish expectations and boundaries. Regardless of whether a journey is a first or one of many, there is anxiety inherent in each match with new people, which can help ease.

On the forum, during the 'getting to know one another' period or soon after deciding to embark on a journey together, people are encouraged to write a 'letter of intent', that allows all parties to cement everyone's expectations. Often based on a template that members can access from the forum, it includes guidelines to the complex questions around how long they will try to become pregnant before giving up, the topic of congenital disabilities and abortion, and who will have the guardianship of the baby if the intended parents die. Oftentimes, this is done in the presence of a lawyer, and even though it cannot be enforced, nevertheless, it can serve as a source of security for everyone. In gestational surrogacy journeys, parties have a mandatory 
obligation to discuss their intentions with fertility counsellors, both separately and then together. However, the physical letter of intent seemed to be practised by both gestational and traditional surrogacy relationships. For Heather, it was an opportunity to have frank conversations with one another, 'I guess it's [also] to check they are on the same wavelength on big issues and that it is a way of memorialising that conversation'.

As a childfree traditional surrogate, it was essential to Joy that the letter be drawn up before any home inseminations took place because she wanted it to also function as a plan of sorts:

Joy: But you know, Pete, Sally, and I, before we did those first inseminations, we talked a lot, and we nailed down the letter of intent, and we got ourselves all on the same page as to what we would and wouldn't do, how long we'd try for, what we were prepared. You know?

Hannah: And what were some of those things that you decided?

Joy: We decided that we would try for six months, so once a month for six months, and at the end of that six months either party could change their mind. We also talked about termination because it was a big thing.

Similarly, Beth, a gestational surrogate, found it helpful as a map of sorts and reference point to refer to if needed: [We] sat down and wrote what we called a 'letter of intent'. So, we actually had it in writing the things we agreed on [even though] we didn't need any of it in the end'. Conversely, Lola thought creating a letter of intent was pointless. 'I always thought that as it's not legally binding, what's the point? We talked about everything. You've just got to trust the other party $100 \%$ either way'. Instead, Lola had frank conversations when her first intended parents visited her and her family for the first time. Even though the 'letter of intent' is not legally binding, it holds value for those who choose to write one. For Joy and Beth, it was a visual reminder of the collective decisions they made with their intended parents. It is a process that can establish greater trust, and an opportunity to walk away before any fertility treatment or inseminations begins. It can also create a sense of control over the uncertain aspects of assisted reproduction so that as they journeyed through, they could refer to their plan. In the US context, Berend and Guerzoni (2019), Berk (2015) and Jacobson (2016) all argue that both surrogates and intended parents appreciate the legally binding contract, seeing it as a form of 
protection and a positive way of documenting mutual expectations. Although they discuss commercial contexts, it was beneficial to all, and by mimicking a legal document, New Zealand surrogates and intended parents experience similar feelings of comfort. In addition, the 'letter of intent' in New Zealand, and legal contracts in the US, are discussed and refined on surrogacy forums in response to ongoing experiences (Berend and Guerzoni 2019). In my research, not everyone feels the need for the 'letter of intent' and found it was enough to verbally share expectations for the future. Lola's logic to not write one reinforces that regardless of how you establish trust, it remains fundamental to every step of the journey thereafter.

Despite it being a legally non-binding document, signing the 'letter of intent' itself in the presence of a lawyer highlights the formality by which all parties approach it. The letter is a useful example of how shadow-legalities such as informal legal contracts can hold the authority to those who create them, even if they are not enforceable. As much as it gives people an opportunity to ask difficult questions and establish boundaries with what they are (not) willing to do, it can help them to identify what may be beneficial to ask or write down ${ }^{129}$. Certain topics are difficult to broach, such as when to stop trying or who gets to decide on abortion. For example, while most surrogates believe the ultimate decision lies with the intended parents, some may not agree to abort a foetus. One traditional surrogate told me that she was not religious, but she would never have an abortion and believed that the intended parents signed up for a baby, regardless of whether they test for a genetic or health condition. Ultimately, in New Zealand, it is up to a pregnant woman to make that decision, surrogate or not, demonstrating the importance of intended parents and surrogates aligning in values during the matching process.

\section{Understanding Surrogacy Shadow-Legalities: Informal Rules and Kin-making}

These various informal rules guide and shape the lives and behaviours of members within the surrogacy community - sometimes mimicking informal online dating rules and at other times highly formal legal documentation mimicking marriage contracts. These informal rules operate as shadow-legalities, as different processes members can rely on to help them make sense of a practice that they have no reference for historically. These shadow-legalities are not extensive of every informal rule but nevertheless reveal nuances of the ways (un)desirable behaviour is

\footnotetext{
${ }^{129}$ When I discussed this with a lawyer, they told me that if there were to be a dispute in court, the judge may potentially take it into consideration, if not as the basis for their final order.
} 
regulated by more senior members within the community. These shadow-legalities equally refer to reproduction practised in the shadows of heteronormative conception and thus requires creativity to navigate successfully. They also exist in conjunction with, or because of, ambiguous laws around surrogacy. With no guidebook to follow, I propose that the senior members in the community have established explicit and implicit codes of conduct within which relationships are carefully crafted and cared for and sometimes only become apparent when things go wrong.

The four shadow laws I have identified in this chapter are encouraged and reinforced where possible by senior members. Rule number one, that everyone is expected to follow the forum rules to remain members of the MBS forum and access support and find a potential match, is underpinned by the assumption that if people stay within these specific parameters set out by moderators, they too may be successful. It functions as a pathway for new members and people to have a clear idea of (un)acceptable behaviour. Those who do not engage with others' stories or build rapport are much less likely to find a match because potential matches do not see what their personality is like or if they want to get to know them more. The specific rules around what constitutes inappropriate behaviour are considered more grievous, and moderators can enforce these by giving a warning to the member or removing them. All my participants referred to and reiterated the forum rules, even if they struggled with them like Anna, demonstrating how they become internalised. Conversely, Anna's experience shows that having very instructive rules can be anxiety provoking and may not always be helpful. Not being able to put the time required into being visible does not necessarily mean people are not worthy of finding a match.

Rule two, taking a leap of faith and trusting fate, is full of romantic imagery and hopes about building a relationship with others. This rule is more complex than rule one because it is based on an intuition that may or may not lead to a positive experience. I identify it as an informal rule because it is equally embedded in my conversations with surrogates and intended parents alongside more overt rules. It almost subverts the notion of a rule because it encourages members to ultimately heed their own intuition and heart when making decisions. It must 'feel' right, and we can see in Madison's case that she had pragmatic criteria but offered to be a surrogate to her intended parents on the second date because it was 'love at first sight'. Equally, Tracey chose Louise and Mike because she felt it was right even though her initial criteria was 
to gestate a baby for a younger couple. Rather than dismiss pragmatism altogether, this rule reminds members that aligning values works well in conjunction with emotional attraction.

Rule three is more about the socially acceptable norms people are encouraged to follow. Exclusivity is a crucial norm and relates to dating one potential match at a time rather than serially dating several people at once. Suppose intended parents are not transparent and are undertaking fertility treatment simultaneously. It is deemed disrespectful, especially because surrogates are in high demand and want to help people who have exhausted all other avenues before seeking one. Some participants emphasised the importance of talking with their previous matches first out of respect before they embark on another journey with a new person/s. Vulnerability can manifest in different forms, and these norms seem to be in place to avoid hurting others as much as possible. As mentioned in rule one, people are more likely to turn to the community for emotional support because they do not feel like their friends or family would understand, given how different surrogacy is to their experiences.

Rule four, creating a letter of intent as an informal contract by those who utilise it. All members can access a template that is on the forum and can ask others what they prioritised. The rule may not always be followed, but it is encouraged because it forces people to talk about complex topics, ask questions and to help establish boundaries and have a clear plan in place if difficulties arise. Signing it in front of a lawyer, even though it is not legally enforceable, still works to help formalise everyone's intentions. Ultimately, it is used to identify and mitigate problems before they happen.

\section{Conclusion}

In this chapter, to understand the complex world of assisted reproduction, technological or not, I have focused on surrogacy arrangements in New Zealand. I have introduced the concept of shadow-legalities to frame the discussion about the informal laws and processes that shape how people approach finding a match and form their relationships with one another to make kin in 'non-traditional' ways. They rely on the informal rules they co-constitute because there is no guidebook or reference beyond what others have experienced and learnt along the way, positive and negative. When new members see clear pathways to success, they may feel more in control. Unfortunately, as shown in Anna's narrative, which is most likely not the only one, the pressure to conform and engage so intensely with the forum was too stressful. Within Euro-American 
kinship ideology, narratives of love, dating, commitment, compatibility, and choice are often seen as essential pre-requisites to legally recognised unions, whether marriage or de-facto partnerships.

It is a space where reproduction is situated, and so, unsurprisingly, members of the surrogacy community in New Zealand rely on familiar terminology of romance and dating to contextualise their experiences in both the period of searching for a surrogate or intended parent, and the ensuing relationship that develops. Whether finding a match, mid-journey or after, members find it helpful to draw on their prior dating experience or knowledge to guide their behaviour in an unfamiliar situation. They transpose and reshape their understanding of other informally constructed spaces - like online dating - into the surrogacy community, and it ultimately helps them feel in control. Although Heather and other moderators emphasise that people should make up their own minds, many members make decisions or act based on how potential or actual matches engage with others on the forum and their behaviour off-line. In this sense, the informal rules co-constitute shadow-legalities that enable kin-making and reproduction in non-traditional ways. In many ways, these shadow-legalities dismantle heteronormative privileges and claims to reproduction and kin-making. Not all, but some - and that is the start of a journey that allows us to talk about assisted reproduction through nonnormative languages, rules, and laws. Ultimately, it is the rules that make the experience of assisted reproduction via traditional surrogacy and ARTs possible. Collectively, shadowlegalities function to make the formal legal process of adoption as straightforward as possible. Developing relationships, trust, and being clear about intentions all count towards the final goal - for the intended parents to be formally recognised as the legal parents. 


\section{Interlude Four - The Embryo Transfer}

\section{Part II}

\section{FIELDNOTES 17 May 2020}

As we waited for Celeste and James to arrive, Lola and I and were led to a small room with a table, computer and three chairs. The embryologist brought out the consent forms she had for Lola to sign to say she understood the dangers of the procedure. After doing the paperwork and deciding to get Celeste to sign her part on arrival, we were led to the treatment room adjacent to the embryology laboratory. The red sensor light was unlit, and at the press of the big black button to the side of the door, it opened. Inside, I found myself on the other side of the hatch that led to the lab. Looking around, I noticed the suction and resuscitation units, a sharpies container and other bits and pieces. On the wall next to the clock was six different laminated sheets of paper that went into detail about emergency care if required. Lola sat on the bed with her legs dangling over the side in her white gown until the nurse re-entered and told her to get comfortable. She crossed her hands behind her head and looked up at the ceiling. I noticed a CD player with a case entitled 'Golden Piano Music' next to the Sharpies container. 'They have music to accompany procedures', I said, to which she laughed saying, 'Pan Pipe Classics?'. 'No, just piano. I'm surprised they don't have both though!'

As we giggled, the doctor entered the room, shook Lola's hand, and then reached for mine. He said it was nice to meet me, and I indicated I was Lola's support person to make sure he knew I was not the intended mother. He did not recognise me from my previous tour and introduction. As he moved to the end of the bed towards the ultrasound machine, he said how frustrating it must be for Celeste. The nurse had already placed a sheet over the lower half of Lola's body, asking her to pull it down to show her stomach. The gel was squirted onto her skin, and they used the ultrasound machine to visualise her full bladder so that they could more easily visualise the uterus. 'How much water did you drink? I can't see much in there'. 'Heaps!' Lola replied. 'I think we should wait for another 10-15 minutes to see if it will fill up more. We really do need more visibility than this' he said, referring to the screen. Before leaving, he stopped and asked at what point Celeste and James were on their journey. 'They 
just arrived and will be getting into a taxi straight away'. The doctor stood thinking about it for a minute - 'It's so close and so special, we should wait for Celeste to arrive'. Then, as he pushed the black button to go out of the door, he said, 'let's call is our good deed for the day' and laughed as the door closed behind him.

Once the nurse had left, Lola took the phone she brought into the room with her to let Celeste know and keep track of them. Lola was still lying back on the reclining bed, and I took a photo of her for Celeste on my phone to record the moment. I then sat down on the stool, moving it further down the bed so that Lola could see me instead of being obscured from view. There was a familiarity in talking with Lola. At one point, she told me how her first intended mother had been public about her surrogacy experience, whereas with Celeste, her Facebook feed did not hold the details of the journey.

When Celeste and James arrived outside the clinic in their taxi, Lola was visibly excited as she relayed the news. The door opened not long after, and Celeste came rushing in. I stepped to the side as she leant down to give Lola a big hug. Both were tearful. 'I made it!' Celeste exclaimed. She turned to say hello to me, kissing my cheek and hugging me tight, 'It's so nice to finally meet you'. Full of nerves and excitement, Lola and Celeste reassured one another that 'the embryo was a good one', even though the first one did not thaw successfully. They said how they had been mentally anticipating maybe having to do this all over again with the third and final embryo. Celeste stood to the left of Lola, stroking her head, hugging her every few minutes. Finally, the doctor was called and came in, shaking Celeste's hand. She stood nervous, watching the screen, the doctor, and Lola - who was told to put her legs back up into the stirrups. The embryologist was getting the embryo ready we were informed. I motioned for Celeste to sit down on the stool and stood further back to give them space. I was cautious, wanting to take photos for Lola and Celeste, but also acutely aware of how it made the professionals in the room visibly uncomfortable. When I took out my phone to take a photo of the screen, I could feel eyes on me. 'You won't need to film it now!' the embryologist said.

Lola was told to scoot down the bed a bit more before the lubrication was reapplied to her stomach, and as the ultrasound glided across, the screen filled up with movement. The light 
illuminated the outline of forms that, like the pre-embryo transfer scan, were indecipherable. I presumed it was the bladder and uterus. Slowly, the doctor inserted the catheter containing the precious embryo - the thin tube visible on the screen as it entered the frame. Celeste was filming it with her left hand, with her right placed on the shoulder/arm of Lola, who brought her left hand up to hold Celeste's until the end. I felt tears prick my eyes, watching them. Although Lola was having the procedure, it was all for Celeste to become a mother again. The doctor said he would place the embryo up into the back of the cavity, and the nurse showed us where to look on the screen. 'It's the brightest light', the embryologist explained. And then, it was over. 'Our job's done now, the rest if up to nature ${ }^{130}$ ', he said, stepping away. Lola was told to stay in that position whilst the embryologist returned to the lab to inspect the catheter to be sure the embryo had been expelled into the uterine cavity. Moments later, it was confirmed as 'empty', which was the cue for everyone to sigh collectively.

'I don't need to stay lying down for this one?' Lola joked as she brought her legs down from the stirrups, referring to the home insemination she did when she was a traditional surrogate. The two women hugged again, more tears falling. I offered to take a photograph of them, and they stood hugging one another, smiling into the camera. A look of triumph mixed with excitement and trepidation. Once dressed, Lola accompanied Celeste to sign her postprocedure consent that was supposed to occur before the transfer. The embryologist brought in a printout of the 3-day embryo and said that although two parts on 9 and 3 o'clock had not thawed, the rest had, and this was a great sign. 'The embryo was attempting to hatch and move onto the next phase', which pleased Celeste and Lola. It made the atmosphere a bit jovial. After we entered the waiting room, James, who was holding their first two-year-old first child named Ella, born via gestational surrogacy, signed his consent. Celeste held up the photo of the embryo and declared, 'there's two dead bits but everything else is great and started to go onto the next part!'

\footnotetext{
${ }^{130}$ While embryologists and fertility doctors that I encountered in New Zealand were not religious, their acknowledgement that conception was not down to science alone, but also up to 'nature', reminds me of Roberts' (2012) portrayal of clinicians in IVF clinics in Ecuador who rely on both science and God's will.
} 

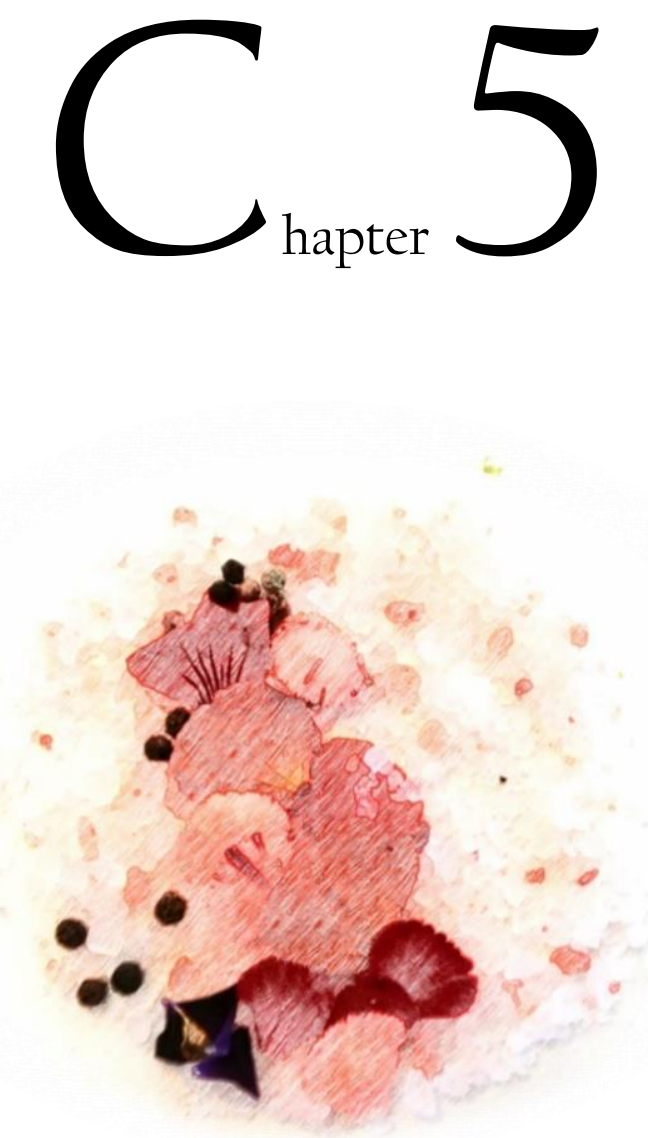

Figure 5 Shades of Pink in the Petri Dish. Pencil Drawing by Hannah Gibson

\section{Making Kin Under the Microscope}

As in other private health providers, a fertility clinic is where business and medicine merge, offering shorter wait times to access fertility specialists in a setting that is more pleasing to the eye than public hospitals. Softer furnishings and light change the sensory experience. Medical assistance without fluorescent strobe lighting - as many attempts at reproduction as your wallet allows, and if lucky, two publicly funded rounds of In Vitro Fertilisation (IVF). IVF is the most used assisted reproductive technology (ART), where the singular egg and millions of smaller spermatozoa (hereafter called sperm) are placed in culture media inside a petri (glass) dish and given the opportunity to fuse together in the first step of fertilisation. The embryology laboratory (hereafter referred to as 'the lab'), where I conducted fieldwork over a week in 2017 , is situated on one level and organised into the various spaces that reflect different stages of fertility care and treatment. Among these domains are multi-functional changing rooms, meeting rooms, a treatment/egg collection/implantation room adjacent to the laboratory, 
consulting rooms, administrators' offices, and a large break room. Collectively, in these spaces, an assemblage of reproductive processes occurs, producing a steady hum of actors all focusing on distinctive tasks, with frequent collaborative efforts as patients pass through each phase of their reproductive journey within the walls of the clinic. It is a humdrum of activity.

Beyond the fertility doctors in their pristine suits and ties that new and returning patients see when they enter the clinic, are a group of embryologists in their indistinctive scrubs that preside over the embryology laboratory in the back of the fertility clinic. Beyond the labyrinth of offices and clinic rooms, the lab is the hub, where techno-biological processes flow into and out of other clinic domains. More specifically, it is where technologies, reproductive material, hopes and dreams, and varying ideas of kinship collide. Everything is run in militarised fashion, and in the thorough preening and prepping of sperm and eggs (hereafter collectively referred to as gametes) before they are placed in a petri dish together in the hope of fertilisation, reproduction appears to be fully mediated by science, even down to making sure that the incubators which host the eggs and embryos between treatments or for hopeful fertilisation, mimic the temperature of the womb. Following Van de Wiel, (2018), the lab is an 'entanglement of cultural and clinical processes that reconceptualise reproduction time', where we see the 'temporal plasticity of cells ${ }^{131}$. Embryologists are among the few scientists who participate in direct care work and patients' treatment by guiding them through consent forms, egg or sperm retrieval, calling them with results, and to talk through any questions they have about their gametes and embryos. In their research with embryologists in New Zealand clinics, Fitzgeald, Legge and Frank (2013, 1290) describe this as producing contextualised engagement with their patients' reproductive material, which I propose later in the chapter is intrinsic to the sense of responsibility they feel in their work.

What fascinated me the most during this week was the interplay between scientific knowledge and the elusiveness of conception. While the former is the more obvious of the two when describing a fertility clinic, the embryologist's sense of care and responsibility, often peppered with jovial endearment where appropriate, was also influenced by the awareness that more often than not, IVF fails. As much as embryologists can technologically and manually mimic all the right conditions, they have no power over which cells will divide successfully and

\footnotetext{
${ }^{131}$ Van de Wiel $(2018,11)$ aptly describes a depiction of eggs which have 'been extracted because of [their] vulnerability to the passage of time and [are] now reframed as "literally frozen in time"".
} 
develop into viable embryos or even if they will result in a pregnancy ${ }^{132}$. Interwoven throughout these routines and processes is the care and time they take in looking after their patients at vulnerable moments in their reproductive journey. Zara, one of the embryologists, describes the paradox of embryology: '[it] is a career that makes you acutely aware of how difficult it is to fix fertility issues while making you think that, sometimes, it is possible to fix'. Seen this way, it is a technology of hope, and calculated risk, and from the periphery of their patients' journeys, they too 'await each test with the same 'balance' of hope and preparedness for failure' ${ }^{133}$ (Franklin 1997, 274-275).

It is highly likely that if someone comes to see a fertility doctor for ARTs, they will also interact with other health care providers within the same clinic, including an in-house fertility counsellor, nurses, and embryologists. In gestational or clinical surrogacy, they will certainly find themselves transitioning between medical professionals and embryologists. During my fieldwork, most of the heterosexual couples I got to know have experienced ARTs at some point in their journey, either themselves or during their gestational, or clinic, surrogacy attempt. Gestational surrogacy has multiple processes, of which the embryology lab is part, and as argued throughout the thesis, different actors at different points, to varying degrees, contribute to the practice of making kin via surrogacy.

In this chapter, I show two things. Firstly, the embryology laboratory is one of the several spaces where we see the precariousness of reproduction at the microscopic level. Scientists can do everything perfectly and still have no certainty that a pregnancy will be achieved. For the embryologists and their patients alike, it requires embracing the unknown, as there is a sense of how close every assisted reproduction moment is to technological defeat ${ }^{134}$. Or success. Further, there are those stories in the shadows of the clinic that will not be made visible under the microscope. My research is as much about realising those intended parents who are missing

\footnotetext{
${ }^{132}$ The happenstance of ARTs makes me think about Ahmed's provocation of the 'hap' in 'happiness', or in this context, the idea that ARTs can lead to a baby (and thus a happy outcome), or not. To have a sense of the happenstance would involve being open to the possibility of good and bad things happening' (Ahmed 2010, 219).

${ }^{133}$ I have re-used Franklin's (1997) original depiction of IVF as a technology of hope to think about how it is enacted within the laboratory.

${ }^{134}$ The phrase 'technological defeat' is not a term that participants used, but my own framing of the way technology can defeat or stop peoples' intentions to create a family using ARTs. Rather than reflect an absolute defeat, it is often a stage in the reproductive journey, a moment that forces people to regroup and consider their next move. Technological defeat is always a possibility, linking in with Franklin's (1997) framing of IVF as a technology of hope and potential failure.
} 
from narratives as about those who are visible. Secondly, I highlight the intricate kin and care work embryologists engage in, from the direct engagement with the gametes and embryos in the petri dish and in the moments of transition and attentiveness in the lab. These show how the embryologists are part of the many actors who undertake kin-work in the surrogacy journey. I propose that the awareness of the elusiveness of reproduction more generally and preciousness of embryonic developmental stages helps embryologists cultivate a sense of care and nurturance towards the gametes and embryos, and by association, the patients they interact with as part of their job. Their care becomes the mechanism that marries the world of science and the art of (re)producing life, as they remain in the shadows and unseen.

\section{Entry and Unfinished Fieldwork}

'Hannah wants to do some observation of a lab, much like Jane Goodall would do'. (Peter, my main contact at the fertility clinic) ${ }^{135}$

In the week I spent in the lab, I mostly observed embryologists at work and had multiple conversations throughout the days that emerged organically. The benefit of observing for 8 hours a day was the opportunity to see them at their busiest and more relaxed moments and get a feel for the flow of the people and reproductive material as they moved around the lab. I also spent time in their shared office and within the breakroom, where other clinic staff congregated at breaks and lunchtimes. Following Fitzgerald and Legge (2017), I focused on the material culture of the IVF laboratory, including the tools, techniques, and routine tasks, and 'the delicate rhythms of biological science that made the collection of boxes, benches, microscopes, computers, telephones, and reagents a 'laboratory' slowly became understandable' (Fitzgerald and Legge 2017, 141). This chapter is a partial view of what I learnt and saw during this week. In a country with just over 5 million people, my biggest challenge in all my ethnographic depictions was to anonymise people and places as much as possible to respect their privacy. In the case of the fertility clinic, Fertility Associates, my initial contact was happy for me to use his name and any personal correspondence. To try and protect the embryologists featured here I have chosen to not reveal which out of the six Fertility Associates clinics I conducted fieldwork in.

\footnotetext{
${ }^{135}$ In her book Born and Bred, Janette Edwards writes of one of her informants looking anthropology up in the dictionary and then thinks that Edwards is studying them like zoo animals.
} 
Between August 2016 and 2018 I visited the branch of Fertility Associates six times in my capacity as a researcher. The first few were tours and introductions to the key medical specialists, nurses, managers, counsellors, and embryologists. The rest of my visits were split between supporting one of my key participants, Lola, in her journey as a gestational surrogate, and in turn meeting her husband and children as well as the intended parents (which I write about in the interlude between this chapter and chapter six, Shadow Mothering) and then the week of participant observation in the lab in August 2017. For the latter, either a sign that I blended into the background or that I was not considered important enough to remember, the fertility specialists and embryologists I had already encountered during my attendance with Lola at different stages of preparation for the implantation, did not recognise my face on my first day of fieldwork. My experience of accessing the laboratory to do fieldwork was challenging. During one of my tours in 2016, I met Ana, the lab manager, for a few minutes. Due to my fieldwork schedule, we discussed my getting in touch the following year to organise fieldwork. In her reply to my email in March 2017, although Ana was not openly hostile, I sensed that she was not entirely thrilled. The emails we exchanged over a five-month period detailed how 'under-resourced and oversupplied with work', (Ana, email communication) they were, making it a challenging and potentially disruptive time for the embryology team even without an observer. I would retreat and then re-email when Ana suggested I do until we finally confirmed that I could visit the laboratory and meet the staff to discuss what I wanted out of the experience.

If I was not so interested in the technology behind gestational surrogacy, I might have taken the hint and not pursued this field site. Instead, I clung to the fact that Ana was happy for me to observe 'some time'. Initially, we spoke about my going consistently over 2-3 months, which turned into one week to see how it went. At the end of the five days, just when I began to feel comfortable, I got an email from Ana saying how much they had enjoyed the time I spent with them but that their schedules were becoming more intense, if that was possible. They were nervous at the idea of having an observer regardless of how quiet they are. Although I had witnessed just how hectic it was during that week, I was still upset when I read this, mainly because it meant I would not even be able to say goodbye, or even hand in my visitor badge they had given me. It felt unfinished, and for a day or two, I did wish that we were of an era where I could do the mundane jobs of washing things to help out as I learnt the way of the lab and not constrained by policies that disallowed anyone untrained to help. Now, three years later, I realise how ego-centric my feelings were. During writing up and making sense of my 
notes, a light bulb went off: Ana's rejection of my being there was another demonstration of her custodian care that I write about below.

\section{The First Day and Fitting In}

On my first day at the lab, I encountered Ruth, one of the senior embryologists, making a hot drink in the large and sparsely furnished breakroom. A task that I would take on during my stay, the morning ritual cup of tea or coffee was the quiet reprieve before everyone began their day. The receptionist had told Ruth that I would be here. 'We are busy and short-staffed', was her second sentence after telling me that my main contact, Ana, the laboratory manager, would not be in until the next day. 'I could leave', I offered, unsure if Ruth was hinting at this - but no, she said it was okay and offered me a hot drink. It did put me on alert, though, to be quiet and self-aware of every noise or movement I made within the laboratory, and less so in the adjoining office used by the embryologists. Decked out in a t-shirt, jeans, and trainers, I was unsure of what the dress protocol was, but thankfully Ruth offered to show me where the scrub trousers and tops were at the morning tea break. 'It will make you feel less awkward when you're dressed like one of us. And it's more comfy than normal clothes'. I readily agreed, thanking her. Each unit in the building had its own attire, with the private male doctors all wearing suits, while the female nurses had similar outfits to the embryologists.

Tea in hand, I followed Ruth as she set off down the hallway with numerous rooms branching out on either side of us. She stopped at one door on the left, that was near two large white doors with a light situated above it that I later learnt could be turned on to emit an amber glow, the signal not to interrupt the treatment inside, and if necessary, to enter with caution. On entry into the small embryology office that housed five desks, I sensed the hum of activity already, with two junior embryologists, Zara, and Jana, getting organised for their morning routines. Ruth gestured to the empty desk that the donor coordinator uses, which was free that day because she was off. I quickly placed my cup of tea down on a coaster, next to a pen and small unused notebook with the words 'Gibson. Fieldnote 1, Fertility Clinic. August 2017' written in black ink on the cover. I placed my small backpack under it, thankful to have a space to avoid the awkwardness of trying to not impose on anyone.

\section{Kin-making Under the Microscope}

In the lab, humans come into the closest proximity to sperm and eggs (referred to collectively as gametes). When you enter the room, big tanks of frozen 'normal' sperm, HIV sperm (with 
a label in red to set it apart), eggs, and embryos frame the andrology section on the left as you enter from the embryologist's office. The shape of substantially large BBQ gas canisters also takes up space in the egg and vitrification (freezing) stations, some protruding from under the benches. It is impossible not to notice them no matter where you are. In their five locations throughout New Zealand, Fertility Associates houses 90,000 straws containing frozen sperm, eggs, or embryos (20,000 of which are embryos) stored for 9500 people at any one time. 'Roughly 3500 people stop storing each year (i.e., use their frozen embryos, use or discard their frozen sperm) and another 3500-start storing each year' (personal communication, John Peek, Fertility Associates). Although New Zealanders are legally allowed to store frozen embryos for ten years, people frequently get an extension at the end of that time. This is different from the commercialised US fertility industry, where there is usually off-site storage containing thousands upon thousands of embryos, eggs, and sperm. In theory they have no expiry date. In the lab, caring about the reproductive outcome is mobilised in the analysing, prepping, and preening of eggs and sperm from the moment they arrive to make sure that they have the best possible chance to fuse and begin cell division. Below I describe the composition of the egg and the breath-catching moments of seeing them for the first time under the microscope during egg collections. In these snapshots, we see the embryologists relating both to the eggs and the hopes of their patients as they lie next door sedated. Each of the three sub-sections focuses on eggs, sperm, and embryos.

\section{i. Mimicking the Womb and Giving Nature a Helping Hand}

Every morning, embryologists go through a checklist of things they need to do before beginning egg collection or embryo transfers scheduled. Firstly, they check the temperature of everything. It is crucial to have a working temperature of 37 degrees Celsius, body temperature, and the cultures themselves. When eggs/embryos are placed into incubators, the PH of the culture media is also maintained at $37 \mathrm{C}$, the same $\mathrm{PH}$ of a womb. The incubators are one of the most essential pieces of equipment in the lab because it is where eggs and embryos spend most of their IVF journey as fresh or thawed eggs/embryos ${ }^{136}$. They are delicately placed inside onto the heating pad and taken out with the utmost care. When eggs/embryos come out of the

\footnotetext{
${ }^{136}$ Fresh refers to eggs or embryos that have been collected recently and not undergone slow freezing or vitrification (a flash-freezing process). 'Thawed' eggs/embryos have been frozen and since thawed. Thawed embryos undergo FET (Frozen Embryo Transfer), where the thawed embryo is transferred into the uterus lining.
} 
incubators for any specific work, they are placed on heated stages, which also maintain optimal temperature. Regardless of what the equipment does, the underlying logic is to maintain the equilibrium and retain the viability of the eggs/embryos. A drop in even one Celsius can have significant disruption to fertilisation. These honed techniques and equipment mimic the womb and hold the eggs/embryos ready before they can be implanted into an actual womb or frozen in that optimal state using liquid nitrogen.

\section{ii. Egg Collection}

Eggs, also known as ova (plural) or ovum (singular), are reproductive cells. A rudimentary explanation is that it is made up of the haploid nucleolus right at the centre, a distinctive oval surrounded by several layers that aid the fertilisation process. These include the egg cytoplasm, cortical granule, egg plasma membrane, the vitelline layer, and protein receptors. They are surrounded by the zona pellucida a jelly-like impenetrable coat that acts as a barrier to sperm. Typically, a woman is born with a store of all the eggs she will ever release in her lifetime, and each month the pituitary gland releases the luteinizing hormone (LH) and follicle-stimulating hormone (FSH) which stimulates the ovaries to produce oestrogen and progesterone that prompt ovulation, or the follicle to release a mature egg. In IVF, she is given hormone stimulating drugs to increase the number of follicles to release more than one egg, which is then retrieved via egg collection. This next section follows two egg collections with different outcomes.

During the morning on the second day, Ana brought me a chair so I could sit next to her at the egg collection point of a privately funded patient. Directly in front of us was a hatch in the wall that, once open, reveals a space between the lab and the treatment room where egg collections and embryo implantations occur. During egg collection, the vials are passed through the hatch in the nurse's hand. Ana took it and deftly tipped the yellowy-reddish follicle fluid between two petri dishes, as her other hand reached for a fresh dish to lay out for the next vial. A dance with repetitive steps, she showed no hesitation. Tip liquid, fresh dish, examine container, extract each egg with a pipette and drop them onto a pre-heated, to 37 degrees Celsius, flat square dish. After dropping the eggs, Ana placed two more clear dishes to her left, as she discarded the follicle liquid to her right - and by then, the next vial was being handed through the hatch. More searching for eggs. During these automatic movements, she leaned over slightly to peer into the microscope directly in front of her. As she found each egg, she called 
out the number through the hatch to the fertility doctor and nurse (I assumed that the patient was sedated). 'That's ten from the first side', she called through, confirming how many eggs one ovary produced, before going onto the next. After going through the same process, Ana called 'final count is 31 ' through the hatch ${ }^{137}$. Without looking up she asked me, 'have you ever seen eggs?', before moving to the side so I could look through the microscope. They were like fluffy clouds, which ironically reflected their official name of cumulus ${ }^{138}$-oocyte complexes (COCs), or the layers of tiny cells called cumulus cells that surround the egg. Later, Ana stripped this cumulus for the fertilisation process.

When Ana began the next collection that morning, all I could see through the hatch was the doctor's yellow shirt and the patient's feet, lying on the bed. She had red nail varnish on her toes. 'First egg', from the first vial. Quietly, so only I could hear, Ana explained that this collection is on the opposite end of the spectrum to the first. 'She only has two follicles'. Egg number two was called, and more follicle fluid, which resembles thin blood, goes into the hazard bag. Silence. 'Final count is two', Ana said out loud, and glanced at me. We are both thinking the same thing. That is very different to 31 . She moved to the left again, silently inviting me to look into the microscope again, explaining that the two eggs have a darker surrounding when compared to the first specimen this morning. 'That means she has been hit with a lot of drugs and it has gone into these two follicles, and they're a bit so-so'. Ana looked sad. Somehow, seeing the patient's red nail polished toes was incredibly intimate, as if I was an unintentional voyeur. I looked away. Sadness prickled at my senses, giving me goosebumps. I had my back to the hatch to give her privacy, aware that she would be leaving the treatment room with the news that the gruelling drug regime she had been through prior to egg collection produced only two. All the medical appointments, examinations, hormones, injections, and likely adverse symptoms ended in an anti-climax of discarded follicle fluid. Now she had two possible chances of fertilisation. I reminded myself that two eggs do not mean this woman would never have an embryo, and eventually a pregnancy and birth of a baby. There was still hope. Yet she is still described as unlucky by the embryologists, both because it is likely she has a low AMH and any future attempt would probably produce similar results, and because

\footnotetext{
${ }^{137}$ If there are over 20 eggs, then they are automatically 'freeze all' which means that the woman is at the risk of ovarian hyper stimulation, and it is too dangerous to place any embryos back. Overstimulated ovaries can compromise the quality of the eggs, leaving less viable ones for fertilisation. Everything is about viability here. Plus, the patient may suffer more from pain.
}

${ }^{138}$ A type of cloud 
even though technology becomes more sophisticated with time, there is still a large percentage of eggs that are not seen as viable, either before they are frozen or after they are thawed out.

\section{iii. Sperm}

By lunchtime on day one, one look at my fieldwork notebook showed rushed acronyms, foreign words about gradients, and quotes about the various lab apparatus. Alongside this, I was now semi-familiar with the sperm section, or andrology section where sperm is processed and readied for whatever place it goes next; into a vat filled with liquid nitrogen to freeze it or to be used for fertilisation on the day it is provided. The sperm section became my spot when I was not observing elsewhere, and from the stool I sat on I could see the entire length of the lab. Although an essential space, I could be relatively out of the way here because it was at one end of the room, with a table island jutting out around six feet from the wall, creating two workspaces on either side. One was used to clean, spin, and count the sperm, all daily jobs. The other side, where I sat, had apparatus that was used less often - and some drums containing liquid nitrogen and from gametes and embryos.

I had never given sperm as much thought as I did that morning. As I actively worked at staying invisible by not saying anything and breathing softly, I heard Ruth ask without looking up from the microscope, 'have you ever seen sperm?' Caught off guard, my brain went blank, and I replied, 'what, you mean ever? Or under the microscope?' Immediately I realised how obtuse this sounded as she clearly meant the latter and stepped to one side, inviting me to look. This, she told me, was an example of 'good' sperm. Peering into the microscope, I saw the minute sample, only a few drops of semen, come alive as fireflies danced around before my eyes. Small spermatozoa (meaning sperm, with the singular spermatozoon), with quick and agile mobility, wiggled. like tadpoles. 'And what does 'bad' sperm look like?' I enquired. 'When some of them look almost paralysed'. 'So, this is what men mean when they say they have 'bad swimmers!' I realised out loud. Their spermatozoa either swim, do not, or struggle to. The embryologists require 10 million spermatozoa per mil to go ahead for use in IVF. 
There is a sensory element to working with sperm, perhaps because as noted above, they move under the microscope, in comparison to eggs. They have three components, the tail (or bottom piece), the midpiece filled with mitochondrial that provides energy and is responsible for the

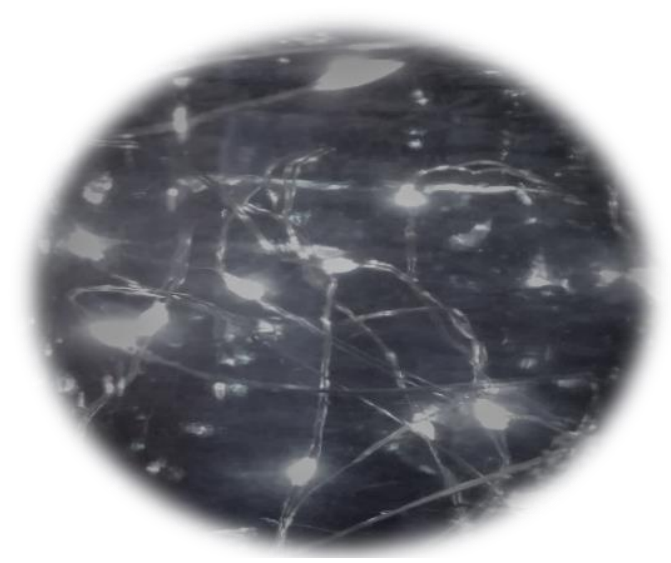

Figure 6 Recreating Sperm as Fireflies: Photography by Hannah Gibson 'swimming' action, and the head covered by a membrane known as the acrosome. In this current state, they cannot fertilise the egg and must go through several changes. After the embryologist notes the viscosity, she places the lens containing the semen under the microscope to check their motility and proceeds to click on a tab next to them to count and register how many she sees in this sample, Towards the end of the week, I was sitting in the office with Jana. I heard the clicks, identifying them out

loud. 'It didn't take you long! Then soon you'll know if the sperm are quick or slow by the speed of the counting' Jana responded. Next, they must 'spin the sperm', which is literally what the name suggests, to separate the different densities into layers, referred to as 'sorting the sperm'. After placing the canister of sperm on a frame that spins clockwise, sperm homogenises because it is naturally quite gelatinous. 'It's like a concrete mixer', Ruth said. This analysis is a pre-IVF treatment, and they check again on the day of treatment to make sure it still has a good number and mobility. Under the microscope, when sperm has been spun, washed, and then homogenised, it looks completely different than before. Pre-spin, the microscopic view reminds me of what they show in television programmes. A few that are static and then lots quite visibly swimming around. Afterwards, the liquid appeared more concentrated and only contained the 'good' ones.

If eggs and sperm are to be frozen, once cleaned and made ready, they are gathered into tubes called straws and inserted into tanks filled with liquid nitrogen, each straw containing either $0.5 \mathrm{ml}$ of diluted (or clean) sperm or one egg or embryo. Although they all end up in tanks, sitting side by side, I noticed differences between the prepping of sperm and eggs. During the egg collection, the embryologist sits at the hatch and counts eggs, one by one, as they tip out each vial of follicle liquid. Each found egg is called out, and when only a few, they are even more valuable. Not all patients have access to publicly funded fertility treatment, and if they do, this could be their last. Similarly, a woman may have a low egg count that increases the likelihood that she will be lucky with one of these eggs or will have to consider another egg 
cycle if she can afford it, or contemplate searching for an egg donor. Whereas with sperm, they have a vast amount per sample and unless there is little or no sperm in the semen, no surgical retrieval from the testes is required. Unlike egg collection, no drugs need to be administered either. While male factor infertility can impact up to 25 percent of couples, the assessment, washing and spinning to increase chances of fertilisation are more robust with less delicate handling. The embryologists that Fitzgerald and Legge (2017) observed consider sperm-work as low-status, with eggs considered much more precious due to the far smaller amount and greater efforts in procuring them.

iv. When Sperm and Egg Meet

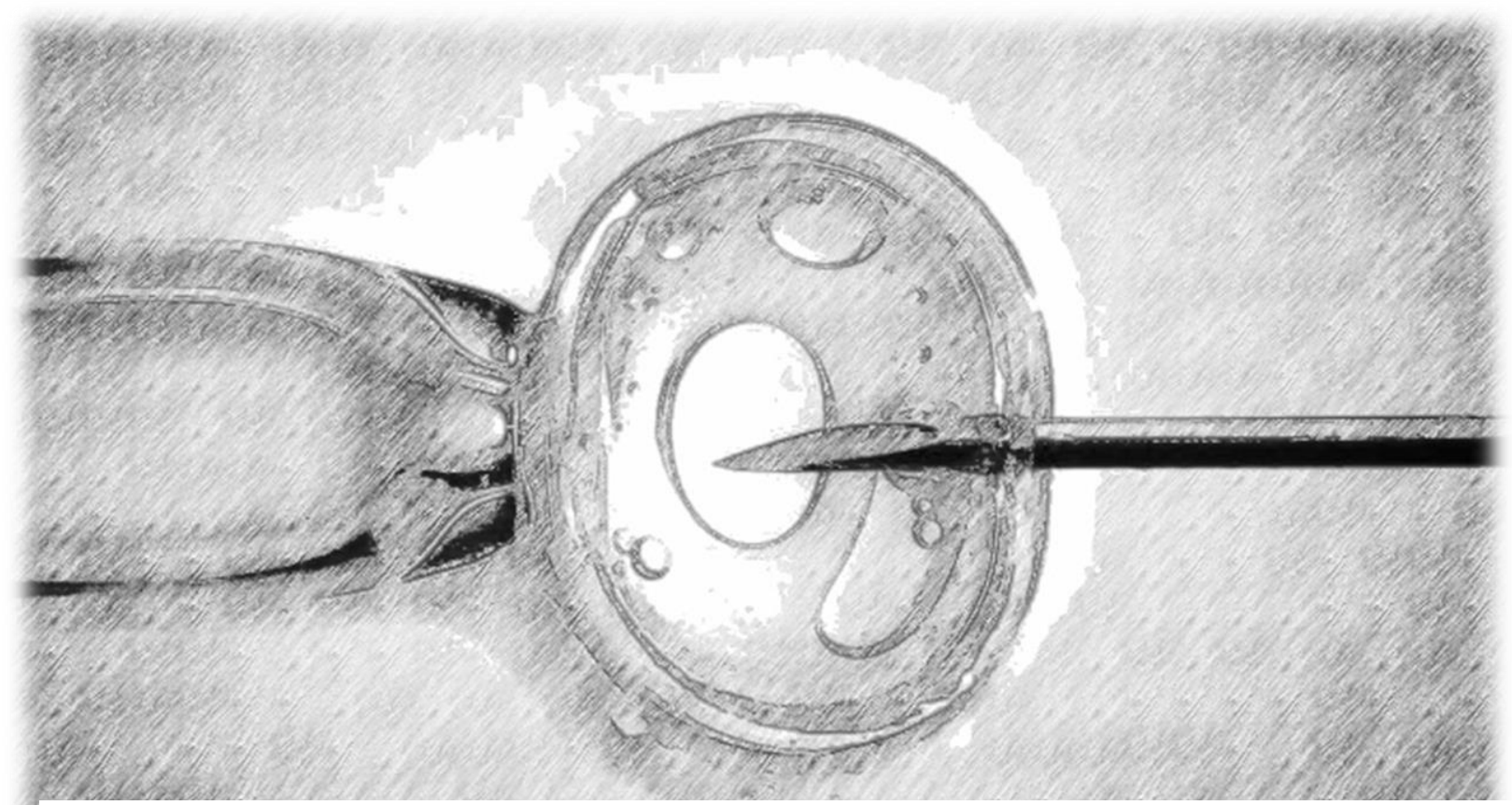

Figure 7: ICSI. Pencil drawing by Hannah Gibson

Ana carried the petri dish of with both hands, one on bottom and one on top. A gentle and fluid movement. Fertilisation involves either fresh eggs and sperm collected that same day or thawed sperm and eggs that have been frozen in the liquid nitrogen. After they are prepared or thawed, eggs are individually placed into the petri dishes containing culture media. For IVF, the prepped and best sperm is placed in the culture alongside the egg followed by careful transfer of the petri dishes to the incubator. The day of egg collection is known as Day 0, with the next day entered as Day 1 because it is the first day for a fertilised embryo. 
'We used to think that the cumulous cells dictated what happened to the egg, but now we think it's the egg itself dictating', Ana explained as she performed ICSI. She stabilised an egg using the needle in her left hand, whilst piercing it on the right side. She pushed the already

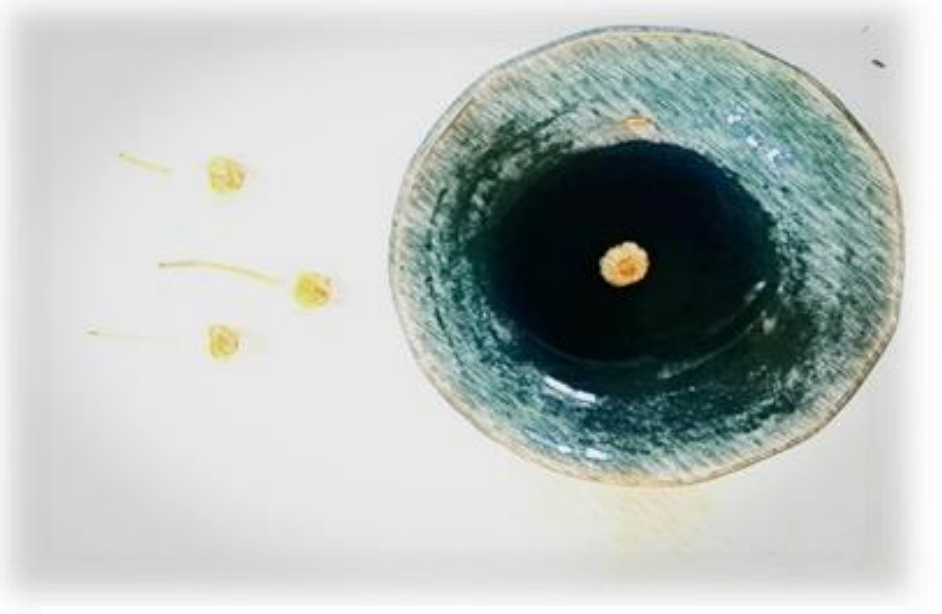

Figure 9: Foregrounding the egg to change the script. Pencil drawing by Hannah Gibson immobilised sperm (by gently knocking the tail against the side of the disk) to the tip of the needle and sucked up cavity fluid from the egg back into the needle to gently flush the sperm into the centre of the egg.

Once all ten eggs were finished, the petri dishes went into the incubator. 'We no longer believe that the sperm chooses the egg', Ana continues. The traditional narrative that has dominated both biological and popular accounts of fertilisation is of the sperm's heroic journey, racing millions of other sperm to be the first to reach and penetrate the egg. The egg is passive, waiting expectantly, and the sperm does the hard toil. Familiar to all kinship studies and anthropology of reproduction scholars, Emily Martin's popular paper published in 1991 describes the way cultural gender stereotypes shaped scientific accounts of the behaviour of eggs and sperm. Her reading of classical medical texts written by both male and female scientists uncovers the use of words and metaphors that discuss the processes that sperm and eggs go through in vastly different ways. While texts were enthusiastic about sperm, evoking the idea of abundance and heroic endeavours of victory, a woman's body was described as wasteful, even though in a forty-year reproductive life, only four hundred to five hundred eggs are released in comparison to the 100 million of sperm men produces per day. Yet her eggs have

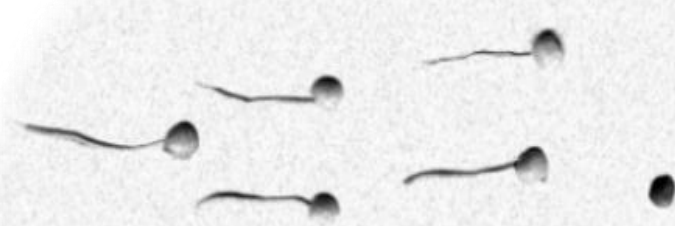

Figure 8: The gendered script of the heroic and the passive egg. Photography by Hannah Gibson been rendered passive actors in reproduction. 
More recently, Campo-Engelstein and Johnson (2014) point out the continued use of sexist language in contemporary scientific accounts of reproductive processes. 'Yet, what was strikingly problematic was the omission of information on the egg, particularly the active role it plays in fertilization' (201). The geneticist Joe Nadeau (2017) describes genetically biased fertilisation, whereby interactions between sperm and eggs are not entirely randomised. Instead, he argues, that eggs and sperm woo one another with specific genes, debunking the scientific myth that eggs are docile. Rather than the woman's role in reproduction is over after coitus, her eggs are active participants. Hence in the petri dish, eggs similarly choose the sperm unless ICSI is performed. In its original form, the sperm cannot bind to the egg's zona pellucida, the jelly-like coat that surrounds it. This protein-rich thick fluid is thought to contain chemical signals that attract the best quality of sperm by activating or triggering the sperm to release the acrosome in a motion of decapitation that helps the uncovered nucleus adhere to and enter the egg. The cortical granules then fuse with the egg plasma membrane to make the vitelline layer impenetrable again to avoid polyspermy, or other sperm from entering. In this account, the egg is the one that manipulates the change in state of the sperm $^{139}$.

\section{v. Picking the Good from the Bad}

During my time in the lab, I was drawn to the time-lapse machine, or Time Lapse Morphometry Imaging (TiMI) Embryoscope machine ${ }^{140}$, which is essentially an incubator that uses timelapse photography to monitor embryos. Every morning I approached it to see how the embryos looked in comparison to the previous day. In traditional IVF, or ICSI, the petri dishes containing one egg each and sperm are placed into incubators maintained in an environment with a specific temperature of $37 \mathrm{C}$, humidity, $\mathrm{pH}$, and gases (such as carbon dioxide, oxygen and nitrogen). Embryologists open the incubators once a day to take out each petri dish to look under the microscope to discern the fertilisation rate, embryo morphology, and whether the

\footnotetext{
${ }^{139}$ In a reading of the video depicting the first successful IVF attempt made by the IVF pioneers Patrick Steptoe and Sir Robert Edwards, Dow $(2019,204)$ writes, 'Edward describes placing the egg in the culture medium as 'putting it home' and declares that 'now the egg is safe'...[later] when he then 'introduces' the egg to the sperm...the reversal of gender roles from standard biological descriptions of fertilisation is not remarked upon, though Edwards's does announce, 'in she goes', as he released the egg'.

${ }^{140}$ Heralded as one of the most important technological developments, an Embryoscope has revolutionised the image of the embryo, and couples who use this can have a photo of their baby's 'first cell division' or mid-development of the embryo in addition to the six-week scan. It is typically used for patients where an earlier IVF cycle was unsuccessful, if the patient had low quality embryos previously, or if there are expectations that there will be several good embryos to choose from. The cost per cycle is NZD\$975 per cycle, not cheap but also not the most expensive 'add on' available.
} 
cells are dividing appropriately in number and shape. Two downsides of this approach are that every time embryologists open the incubator, they disturb the internal environment ever so slightly, so they work quickly. Secondly, they are only documenting the form and morphology of the embryo every 24 hours. In contrast, the microscope and camera inside the TiME machine take a new photograph every 10 minutes to show the temporal development markers from the moment the cells begin to divide. This way, embryologists can annotate and determine minute changes in the cells that may not be visible at the 24-hour point. For example, nuclei can appear and disappear again within a day. Cells can divide and reverse the process, which are early development features that may impact the viability of embryos and something only a timelapse detailed snapshot can provide. Ultimately, having access to this information without disturbing the embryos is incredibly valuable.

Embryologist's use descriptors to code the quality of gametes and embryos. 'Good' eggs refer to those that are looking healthy under the microscope once denuded. 'Good' sperm has good motility or movement and at least 10,000,000 in number per sample, and 'good' embryos have cells that have divided in the expected way, and allocated grades, ascending from ' $\mathrm{A}$ ' downwards. However, this does not necessarily mean that a well-developed 'A' grade embryo will be successful. Burns, Hammond, Cree and Morbeck (2020) describe how blastocyst grading is a relatively subjective process, especially because although odds are smaller, 'low' quality embryos (graded low) can lead to live births (Cimadomo et al. 2019), and perfect looking blastocysts could fail to produce a pregnancy (Irani et al. 2017). Equally, embryologists must use their clinical judgement on which embryos to implant. Although grading systems are based on several morphological parameters ${ }^{141}$, it involves interpretation by individual embryologists. For example, one morning, when Ruth checked fresh embryos for transfer under the microscope, she only had two to choose from. 'One is further along but more abnormally developed', she said, signalling the difference between the rate of maturity and cell division or embryo development. Ruth called Ana over for a second opinion, who advised that she go with the first, despite the abnormal cell division. 'Poor girl', she said, to which Ruth replies 'she's only 33', referring to the patient. Ana sees me there and explains that they have chosen the more developed embryo even though 'it's not the prettiest' because it will have a better chance than the under-matured one that may signal a developmental issue.

${ }^{141}$ There are multiple grading and classification systems, with no consensus within the scientific community about which is the better one (Racowsky et al., 2010). 


\section{Tender Interactions and Custodianship}

'How about we play some John Legend ${ }^{142}$ He puts [the embryos] to sleep nicely,' Jana said happily. 'His voice is smooth, and he lulls the embryos to rest', she added for my benefit. A daily ritual, Jana and Zara were discussing what music would accompany their vitrification (flash freezing) of the embryos. 'You wouldn't use his music to wake them up, though. You'd want to use Queen or something with a bit of "ummph" for that', Jana continued. Even though they knew that it was the liquid nitrogen that freezes embryos, immediately and quickly, their use of analogies of care and gentleness reflects a level of tenderness they feel towards them. Of gentle coaxing. Other songs sometimes played during thawing include 'I will survive' and 'staying alive' 143 .

There is a rhythmic feel to the hum drum of the lab. New days see familiar and well-practised movements of embryologist's bodies and hands. For example, each task is thought out and based on pre-determined procedures and protocols. They require a second embryologist to 'witness' and check the details on vials to be sure the right ones are going into the incubator until they are needed. It is a streamlined and fast-paced environment that also requires meticulous attention to every small detail. Like an intricate dance that relies on every step and movement happening at the right moments, it requires the attentiveness of the dancers themselves to move as if they have always known the choreography while not becoming complacent. The embryologists are familiar with routines ${ }^{144}$ and tasks, as they call 'at your back' to alert others as they move from one bench to another with a petri dish containing eggs or embryos. Both hands protect each dish, above and below. At a conceptual level, in her ethnography, Making Parents: The Ontological Choreography of Reproductive Technologies, Thompson introduces the term 'ontological choreography' to refer to and help make visible (or in the word of Strathern, literalise) the 'dynamic coordination of the technical, scientific, kinship, gender, and emotional, legal, political, and financial aspects of ART clinics....it is a deftly coming together of things that are generally considered parts of different ontological orders (part of nature, part of the self, part of society)' (Thompson 2005, 8). Their bodies

\footnotetext{
${ }^{142}$ John Legend, a famous singer, is well known as a 'family man' so this choice seemed apt. Coincidentally, his supermodel wife, Chrissy Teigen, signed an Instagram collaboration with a small New Zealand company that specialises in breast pumps called Haakaa (Stuff 2019).

${ }^{143}$ Fitzgerald and Legge (2017) describe a similar personification of the embryonic material.

${ }^{144}$ This learned choreography of the space and routines are central to navigating childcare and domestic life.
} 
instinctively know what benches are safe to lean against and ones that are not, as we see when I accidentally did this. These gametes and embryos become known as more than names and details in medical charts. They are connected to the people who are seek the embryologists' help.

Embryologists become translators and mediate between the collections of gametes and the bodies from which they originate ${ }^{145}$. And those they may go into in surrogacy. It is these moments of connection with patients that give the embryologists another layer of responsibility ${ }^{146}$. Spending time with patients is a key part of their work, and they inevitably become invested in the different reproductive journeys with which they are entangled. This is reflected in how each embryologist tries to follow 'their' patients through as many of the processes as possible, even when their work is done. Ruth revealed that knowing someone's story, meeting patients, talking them through egg collection, and embryo implantation, gives her a sense of ownership and motivates her to do a good job. Fitzgerald, Legge and Frank (2013) argue embryologists are akin to health-care workers by virtue of their engagement with the patients. While most health-care staff have one object of care, embryologists must deliver significant care to patients and their reproductive material, which as mentioned, they become custodians of. These contextualised interactions underpin their sense of responsibility custodianship towards the gametes and embryos ${ }^{147}$.

This investment in their patients' journeys often overlaps with nurses 'jurisdictions', who are the ones that call patients with the pregnancy test results. At $2 \mathrm{pm}$ on the third day, everyone was in the office when Zara began calling out pregnancy results off the screen to her colleagues. They are always genuinely excited if someone has a positive result. I asked if they have a list they go through every day, and Zara explained that although the patients have now progressed from the laboratory care, they like to keep up with the outcome for statistics and their personal

\footnotetext{
${ }^{145}$ In trying to situate reproductive material in connection to the laboratory objects and patient's bodies, I am inspired by Elizabeth Roberts' 2012 ethnography on IVF clinics in Ecuador, in which she highlights the relationality and network of attachments that exist between things.

${ }^{146}$ Another unfairly attributed layer of responsibility may also come externally. Fitzgerald and Legge (2017) write of the tendency for doctors and nurses to solely blame embryologists for the fertility rates dropping, rather than acknowledge that their input can contribute as well.

147 'The continual exercise of self-responsibility was also a quality associated with the work.... demonstrated in a variety of ways, including the capacity to maintain documentation even when working under pressure, to regulate one's internal psyche when engaging in meticulous work such as ICSI, to be relied upon to maintain commitment to excellence' (Fitzgerald and Legge 2017, 158-159).
} 
curiosity. 'There will always be ones that you're more happy for, maybe ones that have had a lot of bad luck, or if they are extra lovely'. This moment links clearly to the previous day when one of the embryologists came into the room and said that 'so and so are bringing in their baby - I hope the nurses tell us when it happens so we can meet them too'.

\section{Conclusion}

Technologies are made by people in particular contexts, they are developed by people in particular contexts, and they are used

by people in particular contexts. (Dow 2016, 10)

When I first thought of the lab as an option to conduct fieldwork in, I saw it as a bounded site and less complicated than travelling around the country to meet and spend time with surrogates, their families, and intended parents. From the outside, this bounded space is the umbra of the fertility clinic. Objective and controlled, with clear and rigid boundaries within which the embryologists work. Yet once there and spending time in the penumbra of the lab, it was clearly more driven by care, not just for the 'materials' for reproduction but from who those materials came and the children that those materials might become. In this sense, the boundaries are an act of care rather than (just) control. Thus, rather than being un/bounded, the umbra could be seen as cold and rigid. Yet, the care-work and kin-making they perform reminds us that routines create a sense of security, fairness, safety, which is all very human and humane ${ }^{148}$. One of the central intentions of this chapter is to show what I have learnt since my early perceptions: the lab is not defined by boundaries but by lack of them. Not only do the gametes and embryos flow in and out, so too do the stories of the individuals and couples they belong to. The embryologists themselves become implicated in these journeys as well. On any given workday, embryologists assist in different kin-preserving and kin-making processes. To achieve the desired outcomes of their patients, they utilise technology and their instinctual expertise to preen, prep and monitor gametes and embryos and choose which ones to use for transfer. This is done to preserve good quality gametes and viable embryos to give their patients the best chance possible for success. At the same time, they do this knowing from experience that even the 'A' grade embryos do not necessarily result in a live birth.

${ }^{148}$ Of course, there is a gendered element to this. 
I am conscious that in this laboratory, it is an all-female embryology team, who are integral to kin-making via ARTs and surrogacy. When I was given scrubs to wear to blend in with the others, this was in stark contrast to the male fertility specialist who wore a colourful shirt and tie. Even though my focus was on embryologists, he was visible not solely through his attire but also in his authoritative role as 'the doctor'. Several times during the week, he and another fertility doctor would pop their heads around the door and ask if the embryologists 'have time' to show a medical student what they do. One memorable request was annexed with 'show them something cool', to which the embryologist muttered under her breath so no one bar I could hear it, 'like we have time'. This reminds me of what feminist scholar Deniz Kandiyoti (1988, 286) refers to as the 'patriarchal bargain', which 'is intended to indicate the existence of set rules and scripts regulating gender relations, to which both genders accommodate and acquiesce, yet which may nonetheless be contested, redefined, and renegotiated'. The female embryologists did not openly resist the doctor's requests and deferred to his authority, which Kandiyoti argues is the contradictory nature of negotiating with men in male-dominated institutions. The bargaining the embryologists make is in asserting their autonomy and authority regarding their own expertise. They also seemed to find it less stressful to humour the doctor and allow his student to observe occasionally, but they still maintained the lab as their space. From this perspective, the doctors must also defer to their knowledge when running the lab itself. This constant negotiation and tension are never reconciled but rather continually renegotiated. While I cannot be certain, seeing the embryologists as they fiercely protected the gametes and embryos they worked with, I do believe that if there are days when an observer could mean the difference between doing their job right and making a mistake, they would refuse the doctor's request that his student sees 'cool things' in the lab.

On the surface, it may seem that their job is one purely of scientific processes and procedures, and secondary to the fertility specialists who, as we have seen in chapter two, send the application for each gestational surrogacy arrangement to the Ethics Committee for Assisted Reproductive Technologies (ECART) that either approves, rejects, or defers the application. Instead, embryologists spend more time caring for patients and their reproductive material than other medical professionals in the building do. They must pivot between the lab and the treatment rooms, and as this chapter shows, they are engaged in the precariousness and intimacy of (re)producing kin vis-à-vis ARTs. This interplay between assuredness in the science and elusiveness of conception is most visible in the quotidian moments of the lab. They see failure, and potential success, at the cellular level as they peer into the microscope, in the 
sounds of the counter they click as they check each spermatozoon for motility, as they annotate embryos that have spent three days in the TiME machine, in their checks to see if fertilisation has occurred, and in the pregnancy test results which they give to the patients. Although they understand the potential implications of their work, for the technologies to work, or not, interacting with their patients contextualises the stories of their reproductive material. This is especially evident during the egg collection and the visceral disappointment I witnessed in the drop of Ana's shoulders and change of tone as all her searching of petri dishes filled with follicle fluid only resulted in two eggs. She knew what it meant to the patient.

I propose that care of their patients and their reproductive material becomes the mechanism that marries the world of science and the art of (re)producing life. Some of the moments I have described make visible the tenderness with which they care, like the deftness and preoccupation of keeping the equilibrium within incubators. In this way, they become guardians of the eggs and embryos, engaging in shared kin-making. Meaning, one may work on egg collection and denuding of the eggs, another may prepare the sperm, yet another may place both into the petri dish. This requires them to trust and support one another. In particular, they mobilise carework, seen in how they treated eggs and embryos under the microscope and during moment of transition, which being fiercely protective and untrusting of anyone else that may venture into the lab. Running as an understaffed laboratory, their mantra was 'minimal distraction' so that they were less likely to make any mistake, particularly because some patients may only have one or two embryos. We see care also in the terms of endearment, sometimes jovial, towards the eggs and embryos, throughout their routine tasks.

These snapshots of ARTs in motion signals three crucial things that add nuance to the understanding of gestational surrogacy and what it represents. Firstly, the care-work that embryologists perform supports my point that kin-making via surrogacy involves input from several actors at different times. What defines gestational surrogacy, apart from the surrogate gestating a baby for another, is the unseen work and expertise of embryologists who enact a custodial sense of care and participate in the kin-making. Secondly, it reminds us of the nimbleness and precarity of ARTs, and what happens behind the scenes, giving context to those stories of intended parents trying to create a family this way.

Thirdly, it also highlights the politics of reproduction concerning gestational surrogacy. In chapter two I argue that choice to reproduce this way is always linked to the options that are 
available rather than only reflective of the level of need for these technologies. For example, the gametes and embryos that are seen under the microscope come from intended parents who either qualify for funded ARTs or can afford them. Oftentimes, those who end up doing traditional surrogacy do so as a last resort, due to technological failure or inability to meet the ethical, medical, or/and financial costs associated with gestational surrogacy. Some of these intended parents have already been through the clinic, and the embryologists have worked with their gametes and embryos before, and likely been disappointed on their behalf, sharing the sad news if the blood test at the two-week stage was negative. At the same time, conceptually, those who have been severely restricted or entirely denied access to the clinic, including gay couples until 2015, those who require both an egg and sperm donor, those who have over a certain BMI, are Māori ${ }^{149}$, single women, or those who do not qualify for funding, are the unseen, and the 'othered.' They must create kin in a more shaded part of the reproductive penumbra, unable to participate in the technological innovations available. Throughout the week, I also found myself thinking about the technological opportunities (un)available to preserve my fertility, which added another dimension to the term 'precarity'.

\footnotetext{
${ }^{149}$ For example, we know from statistics that Māori are not accessing ARTs as much as Pākehā, which Glover (2008) and Anderson, Snelling and Tomlins-Jahnke (2012) argue is part of a more general lack of preoccupation for any fertility barriers Māori may experience, as well as wider systemic disparities.
} 


\section{Interlude Five- Embryo Transfer}

\section{Part III}

\section{FIELDNOTES 10 May 2020}

James shook my hand when we were introduced, and they invited me to join them at a visit to Te Papa and hang out. I felt awkward at the thought of intruding on their time together, but Celeste said I was welcome and 'part of the journey'. I offered to take everyone in my car, as Ralph had already left earlier with the two boys. Declining, they decided to walk because I did not have a car seat. I went to get my car as they walked down towards the museum. For a moment, I felt frustrated that I had no energy to walk with them, and how I would have enjoyed it. When I parked at Te Papa five minutes later, I grabbed the box of cupcakes and went inside to locate Lola, who texted they were making their way to the café from the giant squid exhibition. I soon found everyone outside where the kids were running around. Soon Celeste arrived with tea for everyone, and we all stood eating cake.

When the A4 photo of their embryo was not folded up neatly inside her bag, Celeste brought it out a few times, holding it gently with both hands. She took a photo of it to send an electronic copy to Lola, and then it arrived in my inbox a few days later after she added me as a friend on Facebook. Once we all drank our tea, Lola's boys asked to have a look at it. 'Do you think it's a boy or a girl?', one asked. The youngest responded 'a boy! Definitely a boy'. They asked if I could take a photo of them all. The two families stood together, with Lola and Celeste holding either side of the printed embryo. The photograph of the embryo showed the morula, hazy shaped circles with blurry yet distinct edges. Not yet a blastocyst, which occurs when the embryo gets to day five, the embryologist's description of it on the cusp of hatching signals growth, development, and viability. A chance. The scene of the embryo held up proudly for the photograph signals the coming together of the two families. The visual depiction of a disembodied conception. Then, just as the initial photograph the embryologist took of the embryo immortalised it, the one I took re-immortalised it.

This imagining or contemplation of what the embryo will become was coupled with how everyone made a conscious effort to note that this embryo would work, and that no future 
visits would be required. No talk of the third and final embryo, of going through the gruelling drug cycle to make sure Lola's body was ready. On one level, this narrative appears as a product of hope, a decision to be positive. As if any doubt would break the spell. I write 'spell' because of how the fertility doctor referred to the next stage of IVF being 'up to nature', using technology to produce a viable embryo. Ultimately, once in the womb, no one can predict if it will work or not. This experience contrasts greatly to when Lola was a traditional surrogacy. In a later conversation, she said, 'it's a relief that I don't have to "listen to my body"'. Knowing that the embryo was in her womb made her relax a bit, even though she knew there was no guarantee she would get pregnant. Alongside having a firm date to have the pregnancy blood test, she felt like it was entirely out of her hands.

A few days after the transfer, Celeste added me as a friend on Facebook. 'How are you feeling?', I asked in a private message to her. 'Tired!!!!!!!'. When we caught up on Skype a week after we met in person, Celeste was hopeful that the blood tests Lola would have on day 14 post embryo transfer would be positive. We spoke a lot about hope, and how on the one hand it is quite an abstract thing, and on the other, hope alongside the desire propels plans and dreams of what the future may look like. Of course, she was filled with worry, but saw this as part of the rollercoaster of the surrogacy experience. 'If I felt really withdrawn from it and not being worried, then it's like, maybe this is not something we really want or need, but I think it's shown us that this is something we want and are pretty stubborn about it'. Celeste did contemplate what they may do if this and/or the last embryo did not work. She was unsure of her anti-mullerian hormone $(\mathrm{AMH})$ levels, which can help indicate how many follicles a woman can produce, and thus their potential response to stimulation.

Not long after this interview, I got separate messages from Lola and Celeste that the embryo did not lead to a pregnancy. When the final embryo was transferred, this, too, had a negative result. Unfortunately, Celeste's AMH levels were very low, and although they attempted to stimulate her ovaries and collect more eggs, it did not work. In the end, they eventually had a baby via traditional surrogacy with a different surrogate. Lola went on to pair with a new couple, and after a miscarriage, she carried their baby, whose first birthday was being celebrated at the beginning of the thesis, to full term. 

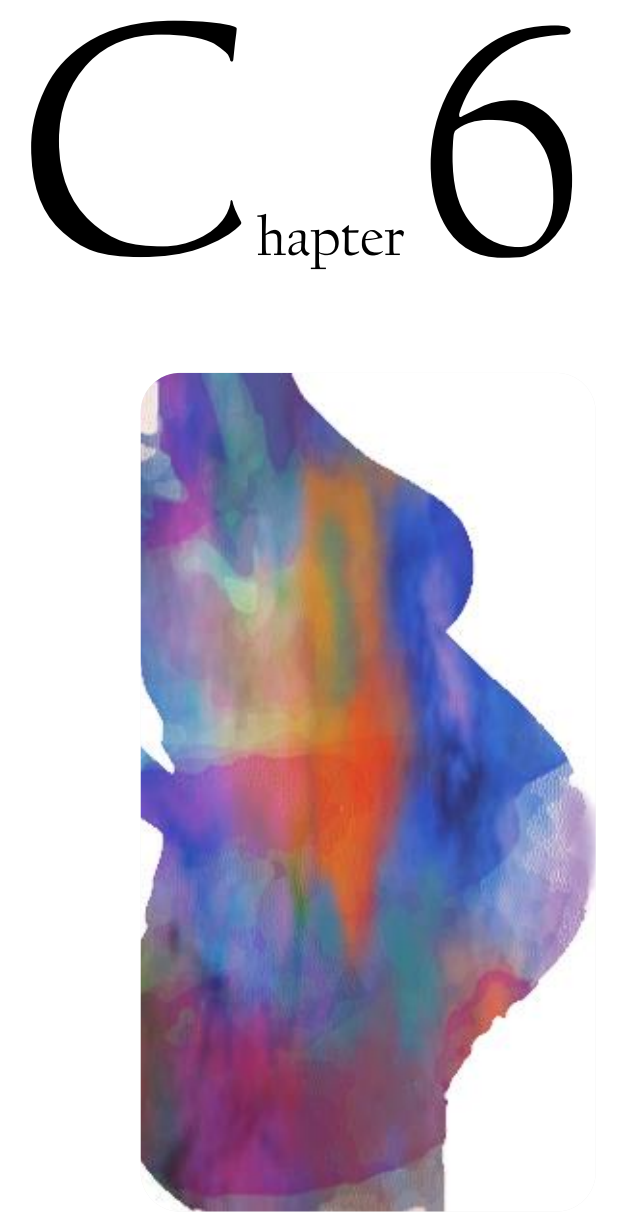

Figure 10: Babysitting. Watercolour by Hannah Gibson

\section{Shadow Mothering in the Home in Aotearoa New Zealand}

On a trip north to meet some intended parents and surrogates, I met with Ruby's second intended mother, Moira, for whom she carried via traditional surrogacy. Moira was single and could not achieve a pregnancy herself. When I visited her in her home for morning tea, her two-and-a-half-year-old daughter spent a moment looking at me with interest before she played on the two stairs that led from the dining room up into the cosy living room. Moira's eyes lit up when she glanced over to see if her daughter was a bit too quiet or potentially getting into mischief. Like Ruby, Moira spoke of the partnership between the surrogacy journey and the navigation of different outlooks (Moira is Christian, while Ruby is not). Part of the success, Moira said, was that she and Ruby embraced the uncertainty and vulnerability that is part of surrogacy. When I asked Moira how she referred to Ruby, and what kind of role, if any, she 
had in their lives, she told me, 'I'm trying to find a new language to talk about the surrogacy relationship, because I think calling your surrogacy, your surrogate, to me doesn't explain [it]. It's not nearly as relational as it should be'. Moira chose the term 'genetic benefactors' for the sperm donor and Rosie, stating, 'I never want to lose sight of the gift [she gave me]'. However, Ruby felt like 'genetic benefactor' downplayed her role. Although she told Moira she was hurt by it, Moira preferred it. Unbeknown to Moira, Ruby had already mentioned it to me the previous evening, expressing her discomfort at the thought of being referred to as a genetic benefactor. She compared it with her first set of intended parents who called her the 'birth mother' in front of others, which was equally uncomfortable:

'To my mind, I'm not a birth mother, because to my mind 'birth mother' is a whole different thing that I'm not. I'm a birth mother to my babies. [And in the case of genetic benefactor] (laughs), that was slightly more removed than Id have liked but there's a medium [ground] somewhere I'm sure.... I'm fine with [being called a] surrogate. But maybe you could invent a term! I'd like that'. (Ruby).

It can be complex negotiating relational terms in the unique context of surrogacy, where the 'mother' can involve up to three women (the intended and social mother, the birth and legal mother, and the egg donor). While Moira did not mean any harm in calling Ruby a genetic benefactor, in the latter's eyes, it diminished her role in helping to create Moira's role as the mother. At the heart of the disagreement is that Ruby felt her part in making kin for Moira was greater than supplying an egg, and the term 'birth mother' did not sit comfortably with her either. In this chapter, I explore the tensions that can arise during the pregnancy as intended mothers, and surrogates, often navigate new terrain.

As argued throughout the thesis, different people at different times take on kin-work to create via surrogacy. In this chapter, I focus on how surrogates enact what I refer to as a type of 'shadow mothering'. As discussed throughout the previous chapters, surrogates do not see themselves as the mother of the baby they gestate for others and believe that it is the intention to parent that 'makes' the parent. Other surrogate researchers are critical of referring to the surrogate as a mother figure in any sense of the word, to not give her a title that she herself is uncomfortable using. I refer to surrogates as shadow mothers or practising shadow mothering because, as mentioned, they represent a facet of motherhood required to gestate the foetus. I 
use the term 'shadow' to reflect this - the 'quasi' mother, but not in any way the mother. Everyone goes into it with a pre-determined intention they accept and work towards: that the intended mother is the mother, regardless of how many women are involved in creating the baby ${ }^{150}$. This does not in any way suggest that they are seen as, or feel like, the central 'mother'. Instead, to support the intended mother in her own journey, some surrogates and intended mothers utilise the fragmentation of the 'mothering' role to their advantage by working together to ensure that the intended mother is the 'only mother' the child will know. Importantly, in using the term shadow mothering, I acknowledge and invert the idea that there is the mother, and all others must fade away for this to happen.

The pregnancy, relationships, and narratives are never static in surrogacy but are determined by the flux of ever-changing dynamics between the intended mother and surrogate as they inhabit the reproductive penumbra. As mentioned throughout the thesis, this is a nebulous space where multiple shadows are layered and interconnected, including the shadow of colonisation, the shadow of the modern state, and shadow-legalities. It signals both the idea of making kin and mothering in the peripheries of mainstream Euro-American kinship, and navigating institutional, legislative, medical, and intimate landscapes. In the context of making a mother, surrogates and intended mothers readjust how the scene is set up as they continually renegotiate the surrogate's shadow mothering enactment without reducing the centrality of the intended mother as the mother. Relying more on the conceptual articulation of the reproductive penumbra, I examine the interplay between light and shadows to represent in/visibility of the surrogate and intended mother as it is choreographed in each scene (even if not intentional) ${ }^{151}$. This, to use Strathern's term, 'literalises' the creativity, tensions and challenges that can arise as part of the process and how well they are navigated, or not. I refer to surrogates as shadow mothers and as practising 'shadow mothering', not to reframe the surrogate's role as a mother, but to make visible the kin-work that represents an important facet of motherhood. Regardless of how many women have been involved in the creation of the baby, the intended mother's position is not in dispute, even though they are not legally recognised by the state as a parent until they adopt the baby. Showing how kin-work and mothering takes place in the shadows,

\footnotetext{
${ }^{150}$ This links in with chapter three where I discuss surrogate's motivations and focus on the intent to explicate their ability to gestate a foetus for others rather than biogenetic links being the basis for kinmaking. See Berend (2016), Teman (2010), Ragone (1994) and Ziff (2017)

${ }^{151}$ Here, 'light' refers more to the societal expectations of mothering, and 'shadows' to demonstrate the ongoing interactions between surrogates and intended mothers
} 
problematises the exclusive nature of motherhood, while celebrating the plurality that is part of surrogacy.

\section{Shadow Kin-Work}

Based on research from the 1990s, Macdonald $(1998 ; 2011)$ explores the micropolitics of interactions inside the linked lives of middle-class mothers in the US that chose to work and the nannies or au pairs they hired to help take care of their children. Macdonald coined the term 'shadow mothers' to help explain the mother's expectation that the child-carer will step into her shoes as much as possible without taking the place of the mother or primary caregiver:

\footnotetext{
'Shadow mother', [is] an extension of [mothers] who would stay home as if she were the mother, but who would vanish upon the real mother's return, leaving no trace of her presence in the psychic lives of the children they shared, and making no claims to mothering knowledge or skill. (Macdonald $2011,110)$
}

The working mother's desire for an au pair/nanny to act as a 'shadow mother' is born from what MacDonald calls 'blanket accountability', which refers to mothers' feelings of accountability no matter where they are, at work and home- and, in turn, in the child's life. Their decision to work out of choice, rather than necessity, is vilified by society and media for relinquishing maternal duties (MacDonald 2011). This narrative highlights the pressure on mothers to do all the 'mothering' roles successfully, and by not being able or wanting to, they are deemed 'bad' mothers. Hay $(1996,8)$ coined the term 'intensive mothering' to describe the 'underlying assumption that the child absolutely requires consistent nurture by a single primary caretaker and that the mother is the best person for the job. When the mother is unavailable, it is other women who should serve as temporary substitutes'. Macdonald argues that the mothers' expectations and treatment of nannies/au-pairs as 'shadow mothers' to their children is a way the mothers themselves can engage in 'intensive mothering'. At the same time, Macdonald $(2011,131)$ found that mothers and nannies/au pairs had different expectations of how the 'mothering work' would be divvied up. Often the mothers wanted the nannies to be an extension of themselves, the epitome of a (shadow) mother. One nanny felt like she did the 'prep work' for 'the commencement of real family life'. In addition to working in the shadow of the real mother, 'they also attempted to fulfil the children's perceived needs according to an 
ideal that the actual mother could not meet, given that she worked outside the home' (MacDonald 2011, 159).

Macdonald's concept of 'shadow mothers' was inspired by the 'shadow work' coined by Illich (1981), which refers to the necessary and unpaid work in the home that occurs alongside the

public production of goods and services within the industrialised world. Often termed reproductive labour, 'women's work', is devalued, frequently invisible, and usually unpaid (Macdonald 2011, 110). Further expanding the definition of reproductive labour as invisible work', Kaplan Daniels argues that it is unseen because society has a fixed view of what work is valuable, which does not include unpaid work in the private sphere and is traditionally performed by women. In the introduction, I outline the positioning of surrogacy as a form of reproductive labour that is performed to make the intended parents, parents. Just as Macdonald's concept of 'shadow mothers' depicts the nannies/au pairs that help take care of the children of working mothers as essential to allow the latter to fulfil all her commitments in/outside of the house, the surrogate is an essential, if not the most essential, person in the equation. Without her, there would be no baby for the intended mother to fulfil her desires of being a mother.

\section{Mothering in the Shadows}

Throughout the thesis, I have examined the elusiveness of surrogacy, both from the outside and by those practising it. A woman carrying a baby for another person is often sensationalised. While there are variations of legal, social, and biological relationships between individual surrogacy cases, in simplistic terms, surrogacy fragments traditional Euro-American heteronormative kinship roles. As elucidated from the start, those who practise surrogacy, whether heterosexual or not, are vulnerable to the dominant narrative of 'natural conception', found within the ideological nuclear family structure. Surrogacy can be the only option for intended parents to have a child after they have exhausted all other possibilities of having a biological or non-biological child via natural conception, adoption, and IVF. For heterosexual couples, it is not their first choice. It can be both the last resort and the only option for others depending on circumstances. Some women have hysterectomies due to cancer treatment or/and debilitating health conditions such as endometriosis. Other women may have had unexplained infertility and, on average, have spent tens or hundreds of thousands of dollars and five to ten years undergoing fertility treatments to try and conceive via IVF or similar techniques. In the following sections, I explore the intimate landscape, explicitly identifying the rituals and 
practices that are features of the dance of sorts that intended mothers and their surrogates have as a duo and solo from another.

\section{i. Creativity and Improvisation in the Shadows}

One way that surrogates involve their intended mothers is to decentralise their own selves while keeping the focus on the pregnancy. This includes working with the intended mother to figure out ways that she can bond with the baby that the surrogate gestates so that she experiences it as much as possible. Using the metaphor of light and dark, in this section, I explore the creative ways that the surrogate highlights the pregnancy as she dims herself to make space for the intended mother to inhabit. I then describe the creative ways that intended mothers support the surrogates.

Joy is a childfree traditional surrogate of two babies. Self-described as not maternal or 'touchyfeely', including disliking hugs, she told her first intended mother that when she visited, she should feel free to touch and talk to her belly anytime. She also requested a recording of her reading stories and singing so she could attach headphones to either side of her belly and press play each evening. When the intended mother attended the ultrasound scan, this was another opportunity to connect with and 'see' her baby. Han $(2019,60)$ writes:

The personal foetus as made lively through what I call "belly talk" or conversations that involve a pregnant woman and an imagined or expected child. The practice of belly talk suggests that during the 1990s and 2000s, pregnancy became experienced less as a period of watchful waiting and more as a time of active preparation and even nascent parenting.

This shift is useful for intended parents who see the surrogate often for short periods of time and are imagining their future lives as a family via the baby-talk and ultrasound images ${ }^{152}$. These practices are private (Han, 2013, 145) and invite intended parents into the surrogate's world and corporeal experience. It also encourages participation and a reaffirmation of the intended parents' role. Similarly, being identified as the mother either by the sonographer or Joy verbalising it at the beginning of the appointment helped reinforce the narrative that both

${ }^{152}$ The ultrasound scan, or sonogram, is a routinised practice of prenatal care and plays a central role in Euro-American kinship (Han 2009). 
the intended mother and Joy were already living. These moments also dictate the focus of the light in the room. These subtle yet profound shifts of illumination re-direct the pregnancy experience to the intended mother, highlighting her role and shading out the surrogate to a degree. Important to note is how creative Joy was in how she included the intended mother while managing to resist any traditional maternal roles that would require any form of intimacy or affection with the developing baby. It matched her trope of 'disliking children immensely', yet she still enacted shadow mothering in how she made sure that the baby was experiencing tactile engagement.

At the same time, when surrogates move into the background of the journey at different times, this does not negate their role. Their intentional actions to detach from the pregnancy creates space for the intended parents to attach themselves to the experience. Ruby did this by putting her intended mothers in charge and to feel more involved in using the ovulation chart. Ruby checked her temperature every morning and texted it to them. 'It's like, you tell me when I'm ovulating, and I can completely hand all of that over'. Then during pregnancy, 'when it kicks, [I think], 'Oh I need to text her right now and say her baby's kicking and sending videos of the stomach moving and going, 27 kicks today, woohoo!" or "by the way sorry I've been watching Doctor Who, so if you want to get them to sleep you might wanna play the Doctor Who theme" (laughs) you know. Everything was about [the intended mother]. It was her pregnancy and I felt almost in the way if that makes sense? If I could've taken this (signals to her abdomen) off and given it to them I would have'. Asking them to become intimate with and have more knowledge of her ovulation cycle than Ruby had herself was her way to share the experience and give the intended mother a sense of involvement and ownership.

Intended mothers must continually negotiate the current regulations that stipulate payment for reasonable costs only. As discussed in chapter two, it is ambiguous and often interpreted differently. I asked Tina about her role in the two pregnancies via gestational surrogacy (via embryos made using her husband's sperm and an egg donor from California). She described doing everything for her two surrogates that she would do for herself. This included booking them in for massages, sending them gifts and doing everything possible to spoil them. Anna similarly tried to be in tune with her surrogate's needs, sending a care parcel when she got sick with a bad cold. It is quite common for the intended mother to either cook and freeze a lot of meals or organise for them to be delivered post-birth so that the surrogate does not have to worry about cooking while recovering from the birth. Even though the regulations are 
ambiguous, intended mothers circumvent them without breaking them by showing their appreciation through practical methods.

\section{ii. Sacrificing in the Shadows}

When surrogates agree to help others create a family, they agree to be physically attached to the foetus for the nine-month gestation period. Even if the relationship breaks down or becomes awkward with the intended parents for a multitude of reasons, surrogates cannot walk away from their role. No two journeys are the same, with the experience being dependant on various factors. One that kept cropping up was the sacrifices that surrogates made to reduce stress on the intended parents. For example, Ruby deliberately shaded herself out by not telling the intended mothers about the challenges of pregnancy.

Pregnancy is really really hard, and I chose not to share, I mean there was heartburn that made me vomit in the night.... [With the second baby] I just bled, like from then on, I've had to have a IUD thing to stop that cause my body was like "right, I'm done with children! Bergh!" The stuff that I didn't wanna go "oh poor me I've got heartburn, oh poor me I've got a haemorrhoid" because... they would do this 100 times if they could themselves and it was almost like rubbing their noses in it, if that makes sense? "Oh, feel sorry for me cause I'm doing all this stuff". Well, they would love to do that stuff. So, I think the surrogates that I have spoken to have been very similar. We've kept the negative side of pregnancy to ourselves.

Despite struggling a lot throughout the pregnancy, Ruby chose only to share the positive aspects. However, she went beyond simply highlighting the pregnancy in their communication. While her decision was based on her belief that the intended mothers would have done this if they could have, it meant that only the 'best parts of pregnancy' saw the light, making everything that was difficult recede into the shadows with her. This idea of presenting a harmonious experience to the intended mother is like those au pairs and nannies in Macdonald's (2011) research who are tasked with presenting a happy child at the end of the day. While in Ruby's case, she decided to mask the hard parts of pregnancy, the result is similar. Doing this also meant that Ruby's experience and role were further dimmed to a certain extent. Here, detaching her struggle from the pregnancy meant holding onto incredibly 
challenging moments alone. Conversely, if only telling the intended mothers about the good parts of the pregnancy shaded part of Ruby's experience, then playfully intermingling her own sense of humour and personality through the stream of information she shared lightened the shadow and momentarily brought her back into the field of focus. In this sense, sacrifice is not the only narrative.

Madison's experience as a traditional surrogate revolved around her intention to pave a clear and uncomplicated path to parenthood for her intended fathers. One of her explicit sacrifices mirrored Ruby's intention not to share the challenges occurred when Madison experienced a lot of physical discomfort as she was recovering. Although she had been well supported in the lead up to the birth with regular rides to the grocery store and help with dog walking, the fall out of the intended fathers focusing on their new baby meant Madison lacked post-partum support. When she eventually shared how hard it was to sit comfortably, the intended father immediately went and got her a cushion designed to relieve pain. Tracey, a traditional surrogate, did not reach out to her parents either post-birth when she fell into a depression. Too ashamed to tell her friends because they would assume that she was depressed about 'giving up' the baby, Tracey contacted me to confide that she felt alone. One of her friends had told her that they expected to be 'the ambulance at the end of the cliff'. Quite showing was my own private assumption that maybe she was having second doubts. When I tentatively tried to understand what was causing her to have the low moods, Tracey told me that her midwife thought that the drop in hormones and the exhaustion from the birth and then having to look after her three children as a single mother were at play. Tracey also admitted she did not think about the child at all, beyond wanting to leave the intended parents to enjoy their moments as parents.

At a baby scan I drove Kelly, a childfree traditional surrogate, to, the sonographer said something was potentially irregular with the kidneys and receiving this knowledge on her own (with only me there as support) made her anxious. 'How will I tell the dads?' she asked. She worried that she had not been a 'good enough' shadow mother, as if she were responsible during the period. This was despite her dedication to the baby, especially evident in her 
agreeing to provide the breast milk post-birth ${ }^{153}$. Her 'shadow mothering' practices extended beyond nine months of gestation and would require further behind-the-scenes work and sacrifices she was willing to make to fulfil her role as a 'kind of mother' to the foetus during pregnancy. She completely gave up alcohol, regularly went to 'baby yoga' and cycled everywhere to stay physically fit. Kelly had clear ideas about what caring for the growing foetus looked like and took all the responsibility of providing the ideal environment in terms of committing herself to eat well, exercising, and not drinking.

The narratives above signal that in the context of surrogacy, some sacrifices are not necessarily expectations that intended parents have of surrogates. Nevertheless, the surrogates' intentions to conceal the more challenging parts of pregnancy, such as the impact of a difficult birth on the body, or anxiety about telling the intended parents about a result of an ultrasound scan, highlights two things. Firstly, they see their sacrifice as lesser than the reproductive disruption their intended parents have experienced. In chapter three, Joy describes her role as 'no big deal', as if it were the supporting act to the main character. This was not reducing the enormity of pregnancy and childbirth, but instead signalling that in comparison to being parents and raising the baby, it was small, even when what they are doing is invaluable for the intended parents and something the intended parents themselves could not do. On the one hand, the surrogates are positioning their own care-work as supplementary, or as Macdonald (2011) points out, a good substitute for when the mother (or father in the case of gay couples) cannot be there. Equally, they are performing vital care-work for the foetus and the intended parents - shielding them from the hard parts and protecting them while simultaneously giving them access to the pregnancy and space to ready for their own impending parenthood.

The second related point is the personal responsibility surrogates take on as part of their role. They are doing something that has potentially h traumatic connotations and want the intended parents to enjoy the impending arrival of their child. This care-work they perform is as much as, or more about, creating parents as it is about birthing a baby. Of course, not all surrogates conceal struggles, nor could they if they wanted to - for example, if they required serious medical attention during or after the birth. At the same time, some surrogates, like Joy in the

\footnotetext{
${ }^{153}$ Providing breast milk was not an isolated case, as it is not uncommon for surrogates to offer to pump milk for a period after the birth for intended mothers or fathers (in the case of same sex male couples). In Kelly's case, she pumped for months, freezing each amount, and couriering them to the intended fathers.
} 
next section, are expected to manage by themselves and are blamed by their intended parents for things outside of their control.

\section{iii. Autonomy and Expectations}

In surrogacy journeys where the surrogate's worldview or needs differ from the expectations of intended parents, tension can arise, especially when finding balance between the formers' autonomy and the comfort of the latter. For example, when Ruby got pregnant, one of her intended mothers would make sure she took the correct vitamins and queried whether she should be a vegetarian. Others want autonomy when deciding whether to have a home or hospital one, which can be stressful for the intended parents, especially if they have had traumatic experiences with miscarrying, and see the hospital as a safer bet. Joy's experience as a surrogate contrasted between the first and second time. She was clear with both sets of intended parents that she did not want to be managed or always checked up on. She described her relationship with her first intended mother as a genuine connection, with a developed friendship before she offered to be her surrogate. There was mutual support, and they trusted Joy to look after the baby she was gestating, just as she felt confident that they would be there when she needed it at every stage, such as flying to every ultrasound scan or appointment. When it came to her second and last surrogacy journey, she chose a couple she saw as friends, if somewhat to a lesser degree than her first intended mother. Unfortunately, the intended parents did not visit her once throughout the pregnancy:

They kept putting it off, "Aw, you know, we're trying to [sort out family stuff]", and "Aw, we've got to do this. Aw, we've got to do that". And finally, I just said, "Look. When are you coming up?" And that's when he turned around and said, "We're not. I know it's important to you, but right now it's not important to us, so we're not coming up".

Joy felt abandoned and as if she only existed to provide them with a baby. After this, she kept them informed of important milestones but distanced herself. Then two events escalated things. First was the diagnosis of gestational diabetes: 'I rang them to say, "This is what's happening", because if nothing else, I still kept them informed. The gist that I got back from them was it was my fault [for being overweight]'. Then when she was eight months pregnant, she wanted to attend an $\mathrm{AC} / \mathrm{DC}$ concert that she had been anticipating: 
'[But the intended father] said no. I said, "Well, actually, I'm not asking for your permission. I'm just running it past you to let you know that this is what I want to do" [he said] "but there'll be drinking". I said, "There's drinking everywhere". He said, "No. You're putting yourself at risk". I said, "I'm putting myself at risk stepping off the pavement onto the side of the road every day". "It would be different if you were going to a Cliff Richard concert". In the end I told him that "I'm not stupid...I've done the research. Loud concerts, a decibel level of concert, a four-hour concert is not going to affect the baby".

This policing of Joy's actions, coupled with the blame they placed on her for developing gestational diabetes, made her experience of pregnancy emotionally traumatic. In the end, she did not want to give them the baby that she had no intention of keeping herself:

I was talking about adopting the baby to the first person who looked sideways at me...they did not deserve it.... I approached CYFS (Child Youth and Family) for a social worker [even though] normally the surrogate doesn't get one, [but I said] 'There's shit going down and I need someone to help me sort it out". I went through Youth Line, which isn't normally where you go, but I had no other options. I couldn't afford a \$400 an hour psychologist. It wasn't depression, so I couldn't go through the health system'.

In the end, Joy gave the baby to intended parents because she did not want to fight with them anymore. Her story is one of the most traumatising ones that I heard and shows the dark side of sacrifice. Even though she never expected to be close friends with her intended parents, she did hope that they would support her during the pregnancy, when she felt most vulnerable. Joy invested time, physical discomfort, and health issues, yet her experience reveals a sense of ownership her intended parents felt over the pregnancy and her body.

\section{iv. Excluding and Including the Surrogate in Baby-Showers}

Sal and Tony's lounge had been transformed into a space of festivities. Balloons were tied to every possible surface, and rainbow coloured bunting crisscrossed above us. It was a happy day. Their gestational surrogate, Sophie, was seven months pregnant and alongside Sal and 
their mutual friends, they came together (except the men) to celebrate Sal's impending motherhood and kinship. It was a bonus that they lived in the same city, because at Sal's invitation, Sophie brought her own mother and a few friends. It took two and a half years to get to this point. 'I'm almost giddy', Sal whispered to me after I asked how she was doing. They were expecting a boy, and Sal refused to 'make everything blue'. Apart from that stipulation, she had embraced the baby theme. The table at the far end corner was laden with finger food and a cake decorated with purple and yellow fondant dots and four fondant alphabet blocks piled on top of one another, spelling out 'BABY'. Next to it were presents with a smorgasbord of colours and shapes. I tried to be inconspicuous, and when asked how I knew either Sal or Sophie, I faltered. Their friend? A researcher? Both? It was an ongoing source of tension throughout my fieldwork, although retrospectively, my presence was more a curiosity to people.

Throughout the afternoon, there was a steady flow of conversation and intermingling between the ten or so women in the room. Sophie was happy that her two children were with their father, giving her a break and 'the opportunity to have a conversation with another adult' she shared. Sal's friends asked her how she was, and Sophie's friends asked Sal if she had the room prepared. When we all sat down to see Sal open her presents, she beckoned Sophie over to the spot on the sofa next to her. Sal's mum was waiting to bring presents over one by one, but Sal said that first, she wanted to give something to Sophie. She placed a package into her hands and watched as Sophie carefully opened it. On top was a cashmere shawl and under was a book. It was filled with photos of Sophie, her family, Sal, and her husband Tony at varying points in the journey. Big smiles at the end of the embryo transfer, of Sophie's growing belly, and one with Sal touching it and smiling at Sophie. 'I got one for both of us', she explained to everyone. The intention was to keep filling it throughout the remainder of the pregnancy, birth, and afterwards. The quiet was interrupted by Sophie putting her hand on the belly, 'ooof he knows how to kick!', making everyone laugh.

When surrogates are minimised, their story remains partial. As we have seen in the narratives above, sometimes they decentralise themselves in creative ways to draw the intended mother closer into the experience. Sacrificing one's own needs also shapes their days, and the fallout of this can be minimal or traumatising. Another space where surrogates can experience in/visibility is the practice of baby-showers. Close examination of the intimate moments reveals where the tension between shadows (to denote the surrogate as a shadow mother) and light (to 
denote the intended mother, who the surrogate is acting as a shadow mother for) is celebrated as complementary and of equal value in some cases, and a manipulation of light that solely focuses on the intent to parent rather than acknowledge the shadow mothering the surrogate is already doing in other cases.

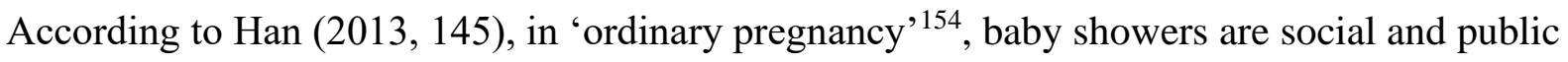
events that 'acknowledge a pregnancy and recognise the changes in a woman's status and identity'. In surrogacy, where the different parts of mothering are fragmented between more than one person, it can pose some challenges. Just as with finding a match, people doing surrogacy for the first time have a reference point grounded more in the idea of a traditional nuclear family. While it is about celebrating the impending baby, as Han suggests, it is also public recognition of motherhood. When I broached the topic of baby-showers with intended mothers, they prefixed their views by saying they usually do not like baby-showers because they can be 'tacky' and 'have ridiculous games'. Some also avoided going to them when they were amid their infertility related grief because it was upsetting. When deciding to have a baby shower, they used their unique way of creating a family as permission to be creative and celebrate the impending birth in their own way. While no two stories were the same, some embraced a celebration of the surrogate alongside the intended mother and those intended parents who held more covert efforts that excluded the surrogate entirely.

Some of the intended mothers I got to know within the New Zealand setting thought it important to throw a baby shower that also celebrated the surrogate's role alongside the intended mother's impending baby. Often it allows intended mothers to share their appreciation in a public setting with close friends and family and offers surrogates the opportunity to participate in the excitement. Both sets of Joni's intended parents planned joint celebrations of 'surrogate/mother' showers to emphasise the duality behind the pregnancy experience. 'First time it was a small afternoon tea with my closest friends. I got gifts like coffee vouchers, booze, etc. to celebrate after the baby was born'. Joni's intended mother and best friend planned her baby shower, which was a great success, with her friends enjoying meeting the intended mother with whom she was going through an intense and intimate journey. Then her second intended parents took Joni out for a meal, along with the intended parent's friends and family. 'Some of her friends and family got me gifts which I didn't expect'. Although Han (2013) describes the

${ }^{154}$ Achieved via natural conception. 
increased involvement of the father-to-be in 'ordinary showers', those of my participants who held them report that more focus was on the intended mother and the intended fathers 'were not included as much' (Joni). Even though this intended father was present, the focus was on the intended mother. Another example was when Tracey, a traditional surrogate, baked a 'gender reveal' cake for her intended parents, who would be visiting for a scan to celebrate the moment. For Ruby, another traditional surrogate, she enjoyed attending the baby showers organised by both of her intended mothers.

Other surrogates remember the baby shower as the event that further relegated them into the shadows. Lola was not invited to her first intended mother's baby shower and felt a bit insulted but did not say anything to her because she did not want to make the pregnancy about herself, even though she was carrying the baby. When Kelly was pregnant for a same-sex couple who lived an hour's flight away, she told me in one of our regular coffee dates that she was hurt that 'the boys' had a baby shower without inviting her, which she only discovered on Facebook when they posted the photos. Unfortunately, this occurred alongside a lack of attentiveness or support at many medical appointments - I took her to a scan once as a support person. By the time she heard about the baby shower they had for the impending baby and parenthood, she had committed to including them as much as she could in the pregnancy journey. Like Lola, she prefaced her disappointment with not wanting to be difficult or 'steal the limelight' and felt embarrassed and worried that the intended fathers were ashamed of her. When she brought the topic up with them tentatively, they said they did not invite her because they thought it would be a hassle for her and an expense for them to fly her to their city. Not long after, Kelly messaged me saying that they had decided to go to a Pacific Island for a 'baby-moon', which she did not begrudge them. Yet, she was living on one wage in a damp house, trying to be careful how she spent money.

In Olivia and Ruby's cases, the duality of surrogate-mother baby showers highlights the interconnected relationship between the surrogate and intended mother. It is perhaps more pronounced on these occasions because their roles are more joined than fragmented. The event acknowledges the time and efforts that the surrogate has put in e while it allows the intended mother to receive gifts and be the centre of attention. Both women are in the spotlight together. In comparison, to be excluded from a baby shower can perplex surrogates, even though both Kelly and Lola were not 'big fans' of them to begin with. By not wanting to share their celebrations, intended parents cast a bigger shadow over their surrogates in the process. Feeling 
left out also changed Kelly's own relationship with the foetus she carried. The more the intended fathers distanced themselves from the pregnancy itself, the more Kelly felt compelled to take care of it, not necessarily by emotional attachment but via practical things.

\section{v. Connection and Disconnection in the Shadows}

I couldn't give you any time frame (laughs). I don't remember. It was all very surreal. I've got some very, very, very vivid snapshots of the time. Yeah, I mean it's interesting. Cos, there was no 'aww she looks like us' or anything like that (laughs). It was none of that. It was just this allencompassing, 'holy shit, she's ours'. - Celeste, an intended mother to two children via gestational and traditional surrogacy.

Throughout my interviews with surrogates and intended mothers, one thing consistently discussed was what happens in the moments immediately after labour ${ }^{155}$. The first time the intended parents held their child in their arms was often described as a vivid memory where everything else in the labour room became hazy. This exact moment, seen from the point of view of the surrogate, is usually one where they say to themselves, 'I did it for this. I did it for her to look at her baby like that'. This is the occasion all parties involved in the surrogacy journey are working towards. In this section, I explore three embodied and tactile practices carried out directly after birth and frame the intended mother's first moments with her baby, which reinforce the intended mother's role as the mother, as the surrogate recedes into the shade. The first, cutting the umbilical cord is a somewhat literal severing of the baby's physical connection to the surrogate. The second, skin-to-skin, where the baby is placed onto the bare chest of the intended mother for an hour or so directly after birth, is the first intimate moment they have together. The third, inducing lactation, is a technique not used by all intended mothers, but those who use it see it as another way to develop a physical bond with the baby. Although these steps do not entirely sever the surrogate's connection to the baby, as will be discussed, they shift the focus in the room and dim the surrogate's role.

\footnotetext{
${ }^{155}$ Some surrogates require caesarean section, and it is typical that the partner of the surrogate, rather than the intended mother, accompanies her into theatre.
} 
Anna, whose traditional surrogate is called Emily, provides vivid imagery of the moments directly after the birth of her son, highlighting the literal and conceptual relationship between connection and disconnection and the emotions that she experienced. The birth was traumatic:

Anna By the time [he] came out, he was sick. He was covered in meconium, and he was just bubbling it, it was in his eyes, his fingernails were stained, he had been in it for I don't know how long. And you know what they [pulled] him out and put them on the table, they have a rating from one to 10 and one terrible, 10 great. And they have to get up to a certain number before they'll hand you the baby, otherwise the baby goes to NICU or whatever. So, he was a one.

Hannah: Did he go to NICU?

Anna: $\quad$ No, no. They managed to pump it out on the table.

Hannah: Gosh, that must have been scary.

Anna: $\quad$ Oh God, yeah. And 'cause they don't answer you. You say, "How is he" You're saying really calmly, "How is he going?" And they don't answer you, they just work on the baby 'cause the one focus is the baby, and you're just sitting there [wondering] 'Is he freaking breathing'.

After Anna's baby stabilised, they handed him to her for skin-on-skin and she cut the umbilical cord, '[it was] that important for me. I was cutting the bond between her and [my baby]'. For Anna, it was symbolic and a way to sever the link and bond she perceived her surrogate to have with the baby she donated an egg for and gestated. Anna believed that for her to connect to the baby, she had to disconnect the surrogates' link. It was also a powerful shifting of responsibility for the baby and Anna enacting her own role as the only mother the child would know:

By the time he was about to be born I felt like the pressure made me feel as though I had been holding my breath for nine months or more. The fear that Emily might feel something for him during the hormones of childbirth and change her mind and want to keep her was intense. All you can do the whole way through the entire process is keep hoping that you might have a child at the end of it...As soon as I held him on my skin, I couldn't help but tell 
him I loved him. It felt very unreal to hold the child we had been trying so hard to have, I looked up from my seat as I held him and saw Emily lying in the bed smiling at us. It felt like we had all achieved bringing this life into the world together. They took the baby and wrapped him ready to go to our room. Emily and I stood hugging beside [my baby boy], it was a very strong and special moment between Emily and I, we had done it, and I was SO grateful to her. As she left, I realised all I wanted to do was take the baby to the room and be alone with him and my husband, for us to feel like a family, for him to feel like ours. I needed the physical distance to Emily to feel like I was a Mum, and he was mine. Taking him to our hospital room was a symbolic moment for me, I was his carer, protector, and Mother now.

This scene literalises the tensions and navigation of motherhood vis-à-vis surrogacy. The emotions and pull that Anna felt to cocoon with her baby and husband, away from Emily, does not render Emily obsolete. Rather, Anna is negotiating the liminality of the moment, of the incredibly traumatic experience of the birth, Emily's central role in literally delivering Anna's son, and the desire to inhabit her own role as mother. Conversely, the connection never fully severs, 'and then when, how does it finish, and does it finish? Or are we still in it? Because the relationship we had with his surrogate will always be that she gave me something amazing and you can't, you don't ever feel you can repay that in any way possible'. It is interesting here that Anna does not talk about the biogenetic link that her surrogate has with her son, but the enormity of the gift she provided. On one level, the disconnection she tried to achieve via the cutting of the cord was successful to a point, as Anna never fully felt like a mother until adoption day came and she was recognised as the legal mother and saw her name on a new birth certificate. This is partly because of the lack of cultural scripts in mainstream society that support non-conventional mothering arrangements (Kelly and Trundle 2018, 86). Both surrogates and intended parents end up embodying a particular facet of mothering that is shaped by a system that assumes that the primary mother is the woman who gestates and gives birth to the baby.

Anna touches on what Strathern (2005) would call 'partial connections', to refer to the notion that disconnections reside alongside connections and vice versa, and it is 'the ability to take things apart and thus make them potentially parts of fresh constellations' (Strathern 2005, 26), becomes a necessary part of surrogacy. The connections the shadow mother makes to the 
growing foetus are not permanent, but rather partial and fragile in the sense that shadow mothering takes work and nurturance, as well as the ability to create space for the intended mother (or/and father/s) to establish connections. For the latter to be fully achieved, a disconnection between the surrogate and foetus must occur first. Anna's assertion that connections can never fully be severed highlights that disconnections do not necessarily equate to cessation of relationships but provide space for the cultivation of the intended parents parental roles, whether through performativity, physically, symbolically, or emotionally.

Closely linked to the concept of disconnection is that of detachment, which is typically considered in opposition to engagement, which is a constrictive dichotomy that does not 'acknowledge or explore the potential productivity that detachment offers' (Candea, Cook, Trundle and Yarrow 2015, 15). Candea et al (19) describes 'the distinction between completed detachment (detachment as a state), and ongoing detachment (detachment as a process or activity)' (19). The authors go on, 'to argue that entities are never fully detached (state) but are detaching (process) is not always the same as arguing that persons are not detached in any ultimate sense (state), but that they sincerely wish, hope or commit to being so (stance) (22). Surrogates, foeti, intended parents, and egg donors are processing an ongoing detachment. For example, if a surrogate donates genetic material and gestates a baby, she is effectively detaching herself from her corporeal connection to the child when she hands them over to the intended parents. The question is whether her detachment is completed detachment given that the entity that she is disengaging from goes on and continues to grow and become their own person but retains a gestational and genetic link. Like disconnection, this invocation of detachment highlights how the process involved in becoming detached does not equate to a cessation of relationships, as postulated in Strathern's writings about disconnections.

However, it is not always the intended mother or the surrogate that cuts the cord. This narrative reflects the majority of births where the surrogate invites the intended parents to do what felt best for them. One exception was when Beth gave birth to a baby via gestational surrogacy, '[The intended father] wanted to but it was something that I wanted to do, it was quite symbolic for me to cut the cord. I wanted that for me'. The umbilical cord was long enough that the baby could be lifted out of the birthing pool and handed to her intended mother while still attached. The instantaneous skin-to-skin and cord cutting that happened whilst he lay on her chest highlights how these two steps can exist in conjunction with one another. Overall, regardless 
of who cuts the cord, it is an important and symbolic act to literally detach the baby from the surrogate.

Skin-to-skin and induced lactation can give the intended mother the opportunity to hold the baby against their bodies and where chosen, to breastfeed them. The quote at the start of this section from Celeste made me teary when I heard it, imagining the surreal and profound moment when she met her baby for the first time. 'I learnt how much love I had waiting for the baby', she told me. It was important for both her and the surrogate that 'the skin-to-skin contact was gonna happen with us and not with her. She saw Arthur and he came to me. And then, she had a cuddle a bit later'. Here, both women are given opportunities to engage with the baby, but the surrogate shifts from having been the one who gestated him to the role as a close friend who supported the intended mother in her quest to have a baby. Most of my participants made sure that the intended mother (or father) would do this part, as a symbolic start to bonding with the baby. Known as 'the golden hour', the first 60 minutes of an infant's life is thought to be critical to help the baby bond with their parent, and aids in their physiological transition from intrauterine to extrauterine life, helping them to regulate body temperature, reduce the saliva cortisol levels, and stabilise the cardio-respiratory system (Gitau et. al., 2002; Moore, Bergman, Anderson, and Medley 2016; WHO 2018).

Some intended mothers decide to try to induce lactation because they want to breastfeed their impending baby. Typically, breast milk production is the result of a complex interaction between oestrogen, progesterone and human placental lactogen that normally occurs in the final months of pregnancy. When the baby is born, the first two hormones reduce, leaving room for the prolactin to increase and begin milk production. Induced lactation occurs when the body successfully mimics this process. One method is to take the prescribed medication Domperidone, which increases the levels of the necessary prolactin. The one difference is that no colostrum would be produced. When adoptive mothers or mothers via surrogacy decide to try and induce lactation, it can begin anywhere from months prior with hormone therapy (that is adjusted as necessary) to replicate the same hormonal changes that occur with pregnancy, to a shorter period where manual pumping, often paired with herbs or/and medication, is used to stimulate milk production. Celeste spoke the most in-depth about wanting to experience feeding her baby and how it helped her to prepare for motherhood in the weeks before the expected birth. She did not produce a lot of milk and had to supplement it, but the very act of holding her baby against her breast helped her create a bond. 
The physical and literal connection between surrogates and the babies is never more prominent than directly after the birth when the cord is still attached to the placenta that has not yet been birthed. These three practices highlight the moments where connections shift in the birthing room. The desire to cut the cord represents a physical severing of the intimate connection that the surrogate has with the baby whilst gestating it. For Anna, and perhaps others, it is a prerequisite for her to immerse herself in motherhood that does not include her surrogate. As a symbolic ritual, it signals a change in dynamics between all parties, and a valuable practice, even if New Zealand regulations stipulate the surrogate is the legal mother because she births the baby, requiring an adoption hearing to cut the legal ties. When the intended mother practises skin-to-skin, this is both a physical attaching of the baby to the mother and, in turn, the surrogate steps back from her role. However, inhabiting the shadows does not necessarily mean that surrogates are necessarily out of sight. For many, not all, intended mothers, their bond with the surrogate continues after the birth, adoption, and childhood.

\section{Conclusion}

When I visited Ruby's house, I noticed Ella Teman's 2010 ethnography Birthing a Mother, The Surrogate Body and the Pregnant Self on her bookshelf. I exclaimed, surprised, holding it in the air for Ruby to see. She exclaimed back, 'I love her! This book made me really understand my role as a surrogate. I'm not making a baby, well I am, but I'm mostly making a mother. It's all about her'. Teman's ethnography was my introduction to surrogacy research, encouraging me to follow in her academic footsteps. And here I was, in my own participant's house, seeing the book. It instantly connected us and marked the moment where our discussions about surrogacy entangled with intellectual musings on kinship began. It is also an apt metaphor that underpins this chapter and my own use of the 'shadow mother' by Macdonald. Ruby, and other surrogates are literally helping to make a mother (or mothering role). Teman discovered that gestational surrogates in Israel manage to separate their own body into different segments by embracing the medicalisation of surrogacy. For example, the medical files were under the intended mother's name rather than the surrogate. Where I deviate from Teman's work is in my framing of how surrogates help to make a mother. The surrogates are never conflated with the intended mothers, and in traditional surrogacy especially, medical professionals do not de-emphasise the surrogate (of course, the ultrasound scans are an opportunity to affirm the intended mother's place). Instead, I argue that those practising 
surrogacy in New Zealand improvise ways to successfully dis/connect from their assumed (in the case of the surrogate) and intended roles (in the case of the intended mother).

At the start of writing my thesis, I thought that the surrogate inhabited the shadows as she grappled with how to best interact with the intended parents, society, her family, friends, and institutions. After immersing myself in the data, I now see moments where dynamics shift depending on how the actors position themselves in connection to one another. Neither is completely in the shadows, and both surrogate and intended mother are vulnerable as they figure things out in the surrogacy journey. By carrying a baby for the intended parents, the surrogate is acting on behalf of that woman ${ }^{156}$, which allows her to represent a facet of motherhood without taking on the role of being the 'real' or intended mother. 'Indeed, it is precisely because she stands in for that element that otherwise defines motherhood that she is the surrogate.... the relationship in question is at once social, between persons, and conceptual, between the significance of what the persons are doing' (Strathern, 1998, 185). Surrogacy creates new, unexpected connections, whereby 'people find themselves related in unexpected ways' (Strathern, 2005, 15). This includes both consanguineal relations and affinal, where new kin configurations that do not conform to any specific trajectory are possible (Almeling, 2011,43; Grebeldinger, 2013, 9). Throughout this chapter, the metaphor of light and shadows reveals the connections and disconnections surrogates and intended mothers make during pregnancy and birth. These help to visualise the implicit and explicit 'shadow mothering' that surrogates do in conjunction with the intended mother as she enacts her own role as the mother. The shadows are not necessarily negative spaces but brim with various articulations of 'mothering' and constant negotiations of what in-put looks like.

The premise behind surrogacy is that the embodied and intimate labour of gestation and childbirth are not where kinship is located. Although the surrogate does not see herself as a mother in a traditional sense of the word, I propose that kin is being made, but for others. By creatively helping the intended mother to feel connected to the baby, the surrogate is implicated as a shadow mother, making sure that the mother has ample opportunity to evolve her role. Here, the shadow mother highlights the pregnancy by devising ways that the intended mother can bond with the baby at this stage. The latter takes the cues from the former. Similarly, many

\footnotetext{
${ }^{156}$ In the case of gay couples, the surrogate is providing the role and thus still representing a facet of motherhood without taking on a parenting role.
} 
of the sacrifices are underpinned by the motivation to give the mother (and/or intended father) space, even at the cost of her own comfort. Yet, sacrifices are not always self-imposed, as Joy's case clearly shows. This is an extreme example of intended parents making their surrogate invisible, and Jo was traumatised having to fight to retain her autonomy, and in response to their policing of her body. Even though Joy does not see herself as maternal in any sense, her desire to put the baby up for adoption was because she did not believe the intended parents were trustworthy or had the baby's best interests at heart. This is also shadow mothering, looking out for the baby when no one else will. In these stories, 'sacrificing' is underpinned by the surrogate believing that she is second to the baby and intended parents' needs. Taking on a facet of mothering and putting others first and trying to ease the journey for the mother through not asking for support was Ruby's way of being a 'good' shadow mother. Decentralising does not always denote sacrifice but an intention to find innovative ways to support the intended mother.

The baby shower stories reveal the tension between the intended mother's needs and honouring the role of the surrogate. Firstly, the baby-shower tradition is to publicly celebrate the impending birth and changing status of the mother. Secondly, in the context of surrogacy, this narrative is redefined in both scenarios that I describe; where the mother-surrogate have a shared celebration, or where the surrogate is not invited, are creative interpretations of a traditional approach to the event. The difference is that the surrogate and her 'shadow mothering' efforts are celebrated without taking away any light from the intended mother. They are co-mothering to an extent. When intended parents render the surrogate invisible, and do not want her at the baby-shower, it reveals more about their need to detach the surrogate from their own narrative. In the vignette at the start of the chapter, Moira's narrative also shows an attempt to disconnect Ruby from her role as surrogate. Although Moira did not intend to reduce Ruby's input, calling Ruby the same name that she uses for the sperm donor, a genetic benefactor, diminishes the enormity of Ruby's role in creating kin for her. This demonstrates that while making kin and mothers in the shadows complicates normative kinship structures, it is not free from the exclusive nature of motherhood. 


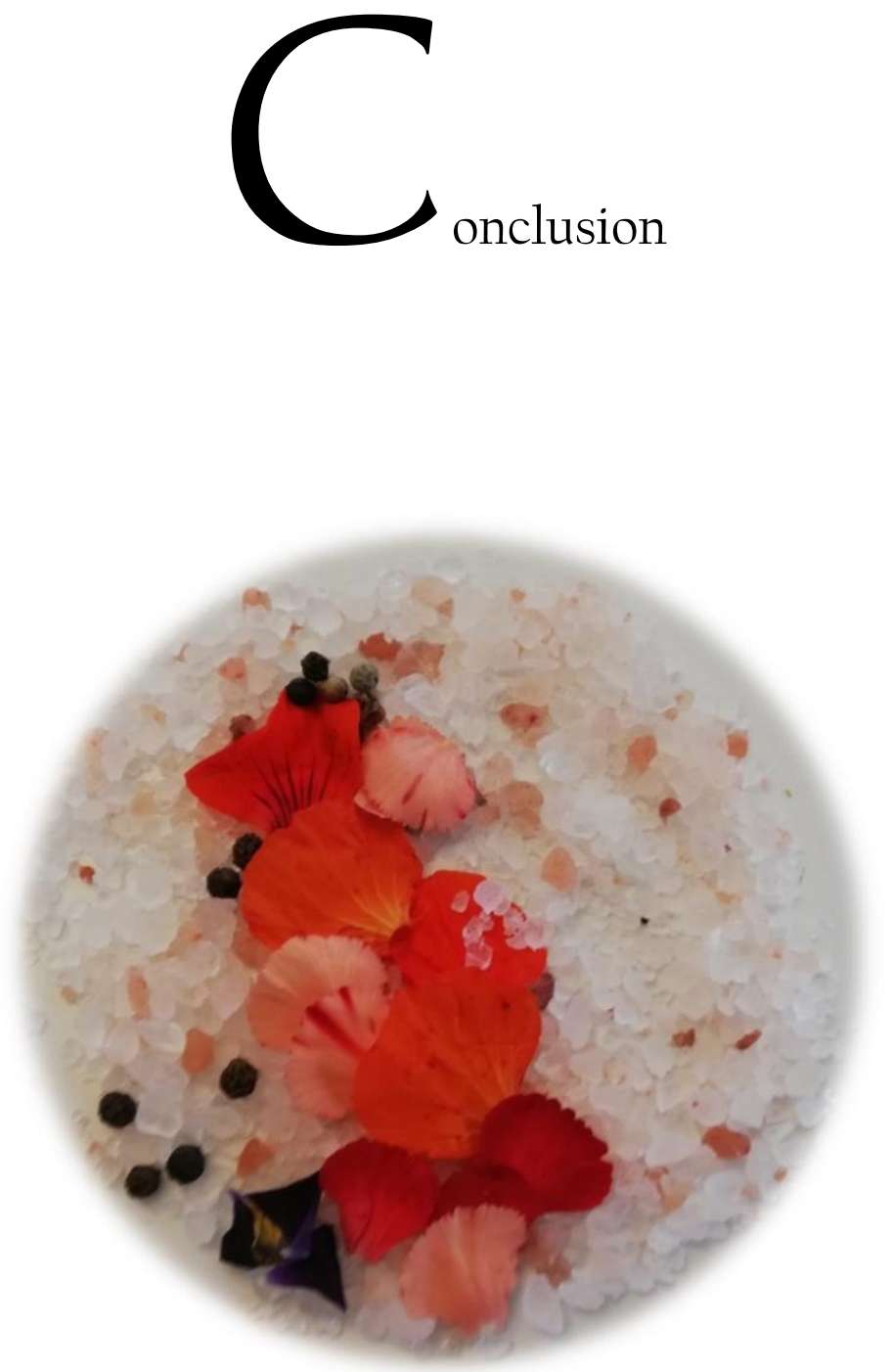

Figure 11: Petals Make a Beautiful Embryo. Photograph by Hannah Gibson

On the 17th of November 2020, I logged onto Facebook and saw a memory shared by Ruby a photo of her holding the first surrogate baby she carried, alongside her own daughter. Her text to accompany the memory read:

Wow 8 years since my first surrogacy...seems like a lifetime ago - I guess it's because they all seem like they've been family forever. One of the best things I've ever done. Still get warm fuzzies. 
This reminded me of the essence of surrogacy. Beyond, or in spite of, the ambiguous legislation, societal discomfort, home insemination attempts, a difficult pregnancy at times, and having to navigate the whole process with her intended parents - is her celebration of kinship and making kin. This feeling that the surrogates talk about has been one of my anchors throughout these past four years, especially when trying to make sense of the complexities inherent in the practice. All the ethnographic vignettes, narratives, rituals, and practices are about making kin in contemporary Aotearoa New Zealand. While surrogacy is the reason that intended parents have children, in time, it recedes as people become engaged in parenting. Seeing the milestones or photos they share on social media highlights how ordinary their lives seem. It reminds me of poignant reflections by two participants. The first was a lawyer with a keen eye for detail and known as 'the surrogacy lawyer' in New Zealand. When I first met her, she told me that, despite what society may think, 'people who do surrogacy are not desperate. They desire to have a family. It just so happens they have to work harder to get it'. This sentiment was reflected by a gestational surrogate, Holly, who carried twins and then a third baby for her sister. She aptly pointed out that:

Some say that instead of doing surrogacy, people should just adopt. Or not add to the world's population problem. But why is it my sister's responsibility to do that? Why are infertile people made to feel like they should accept their situation? She is as deserving as being a mother as I am.

Both comments speak to the societal discomfort toward those who cannot have a baby via natural conception, either due to medical or social infertility. Of course, as argued throughout this thesis, some people are more likely to be marginalised and experience disapproval more than others. Equally, the pervasive colonial policies that continue to privilege the nuclear family, also manifest in subtle and often understated ways in which Māori and Pacific peoples are marginalised, undermined, and belittled about how they make kin and raise children.

In this thesis, I argue that the far-reaching effects of colonisation have created a nation where legislation, judicial practices, and institutions privilege the biological, nuclear family. Those who cannot create a child via natural conception and require a surrogate are pushed into what I call the reproductive penumbra. This is a literal and conceptual space on the peripheries of the regulations and policies that do not recognise surrogacy as a legitimate way to create a family. A critical intervention of my thesis is the framing of shadow spaces that the 
reproductive penumbra mobilises. While other scholars have examined shadow spaces or processes at specific levels (Macdonald 2011; Nordstrom 2000), I ethnographically explore the features of shadows through each stage of surrogacy, from the intimate and inter-personal relationships, the surrogacy community, at the fertility clinic, the embryology laboratory, to the institutional and state level. The metaphors of light and shadow are useful frameworks to explore the various rituals and narratives employed at different points depending on what the actors intend the outcome to be. For example, in chapter six, I have described the rituals and everyday moments that surrogates and intended mothers participate in individually and together to 'make a mother'. By engaging in 'shadow mothering', surrogates work to make space for the intended mother to feel confident in her role as the mother (or for the intended father in the case of gay couples to prepare as primary caregiver).

With no reified regulations pertaining to surrogacy alone, those who practise it must contend with various piecemeal processes and archaic legislation. Regardless of the type of surrogacy and genetic relationships, an Adoption Order must be filed to transfer legal parentage from the surrogate and her partner to the intended parents. By having to present their family as an adoptive one undermines the intentions of both the intended parents and surrogates. Intended parents, whether genetically related to the baby or not, do not see themselves reflected in the law, and must redefine their roles legitimised by the state. As discussed in chapter two, current debates within academia and increasingly seen in the political spheres in New Zealand on law reform are calling attention to the inadequacies of current regulations. My own contribution to this contentious debate is to highlight the narratives and experiences of my participants that I have gathered over the past three years. This is the first in-depth ethnography of surrogacy in New Zealand, and my intention has been to unpack the complexities of how people create families via this form of assisted conception. While other studies have contributed valuable findings, including perspectives of lawyers and the public, the anthropological endeavour is to prioritise, as much as possible, the viewpoints and experiences of those intimately involved in and impacted by surrogacy.

This thesis makes visible the experiences and narratives of surrogates and intended parents who navigate the world of surrogacy in New Zealand. On the surface, traditional and gestational surrogacy are opposing practices. While gestational is highly technologised and under the scrutiny of the fertility clinic and ECART, traditional is performed outside these spaces. Intended parents typically choose traditional surrogacy because of either technological defeat, 
inability to access fertility clinics due to public funding criteria, the financial cost, or not gaining ethics approval. Traditional surrogates' reasons are more varied, and chapter three outlines the motivations beyond the 'help' narrative associated with the altruistic surrogacy model. Very similar reasons were also reflected in the stories of gestational surrogates, exemplified by Lola having been both. In addition to their goal assisting others to have a family, surrogates want to do something unique and important with their lives. It is a fulfilling experience, even though at times it can feel unsatisfactory (such as when Joy, a childfree traditional surrogacy was treated poorly by her second set of intended parents, expressed satisfaction for having done it).

Gestational and traditional surrogacy diverge in the technique used to conceive, but intended parents go through similar vulnerabilities when they first consider surrogacy. How do they find a surrogate? How do they navigate the inter-personal intricacies, the practical getting to know one another, and the period of trying to conceive, the pregnancy itself, and after the birth? Surrogates also have similar questions, including whether the intended parents will support them through pregnancy. This thesis explores what happens after either intended parents or surrogates make the decision to venture down this path. Each chapter examines the potential vulnerabilities that may arise and how people make sense of their experiences. The value of having a roadmap or recipe for success that new members of the surrogacy community can follow is highlighted in chapter four. Accessing advice or support from others is paramount, especially because outside of the community, it is hard to find people who understand the complexities and challenges involved in the process.

From chapter three onwards, I bring attention to the different facets of kin-making in the context of surrogacy. I highlight how kin-making is enacted at each level, from the embryology clinic, via home insemination, in everyday rituals performed by surrogates and intended parents, and to the courtroom where the adoption order is granted. In line with Brigg's arguments, rather than being limited to parents, the raising of children and making of kin involves the input of others and is shaped by everyday politics. Particularly with the context of Māori, whose approach to kin raising is whānau-centred care, an integral part of their culture that has been contested and marginalised within colonial policies and the ongoing privileging of the nuclear family within legislation and institutional practices in New Zealand. In the context of surrogacy, this notion expands to include the various actors involved at various points through conception and gestation. Lola's story elucidates this well. In the chapter 
interludes, different people at various points have had a role in her attempt to conceive with Celeste and James' embryo. The preparation leading up to the embryo transfer and the day itself was a group effort. Those involved included: the fertility doctor checking the thickness of Lola's uterus lining, the nurses giving her injections, the phlebologist taking a blood sample, the embryologists thawing and taking care of the embryo before it was transferred, and another fertility doctor implanting it. Ralph also attended counselling sessions with Lola, and then with Celeste and James. Even though the transfer was unsuccessful, Celeste and James eventually had a baby girl with a traditional surrogate. As I mentioned in the introduction, Lola gave birth to her second surrogate baby, who was conceived via gestational surrogacy, a year ago.

These stories animate this research as this thesis brings to the forefront the under-researched topic of traditional surrogacy. Critical kinship studies scholars and anthropologists of reproduction have tended to have a technology bias, with traditional surrogacy receiving substantially less scholarly attention than gestational surrogacy. One of the reasons for this is the proliferation of ARTs and ever-evolving techniques that can manipulate conception and define what kinds of families are made. As such, traditional surrogacy is practised less int countries where it is legal alongside gestational surrogacy. At the start of my fieldwork, I, too, was more excited about researching ARTs than I was about discussing home inseminations because I thought it sounded relatively simple and straightforward. However, by only considering traditional surrogacy in passing as a pre-technological answer to infertility, scholars (and I, until I got to know my participants) unfairly minimise traditional surrogacy and do those who practise it a disservice. It is a modern way to create kin and a revolutionary low-tech practice that is as carefully thought out as ARTs are within the fertility clinic and embryology laboratory. In this thesis, I argue that, rather than a redundant low-tech option, home insemination via syringe is what I call a repro-hack. I use this term as opposed to Mamo's 'hybrid-technological' mentioned in chapter three because of how those practicing traditional surrogacy via home insemination circumvent the privatisation of fertility medicine, hegemony of the clinic, and regulatory processes that only allow certain people access to gestational surrogacy. Of course, for intended parents, it could be argued that they do this out of necessity. However, this is utilising ingenuity and a determination to find another way to have a family.

All traditional surrogates demonstrate how malleable kin relations can be, conceiving using their own eggs, gestating children for themselves and for others. The motivations of traditional surrogates with children, as opposed to the childfree surrogates, are underpinned by their 
appreciation of - and personal investment in - motherhood and the desire to provide this for others. This does not negate their love of their own children, as we see in Ruby's narratives. Instead, it reveals an ongoing tension between appreciating their own biogenetic relationship with their children and seeing this very link as inessential to the creation of kin for others. This is an example of what Thompson (2005) describes as strategic naturalising or re-narrating their reproductive story to suit their circumstances and intentions. For instance, if an egg donor or traditional surrogate's egg is used, then intended mothers focus on both the intention to parent and their husband/partner's genetic connection. If the egg of an intended mother is used, then genetics is often seen as valuable. Just as, for women who require an egg donor but not a surrogate, they emphasise the importance of gestation and not genetics as the foundation of motherhood. One of the key interventions this thesis makes is calling attention to childfree surrogates. As one of the most controversial aspects of surrogacy, it makes the public and some members of the surrogacy community uncomfortable, which indicates the pervasiveness of normative discourses about maternal desire. The idea that a woman can intentionally donate her own egg and gestate a baby for another without having been pregnant before challenges cultural myths regarding motherhood. At the same time, childfree traditional surrogates further demonstrate the nimbleness of kin-making and challenge the normative assumptions about women having an innate desire to have children. Kelly, Madison, and Joy all made the decision to have children for others, but without the desire to have any of their own.

Surrogacy, in general, disrupts the conventional formation of kin, and critics argue that the woman that gives birth to the baby is always the mother. Within this cultural script, surrogacy is understood as potentially exploitative of both the surrogate and the child. My intention is not to deny that exploitation exists in some spaces, as we see in some narratives of the times where surrogates such as Joy and Heather have felt used and unappreciated by their intended parents. Instead, I argue that surrogacy itself is not inherently exploitative but a practice that creates new kinds of families. If we shifted the cultural expectations of kin-making and rearing, perhaps more in tune with Māori kin practices as opposed to colonial legacies, we can be encouraged to see kinship anew. I concur with the argument made by some critical kinship scholars (including Franklin 1995; 2002; Inhorn and Birenbaum-Carmeli 2008; Mamo 2007; Nordqvist 2012, 2014; Ragoné 1998; Smietana 2017; and Thompson 2005) that ARTs and surrogacy can reaffirm the values of the nuclear family. At the same time, these values continue to be upheld because of their privileged position within the legislation and judicial practices that grant citizens protections and rights. This is seen in the necessity to go through an adoption 
process, in childfree women being criticised for their lack of desire for children, and in the denial (until recently) of gay men being allowed to co-adopt the child born of surrogacy.

The combination of privatised fertility medicine, strict criteria for public funding, and ambiguous regulations result in some people in New Zealand being encouraged to reproduce using gestational surrogacy more than others. If we only consider the formal processes of surrogacy - through the fertility clinics, embryology laboratories, ethics committee meetings, medical procedures, and counselling offices, then we would only have half the story of how surrogacy is practised in New Zealand. In taking seriously these surrogacy spaces and practises in the shadows, we begin to see the ingenuity found in kin-making. Those who are pushed into the reproductive penumbra are discriminated against within a system that privileges the ideological nuclear family. Shaped by pervasive colonial approaches to governance and kinship, those that do not align with this image - of heterosexual, white, and married, have been discouraged to reproduce. By giving more priority to those who meet the criteria for funded fertility treatment or have all the necessary components required for gestational surrogacy aligned, we run the risk of silencing those who create kin on the peripheries of these spaces. And yet, it is these stories we need to highlight and amplify to destabilise any tendencies to normative kinship with the hope that kin-making is recognised for all the diversity it can encompass. My ethnographic research on surrogacy in New Zealand contributes to an array of diverse scholarship from the anthropology of kinship and reproduction. By highlighting traditional surrogacy and home insemination alongside gestational surrogacy, I destabilise a scholarly tendency towards treating traditional surrogacy as an assisted reproductive technique with nothing new to reveal. Instead, through detailed ethnographic narratives, I argue that traditional surrogacy is a modern repro-hack of the hegemony of the fertility clinic, criteria for funding, and restrictive state regulations. Finally, rather than positioning kin-making in the shadows as inherently negative, this thesis celebrates the potentiality and plurality of reproduction that underpins and emerges from surrogacy. 


\section{Bibliography}

Advisory Committee on Assisted Reproductive Technologies. 2012. Proposed Amendments to Guidelines on Surrogacy Arrangements involving Providers of Fertility Services and Guidelines on Donation of Eggs or Sperm between Certain Family Members: Consultation document. Wellington: Advisory Committee on Assisted Reproductive Technology.

- 2013. Annual Report 2012/13. Wellington: Advisory Committee on Assisted Reproductive Technology.

Adoption Act1955.

http://www.legislation.govt.nz/act/public/1955/0093/latest/DLM292661

Ahmed, Sara. 2010. The Promise of Happiness. Durham, North Carolina: Duke University Press.

Alhusen, Jeanne L. 2008. “A Literature Update on Maternal-Fetal Attachment.” Journal of Obstetric, Gynaecologic \& Neonatal Nursing 37(3): 315-328.

Almack, Kathryn. 2006. “Seeking Sperm: Accounts of Lesbian Couples’ Reproductive Decision-Making and Understandings of the Needs of the Child." International Journal of Law, Policy and the Family 20(1): 1-22.

Almeling, Rene. 2011. Sex Cells: The Medical Market for Eggs and Sperm. University of California Press.

Anderson, Lynley, Jeanne Snelling, and Huia Tomlins-Jahnke. 2012. "The Practice of Surrogacy in New Zealand." Australian and New Zealand Journal of Obstetrics and Gynaecology 52(3): 253-257.

Baird, Natalie. 2019. "Commercial Surrogacy and the Sale of Children: A Call to Action for the Committee on the Rights of the Child. In Perspectives on Commercial Surrogacy 
in New Zealand: Ethics, Law, Policy and Rights, edited by Annick Masselot and Rhonda Powell. Centre for Commercial \& Corporate Law Incorporated, University of Canterbury.

Baird, Natalie, and Rhonda Powell. 2020. "Surrogacy and Human Rights in New Zealand: Rethinking Surrogacy Laws Te Kohuki Ture Kopu Whangai." School of Law, University of Canterbury. Christchurch. School of Law, University of Canterbury. 160.

Baker Wilson, Kim. 2016. "NZers Surrogate Babies Stranded in Mexico.” Radio New Zealand, March 29, 2016. https://www.rnz.co.nz/news/national/300132/nzers-surrogate-babies-stranded-inmexico

Bartlett, Jane. 1994. Will You Be Mother?: Women Who Choose to Say No. London: Virago.

Baslington, Hazel. 2002. "The Social Organization of Surrogacy: Relinquishing A Baby and The Role of Payment in The Psychological Detachment Process." Journal of Health Psychology 7(1): 57-71.

Behar, Ruth. 1996. The Vulnerable Observer: Anthropology That Breaks Your Heart. Boston, Massachusetts: Beacon Press.

Berend, Zsuzsa, and Corinna Sabrina Guerzoni. 2019. "Reshaping Relatedness? The Case of US Surrogacy.” Antropologia 6(2): 83-100.

Berend, Zsuzsa. 2012. "The Romance of Surrogacy.” Sociological Forum 27(4):913-36.

- 2016. The Online World of Surrogacy. New York: Berghahn Books.

Bergen, Nicole, and Céline Delacroix. 2019. "Bypassing the Sperm Bank: Documenting the Experiences of Online Informal Sperm Donors." Critical Public Health 29(5): 584595. 
Bergmann, Sven. 2011 Fertility Tourism: Circumventive Routes that Enable Access to Reproductive Technologies and Substances." Signs: Journal of Women in Culture and Society 36(2): 280-289.

Berk, Hillary L. 2015. “The Legalization of Emotion: Managing Risk by Managing Feelings in Contracts for Surrogate Labor." Law \& Society Review 49(1): 143-177.

Bharadwaj, Aditya. 2016. Conceptions: Infertility and Procreative Technologies in India. Vol. 34. New York: Berghahn Books.

Bjork-James, Sophie. 2015. "Feminist Ethnography in Cyberspace: Imagining Families in the Cloud." Sex Roles 73(3-4): 113-124.

Bluebond-Langner, Myra. 1996. In the Shadow of Illness: Parents and Siblings of the Chronically Ill Child. New Jersey: Princeton University Press.

Blyth, Eric. 1994. “'I Wanted to Be Interesting. I Wanted to Be Able to Say 'I've Done Something Interesting with my Life': Interviews with Surrogate Mothers in Britain.” Journal of Reproductive and Infant Psychology 12(3): 189-198.

Bold-Wilson, Paula. 2018. "The Injustice in Justice. An Examination of the Quality of Legal Representation Young Māori Men Receive in the Criminal Justice System.” Master's thesis., UNITEC New Zealand.

Bonnett, Gill. 2020. "Covid Turmoil Sops Parents Reaching Overseas Surrogate Babies.” Radio New Zealand, September 8, 2020. https://www.rnz.co.nz/news/national/425509/covid-turmoil-stops-parents-reachingoverseas-surrogate-babies

Bossema, Ercolie R, Pim MW Janssens, Roswitha GL Treucker, Frieda Landwehr, Kor van Duinen, Annemiek W. Nap, and Rinie Geenen. 2014. “An Inventory of Reasons for Sperm Donation in Formal Versus Informal Settings." Human Fertility 17(1): 21-27. 
Bradley, John. 1997. "Kei Konei Tonu Matou (We Are Still Here)." Adoption and Healing: Proceedings of the International Conference on Adoption and Healing, 37-44. Wellington: Uniprint.

Briggs, Laura. 2017. How All Politics Became Reproductive Politics: From Welfare Reform to Foreclosure to Trump. Vol.2. University of California Press.

Brilliant Beginnings. 2020. UK Surrogacy Pathway. https://www.brilliantbeginnings.co.uk/uk-surrogacy-pathway/

Brittain, Eleanor, and Keith Tuffin. 2017. "Ko Tēhea Te Ara Tika? A Discourse Analysis of Māori Experience in the Criminal Justice System." New Zealand Journal of Psychology (Online) 46(2): 99-107

Broughton, John. 1993. “Being Maori.” The New Zealand Medical Journal 106(968): 506508.

Brubaker, Sarah Jane., and Heather E. Dillaway. 2009. "Medicalization, Natural Childbirth and Birthing Experiences.” Sociology Compass 3(1): 31-48.

Burgess, Taylor Clare. 2019. "Reconstructing State Intervention in Pregnancy to Empower New Zealand Women.” Yale Journal of Law \& Feminism 31: 167-200.

Burns, T, E. R. Hammond, L. Cree, D. E. Morbeck, and N. S. Consedine. 2020. "Do Patient Factors Influence Embryologists’ Decisions to Freeze Borderline Blastocysts?” Journal of Assisted Reproduction and Genetics 37(8): 1975-1997.

Busby, Karen, and Delaney Vun. 2010. "Revisiting the Handmaid's Tale: Feminist Theory Meets Empirical Research on Surrogate Mothers.” Canadian Journal of Family Law 26: 13-94.

Came-Friar, Heather., Tim McCreanor, Maria Haenga-Collins, and Rhonda Cornes. 2019. “Māori and Pasifika Leaders' Experiences of Government Health Advisory Groups in 
New Zealand.” Kōtuitui: New Zealand Journal of Social Sciences Online 14(1): 126135.

Campbell, Annily. 1999. Childfree and Sterilized: Women's Decisions and Medical Responses. London: A\&C Black.

- 2003. "Cutting Out Motherhood: Childfree Sterilized Women.” In Gender, Identity \& Reproduction, edited by Sarah Earle, 191-204. London: Palgrave Macmillan.

Campo-Engelstein, Lisa, and Nadia L. Johnson. 2014. "Revisiting 'The Fertilization Fairytale:' An Analysis of Gendered Language Used to Describe Fertilization in Science Textbooks from Middle School to Medical School.” Cultural Studies of Science Education 9(1): 201-220.

Candea, Matei, Joanna Cook, Catherine Trundle, and Thomas Yarrow. 2015. Detachment: Essays on the Limits of Relational Thinking. Manchester University Press.

Carsten, Janet. 2000. Cultures of Relatedness: New Approaches to the Study of Kinship. Cambridge University Press.

Casey, Margaret. 2014. Surrogacy in New Zealand: The Current Legal Landscape. New Zealand Law Society.

Ciccarelli, Janice C, and Linda J. Beckman. 2005. "Navigating Rough Waters: An Overview of Psychological Aspects of Surrogacy.” Journal of Social Issues 61(1): 21-43.

Cimadomo, Danilo, Daria Soscia., Alberto Vaiarelli., Roberta Maggiulli., Antonio Capalbo., Filippo Maria Ubaldi., and Laura Rienzi. 2019. "Looking Past the Appearance: A Comprehensive Description of the Clinical Contribution of Poor-Quality Blastocysts to Increase Live Birth Rates During Cycles with Aneuploidy Testing." Human Reproduction 34(7): 1206-1214.

Coffey, Tamati. 2019. "Facebook Live." Facebook. December 42019. https://www.facebook.com/tamaticoffeymp/videos/737801576703515/ 
Cohen, Lawrence. 2007. “Operability, Bioavailability, and Exception.” In Global Assemblages: Technology, Politics, and Ethics as Anthropological Problems, edited by Aihwa Ong and Stephen J. Collier, 79-90. Oxford: Blackwell Publishing.

Coleman, E. Gabriella. 2010. "Ethnographic Approaches to Digital Media.” Annual Review of Anthropology 39:487-505.

Colen, Shellee. 2005. "Like a Mother to Them: Stratified Reproduction and West Indian Childcare Workers and Employers in New York." In Conceiving the New World Order, edited by Faye Ginsburg and Rayna Rapp, 78-102. Berkeley: University of California Press.

Collier, Jane Fishburne., and Sylvia Junko Yanagisako. 1987. Gender and Kinship: Essays Toward a Unified Analysis. Stanford University Press.

Committee of Inquiry into Human Fertilisation and Embryology. 1984. "Report of the Committee of Inquiry into Human Fertilisation and Embryology (the Warnock Report).” London: Department of Health and Social Security.

Condon, John T, and Carolyn Corkindale. 1997. "The Correlates of Antenatal Attachment in Pregnant Women.” British Journal of Medical Psychology 70(4): 359-372.

Corea, Gena. 1985. The Mother Machine: Reproductive Technologies from Artificial Insemination to Artificial Wombs. New York: Harper and Row.

Cormack, Donna, James Stanley, and Ricci Harris. 2018. "Multiple Forms of Discrimination and Relationships with Health and Wellbeing: Findings from National CrossSectional Surveys in Aotearoa/New Zealand.” International Journal for Equity in Health 17(1): 1-15.

Crapanzano, Vincent. 2006. “The Scene: Shadowing the Real.” Anthropological Theory 6(4): 387-405. 
Daniels, Ken. 1990. “Attitudes to Donor Insemination and In Vitro Fertilisation - A Community Perspective." Social Work Review 1(1): 4-10.

- 2003. "The Policy and Practice of Surrogacy in New Zealand.” In Surrogate Motherhood: International Perspectives, edited by Felicity Kaganas, 55-74. Oxford: Portland.

Daniels, Ken, and I. Burn. 1997. “Access to Assisted Human Reproduction Services by Minority Groups.” Australian and New Zealand Journal of Obstetrics and Gynaecology 37(1): 79-85.

Daniels, Ken, and Katrina Hargreaves. 1997. "The Policy and Ethics of Surrogacy in New Zealand: Who Is Left Holding the Baby?" Otago Bioethics Report 6(2): 1 - 9.

Daniels, Ken, Wayne Gillett, and Victoria Grace. 2009. "Parental Information Sharing with Donor Insemination Conceived Offspring: A Follow-up Study.” Human Reproduction 24(5): 1099-1105.

Das, Veena and Deborah Poole. 2004. “Anthropology in the Margins of the State." PoLAR: Political and Legal Anthropology Review 30(1): 140-144.

Dastgheib, Shabnam. 2011. “'Rent-a-Womb' Babies Could End Up Stateless.” Stuff, August 20, 2011. https://www.stuff.co.nz/national/health/5477716/Rent-a-womb-babies-could-end-upstateless

Davis, Angela. 1993. Outcast Mothers and Surrogates: Racism and Reproductive Politics in the Nineties. In American Feminist Thought at Century's End: A Reader, edited by Linda S. Kaufman. Cambridge, MA: Blackwell.

Delfanti, Alessandro. 2013. Biohackers: The Politics of Open Science. Pluto Press, London.

Deomampo, Daisy. 2013. "Transnational Surrogacy in India: Interrogating Power and Women's Agency." Frontiers: A Journal of Women Studies 34(3): 167-188. 
- 2016. Transnational Reproduction: Race, Kinship, and Commercial Surrogacy in India. Vol. 1. NYU Press.

Douglass, Alison, and Mike Legge. 2019. "Regulating, Surrogacy in New Zealand: Evolving Policy and Cautious Liberalism Under the HART Act.” In Perspectives on Commercial Surrogacy in New Zealand: Ethics, Law, Policy and Rights, edited by Annick Masselot and Rhonda Powell, 1-24. Christchurch, New Zealand: Centre for Commercial \& Corporate Law, University of Canterbury.

Dow, Katharine. 2017. “"The Men Who Made the Breakthrough': How the British Press Represented Patrick Steptoe and Robert Edwards in 1978." Reproductive Biomedicine \& Society Online 4: 59-67.

Dow, Katharine. 2019. "Looking into the Test Tube: The Birth of IVF on British Television.” Medical history 63(2): 189-208.

Dwyer, Sarah. 2009. “Childbirth Education: Antenatal Education and Transitions of Maternity Care in New Zealand.” Families Commission in conjunction with Parents Centres New Zealand Inc and Parenting Council.

Ebrahimi, H, E. Mohammadi, M. Shamshiri, K. Vehviläinen-Julkunen, and M. A. Mohammadi.e2016. "Living in the Shadow of Shame and Stigma: Lived experience of Mothers with Deaf Children.” International Journal of Medical Research \& Health Sciences, 5(11): 1-8.

Edelmann, Robert J. 2004. "Surrogacy: The Psychological Issues. Journal of Reproductive and Infant Psychology 22(2): 123-136.

Edwards, Jeanette. 2000. Born and Bred: Idioms of Kinship and New Reproductive Technologies in England. Oxford University Press. 
Faircloth, Charlotte, and Zeynep B. Gürtin. 2018. "Fertile Connections: Thinking Across Assisted Reproductive Technologies and Parenting Culture Studies." Sociology 52(5): 983-1000.

Falzon, Mark-Anthony. 2016. Multi-Sited Ethnography: Theory, Praxis and Locality in Contemporary Research. Routledge.

Farquhar, Cynthia, Y. A. Wang, and E. A. Sullivan. 2010. "A Comparative Analysis of Assisted Reproductive Technology Cycles in Australia and New Zealand 20042007." Human Reproduction 25(9): 2281-2289.

Ferguson, James. 2006. Global Shadows: Africa in the Neoliberal World Order. Duke University Press.

Firth, Richard. 1959. "Economics of the New Zealand Maori [1929].” Wellington: Government Printer.

Fitzgerald, Ruth P, Michael Legge, and Julie Park. 2015. "Choice, Rights, and Virtue: Prenatal Testing and Styles of Moral Reasoning in Aotearoa/New Zealand." Medical Anthropology Quarterly 29(3): 400-417.

Fitzgerald, Ruth P, Michael Legge, Poia Rewi, and Ella J. Robinson. 2019. "Excluding Indigenous Bioethical Concerns When Regulating Frozen Embryo Storage: An Aotearoa New Zealand Case Study." Reproductive Biomedicine \& Society Online 8: $10-22$

Fitzgerald, Ruth. P, Michael Legge, and Nicholas Frank. 2013 "When Biological Scientists Become Health-Care Workers: Emotional Labour in Embryology.” Human Reproduction 28(5): 1289-1296.

Fox, Bonnie, and Diana Worts. 1999. "Revisiting the Critique of Medicalized Childbirth: A Contribution to the Sociology of Birth." Gender \& Society 13(3): 326-346. 
Frank, Andrew, Jonathan Raper, and Jean-Paul Cheylan, eds. 2000. "The Structure of Shadows." In Life and Motion of Socio-Economic Units: 103-113. CRC Press.

Franklin, Sarah. 1993. "Essentialism, Which Essentialism? Some Implications of Reproductive and Genetic Techno-Science." Journal of Homosexuality 24(3-4): 2740.

- 1997. Embodied Progress: A Cultural Account of Assisted Conception. Routledge Press.

1995. Postmodern Procreation: A Cultural Account of Assisted Reproduction. In Conceiving the New World Order: The Global Politics of Reproduction, edited by Faye Ginsburg, and Rayna Rapp, 323-45. University of California Press.

- $\quad$ 2006. "Origin Stories Revisited: IVF as an Anthropological Project." Culture, Medicine and Psychiatry 30(4): 547-555.

2008. “The Reproductive Revolution: How Far Have We Come?” (2005 Inaugural Lecture) BIOS Working Paper 2, BIOS Centre. London School of Economics.

2018. "Somewhere Over the Rainbow, Cells Do Fly." In Global Perspectives on Stem Cell Technologies, edited by Aditya Bharadwaj, 27-49. Palgrave Macmillan: Cham.

Franklin, Sarah, and Susan McKinnon. 2000. "New Directions in Kinship Study: A Core Concept Revisited.” Current Anthropology 4(2): 275-279.

Freeman, Tabitha, Vasanti Jadva, E. Tranfield, and Susan Golombok. 2016. “Online Sperm Donation: A Survey of the Demographic Characteristics, Motivations, Preferences and Experiences of Sperm Donors on a Connection Website." Human Reproduction 3(9): 2082-2089. 
Friedner, Michelle, Devva Kasnitz, and Zoë Wool. 2018. "What I Wish I Knew about Anthropology and Disability: Notes toward a More Enabling Anthropology." Anthrodendum.

https://anthrodendum.org/2018/01/10/what-i-wish-i-knew-about-anthropology-anddisability-notes-toward-a-more-enabling-anthropology/.

Galemba, Rebecca B. 2008. "Informal and Illicit Entrepreneurs: Fighting for a Place in the Neoliberal Economic Order.” Anthropology of Work Review 29(2): 19-25.

Gallagher, Dympna, Marjolein Visser, Dennis Sepulveda, Richard N. Pierson, Tamara Harris, and Steven B. Heymsfield. 1996. "How Useful is Body Mass Index for Comparison of Body Fatness Across Age, Sex, and Ethnic Groups?” American Journal of Epidemiology 143(3): 228-239.

Geertz, Clifford. 1973. "Thick Description: Toward an Interpretive Theory of Culture." Turning Points in Qualitative Research: Tying Knots in a Handkerchief 3: 143-168.

Gibbs, Jennifer L., Nicole B. Ellison, and Chih-Hui Lai. 2011. First Comes Love, Then Comes Google: An Investigation of Uncertainty Reduction Strategies and SelfDisclosure in Online Dating." Communication Research 38(1): 70-100.

Gibson, Hannah. 2019. "Living a Full Life.” Medicine Anthropology Theory 6(2): 72-78.

Gillespie, Rosemary. 2000. "The Post-Modernisation of Motherhood.” In Women, Health and the Mind, edited by Lorraine Sherr, and Janet S. St Lawrence, 213-228. Chichester: John Wiley and Sons.

- 2003. "Childfree and Feminine: Understanding the Gender Identity of Voluntarily Childless Women." Gender \& Society 17(1): 122-136.

Gillett, Wayne, and John Peek. 1997. "Access to Infertility Services: Development of Priority Criteria." Wellington (New Zealand): New Zealand National Health Committee. 
Ginsburg, Faye, and Rayna Rapp, eds. 1995. Conceiving the New World Order: The Global Politics of Reproduction. University of California Press.

Gitau, R, N. Modi, X. Gianakoulopoulos, C. Bond, V. Glover, and J. Stevenson. 2002. "Acute Effects of Maternal Skin-to-Skin Contact and Massage on Saliva Cortisol in Preterm Babies.” Journal of Reproductive and Infant Psychology 20(2): 83-88.

Glover, Marewa. 2008. Maori Attitudes to Assisted Human Reproduction: An Exploratory Study. Auckland: Social and Community Health, School of Population Health, University of Auckland.

Glover, Marewa, Pat Dudgeon, and Ingrid Huygens. 2004. “Colonisation and Racism.” In Community Psychology: In Pursuit of Liberation and Well-Being, edited by Geoffrey Nelson, and Issac Prilleltensky, 330-347. New York, NY: Palgrave.

Glover, Marewa, and Benedicta Rousseau. 2007. "'Your Child is Your Whakapapa': Maori Considerations of Assisted Reproduction and Human Relatedness." Sites: a Journal of Social Anthropology and Cultural Studies 4(2): 117-136.

Glover, Marewa, McCree, Alvie and Lorna Dyall 2007 Maori Attitudes to Assisted Human Reproduction: An Exploratory Study. Summary Report, Auckland: School of Population Health, University of Auckland.

Goodfellow, Aaron. 2015. Gay Fathers, Their Children, and the Making of Kinship. Fordham University Press.

Gotlib, Anna. 2016. "But You Would Be the Best Mother": Unwomen, Counterstories, and the Motherhood Mandate." Journal of Bioethical Inquiry 13(2): 327-347.

Graham, Geo. 1948. "Whāngai Tamariki." The Journal of the Polynesian Society 57(3): 268278. 
Grebeldinger, Jessica. 2013. Assisted reproductive technologies: Reviewing recent Perspectives and Addressing Research Gaps.

https://anthropologyworks.com/2013/02/14/assisted-reproductive-technologiesreviewing-recent-perspectives-and-addressing-research-gaps-in-medicalanthropology-4/

Green, Jane Alison. 2011. "A Discursive Analysis of Maori in Sexual and Reproductive Health Policy." PhD diss., University of Waikato.

Griffith, Keith. 1997. "The Legal and Social History of Adoption in New Zealand: Adoption and Healing." In Proceedings of the International Conference on Adoption and Healing.

GVR. 2019. "IVF Market Size Worth \$36.2 Billion By 2026 | CAGR: 10.2\%.” Grand View Research, March 2019.

https://www.grandviewresearch.com/press-release/global-ivf-market

Hall Durie. and Joan Metge. 2002 "Kua Tutu Te Puehe, Kia Mau: Māori Aspirations and Family Law" In Family Law Policy in New Zealand, edited by Mark Henaghan, and Bill Atkin. Wellington: Lexis Nevis Butterworths.

Hallett, Ronald E, and Kristen Barber. 2014. "Ethnographic Research in a Cyber Era.” Journal of Contemporary Ethnography 43(3): 306-330.

Han, Sallie. 2009. "Seeing like a family: Fetal Ultrasound Images and Imaginings of Kin." Imagining the Fetus: The Unborn in Myth, Religion, and Culture, edited by Vanessa R. Sasson, 270-290.

- 2013. Pregnancy in Practice: Expectation and Experience in the Contemporary US. Vol. 25. Berghahn Books.

Han, Sallie. 2019 "Pregnant with Ideas: Concepts of the Fetus in the Twenty-First Century United States”. In Sallie Han, Tracy K. Betsinger, and Amy B. Scott, eds. The Anthropology of the Fetus: Biology, Culture, and Society. Vol. 37. Berghahn Books. 
Hannan, Judith. 2014. "Shadow Mothers." In Motherhood, Mental Illness and Recovery: Stories of Hope, edited by Nikole Benders-Hadi, and Mary E. Barber, 329-332. Springer, Cham.

Harrington, Rebecca. 2019. "Childfree by Choice." Studies in Gender and Sexuality 20(1): $22-35$

Harris, Ricci B, James Stanley, and Donna M. Cormack. 2018. "Racism and Health in New Zealand: Prevalence Over Time and Associations Between Recent Experience of Racism and Health and Wellbeing Measures Using National Survey Data." PloS One 13(5).

Harte, Helen Mountain. 2001. "Home Births to Hospital Births: Interviews with Maori women who had their babies in the 1930s." Health and History 3(1): 87-108.

Hays, Sharon. 1996. The Cultural Contradictions of Motherhood. Yale University Press

Henry, Nicola, and Anastasia Powell. 2018. "Technology-Facilitated Sexual Violence: A Literature Review of Empirical Research." Trauma, Violence, \& Abuse 19(2): 195208.

Hintz, Elizabeth A, and Clinton L. Brown. 2019. "Childfree by Choice: Stigma in Medical Consultations for Voluntary Sterilization." Women's Reproductive Health 6(1): 62-75.

Hubbard, Ruth. 1984. "Personal Courage is Not Enough: Some Hazards of Childbearing In the 1980s." In Test-Tube Women: What Future for Motherhood, edited by Rita Arditti, Renate Duelli Klein, and Shelley Minden, 331-355. Boston, MA: Pandora Press.

Human Assisted Reproductive Technology Act 2004. http://www.legislation.govt.nz/act/public/2004/0092/latest/whole.html 
Human Assisted Reproductive Technology Order 2005. http://www.legislation.govt.nz/regulation/public/2005/0181/latest/DLM335192.html

Human Rights Act 1993.

http://www.legislation.govt.nz/act/public/1993/0082/latest/DLM304212

Humphreys, Stephen. 2010. "The Unethical Use of BMI in Contemporary General Practice." The British Journal of General Practice: The Journal of the Royal College of General Practitioners 60,578: 696-7.

Hurley, Ben and Steve Kilgallon 2015. Thai Surrogacy Deal Sours as Kiwi Mum and Dad Given Wrong Baby. Stuff, November 28, 2015. https://www.stuff.co.nz/national/74523029/thai-surrogacy-deal-sours-as-kiwi-mumand-dad-given-wrong-baby

Illich, Ivan. 1981. Shadow Works. Boston, MA: M Boyars.

Imrie, Susan, and Vasanti Jadva. 2014. "The Long-Term Experiences of Surrogates: Relationships and Contact with Surrogacy Families in Genetic and Gestational Surrogacy Arrangements." Reproductive Biomedicine Online 29(4): 424-435.

Ingold, Tim. 2000. The Perception of the Environment: Essays on Livelihood, Dwelling and Skill. Psychology Press.

Inhorn, Marcia C. 1994. Quest for Conception: Gender, Infertility and Egyptian Medical Traditions. University of Pennsylvania Press.

- 2003a. "Global Infertility and the Globalization of New Reproductive Technologies: Illustrations from Egypt." Social Science \& Medicine 56(9): 1837-1851.

- 2003b. Local Babies, Global Science: Gender, Religion, and In Vitro Fertilization in Egypt. Psychology Press. 
- 2006. "Defining Women's Health: A Dozen Messages from More Than 150 Ethnographies." Medical Anthropology Quarterly 20(3): 345-378.

- Inhorn, Marcia C, and Pasquale Patrizio. 2012. "The Global Landscape of CrossBorder Reproductive Care: Twenty Key Findings for the New Millennium." Current Opinion in Obstetrics and Gynecology 24(3): 158-163.

- 2015. "Infertility Around the Globe: New Thinking on Gender, Reproductive Technologies and Global Movements in the 21st Century." Human Reproduction Update 21(4): 411-426.

Inhorn, Marcia. C, and Frank Van Balen, eds. 2002. Infertility Around the Globe: New Thinking on Childlessness, Gender, and Reproductive Technologies. University of California Press.

Inhorn, Marcia. C, \& Daphna Birenbaum-Carmeli. 2008. “Assisted Reproductive Technologies and Culture Change." Annual Review of Anthropology 37:177-196.

Irani, Mohamad, David Reichman, Alex Robles, Alexis Melnick, Owen Davis, Nikica Zaninovic, Kangpu Xu, and Zev Rosenwaks. 2017. "Morphologic Grading of Euploid Blastocysts Influences Implantation and Ongoing Pregnancy Rates." Fertility and Sterility 107(3): 664-670.

Irwin, Kathie. 1992. "Maori Research Methods and Processes: An Exploration and Discussion." In Paper Presented at the Joint New Zealand Association for Research in Education/Australian Association for Research in Education Conference, Geelong, Australia.

Jackson, Moana. 1987. "The Maori and the Criminal Justice System, A New Perspective: He Whaipaanga Hou." Wellington, Policy and Research Division, Department. of Justice.

Jacobson, Heather. 2016. Labor of love: Gestational Surrogacy and the Work of Making Babies. Rutgers University Press. 
Jadva, Vasanti, Clare Murray, Emma Lycett, Fiona MacCallum, and Susan Golombok. 2003."Surrogacy: The Experiences of Surrogate Mothers." Human Reproduction 18(10): 2196-2204.

Jadva, Vasanti, Susan Imrie, and Susan Golombok. 2015. "Surrogate Mothers 10 years on: A Longitudinal Study of Psychological Well-Being and Relationships with the Parents and Child." Human Reproduction 30(2): 373-379.

Jadva, Vasanti, Tabitha Freeman, Erika Tranfield, and Susan Golombok. 2018. "Why Search for a Sperm Donor Online? The Experiences of Women Searching for and Contacting Sperm Donors on the Internet." Human Fertility 21(2): 112-119.

Jent, Karen Ingeborg. 2018. "Making Stem Cell Niches: An Ethnography of Regenerative Medicine in Scotland and the United States." PhD diss., University of Cambridge.

Justice, Department of Law Reform Division. 1985. "New Birth Technologies. An Issues Paper on AID, IVF, and Surrogate Motherhood.” Wellington. Department of Justice.

Kahn, Susan Martha. 2000. Reproducing Jews: A Cultural Account of Assisted Conception in Israel. Duke University Press.

Kandiyoti, Deniz. 1988. "Bargaining with Patriarchy." Gender \& Society 2(3): 274-290.

Kelly, Karena, and Catherine Trundle. 2018. "Mine, Yours or Ours?" Commoning Ethnography 1(1): 82-93.

Kelty, Christopher M. 2010. "Outlaw, Hackers, Victorian Amateurs: Diagnosing Public Participation in the Life Sciences Today." Journal of Science Communication 9(1): $\mathrm{C} 03$.

Kerekere, Elizabeth. 2017. "Part of the Whānau: The Emergence of Takatāpui Identity-He Whāriki Takatāpui." PhD Diss, Victoria University of Wellington.

Kim McBreen. 2012. “It's About Whānau—Oppression, Sexuality and Mana.” In Kei Tua o Te Pae Hui Proceedings: Changing Worlds, Changing Tikanga: 55-64. 
Krishnan, Vijaya. 1994. "Attitudes Toward Surrogate Motherhood in Canada." Health Care for Women International 15(4): 333-357.

Kroløkke, Charlotte Halmø, and Saumya Pant. 2012. "“I Only Need her Uterus": Neo-Liberal Discourses on Transnational Surrogacy." NORA-Nordic Journal of Feminist and Gender Research 20(4): 233-248.

Kruger, Rozanne, Sarah P. Shultz, Sarah A. McNaughton, Aaron P. Russell, Ridvan T. Firestone, Lily George, Kathryn L. Beck et al. 2015. "Predictors and Risks of Body Fat Profiles in Young New Zealand European, Māori and Pacific Women: Study Protocol for the Women's EXPLORE Study." Springer Plus 4(1): 128.

Lasker, Judith, and Susan Borg. 1994. In Search of Parenthood: Coping with Infertility and High-Tech Conception. Temple University Press.

Le Grice, Jade. 2014. "Māori and Reproduction, Sexuality Education, Maternity, and Abortion." PhD diss, Auckland University.

Le Grice, Jade Sophia, and Virginia Braun 2016. "Mātauranga Māori and Reproduction: Inscribing Connections Between the Natural Environment, Kin and the Body." AlterNative: An International Journal of Indigenous Peoples 12(2): 151-164.

Lee, Soojeong, and Roger C. Shouse." 2011. The Impact of Prestige Orientation on Shadow Education in South Korea." Sociology of Education 84(3): 212-224.

Legge, Michael, Ruth Fitzgerald, and Nicole Frank. 2007. "A Retrospective Study of New Zealand Case Law Involving Assisted Reproduction Technology and the Social Recognition of 'New' Family." Human Reproduction 22(1): 17-25.

Letherby, Gayle. 1999. "Other Than Mother and Mothers as Others: The Experience of Motherhood and Non-Motherhood in Relation to 'Infertility' and 'Involuntary Childlessness'." In Women's Studies International Forum, 22(3): 359-372. 
- 2002. 'Childless and Bereft?: Stereotypes and Realities in Relation to 'Voluntary' and 'Involuntary' Childlessness and Womanhood.' Sociological Inquiry 72: 7-20.

Levine, David. 1985. "Industrialization and the Proletarian Family in England." Past \& Present 107(1): 168-203.

Levine, Nancy E. 2008. "Alternative Kinship, Marriage, and Reproduction." Annual Review of Anthropology 37: 375-389.

Lev-Wiesel, Rachel. 2006. "Intergenerational Transmission of Sexual Abuse? Motherhood in the Shadow of Incest." Journal of Child Sexual Abuse 15(2): 75-101.

Liu, Xin. 2000. In One's Own Shadow: An Ethnographic Account of the Condition of PostReform Rural China. University of California Press.

Lovelock, Kirsten. 2010. "Conceiving Reproduction: New Reproductive Technologies and the Redefinition of the Kinship Narrative in New Zealand Society." Anthropological Forum, 20(2): 125-146.

Lozanski, Kristin, and Irene Shankar. 2019. "Surrogates as Risk or Surrogates at Risk? The Contradictory Constitution of Surrogates' Bodies in Transnational Surrogacy." Social Theory \& Health 17(1): 40-56.

Macdonald, Cameron L. 1998. "Manufacturing Motherhood: The Shadow Work of Nannies and Au Pairs." Qualitative Sociology 21(1): 25-53.

- 2011. Shadow Mothers: Nannies, Au pairs, and the Micropolitics of Mothering. University of California Press.

Mamo, Laura, and Eli Alston-Stepnitz. 2015. "Queer Intimacies and Structural Inequalities: New Directions in Stratified Reproduction." Journal of Family Issues 36(4): 519-540.

Mamo, Laura. 2007a. Queering Reproduction: Achieving Pregnancy in the Age of Technoscience. Duke University Press. 
- 2007b. "Negotiating Conception: Lesbians' hybrid-technological practices." Science, Technology, \& Human Values 32(3): 369-393.

- 2013. "Queering the Fertility Clinic." Journal of Medical Humanities 34(2): 227-239.

Manihera, Colleen, and Tessa Turnbull. 1990. "Some Gynaecological Issues from a Rural and Maori Perspective." The New Zealand Medical Journal 103(898): 458-459.

Marcus, George E.1995 "Ethnography In/Of the World System: The Emergence of MultiSited Ethnography." Annual Review of Anthropology 24(1): 95-117.

Margaret, Jennifer. 2017. "Ka Pū Te Ruha, Ka Hao Te Rangatahi: Change in the Pākehā Nation." Sate of the Pākehā Nation: Collected Waitangi Day Speeches.

Markens, Susan. 2007. Surrogate Motherhood and the Politics of Reproduction. University of California Press.

Marriage (Definition of Marriage) Amendment Act 2013. http://www.legislation.govt.nz/act/public/2013/0020/latest/DLM4505003.html

Martin, Emily. "Egg and Sperm: A Scientific Fairy Tale." In Gender and Scientific Authority, edited by Barbara Laslett, 324-339. University of Chicago Press

Masselot, Annick, and Rhonda Louise Powell, eds. 2019. Perspectives on Commercial Surrogacy in New Zealand: Ethics, Law, Policy and Rights. Centre for Commercial \& Corporate Law Incorporated, University of Canterbury.

May, Amy, and Kelly Tenzek. 2016. "“A Gift We Are Unable to Create Ourselves": Uncertainty Reduction in Online Classified Ads Posted by Gay Men Pursuing Surrogacy." Journal of GLBT Family Studies 12(5): 430-450.

McKinley, Elizabeth. 2005. "Brown Bodies, White coats: Postcolonialism, Maori Women and Science." Discourse: Studies in the Cultural Politics of Education 26(4): 481-496. 
McPherson, Naomi, and Michelle Walks, eds. 2011. An Anthropology of Mothering. Demeter Press.

McRae, Karyn Okeroa, and Linda Waimarie Nikora. 2006. "Whāngai: Remembering, Understanding and Experiencing." MAI Review 1(7): 1-18.

Mead, Aroha. 1994. "Maori Leadership." Te Pua 3(1): 11-20.

Mead, Hirini Moko. 2003. Tikanga Maori: Living by Maori Values. Huia Publishers.

Merleau-Ponty, Noémie, Sigrid Vertommen, and Michel Pucéat. 2018. "Passages: On the Reproduction of a Human Embryonic Stem Cell Line from Israel to France." New Genetics and Society 37(4): 338-361.

Metcalf, P. A., R. K. R. Scragg, P. Willoughby, S. Finau, and D. Tipene-Leach. 2000. "Ethnic Differences in Perceptions of Body Size in Middle-Aged European, Maori and Pacific People Living in New Zealand." International Journal of Obesity 24(5): 593-599.

Metge, Joan. 2014. New Growth from Old: The Whānau in the Modern World. Victoria University Press.

Meyers, Diana Tietjens. 2001. "The Rush to Motherhood: Pronatalist Discourse and Women's Autonomy." Signs: Journal of Women in Culture and Society 26(3): 735-773.

Miall, Charlene E. 1989. "Reproductive Technology vs. the Stigma of Involuntary Childlessness." Social Casework 70(1): 43-50.

Michelle, Carolyn. 2006. "Transgressive Technologies? Strategies of Discursive Containment in the Representation and Regulation of Assisted Reproductive Technologies in Aotearoa/New Zealand." Women's Studies International Forum, 29(2): 109-124. 
- 2007. "Human Clones Talk About Their Lives': Media Representations of Assisted Reproductive and Biogenetic Technologies." Media, Culture \& Society 29(4): 639-663.

Mikaere, Anne. 1994. "Maori Women: Caught in the Contradictions of a Colonised Reality." Waikato Law Review 2.

Ministerial Advisory Committee. 1988. Puao-Re-Ata-Tu: The Report of the Ministerial Advisory Committee on a Māori Perspective for the Department of Social Welfare.

Ministerial Committee on Assisted Reproductive Technology. 1994. Assisted Human Reproduction - Navigating Our Future.

Ministry of Health. 2018. Treaty Waitangi Principles.

https://www.health.govt.nz/our-work/populations/maori-health/he-korowaioranga/strengthening-he-korowai-oranga/treaty-waitangi-principles

Mnookin, Robert H., and Lewis Kornhauser. 1979. "Bargaining in the Shadow of the Law: The Case of Divorce." The Yale Law Journal 88(5): 950-997.

Modell, Judith. (1989). "Last Chance Babies: Interpretations of Parenthood in an In Vitro Fertilization Program.” Medical Anthropology Quarterly 3(2). 124-138.

Moeke-Pickering, Taima Materangatira. 1996. "Māori Identity Within Whānau: A Review of Literature." 1-17. Hamilton: University of Waikato.

Moore, Elizabeth R., Nils Bergman, Gene C. Anderson, and Nancy Medley. "Early Skin-toSkin Contact for Mothers and their Healthy Newborn Infants." Cochrane Database of Systematic Reviews 11.

Moran, G. 2015. "Who Will Be the Uber of Fertility." Fortune, August 6, 2015. https://fortune.com/2015/08/05/uber-of-fertility. 
Morgan, Lewis Henry. 1871. Systems of Consanguinity and Affinity of the Human Family. Vol. 218. Smithsonian Institution.

Nadeau, Joseph H. 2017. "Do Gametes Woo? Evidence for their Non-Random Union at Fertilization." Genetics 207(2): 369-387.

Nahman, Michal Rachel. 2013. Extractions. Palgrave Macmillan, London.

Nandy, Amrita. 2017. Motherhood and Choice: Uncommon Mothers, Childfree Women. Zubaan.

Native Land Act 1862. http://www.nzlii.org/nz/legis/hist_act/nla186226v1862n42251/

New Jersey Supreme Court. 1987. In the Case of Baby M.

New Zealand Herald. 2019. Tāmati Coffey Submits Bill to Change Surrogacy Laws. https://www.nzherald.co.nz/bay-of-plenty-times/news/tamati-coffey-submits-bill-tochange-surrogacy-laws/W67RD6RCPBABWEHWHKGZW4LU3A/

New Zealand Listener. 1995. Who is Left Holding the Baby? New Zealand Listener, January $211995,14-15$.

New Zealand Ministerial Committee on Assisted Reproductive Technologies (1994). “Assisted Human Reproduction: Navigating New Zealand.” Ministry of Health.

Nikora, Linda Waimarie, Ngahuia Te Awekotuku, and Virginia Tamanui. 2013. "Home and the Spirit in the Maori World." In He Manawa Whenua: Indigenous Research Conference.

Nordqvist, Petri. 2012. “II Don't Want Us to Stand out More than We Already Do': Lesbian Couples Negotiating Family Connections in Donor Conception." Sexualities 15(5): 644-61. 
- 2014. "Bringing Kinship into Being: Connectedness, Donor Conception and Lesbian Parenthood." Sociology 48(2): 268-83.

Nordstrom, Carolyn. 2000. "Shadows and Sovereigns." Theory, Culture, and Society 17(4): 3554.

- 2003. "Casting Long Shadows: War, Peace, and Extra-Legal Economies." In Contemporary Peacemaking, edited by John Darby, and Roger MacGinty, 289-299. Palgrave Macmillan, London.

- 2006. "The Jagged Edge of Peace: The Creation of Culture and War Orphans in Angola." Troublemakers or Peacemakers: Youth and Post-Accord Peace Building, edited by Siobhán McEvoy-Levy, 99-116. University of Notre Dame Press.

Ombelet, Willem, and Johan Van Robays. 2015. "Artificial Insemination History: Hurdles and Milestones." Facts, Views \& Vision in Obstetrics and Gynecology 7(2): 137.

Overall, Christine. 2013. Ethics and Human Reproduction (RLE Feminist Theory): A Feminist Analysis. Routledge.

Palmer, Stephanie. 2002. "Hei Oranga Mo Ngā Wāhine Hapū (o Hauraki) I Roto I Te Whare Ora." PhD diss, The University of Waikato.

Pande, Amrita. 2011. "Transnational Commercial Surrogacy in India: Gifts for Global Sisters?" Reproductive Biomedicine Online 23(5): 618-625.

Park, Kristin. 2005. 'Choosing Childlessness: Weber's Typology of Action and Motives of the Voluntary Childless.' Sociological Inquiry 75: 372-402.

Parker, George, Cat Pausé, and Jade Le Grice. 2019. “You're Just Another Friggin' Number to Add to the Problem"." In Thickening Fat: Fat Bodies, Intersectionality, and Social Justice, edited by May Friedman, Carla Rice, and Jen Rinaldi. Routledge. 
Pere, Ranimarie Rose. (1994). Ako. Wellington, New Zealand: Te Kohanga Reo National Trust Board.

Peterson, Helen, and Kristina Engwall. 2013. "Silent Bodies: Childfree Women's Gendered and Embodied Experiences." European Journal of Women's Studies 20(4): 376-389.

Petitfils, Charlotte, Maria Teresa Munoz Sastre, Paul Clay Sorum, and Etienne Mullet. 2017. "Mapping People's Views Regarding the Acceptability of Surrogate Motherhood." Journal of Reproductive and Infant Psychology 35(1): 65-76.

Pfeffer, Naomi. 2011. "Eggs-ploiting Women: A Critical Feminist Analysis of the Different Principles in Transplant and Fertility Tourism." Reproductive Biomedicine Online 23(5): 634-64i.

Pihama, Leoni. 2001. "Tīhei Mauri Ora: Honouring Our Voices: Mana Wahine as a Kaupapa Māori: Theoretical Framework." PhD diss, Auckland University.

- 2011. "Overview of Māori Teen Pregnancy." Wellington: Families Commission http://www. familiescommission. org. nz/publications/researchreports/overview-of-m\% C4\% 81ori-teen-pregnancy

- 2012. Experiences of Whānau Māori within Fertility Clinics. In The Gift of Children: Māori and Infertility, edited by Paul Reynolds, and Cherryl Smith, 203-234. Hui Publishers, Wellington.

Pollard, Amy. 2009. "Field of screams: Difficulty and Ethnographic Fieldwork." Anthropology Matters 11(2).

Poote, Aimee E. and Olga BA van den Akker. 2008 "British Women's Attitudes to Surrogacy." Human Reproduction 24(1): 139-145.

Powell, Rhonda. 2015. 'What Have Genes Got to Do With It?' Socio-Legal Studies Association Conference. 
- 2017. "International Surrogacy and Parenthood in New Zealand: Crossing Geographical, Legal and Biological Borders." Child and Family Law Quarterly 29(2).

Racowsky, Catherine, Michael Vernon, Jacob Mayer, G. David Ball, Barry Behr, Kimball O. Pomeroy, David Wininger, William Gibbons, Joseph Conaghan, and Judy E. Stern. 2010. "Standardization of Grading Embryo Morphology." Journal of Assisted Reproduction and Genetics, 27(8): 437-439.

Ragoné Helena. 1994. Surrogate Motherhood. Conception in the Heart. Boulder: Westview.

- $\quad$ 1996. "Chasing the Blood Tie: Surrogate Mothers, Adoptive Mothers and Fathers." American Ethnologist 23(2): 352-365.

- 2003. The Gift of Life: Surrogate otherhood, Gamete Donation and Constructions of Altruism. In Surrogate Motherhood: International Perspectives, edited by Rachel Cook, Shelley Day Sclater, \& Felicity Kaganas, 209-226. Hart Publishing.

Rapp, Rayna. 2011. "Reproductive Entanglements: Body, State, and Culture in the Dys/regulation of Child-Rearing." Social Research 78(3): 693-718

Raymond, Robin. 2012. "Māori Need to Tackle Abuse." Stuff, October 29 https://www.stuff.co.nz/marlborough-express/7876098/Maori-need-to-tackle-abuse

Re CGL. 2012. NZFC 9828,

Re Reynard. 2014. NZFC 765.

Re Witt. 2019. NZFC 2482.

Re Pierney. 2015. NZFC 9404.

Reents, Jennifer Newton. 2003. “Breastfeeding: For Dads.” And Baby. 59-62. 
Resnick, Rita F. 1990. "Surrogate Mothers: The Relationship Between Early Attachment and the Relinquishing of a Child." PhD dis., Fielding Institute.

Rethinking Surrogacy Laws. 2019. PERCEPTIONS OF SURROGACY THROUGH EMPIRICAL RESEARCH'. Rethinking Surrogacy Laws Project, Canterbury Law School.

Reynolds, Paul Frederick Alec, and Cherryl Waerea-i-te-Rangi Smith, eds. 2012. The Gift of Children: Māori and Infertility. Huia Publishers.

Riggs, Damien W, and Clemence Due. 2010. "Gay Men, Race Privilege and Surrogacy in India." Outskirts: Feminisms Along the Edge 22.

- 2013. "Representations of Reproductive Citizenship and Vulnerability in Media Reports of Offshore Surrogacy." Citizenship Studies 17(8): 956-969.

- 2014. "The Contented Faces of a Unique Australian Family": Privilege and Vulnerability in News Media Reporting of Offshore Surrogacy Arrangements." Feminist Media Studies 14(5): 869-872.

- 2019. A Critical Approach to Surrogacy: Reproductive Desires and Demands. Routledge.

Riggs, Damien W, and Elizabeth Peel. 2016. Critical Kinship Studies: An Introduction to the Field. Springer.

Righarts, Antoinette, Nigel P. Dickson, Lianne Parkin, and Wayne R. Gillett. 2015. "Infertility and Outcomes for Infertile Women in Otago and Southland." NZ Medical Journal 128(1425): 43-53.

Rimene, Christine, Connie Hassan, and John Broughton. 1998. Ukaipo: The Place of Nurturing: Maori Women and Childbirth: He Mahi Rangahau Hauhora Maori. Te 
Roopu Rangahau Hauora Maori o Ngai Tahu, Department of Preventive and Social Medicine, University of Otago.

Rist, Marilee C. 1990. "The Shadow Children" American School Board Journal 177(1): 1824.

Roberts, Elizabeth FS. 20120. God's Laboratory. University of California Press,

Rothman, Barbard Katz. 1989. Recreating Motherhood: Ideology and Technology in a Patriarchal Society. New York: W. W. Norton

Royal Society of New Zealand. 1985. "Issues Arising from In Vitro Fertilisation, Artificial Insemination by Donor and Related Problems in Biotechnology." New Zealand Medical Journal 22: 396 - 398.

Rubin, Gayle. 1975. "The Traffic in Women: Notes on the "Political Economy" of Sex." Toward an Anthropology of Women, edited by Rayna R. Reiter, 157-210. New York: Monthly Review Press.

Rudrappa, Sharmila. 2015. Discounted Life: The Price of Global Surrogacy in India. NYU Press.

Rumball-Smith, Juliet M L. 2009. "Not in My Hospital? Ethnic Disparities in Quality of Hospital Care in New Zealand: A Narrative Review of the Evidence.” The New Zealand Medical Journal 122(1297): 68-83.

Ruparelia, Rakhi. 2007. "Giving Away the Gift of Life: Surrogacy and the Canadian Assisted Human Reproduction Act." Canadian Journal of Family Law 23: 11-54.

Ryan, Maura. 2009. Beyond Thomas Beatie" Trans Men and the New Parenthood. In Who's Your Daddy? And Other Writings on Queer Parenting, edited by Rachel Epstein. Toronto: Sumach Press. 
Sampson, Steven. 2003. “Trouble Spots"': Projects, Bandits, and State Fragmentation. In Globalization, the State, and Violence, edited by Jonathan Friedman, 309-342. Walnut Creek, CA: AltaMira Press

Sanders, Rachel. 2019. "The Color of Fat: Racializing Obesity, Recuperating Whiteness, and Reproducing Injustice." Politics, Groups, and Identities 7(2): 287-304.

Satz, Debra. 2007. "Remaking Families: A Review Essay." Signs: Journal of Women in Culture and Society 32(2): 523-538.

Scheper-Hughes, Nancy. 1993. Death Without Weeping: The Violence of Everyday Life in Brazil. University of California Press.

Schiebinger, Londa. 1989. The Mind Has No Sex? Cambridge, MA: Harvard University Press.

Schmidtz, David. 1996. "Reasons for Altruism." in The Gift: An Interdisciplinary Perspective, edited by A.E. Komter, Amsterdam: Amsterdam University Press.

Schneider, David M. 1968. American Kinship: A Cultural Account. University of Chicago Press.

1984. A Critique of the Study of Kinship. Ann Arbor, MI: University of Michigan Press.

Schurr, Carolin. (2019). "Multiple Mobilities in Mexico’s Fertility Industry." Mobilities 14(1): 103-119.

Shapiro, Gilla. 2014. "Voluntary Childlessness: A Critical Review of the Literature." Studies in the Maternal 6(1): 1-15

Shaw, Rhonda M. -2007. "The Gift-Exchange and Reciprocity of Women in Donor-Assisted Conception." The Sociological Review 55(2): 293-310. 
- 2008a. "The Notion of the Gift in the Donation of Body Tissues." Sociological Research Online 13(6): 1-10.

- $\quad$ 2008b "Rethinking Reproductive Gifts as Body Projects." Sociology 42(1): 11-28.

- 2010. "Perceptions of the Gift Relationship in Organ and Tissue Donation: Views of Intensivists and Donor and Recipient Coordinators." Social Science \& Medicine 70(4): 609-615.

- 2017. Ethics, Moral Life and the Body: Sociological Perspectives. Springer.

- 2020 "Should Surrogate Pregnancy Arrangements be Enforceable in Aotearoa New Zealand?" Policy Quarterly 16(1): 18-25.

Sheoran, Nayantara. 2012. "Once an Insider, Always an Outsider:(Re) Negotiating Boundaries When Researchers Return 'Home,'." Anthropology News 53(2): 1-6.

Shildrick, Margrit (1997). Leaky Bodies and Boundaries: Feminism, Postmodernism and (Bio)ethics. New York: Routledge.

Smietana, Marcin. 2016. "“Families Like We'd Always Known”? Spanish Gay Fathers' Normalization Narratives in Transnational Surrogacy." In Assisted Reproduction Across Borders, edited by Merete Lie, and Nina Lykke, 67-78. Routledge.

- 2017. "Affective De-Commodifying, Economic De-Kinning: Surrogates and Gay Fathers Narratives in US Surrogacy." Sociological Research Online 22(2): 15 .

Smith, Linda Tuhiwai. 2013. Decolonizing Methodologies: Research and Indigenous Peoples. Zed Books Ltd.

Status of Children Amendment Act 2004 (New Zealand). http://www.legislation.govt.nz/act/public/2004/0091/latest/whole.html 
Status of the Child Act 1969.

http://www.legislation.govt.nz/act/public/1969/0018/latest/whole.html

Stefansdottir, Astridur. 2018. "Is 'Surrogacy' an Infertility Treatment?" Clinical Ethics 13(2): $75-81$

Stoller, Paul and Cheryl Olkes. 1987. In Sorcery's Shadow: A Memoir of Apprenticeship Among the Songhay. University of Chicago Press.

Strathern, Marilyn. 1988. The Gender of the Gift: Problems with Women and Problems with Society in Melanesia, $6^{\text {th }}$ ed. University of California Press.

- 1992a. After Nature: English Kinship in the Late Twentieth Century. Cambridge University Press.

- 1992b. Reproducing the Future: Essays on Anthropology, Kinship and the New Reproductive Technologies. Manchester University Press.

- 1995. "Displacing Knowledge: Technology and the Consequences for Kinship.” In Conceiving the New World Order: The Global Politics of Reproduction, edited by Faye Ginsburg, and Rayna Rapp, 346-363. University of California Press.

- 1998. "Surrogates and Substitutes: New Practices for Old?" In The Politics of Postmodernity, edited by James MM. Good and Velody Irving: Cambridge University Press.

- 2005a. Kinship, Law and the Unexpected: Relatives are Always a Surprise. Cambridge University Press.

- 2005b. Partial Connections. Rowman Altamira. 
Stuff. 2019. "NZ Parenting Company Haakaa Signs Supermodel Chrissy Teigen in Instagram Collab.”Stuff, August 9, 2019.

https://www.stuff.co.nz/entertainment/celebrities/114895950/nz-parenting-companysigns-supermodel-chrissy-teigen-as-brand-ambassador

Swinburn, Boyd A., Ian Caterson, Jaap C. Seidell, and W. Philip T. James. 2004. "Diet, Nutrition and the Prevention of Excess Weight Gain and Obesity." Public Health Nutrition 7(1a): 123-146.

Tauri, Juan. 2005. "Indigenous Perspectives and Experience: Maori and the Criminal Justice System." Introduction to Criminological Thought: 129-145. New Zealand: Pearson.

Burgess. Taylor Clare. 2019. "Reconstructing State Intervention in Pregnancy to Empower New Zealand Women." Yale Journal of Law and Feminism 31(1): 167-200.

Te Tiriti o Waitangi [Māori version] 1840.

Teman, Elly. 2003. "The Medicalization of "Nature" in the "Artificial Body": Surrogate Motherhood in Israel." Medical Anthropology Quarterly 17(1): 78-98.

Teman, Elly.2010. Birthing a Mother: The Surrogate Body and the Pregnant Self. University of California Press.

Teman, Elly, and Zsuzsa Berend. 2018. "Surrogate Non-Motherhood: Israeli and US Surrogates Speak about Kinship and Parenthood." Anthropology \& Medicine 25(3): 296-310.

The Care of Children Amendment Act (no 2). 2013. http://www.legislation.govt.nz/act/public/2013/0074/latest/DLM4896280.html

The Guardian. 2016. "Gay Couple in Fight to Bring 'Triplings' Home to New Zealand." https://www.theguardian.com/world/2016/mar/27/gay-couple-in-fight-to-bringtriplings-home-to-new-zealand 
The Native Land Claims and Adjustment and Amendment Act 1901. http://www.nzlii.org/nz/legis/hist_act/nlcaalaa19011ev1901n65521/

Thomas, David Robert. 1992. Culture, Ethnicity and Learning: Applications for Educational Policy and Practice. University of Waikato.

Thompson, Charis. 2002. "Fertile Ground: Feminists Theorize Infertility." In Infertility Around the Globe: New Thinking on Childlessness, Gender, and Reproductive Technologies, edited by Marcia C. Inhorn and Frank van Balen. Berkeley: University of California Press.

- 2005. Making Parents: The Ontological Choreography of Reproductive Technologies. MIT Press.

Tober, Diane M. 2001. "Semen as Gift, Semen as Goods: Reproductive Workers and the Market in Altruism." Body \& Society 7(2-3): 137-160.

Charters, Claire, and Tracey Whare. 2017. "Shaky Foundations: The Fundamental Flaw at the Heart of a "Model” Treaty Involving New Zealand and the Indigenous Māori Community." World Policy Journal 34(4): 11-14.

Trundle, Catherine, Hannah Gibson, and Lara Bell. 2019. "Vulnerable Articulations: The Opportunities and Challenges of Illness and Recovery." Anthropology \& Medicine 26(2): 197-212.

Van de Wiel, Lucy. 2018. "Prenatal Imaging: Egg Freezing, Embryo Selection and the Visual Politics of Reproductive Time." Catalyst: Feminism, Theory, Technoscience 4(2): 135.

Van Den Akker, Olga. 2003. "Genetic and Gestational Surrogate Mothers' Experience of Surrogacy." Journal of Reproductive and Infant Psychology 21(2): 145-161.

- 2007. "Psychosocial Aspects of Surrogate Motherhood." Human Reproduction Update 13(1): 53-62. 
- 2017. Surrogate Motherhood Families. Springer International Publishing.

Van den Akker, Olga, Isatou Camara, and Ben Hunt. 2016. "'Together... For Only a Moment': British Newspaper Constructions of Altruistic Non-Commercial Surrogate Motherhood." Journal of Reproductive and Infant Psychology 34(3): 271-281.

Van den Akker, Olga, Patricia Fronek, Eric Blyth, and Lucy Frith. 2016. "'This Neo-Natal Ménage à Trois': British Media Framing of Transnational Surrogacy." Journal of Reproductive and Infant Psychology 34(1): 15-27.

Van Ee, Elisa, and Rolf J. Kleber. 2013. "Growing Up Under a Shadow: Key Issues in Research on and Treatment of Children Born of Rape." Child Abuse Review 22(6): 386-397.

Van Roode, Thea, Nigel Patrick Dickson, Alida Antoinette Righarts, and Wayne Richard Gillett. 2015. "Cumulative Incidence of Infertility in a New Zealand Birth Cohort to Age 38 by Sex and the Relationship with Family Formation." Fertility and Sterility 103(4): 1053-1058.

Van Wichelen, Sonja. 2016. "Changing rights to family life: Biolegalities in the Globalization of Reproduction." Socio-Legal Rev. 12: 26-50.

Van Wichelen, Sonja. 2018. Legitimating life: Adoption in the Age of Globalization and Biotechnology. New Brunswick: Rutgers University Press

Van Zyl, Liezl, and Ruth Walker. 2015. "Surrogacy, Compensation, and Legal Parentage: Against the Adoption Model." Journal of Bioethical Inquiry 12(3): 383-387.

Vezich, Dianne (2020). "Fertility Specialists Call for More Funding to Help Couples Get IVF in New Zealand." NewsHub. November 4, 2020. https://www.newshub.co.nz/home/new-zealand/2020/11/fertility-specialists-call-formore-funding-to-help-couples-get-ivf-in-new-zealand.html 
Vora, Kalindi. 2009. "Indian Transnational Surrogacy and the Commodification of Vital Energy." Subjectivity 28(1): 266-278.

Wahlberg, Ayo. 2016. "The Birth and Routinization of IVF in China." Reproductive Biomedicine \& Society Online 2: 97-107.

Wahlberg, Ayo, and Tine M. Gammeltoft. 2018. "Introduction: Kinds of Children." In Selective Reproduction in the $21^{\text {st }}$ Century, edited by Ayo Walhberg, and Tine M. Gammeltoft, 1-24. Palgrave Macmillan, Cham.

Walker, Ruth, and Liezl Van Zyl. 2015. "Surrogate Motherhood and Abortion for Fetal Abnormality." Bioethics 29(8): 529-535.

- 2016. "Altruism and Generosity in Surrogate Motherhood." In Contemporary Issues in Applied and Professional Ethics, edited by Marco Grix, and Tim Dare, 121133. Emerald Group Publishing Limited.

- 2017. Towards a Professional Model of Surrogate Motherhood. Springer.

- 2020. "Surrogacy and the Law: Three Perspectives." New Zealand Family Law Journal 10: 9-16.

Ware, Syrus Marcus. 2009. "Boldly Going Where Few Men Have Gone Before: One Trans Mans' Experience." In Who's Your Daddy?: And Other Writings on Queer Parenting. edited by Rachel Epstein, 65-72. Toronto: Sumach Press.

Weiss, Meira. 1994. Conditional Love: Parents' Attitudes Toward Handicapped Children. Greenwood Publishing Group.

Whittaker, Andrea, and Amy Speier. 2010. "“Cycling Overseas”: Care, Commodification, and Stratification in Cross-Border Reproductive Travel." Medical Anthropology 29(4): 363-383. 
Whittaker, Andrea, Marcia C. Inhorn, and Francoise Shenfield. 2019. "Globalised Quests for Assisted Conception: Reproductive Travel for Infertility and Involuntary Childlessness." Global Public Health 14(12): 1669-1688.

Wilson, Debra. 2017. "Avoiding the Public Policy and Human Rights Conflict in Regulating Surrogacy: The Potential Role of Ethics Committees in Determining Surrogacy Applications." UC Irvine Law Review 7: 653-678.

- 2018. "Reflecting on Surrogacy: Perspectives of Family Lawyers.” New Zealand Family Law Journal 9(5): 67-77.

- 2019. "The Emerging Picture of the Role Played by Surrogacy Contracts in New Zealand." In Perspectives on Commercial Surrogacy in New Zealand: Ethics, Law, Policy and Rights, edited by Annick Masselot and Rhonda Powell, Centre for Commercial \& Corporate Law Incorporated, University of Canterbury.

World Health Organization. (2018). Implementation Guidance: Protecting, Promoting and Supporting Breastfeeding in Facilities Providing Maternity.

Woulfe, C. 2013. “The Untold Story of NZ's Surrogate Babies.” New Zealand Listener, September 26, 2013.

http://www.listener.co.nz/current-affairs/the-untold-story-of-nzs-surrogate-babies/

Yates, Dianne, Rhonda Shaw, George Parker, Liezl Van Zyl, and Ruth Walker. 2015. "DIALOGUE: Proposed Changes to the Human Assisted Reproductive Technology Act (2004)." Women's Studies Journal 29(1): 34-55.

Yee, Samantha, Carly V. Goodman, and Clifford L. Librach. 2019. "Determinants of Gestational Surrogates' Satisfaction in Relation to the Characteristics of Surrogacy Cases." Reproductive biomedicine online 39(2): 249-261.

Yovich, John Lui. 2020. "Founding Pioneers of IVF Update: Innovative Researchers Generating Livebirths by 1982." Reproductive Biology 20(1): 111-113. 
Ziff, Elizabeth. 2020. "Surrogacy and Medicalization: Navigating Power, Control, and Autonomy in Embodied Labor." The Sociological Quarterly: 1-18. 


\section{APPENDIX \#1: Research Project Information Sheet}

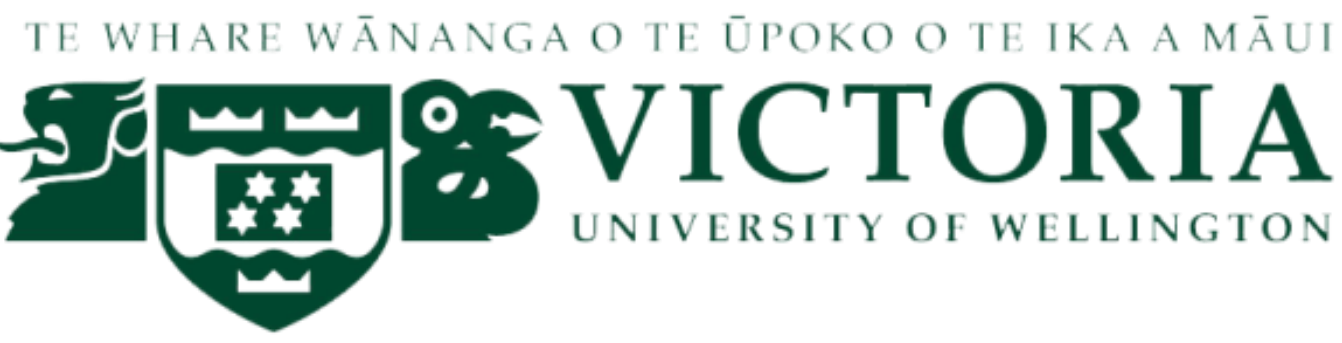

\section{Information Sheet for Participants}

Project Title: Exploring Surrogacy within a New Zealand Context

Researcher: Hannah Gibson, School of Social and Cultural Studies, Victoria University of Wellington.

Purpose and Object of Study

I invite you to participate in my $\mathrm{PhD}$ project which will explore surrogacy within New Zealand context, examining both the domestic context as well as why some New Zealanders choose to go overseas for assisted reproduction.

Aims of the Study

With a lack research about the experiences of both intended parent (s) and surrogates, little is known both academically and publically about the topic. I aim to investigate the lived experiences, viewpoints and practices involved in this journey. To do this, I plan to interview surrogates (either gestational or traditional) and their families, intended parent (s), egg donors, and those involved in the process, including lawyers, fertility providers, fertility counsellors, members of the ethical committees that consider surrogacy applications and governmental agencies.

\section{How You Can Help}

If you agree to take part I will interview you in a place of your choosing. The interview will take approximately 45 minutes to an hour and a half. I may request a follow up interview. I will record the interview (s) and write it up later. You can stop the interview at any time, without giving a reason.

\section{Confidentiality and Use of Information}

These interviews will form the basis of my research project. In writing my thesis your interview material will be treated confidentially and I will assign you a pseudonym. Any other identifying features will also be removed from the thesis to ensure your confidentiality. No other person besides me and my supervisor, Catherine Trundle, and a transcriber (who will sign a confidentiality agreement) will see interview transcripts and audio recordings. The thesis will be submitted for marking to Victoria University and will be deposited in the University Library. It is intended that one or more articles will 
be submitted for publication in scholarly journals. Audio recordings of interviews and interview transcripts will be kept for up to 15 years after the end of the project. The reason for this is that anthropological research is usually long term, tracking social change over time and engaging with communities over decades. I would like to pursue an academic career and intend to publish out of this research for many years and would like to track changing approaches to surrogacy in the future. However after 5 years, the only data that will be retained will be anonymised data, with no identifiable information, in order to protect the privacy rights of participants and any offspring from surrogacy arrangements.

This research project has received approval from the Victoria University Human Ethics Committee (Approval Number 22968).

\section{If you Accept this Invitation, What Are Your Rights as a Research Participant?}

You do not have to accept this invitation if you don't want to. If you do decide to participate, you have the right to:

- $\quad$ choose not to answer any question;

- $\quad$ ask for the recorder to be turned off at any time during the interview;

- withdraw from the study up until one month after your interview; If you withdraw, the information you provided will be destroyed or returned to you.

- $\quad$ ask any questions about the study at any time;

- $\quad$ receive a copy of your interview recording (if it is recorded);

- $\quad$ read over and comment on a written summary of your interview;

- $\quad$ agree on another name for me to use rather than your real name;

- be able to read any reports of this research by emailing the researcher to request a copy.

If you experience unsettling or upsetting emotions from discussing any aspect of your experience during the interview then you can call any of the following organisations to talk to someone anonymously for free:

- Lifeline - 0800543354

- Depression helpline - 0800111757

- Healthline - 0800611116

- Samaritans - 0800726666

If you have any questions or would like to receive further information about the project, please contact me at Hannah.Gibson@vuw.ac.nz or by phone (04) 4635233 ext. 6032. Alternatively, you can contact my supervisor Catherine Trundle, at the School of Social and Cultural Studies at Victoria University catherine.trundle@vuw.ac.nz or by phone, (04) 4635134.

If you have any questions regarding the ethics process itself then do not hesitate to contact the Victoria University Ethics Convener, Associate Professor Susan Corbett on susan.corbett@vuw.ac.nz or by phone (04) 4635480. 


\section{CONSENT TO PARTICIPATE IN RESEARCH}

\section{Project Title: Exploring Surrogacy within a New Zealand Context}

Researcher: Hannah Gibson, School of Social and Cultural Studies, Victoria University of Wellington.

- I have read the Information Sheet and the project has been explained to me. My questions have been answered to my satisfaction. I understand that I can ask further questions at any time.

- I agree to take part in an interview.

I understand that:

- I may withdraw from this study up to one month without having to give any reasons, and any information that I have provided will be returned to me or destroyed.

- Any information I provide will be kept confidential to the researcher and the supervisor. I understand that the results will be used for a PhD report and a summary of the results may be used in academic publications and presented at conferences.

- My name will not be used in reports, nor will any information that would identify me.

I agree to having the interview recorded (audio)

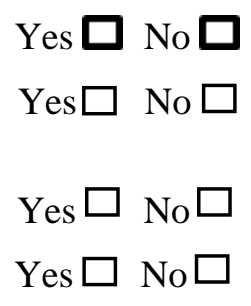

I would like a copy of the tape recordings of my interview provided to me at the conclusion of the project.

I would like to be given a copy of the interview transcript

I understand that the data I provide will not be used for any other purpose or released to others without my written consent.

I would like a summary of the thesis to be made available to me at the completion $\quad$ Yes $\square$ No $\square$ of the research. 
If you have any questions or would like to receive further information about the project, please contact me at Hannah.Gibson@ vuw.ac.nz or by phone, (04) 4635233 extension 6032, or my supervisor Catherine Trundle, at the School of Social and Cultural Studies at Victoria University catherine.trundle@vuw.ac.nz or by phone, (04) 4635134.

Signed: Date:

Name of participant:

Email address:

Postal Address:

Phone Number: 